\title{
Finite Element Modeling of Geosynthetic Soil Reinforcement Over Shallow Buried Pipes
}

Andrew L. Dietz

West Virginia University

Follow this and additional works at: https://researchrepository.wvu.edu/etd

\section{Recommended Citation}

Dietz, Andrew L., "Finite Element Modeling of Geosynthetic Soil Reinforcement Over Shallow Buried Pipes" (2013). Graduate Theses, Dissertations, and Problem Reports. 4961.

https://researchrepository.wvu.edu/etd/4961

This Thesis is protected by copyright and/or related rights. It has been brought to you by the The Research Repository @ WVU with permission from the rights-holder(s). You are free to use this Thesis in any way that is permitted by the copyright and related rights legislation that applies to your use. For other uses you must obtain permission from the rights-holder(s) directly, unless additional rights are indicated by a Creative Commons license in the record and/ or on the work itself. This Thesis has been accepted for inclusion in WVU Graduate Theses, Dissertations, and Problem Reports collection by an authorized administrator of The Research Repository @ WVU. For more information, please contact researchrepository@mail.wvu.edu. 
Finite Element Modeling of Geosynthetic Soil Reinforcement Over Shallow Buried Pipes

Andrew L. Dietz

Thesis submitted to the

Benjamin M. Statler College of Engineering and Mineral Resources

at West Virginia University

in partial fulfillment of the requirements

for the degree of

Master of Science

in

Civil Engineering

Hema J. Siriwardane, Ph. D., P.E., Chair

Udaya B. Halabe, Ph. D., P.E.

John D. Quaranta, Ph.D., P.E.

Department of Civil and Environmental Engineering

Morgantown, West Virginia

2013

Keywords: Geosynthetics; Geotextiles; Soil Reinforcement; Finite Element; Buried Pipe; HDPE; HS-25 Loading; FEM 


\begin{abstract}
Finite Element Modeling of Geosynthetic Soil Reinforcement Over Shallow Buried Pipes
\end{abstract}

Andrew L. Dietz

Buried pipes serve an important role in many engineering applications and are vital to the infrastructure of our everyday life. It is imperative that, once in place, these pipes last as long as possible to avoid failure and costly replacement. Advancements in technology and understanding of soil-pipe interactions can extend the service life of these pipes. In this study, a new approach is taken to increase buried pipe performance.

The purpose of this research work is to explore the potential improvements of pipe performance under surface loading by using a geosynthetic reinforcement in the soil layer above a buried pipe. Various aspects of soil-pipe interactions and geosynthetic-soil interactions are considered to develop a plausible scenario where geosynthetic reinforcement can be a benefit. An extensive series of numerical investigations were conducted to analyze various aspects of this buried pipe system by using the Finite Element Method. The influence of geotextile width, geotextile stiffness, pipe depth, pipe size, trench soil stiffness, and frictional interactions on the pipe performance is investigated.

Results from this study show that at shallow pipe depths a layer of geotextile soil reinforcement can reduce pipe deflections by up to $36 \%$ when the trench soil above the pipe is weak. The improvement decreases significantly when pipe depth is increased or when the soil over the pipe is stiff. Further research work including an economic analysis may prove that the ideas put forth in this study have relevance in other field applications. 


\section{ACKNOWLEDGEMENT}

I would like to take this opportunity to thank several people who played a vital role in the creation and completion on this thesis. First, I would like to thank my advisor and committee chairman, Dr. Hema Siriwardane, for giving me the opportunity to continue my education and for his thorough review of my research work. I would like to thank Dr. Udaya Halabe and Dr. John Quaranta for serving as members of my examination committee. I also thank Dr. Raj Gondle and Mr. Sai Varre for their help throughout the entire process of this research.

My special thanks go to my parents, Thomas and Martha Dietz whose support was vital to the completion of this work. 


\section{TABLE OF CONTENTS}

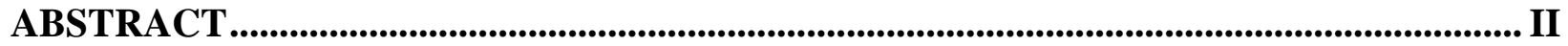

ACKNOWLEDGEMENT ..............................................................................................III

TABLE OF CONTENTS .................................................................................................... IV

LIST OF FIGURES ................................................................................................................. VII

LIST OF TABLES ...........................................................................................................................XI

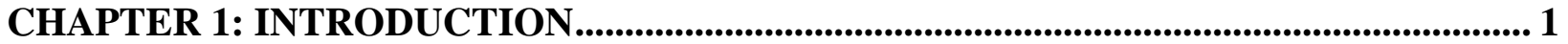

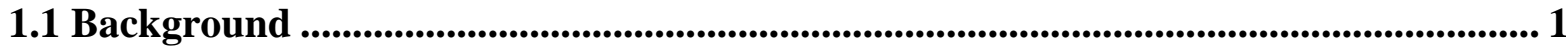

1.2 Introduction to buried pipes and soil-pipe interaction........................................................ 3

1.3 Introduction to geosynthetics..................................................................................................... 4

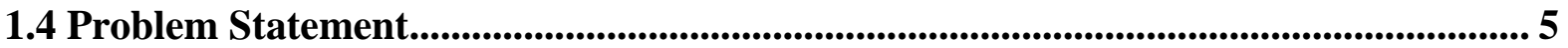

1.5 Previous studies................................................................................................................. 7

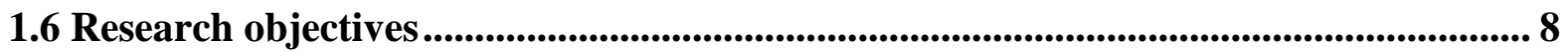

1.7 Report Summary ....................................................................................................................... 9

CHAPTER 2: OVERVIEW OF GEOTEXTILES .............................................................. 10

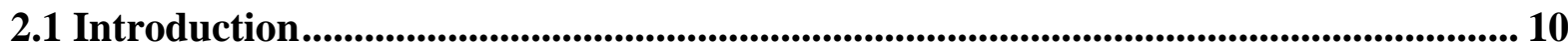

2.2 Introduction to Geotextiles..................................................................................................... 10

2.2.1 Non-woven Geotextiles. ..................................................................................... 11

2.2.2 Woven Geotextiles.............................................................................................. 11

2.3 Geotextile Functions ........................................................................................................ 12

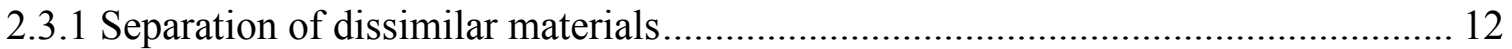

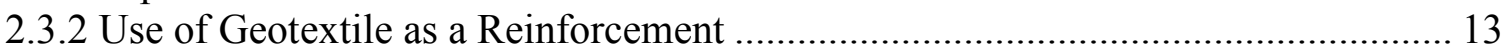

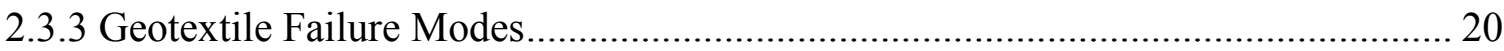

2.4 Geotextile Properties and Test Methods............................................................................ 21

2.4.1 Physical Properties........................................................................................... 21

2.4.2 Mechanical Properties................................................................................... 22

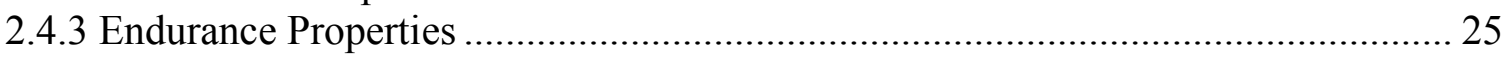

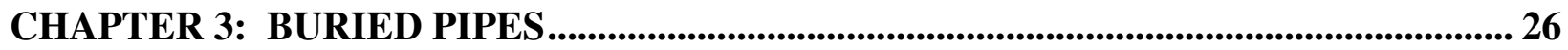

3.1 Introduction .......................................................................................................................... 26

3.2 Flexible Pipe Design.............................................................................................................. 27

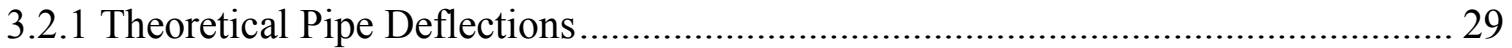

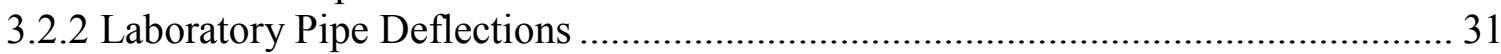

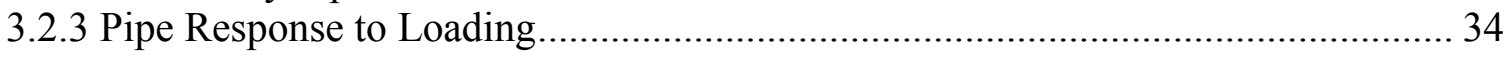

3.3 HDPE Pipes ................................................................................................................................ 35 


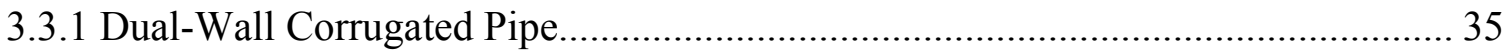

3.3.2 Determining pipe dimensions and properties for modeling..................................... 39

3.4 Soil properties and mechanics ............................................................................................. 40

3.4.1 Shear strength of soil ...................................................................................... 41

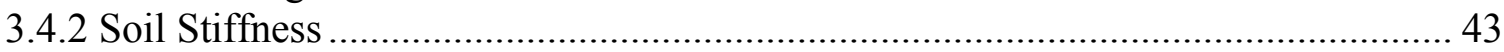

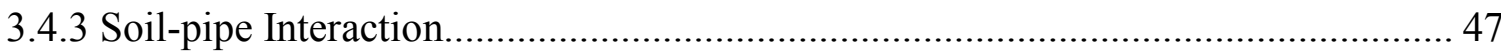

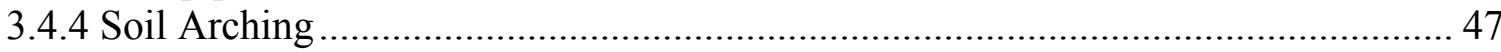

CHAPTER 4: NUMERICAL METHODOLOGY …......................................................... 49

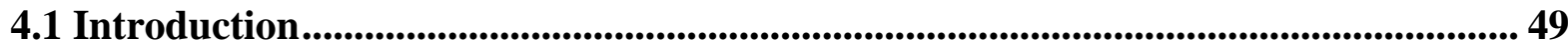

4.2 Details of the finite element method ................................................................................... 49

4.3 Element types and meshing..................................................................................................... 51

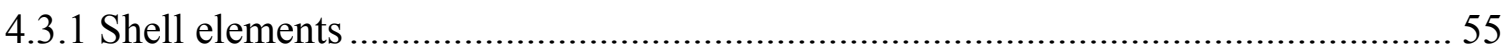

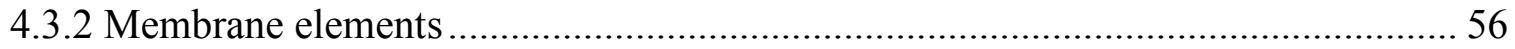

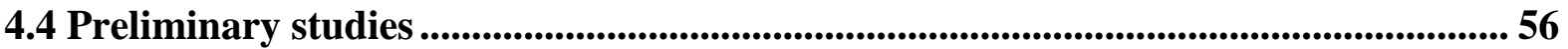

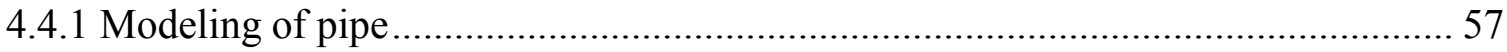

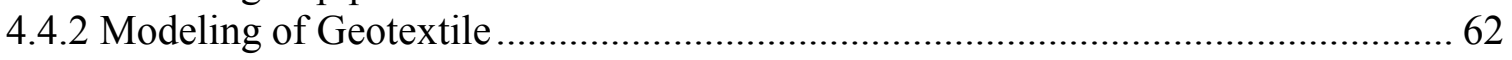

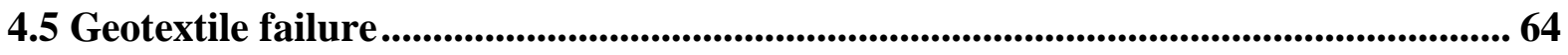

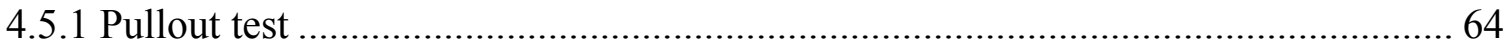

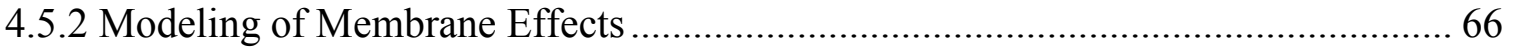

4.6 Loading and boundary conditions..................................................................................... 68

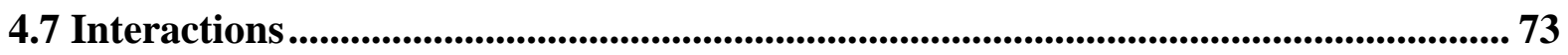

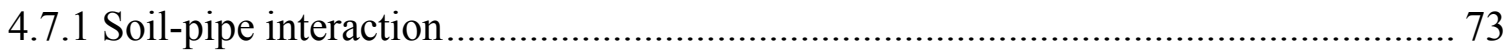

4.7.2 Geotextile interactions .................................................................................. 74

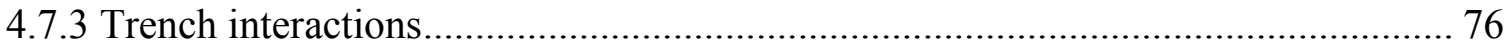

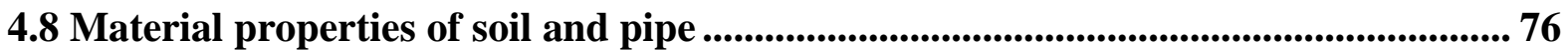

4.9 Material properties of geotextile............................................................................................ 79

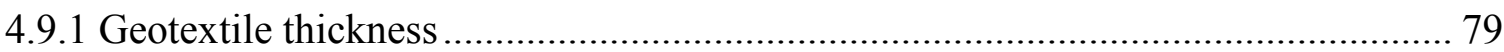

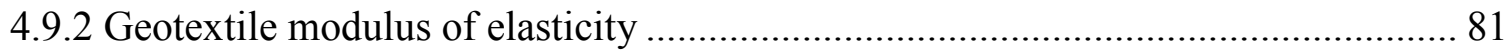

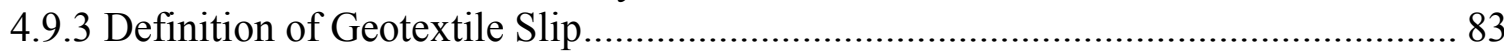

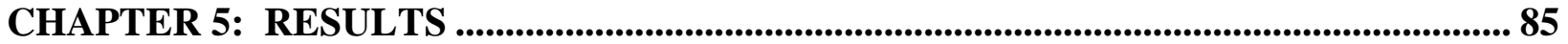

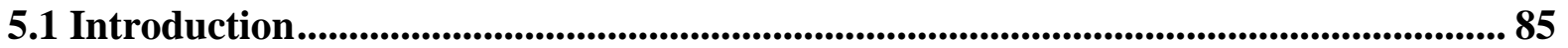

5.2 Geotextile effectiveness with varying pipe depth ................................................................ 86

5.3 Effect of Depth of Cover................................................................................................................. 92

5.4 Effect of varying geotextile stiffness ........................................................................................ 101

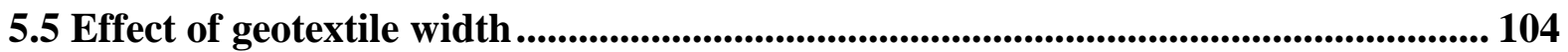

5.6 Geotextile effectiveness with varying trench stiffness .................................................... 106 
5.7 Geotextile effectiveness with larger diameter pipe ............................................................ 113

CHAPTER 6: SUMMARY AND CONCLUSIONS ................................................................ 115

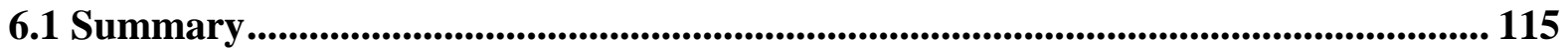

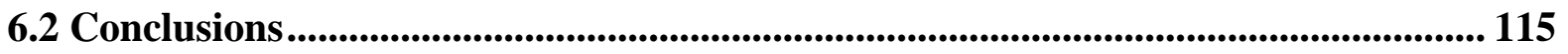

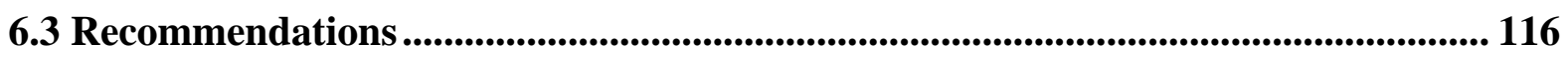

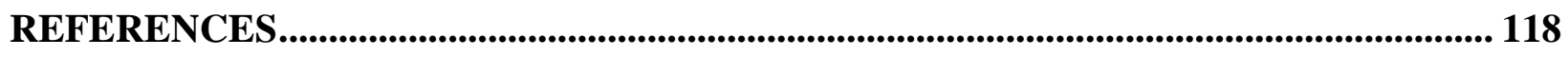




\section{LIST OF FIGURES}

Figure 1.1: Schematic of a HDPE pipe buried in a granular backfill. ........................................2

Figure 1.2: Profile view of a geosynthetic layer used in buried pipe installation.........................2

Figure 1.3: Profile view of a geosynthetic layer used in buried pipe installation........................6

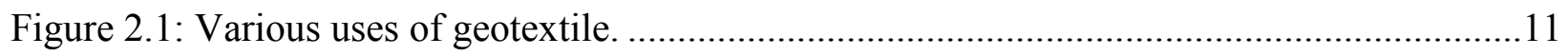

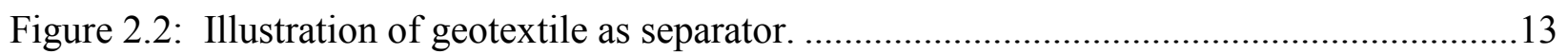

Figure 2.3: Diagram of membrane effect dimensions. ...................................................... 15

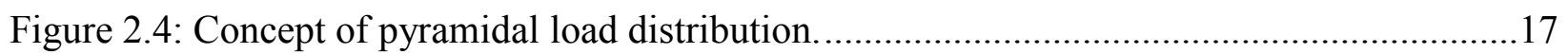

Figure 2.5: Illustration of geotextile direct shear test. ....................................................... 19

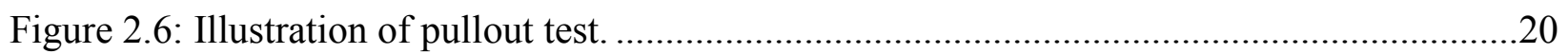

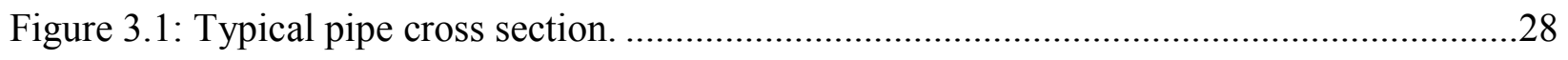

Figure 3.2: Typical trench arrangement for buried pipe. ...................................................28

Figure 3.3: Illustration of pipe deflection under vertical load. ............................................29

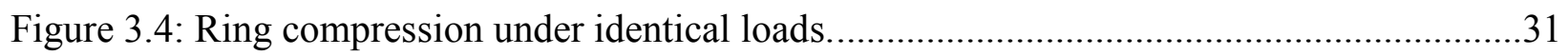

Figure 3.5: Parallel plate testing (ASTM D 2412 Test) for flexible pipe..................................32

Figure 3.6: Profile of double-wall corrugated HDPE pipe (Varre, 2011). .................................36

Figure 3.7: Profile view of single-wall corrugated HDPE pipe (Varre, 2011) ..........................37

Figure 3.8: (a) Mohr circle for stress, (b) Illustration of typical failure plane in soil..................43

Figure 3.9: Vertical soil arching (Moser, 2008; Gondle, 2006).............................................48

Figure 4.1 Three dimensional brick element (Mada, 2005).....................................................50

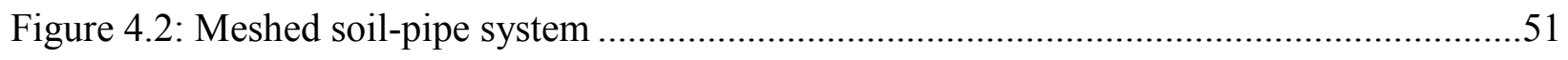

Figure 4.3: Nodal displacements along $\mathrm{x}, \mathrm{y}$, and $\mathrm{z}$ directions for solid element (Abaqus, 2010). 52

Figure 4.4: Continuum versus conventional shell elements (Abaqus, 2010). ...........................55

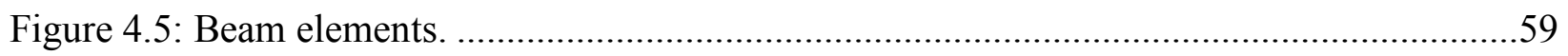

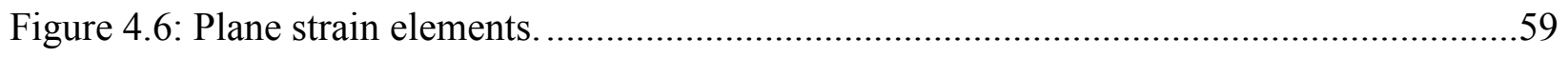

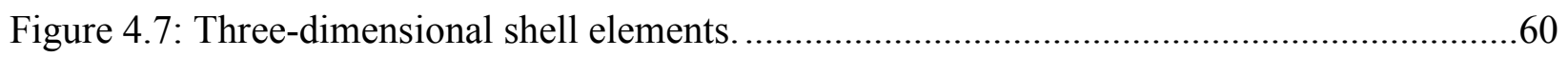

Figure 4.8: Three-dimensional solid elements............................................................60

Figure 4.9: Percent pipe deflection with variation of mesh density for different element types...61

Figure 4.10: Geotextile constructed with membrane elements..........................................63 
Figure 4.11: Geotextile constructed with solid elements...............................................63

Figure 4.12: FEM pullout test (before loading)............................................................65

Figure 4.13: FEM pullout test after 5 inch displacement....................................................65

Figure 4.14: Geometry of "No Trench Test". ....................................................................66

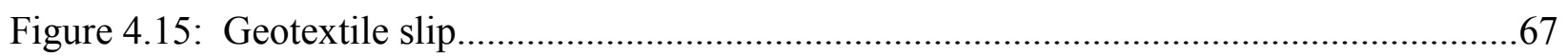

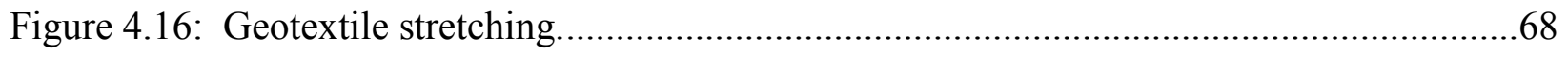

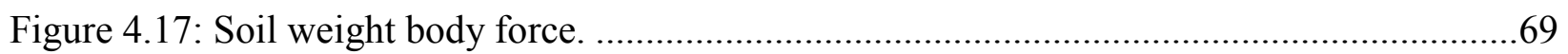

Figure 4.18: Normal force from overburden................................................................ 70

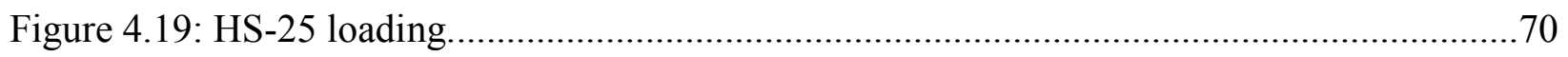

Figure 4.20: HS-25 load distribution (Varre, 2011) ........................................................ 71

Figure 4.21: ENCASTRE boundary condition on bottom face. .............................................72

Figure 4.22: Z-SYMM boundary condition on front/back face...........................................72

Figure 4.23: X-SYMM boundary condition on side faces..................................................73

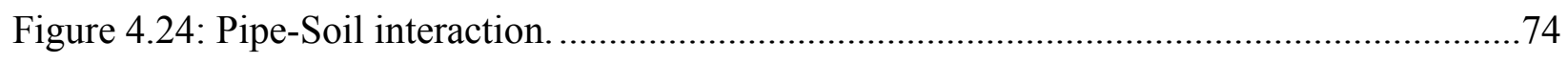

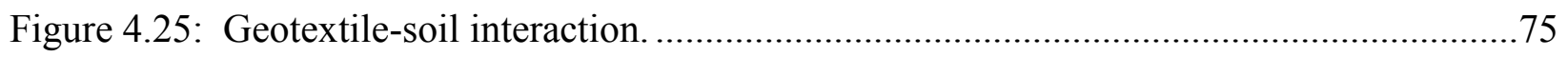

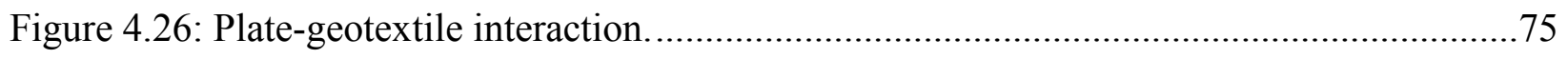

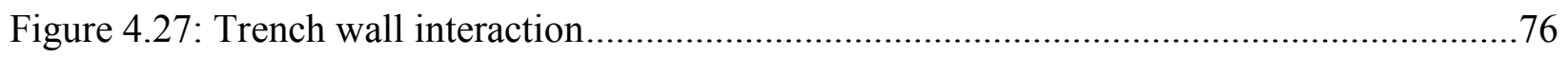

Figure 4.28: Soil sections used in finite element modeling. .................................................77

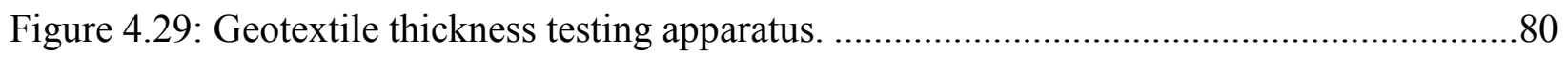

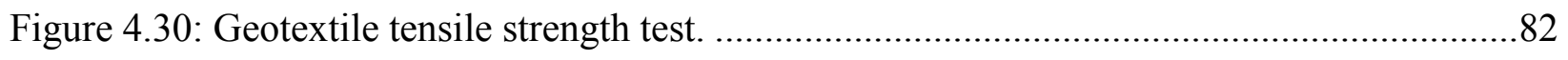

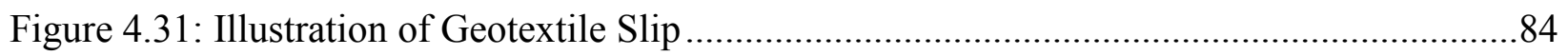

Figure 5.1: Schematic of buried pipe with geotextile overlay..............................................85

Figure 5.2: Percent pipe deflection vs. geotextile width with varying pipe depths for 24 in.

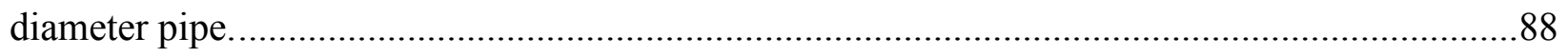

Figure 5.3: Percent reduction in pipe deflection vs. geotextile width with varying pipe depth for

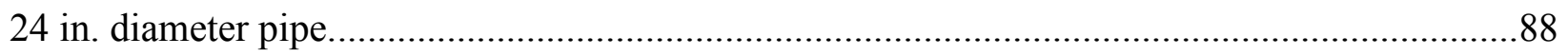

Figure 5.4: Geotextile slip distance vs. geotextile width with varying pipe depths for 24 inch pipe.

Figure 5.5: Percent pipe deflection vs. geotextile width with varying pipe depths for 60 in. diameter pipe. 
Figure 5.6: Percent reduction in pipe deflection vs. geotextile width with varying pipe depth for 60 in. diameter pipe.

Figure 5.7: Geotextile slip distance vs. geotextile width with varying pipe depths for 60 inch pipe.

Figure 5.8: Percent pipe deflection vs. geotextile width with varying normal loading for 24 inch diameter pipe.

Figure 5.9: Percent reduction in pipe deflection vs. geotextile width with varying normal loading for 24 inch diameter pipe.

Figure 5.10: Geotextile slip distance vs. geotextile width with varying normal loading for 24 inch pipe diameter. .95

Figure 5.11: Percent pipe deflection vs. geotextile width with varying normal loading for 24 inch diameter pipe.

Figure 5.12: Percent reduction in pipe deflection vs. geotextile width with varying normal loading for 24 inch diameter pipe.

Figure 5.13: Geotextile slip distance vs. geotextile width with varying normal loading for 24 inch pipe diameter.. . .98

Figure 5.14: Percent pipe deflection vs. geotextile width with varying normal loading for 60 inch diameter pipe.

Figure 5.15: Percent reduction in pipe deflection vs. geotextile width with varying normal loading.

Figure 5.16: Geotextile slip distance vs. geotextile width with varying normal loading for 60 inch pipe diameter..

Figure 5.17: Percent pipe deflection vs. geotextile width with varying geotextile stiffness for 24 inch diameter pipe.

Figure 5.18: Percent reduction in pipe deflection vs. geotextile width with varying geotextile stiffness for 24 inch diameter pipe.

Figure 5.19: Geotextile slip distance vs. geotextile width with varying geotextile stiffness for 24 inch diameter pipe.

Figure 5.20: Effect of Geotextile Width

Figure 5.21: Percent pipe deflection vs. geotextile width with varying trench stiffness for 24 inch diameter pipe.

Figure 5.22: Percent reduction in pipe deflection vs. geotextile width with varying trench stiffness for 24 inch diameter pipe. 
Figure 5.23: Geotextile slip distance vs. geotextile width with varying trench stiffness for 24 inch

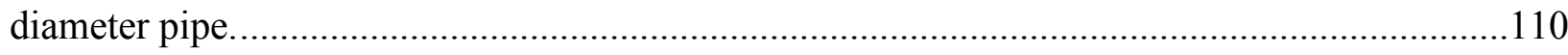

Figure 5.24: Percent pipe deflection vs. geotextile width with varying trench stiffness for 60 inch diameter pipe.

Figure 5.25: Percent reduction in pipe deflection vs. geotextile width with varying trench

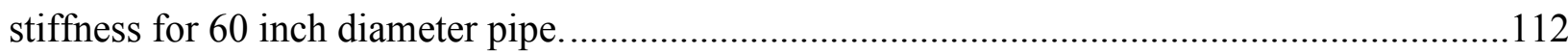

Figure 5.26: Geotextile slip distance vs. geotextile width with varying trench stiffness for 60 inch

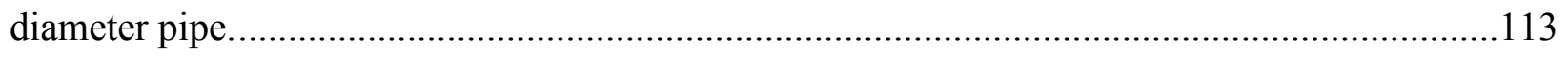




\section{LIST OF TABLES}

Table 1.1: Types of geosynthetics and their primary functions (Koerner, 2005).

Table 2.1: Peak soil-to-geotextile friction angles and efficiencies (in parenthesis) in cohesionless soils (Koerner, 2005).

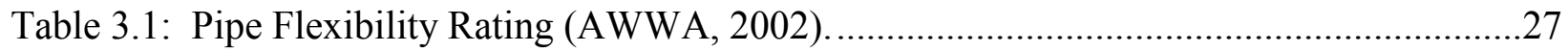

Table 3.2: Section Properties of Double-Wall Corrugated HDPE Pipes ${ }^{*}$ (ADS, 2012)...............38

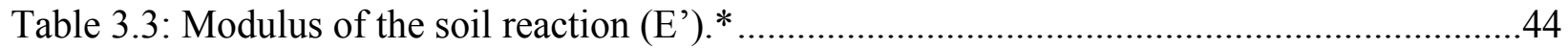

Table 3.4: Degree of compaction of backfill materials. * ....................................................45

Table 3.5: Recommended values of different soil modulus used by various researchers (Gondle, 2006). 46

Table 4.1: Finite element types used for soil-pipe geometry in previous studies. ${ }^{*}$.....................57

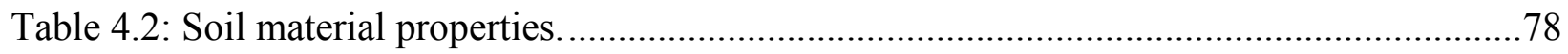

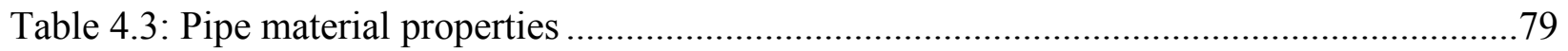

Table 4.4: Measured geotextile sample thickness............................................................81

Table 4.5: Geotextile material properties..............................................................................83

Table 5.1: Pipe deflections with varying pipe depth for 24 inch diameter pipe. .......................87

Table 5.2: Pipe deflections with varying pipe depth for 60 inch diameter pipe. .........................90

Table 5.3: Pipe deflections with varying normal loading for 24 in. diameter pipe at 24 in. pipe

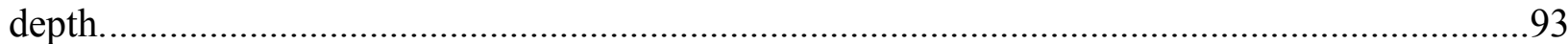

Table 5.4: Pipe deflections with varying normal loading for 24 in. diameter pipe at 48 in. pipe

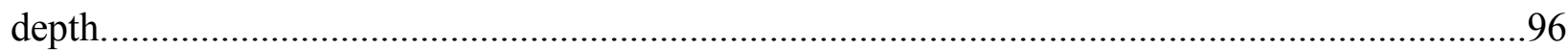

Table 5.5: Pipe deflections with varying normal loading for 60 in. diameter pipe at 24 in. pipe

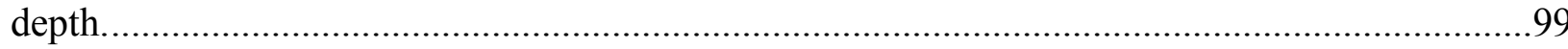

Table 5.6: Pipe deflections with varying geotextile stiffness for 24 inch diameter pipe............102

Table 5.7: Geotextile performance with varying trench stiffness for 24 in. diameter pipe. ........108

Table 5.8: Geotextile performance with varying trench stiffness for 60 in. diameter pipe.........111 


\section{CHAPTER 1: INTRODUCTION}

\subsection{Background}

Buried pipes play an important role in engineering applications such as water conveyance, sewer systems, highway drainage systems, and landfill drainage systems. With such large usage of buried pipes it is important to identify a suitable type of pipe and backfill soil with satisfactory long-term performance. Several studies have been conducted in the past to investigate new materials and installation techniques to enhance the performance and durability of buried pipes (Varre, 2011; Arockiasamy et al., 2006; Gondle, 2006; Mada, 2005). Such contributions lead to advancements in technology and understanding of soil-pipe interactions. Figure 1.1 shows a schematic of a HDPE pipe buried in a backfill material. The overall performance of buried pipes is determined by both, the pipe and soil mass surrounding the pipe. Efforts are continuously made to develop new pipe and backfill materials, improved pipe profiles, and new design procedures to increase the durability and service life of these pipes (Sesack, 2011; Arockiasamy et al., 2006; Gondle 2006). It is also important to have a good interaction between the pipe, backfill material, and insitu soil to improve the structural performance of a buried pipe and extend the service life. More details on the pipe, backfill soil, and insitu soils are provided in later sections of this chapter.

A significant amount of government resources are spent every year by the Division of Highways (DOH) and Department of Transportation (DOT) for the maintenance and rehabilitation of currently installed pipes as well as the development of new infrastructure (Palomino, 2010). Construction materials such geotextiles are common to earth work and provide various benefits for applications such as drainage and reinforcement; however, they have not been extensively explored for use in buried pipe applications. Installation of geotextiles in the soil above a buried pipe could lead to improved pipe performance by dissipating part of the surface loading acting on the pipe over a larger area and hence reduce vertical displacements in the pipe. The concept of using a geosynthetic above the crown of the pipe is investigated in the research work presented in this report. Figure 1.2 illustrates a profile view of this concept. Details of different geosynthetic materials and their applications are presented in later sections of this chapter. 


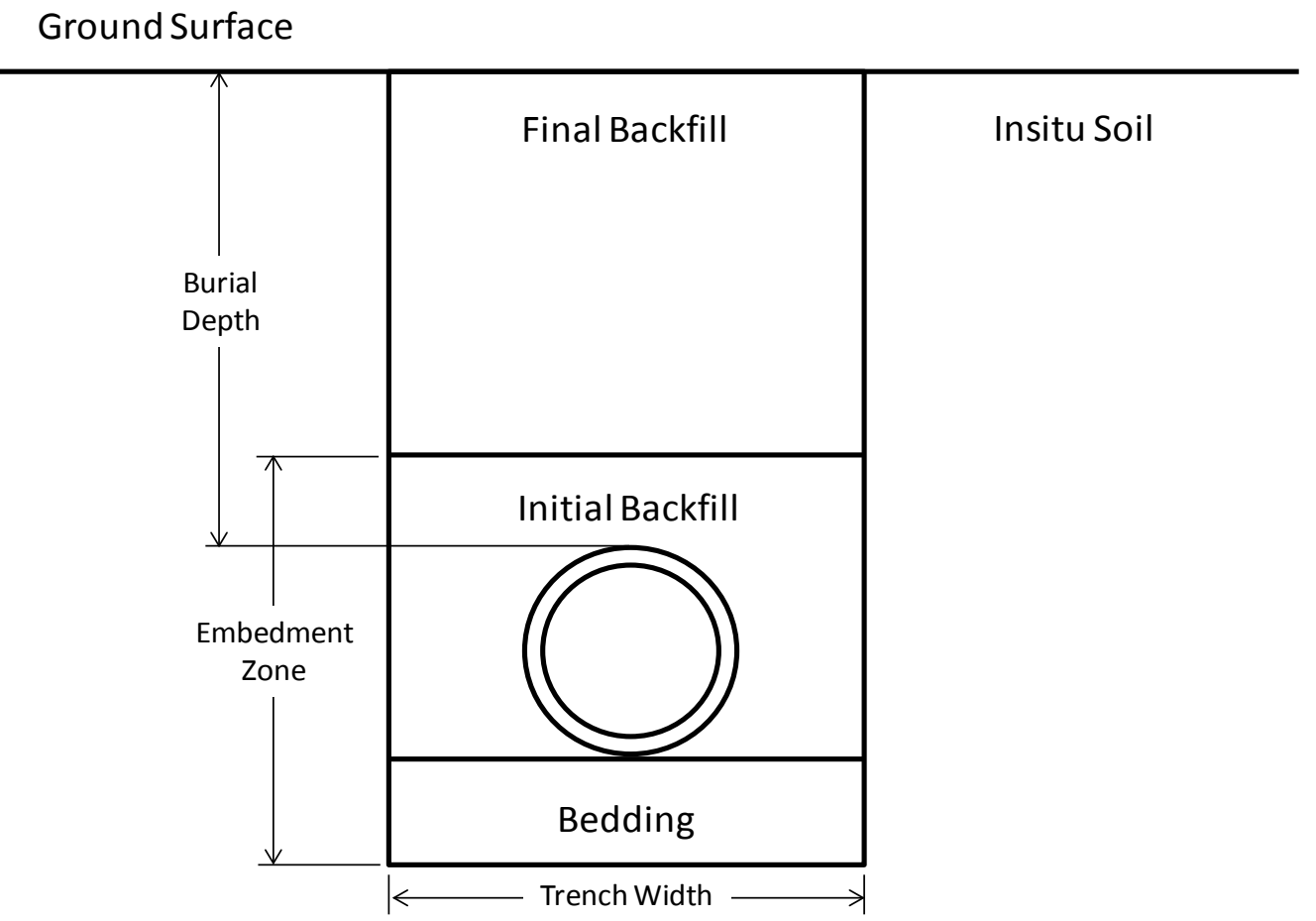

Figure 1.1: Schematic of a HDPE pipe buried in a granular backfill.

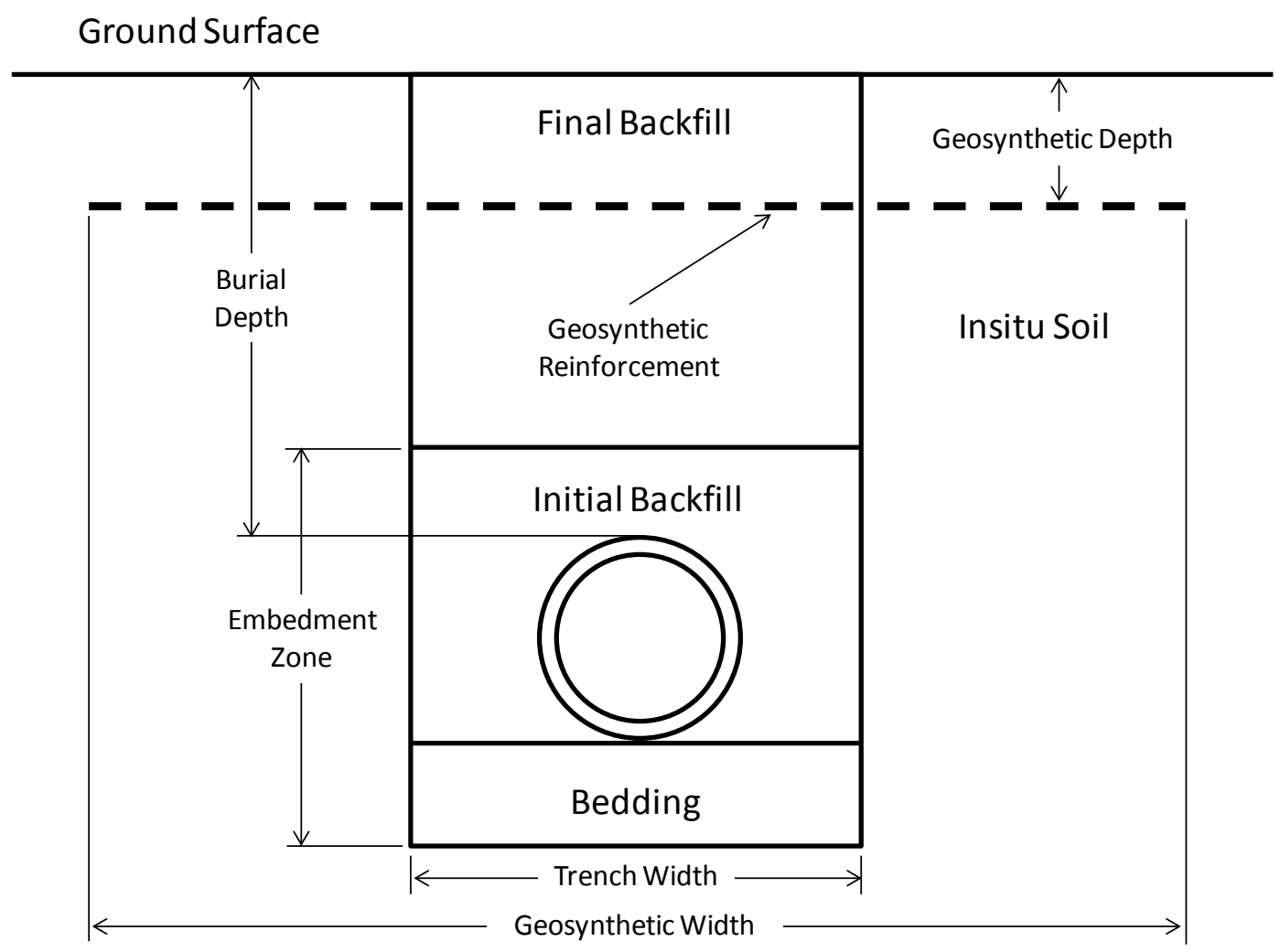

Figure 1.2: Profile view of a geosynthetic layer used in buried pipe installation. 


\subsection{Introduction to buried pipes and soil-pipe interaction}

Different types of pipes and culverts ranging from rigid (eg. concrete, ceramic) to flexible (eg. thermoplastic, metallic) are available on the market (Koerner 2005; Moser, 1990). Rigid pipes, typically concrete, are very common to low pressure applications such as sewage or gravity-flow transport of storm water (ACPA, 2012). Flexible pipes such as steel, HDPE (High Density Polyethylene), and PVC (Polyvinyl Chloride) are common to several highway applications such as pavement underdrains (Gondle, 2006; Koerner, 2005). Strength, stiffness, corrosion resistance, abrasion resistance, lightness, flexibility and ease of joining are often deciding factors for choosing a particular type of pipe for a given project (Koerner 2005; Mada, 2005). In the current study, HDPE pipes were selected to investigate the influence of geosynthetic soil reinforcement above a buried pipe. HDPE pipes are available with different pipe profiles such as single-wall corrugated, double-wall corrugated, etc. (Mada, 2005; ADS, 2012). This study is limited to double-wall corrugated pipes. More details on double-wall corrugated pipes are presented in Chapter 3 of this paper.

The performance of a buried pipe is not only determined by the pipe alone but is also influenced by the surrounding soil mass. The interface between the backfill material and pipe is typically referred to as the soil-pipe interaction (ASTM, 2011; Goddard, 2003). Some of the factors that influence the soil-pipe interaction include: type of backfill material, pipe material and profile, field conditions, and installation practices (Gondle, 2006; Arockiasamy et al., 2006). Typically, these buried pipes are referred to as a single composite structure comprised of the pipe and soil envelope (ASTM, 2011; AASHTO, 2007). More details on the soil-pipe interaction are presented in later chapters. Several types of backfill materials which allow for satisfactory buried pipe performance have been proposed in the literature (Varre, 2011; Sesack, 2011; Mada, 2005); however, for the purpose of this study only a granular backfill has been considered. Such a backfill is commonly used in highway applications and is recommended by several pipe manufacturers and highway officials (ASTM, 2011).

Time dependent properties such as creep are normally associated with high density polyethylene (HDPE) pipes and other plastic pipes. Creep in a pipe can be defined as continuous deformation in the pipe material when subjected to a constant mechanical load. This type of deformation can result in the failure of the pipe over time (Gondle and Siriwardane, 2008; Moore and Fuping, 1995). Several factors have an effect over the rate of creep deformation, these include: 
magnitude of initial loading, rate of loading, temperature, and loading medium. Therefore, it is also important to acknowledge the time dependent nature of HDPE pipes in order to avoid unexpected pipe failures. This study only considers instantaneous reactions; therefore, time dependent response was not factor.

\subsection{Introduction to geosynthetics}

Geosynthetics are used in many different types of applications due to their wide variety of uses and favorable characteristics such as non-corrosiveness and durability. Several different types of geosynthetic materials are available on the market with different combinations of polymeric materials and manufacturing methods (eg. fabrics, grids, nets, and membranes). This diversity allows for a wide selection of geosynthetic products including: geotextiles, geogrids, geonets, geomembranes, geosynthetic clay liners, geopipe, geofoam, and geocomposites (Koerner, 2005; TenCate, 2012). Each family of geosynthetics is specialized for use in certain primary functions ranging from water filtration and containment to soil reinforcement. Table 1.1 shows a list of common geosynthetics and their major functions. Since the main purpose of this study is to investigate the effect of geosynthetic reinforcement above a buried pipe, only geotextiles have been considered in this research work. More details on the geotextiles used in this study are discussed in later chapters.

Table 1.1: Types of geosynthetics and their primary functions (Koerner, 2005).

\begin{tabular}{cccccc}
\hline & \multicolumn{5}{c}{ Primary Function } \\
\cline { 2 - 6 } $\begin{array}{c}\text { Type of } \\
\text { Geosynthetic }\end{array}$ & Separtaion & Reinforcement & Filtration & Drainage & Containment \\
\hline Geotextile & $\square$ & $\square$ & $\square$ & $\square$ & \\
Geogrid & $\square$ & & & \\
Geonet & & & & & \\
Geomembrane & & & & $\square$ \\
Geosynthetic & & & & $\square$ & \\
Clay Liner & & & & & \\
Geopipe & & & & & \\
Geofoam & $\square$ & & & & $\square$ \\
Geocomposite & $\square$ & $\square$ & & & \\
\hline
\end{tabular}




\subsection{Problem Statement}

A significant amount of resources are spent every year for the maintenance and rehabilitation of currently installed buried pipes. As discussed above, the performance of buried pipes is not only influenced by the pipe and the soil used, but also depends on the nature and magnitude of loading coming on to the pipe. The flexible nature of thermoplastic pipes, such as HDPE pipe, allows the pipe to displace and redirect part of the vertical forces into the surrounding soil. Vertical pipe displacements of up to $7.5 \%$ are considered as tolerable values by various researchers (Goddard, 2003; ADS, 2006; Plastic Pipe Institute, 2012; Reddy and Ataoglu, 2002). Most design considerations are based on HS-20 truck loading or lighter loading conditions. Recently, larger loading configurations, such as HS-25 truck loading, have become more prominent in buried pipe design and tolerable displacement values have yet to be evaluated completely. Also, time-dependent properties such as creep (associated with the HDPE pipe) and consolidation of soil could lead to additional displacements. Therefore, it is important to reevaluate structural design considerations or develop a new approach for the expansion of new pipe infrastructure. In the current study, a methodology for the use of geosynthetics in pipe installation practices is proposed with the intent to improve the performance of the soil-pipe system and extend the service life of buried pipes.

Currently, geosynthetic materials (geotextiles and geogrids, in particular) are used as soil reinforcement in many applications such as embankments, retaining walls, and foundation subbases (Hinchberger , 2003; Alawaji, 2001; Moayedi, 2009). However, the use of geosynthetics in buried pipe applications is limited. Installation of geotextiles in the backfill soil above a buried pipe could lead to improved pipe performance by dissipating part of the surface loading acting on the pipe over a larger area, reducing the magnitude of vertical load on the pipe. Figure 1.3 illustrates this concept. Field-scale testing of this method would be expensive and time consuming; consequently, numerical modeling techniques have been used to investigate the use of geosynthetics in buried pipe applications. Two-dimensional and three-dimensional finite element modeling was performed to investigate the influence of soil reinforcement on the structural behavior of buried pipes. Pipe diameter, pipe depth, frictional resistance, geotextile width, geotextile stiffness, and trench fill stiffness are some of the factors considered in this study. The primary objective is to determine whether this reinforcing layer could be helpful in reducing pipe displacements in a significant way. 


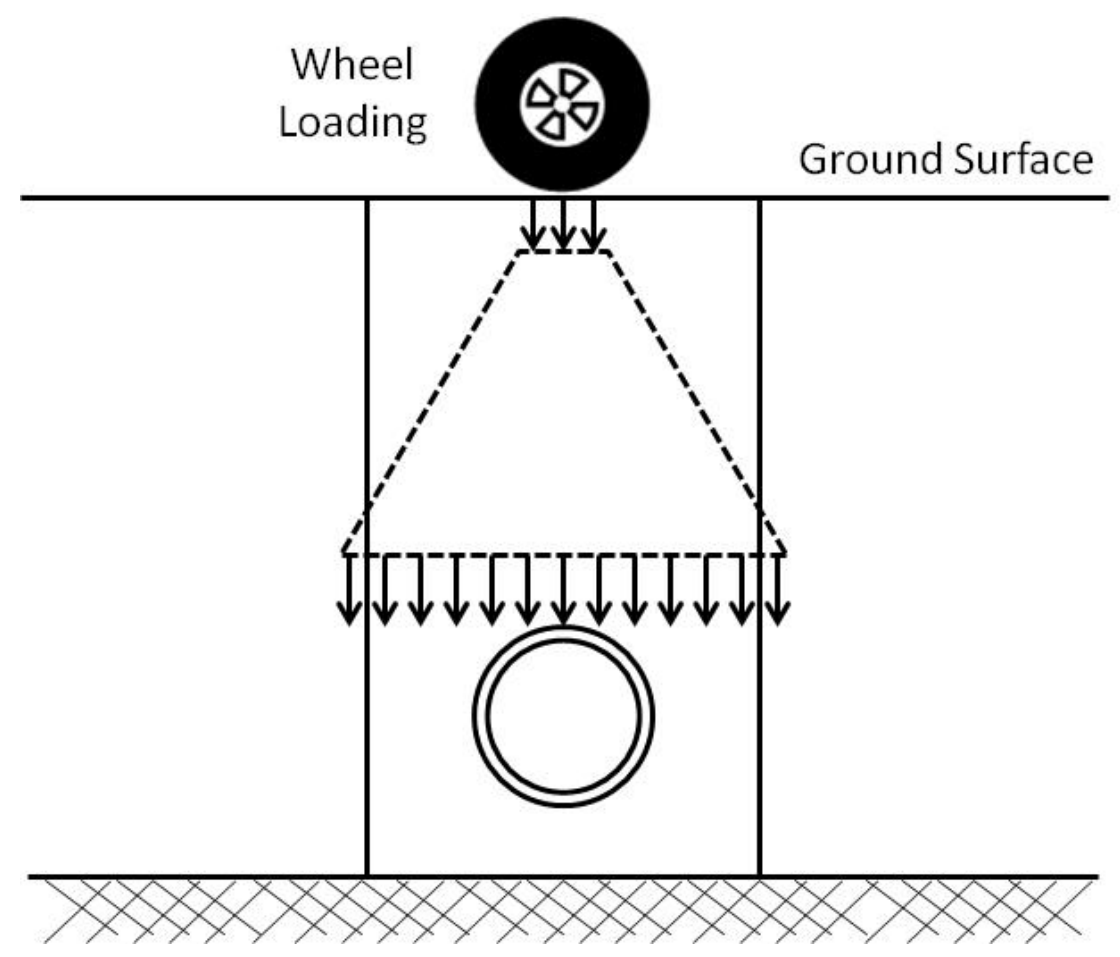

(a) without geosynthetic (prism loading)

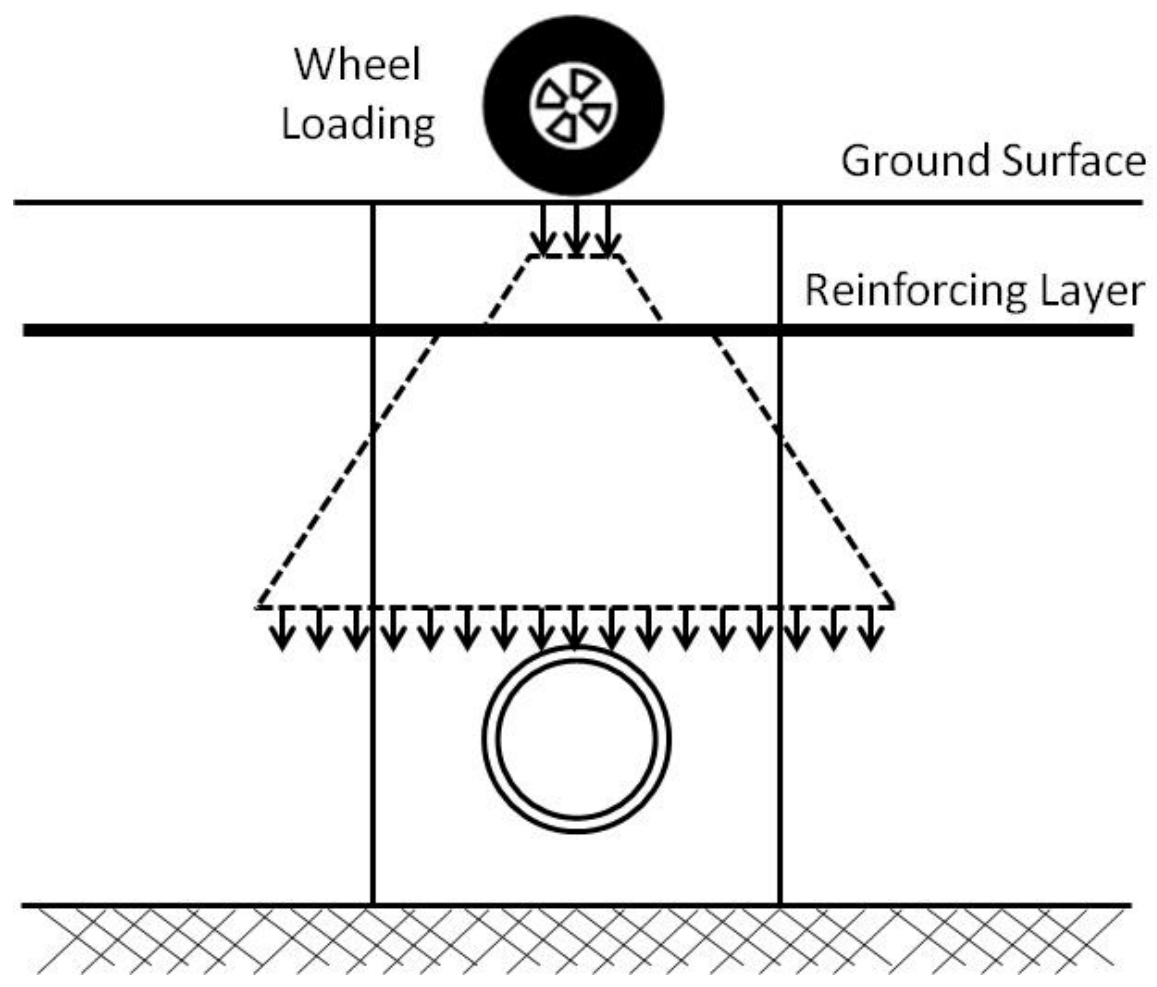

(b) with the inclusion of geosynthetic (prism loading)

Figure 1.3: Profile view of a geosynthetic layer used in buried pipe installation. 


\subsection{Previous studies}

Previous research studies at West Virginia University (Simmons, 2002; Mada, 2005; Gondle, 2006; Varre, 2011; Sesack, 2011) used flowable fill as backfill materials for buried pipes in numerical and experimental studies. The experimental study was limited to small diameter (6 inch and 8 inch) HDPE pipes (Simmons, 2002). Two-dimensional and three-dimensional finite element analyses were also performed on small (6 inch and 8 inch) and large diameter (18 inch and 24 inch) HDPE pipes under field conditions to investigate the structural performance of these pipes (Mada, 2005). The results of this research work shows that trench width ratios for the installation of buried pipes can be reduced to as low as 1.5 for pipe certain depths. The trench width ratio is defined as the ratio of trench width divided by the pipe diameter. In addition, the use of interface elements between the insitu and backfill soils were reported to have a significant influence on vertical pipe deflections (Mada, 2005). In a similar study, field tests and numerical simulations were conducted to analyze the performance of large diameter HDPE, PVC, and metal pipes that are installed under roadways (Arockiasamy et al., 2006). Pipes with diameters of 36 inch $(91.44 \mathrm{~cm})$ and 48 inch $(121.92 \mathrm{~cm})$ were tested at depths ranging from 1.5 feet to 8 feet under external loading conditions of 142-kN (32kip) per axel. Two-dimensional and three-dimensional finite element analyses were performed on field scale tests assuming the soil-pipe interface to be fully bonded. The findings of this research work show lower soil pressures at the crown of the pipe with an increase in the burial depth. Likewise, field scale tests and field-scale modeling work was performed and are reported in the literature (Faragher et al., 2000; Sargand and Masada, 2000; Phares et al., 1998; Conard, 1998). All of these modeling studies were limited and did not consider the transient behavior resulting from time-dependent characteristics (such as creep) of HDPE pipe.

The time-dependent nature of buried HDPE pipes was considered in another study (Gondle and Siriwardane, 2008; Gondle, 2006). Single-wall and double-wall corrugated HDPE pipes with burial depths up to 60 feet were considered. Results show that the majority of creep deformation takes place shortly after the initial pipe loading. This research work also reports that double-wall corrugated HPDE pipes (24 inch and 48 inch) can be successfully used for a service period of 50 years at depths of 20 feet with a trench width ratio of 1.5 while under live load conditions (HS-20 truck load) and the self-weight of the soil (Gondle and Siriwardane, 2008; Gondle, 2006). However, several reports show instances where buried pipes exceed tolerable displacements and are not meeting the expected service life under field conditions (Davis et al., 2007; Fleckenstein and Alan, 1993; Moore and Fuping, 1995). In addition to such failures, requirements for use of higher loading 
configurations (such as HS-25 truck loads) in buried pipe design may require exploration of new installation practices to enhance the performance and durability of buried flexible pipes.

The benefits gained from geosynthetic reinforcement on bearing capacity, settlement, and subgrade modulus have been recognized for some time now and are reported elsewhere (Moayedi, 2009; Koerner, 2005; Hinchberger, 2003; Alawaji, 2001). However, for buried pipe applications, limited field, lab, or computational tests have been completed. In a recent study (Tafreshi and Khalaj, 2008), laboratory tests were performed on pipes with geogrid as soil reinforcement. Laboratory experiments were carried out on small-diameter pipes buried in reinforced and unreinforced sand. Repeated loads were then administered with an objective to simulate traffic loading. Various parameters such as the number of reinforcing layers, depth of reinforcement, width of reinforcement, pipe embedment depth, and relative density of the surrounding soil were considered. Results of this particular laboratory test show reduced pipe deflections in reinforced sand. The optimal depth to place a reinforcing layer was found to be when the ratio of the depth of reinforcement to the width of the loading surface is equal to 0.35 . The study also states that reinforcement width needs to be long enough to fully mobilize

frictional resistance and recommends the minimum width of geogrid to be at least five times the pipe diameter. In addition, backfill soil with high density and soil stiffness reduced the pipe deflections. It should also be noted that the reinforcement was more effective at a lower relative density than higher relative density. In short, soil reinforcement was more beneficial in weak soil than strong soil.

\subsection{Research objectives}

The research objectives of the present research work include:

- Conduct a critical literature review to identify potential geosynthetic applications with buried pipes.

- Perform two-dimensional and three-dimensional finite element modeling of parallel plate loading test and compare the results with theoretical calculations.

- Perform three-dimensional finite element modeling of buried HDPE pipes with and without geosynthetic reinforcement 
- Compare the results from three-dimensional models to two-dimensional modeling and theoretical calculations.

- Determine the effectiveness of geosynthetic soil reinforcement in reducing the magnitude of vertical deflections in a buried pipe.

- Investigate the effects of geosynthetic positioning within the soil system.

- Perform sensitivity study on geosynthetic properties to determine what parameters influence the performance of the buried pipe

- Investigate the soil-geosynthetic interaction on the performance of the buried pipe.

\subsection{Report Summary}

The following chapters of the report include an in depth literature review, methodology for modeling a buried pipe with geotextile soil reinforcement, and the results from the modeling. Chapter 2 contains background information on geotextiles based on a literature review. Different geotextile types, geotextile functions and the mechanisms that allow those functions, as well as physical, mechanical, and endurance properties of geotextiles are discussed to build an understanding of how geotextiles can be implemented into other applications such as buried pipes. Chapter 3 is an overview of the concepts involved with buried pipes. In this chapter flexible pipe design characteristics of common flexible pipes, such as HDPE pipe, are described. Concepts of soil-pipe interactions are presented along with how aspects such as soil stiffness, soil shear strength, and soil arching can effect overall buried pipe design. Chapter 4 contains information on all aspects of the numerical modeling methodology. Background information such as element types and mathematical formulation of the Finite Element Method is discussed. Studies were carried out to choose appropriate modeling techniques for the pipe-geotextile system. Other characteristics of the modeling study discussed include the use of interactions and constraints, boundary conditions, and the loading step sequence. All of the material properties used for soil, pipe, and geotextile are also listed in this chapter. Chapter 5 contains the results of the numerical analysis of two pipe sizes. These results display data on geotextile effectiveness with varying: pipe depth, frictional resistance, geotextile stiffness, geotextile width, and trench stiffness. The conclusions drawn from these results can be found in Chapter 6 . 


\section{CHAPTER 2: OVERVIEW OF GEOTEXTILES}

\subsection{Introduction}

Geosynthetic materials are common to earth work in various applications such as drainage and reinforcement (Polomino et al, 2010; Ling et al, 2010; Koerner, 2005; Hinchberger, 2003; Alawaji, 2001); however, their use is limited in buried pipe applications. Installation of certain geosynthetics, such as geotextiles, in the soil above a buried pipe could lead to improved pipe performance by dissipating part of the surface loading over a larger area and consequently reduce pipe deflections. This is the topic of research presented in this report. More details on geotextiles are presented in subsequent sections of this chapter. Figure 2.1 shows typical applications of geotextiles. Details on other geosynthetic materials and their applications can be found elsewhere (Tahmasebi poor et al., 2010; Koerner, 2005; Holtz, 2001; Wang et al., 1996).

\subsection{Introduction to Geotextiles}

A geotextile is a permeable geosynthetic comprised solely of synthetic textile materials. Geotextiles are used with soil, gravel, and other materials to improve their structural performance in various engineered geotechnical systems. Geotextiles are usually made from synthetic polymers such as polypropylene, polyester, polyethylene, or polyamides (Koerner, 2005; Holtz, 2001). These polymers are formed into fibers or yarns which can be woven, knitted, or bonded together to form a fabric. Varying polymers and manufacturing processes result in an array of geotextiles suitable for a wide variety of civil construction applications (Koerner, 2005; Holtz, 2001). 

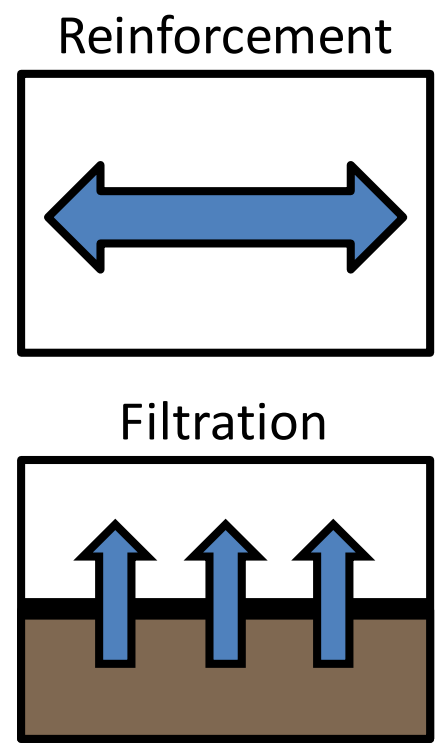
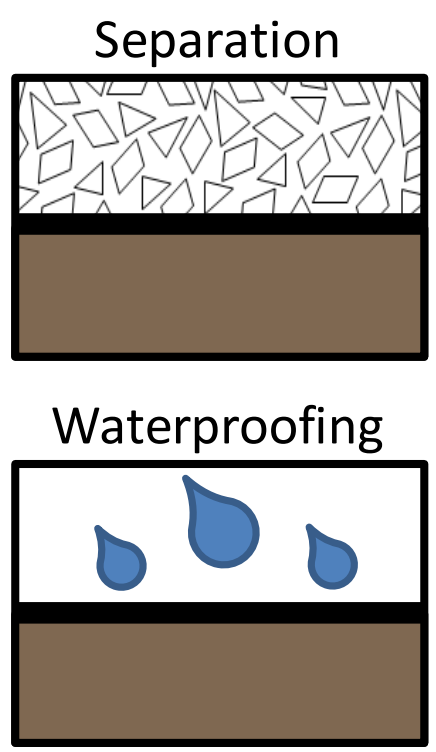
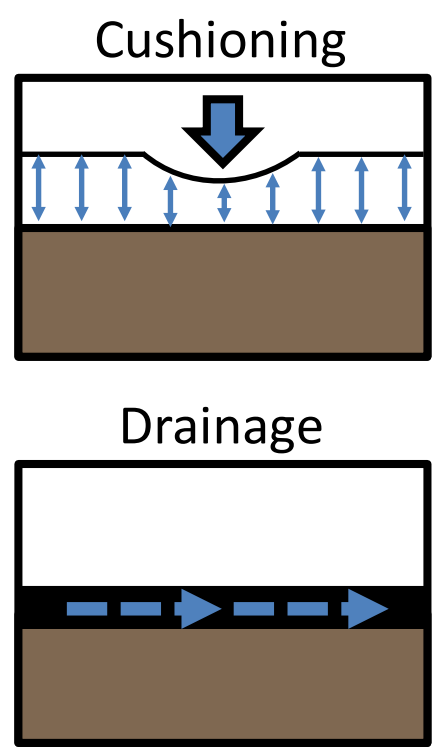

Figure 2.1: Various uses of geotextile.

\subsubsection{Non-woven Geotextiles.}

Non-woven geotextiles bear a resemblance to fabrics such as felt and are useful because they provide planar water flow through the fabric. For this reason they are commonly referred to as filter fabrics. Woven monofilament geotextiles can also be referred to as filter fabrics. Typical applications for non-woven geotextiles include aggregate drains, asphalt pavement overlays, and erosion control. Non-woven geotextiles have poor strength characteristics and are not used for soil reinforcement; therefore, they have been kept from consideration as a potential geosynthetic material to be used in the analysis portion of this research (Koerner, 2005; Holtz, 2001). Nonwoven geotextiles are typically available in two forms: needle punched and heat bonded (Koerner, 2005).

\subsubsection{Woven Geotextiles}

Woven geotextiles are planar textile fabrics formed by interlacing strands of polymeric fibers at right angles. Normally, two types of stands are used for their creation: slit films, which are flat and monofilaments, which are rounded. Woven slit-film geotextiles have high strength properties and are generally preferred when large loads are expected and filtration requirements are less critical. Once in place these fabrics can reduce localized shear failure in weak subsoil conditions. Woven monofilament geotextiles are favored for applications where both strength 
and filtration are a considered. Complete descriptions of the manufacturing methods of geotextiles can be found in references (Holtz, 2001; Koerner 2005).

\subsection{Geotextile Functions}

Geotextiles are undoubtedly the most versatile of all geosynthetics. They can fill many different roles within geotechnical and environmental engineering. Some of these functions include filtration, drainage, separation, and reinforcement. While all of these traits are significant, only those that are directly related to buried pipe applications are discussed below.

\subsubsection{Separation of dissimilar materials}

Geotextile materials can be placed between dissimilar materials so that the integrity and function of both materials can remain intact or be improved (Narejo, 2003). When stone aggregate is placed on fine-grained soil such as silt or clay there are two mechanisms that tend to occur simultaneously with time. The first mechanism is that fine soils try to fill the voids of the stone aggregate resulting in diminished drainage capabilities for the aggregate; this is known as soil pumping. The other mechanism is aggregate intrusion, which is the tendency of the stone to sink into the fine soil, reducing the stone aggregate's strength (Koerner, 2005). Both of these problems can be avoided with the proper placement of a geotextile between soil layers. Figure 2.2 illustrates the different mechanisms involved in the use of geotextiles for separation. 


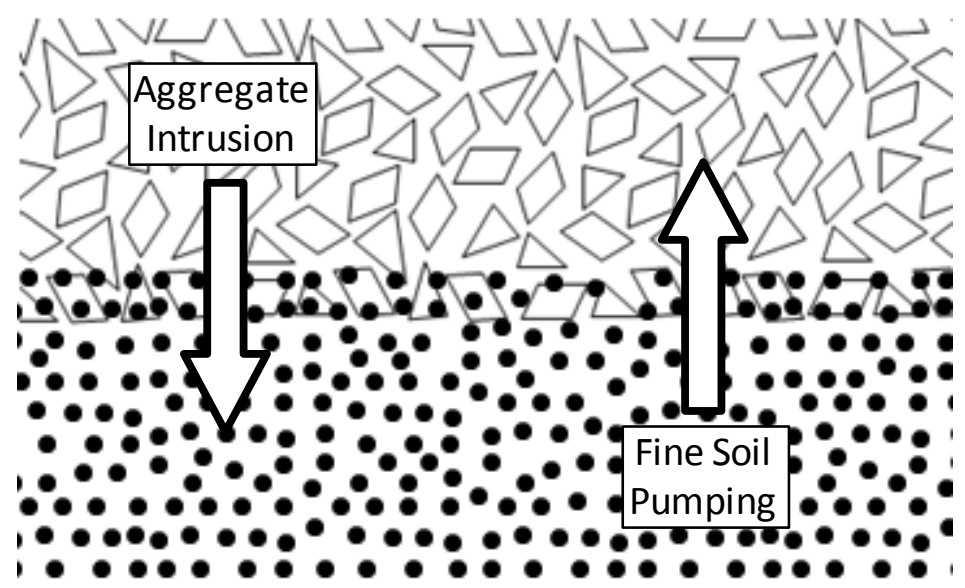

(a) without geotextile

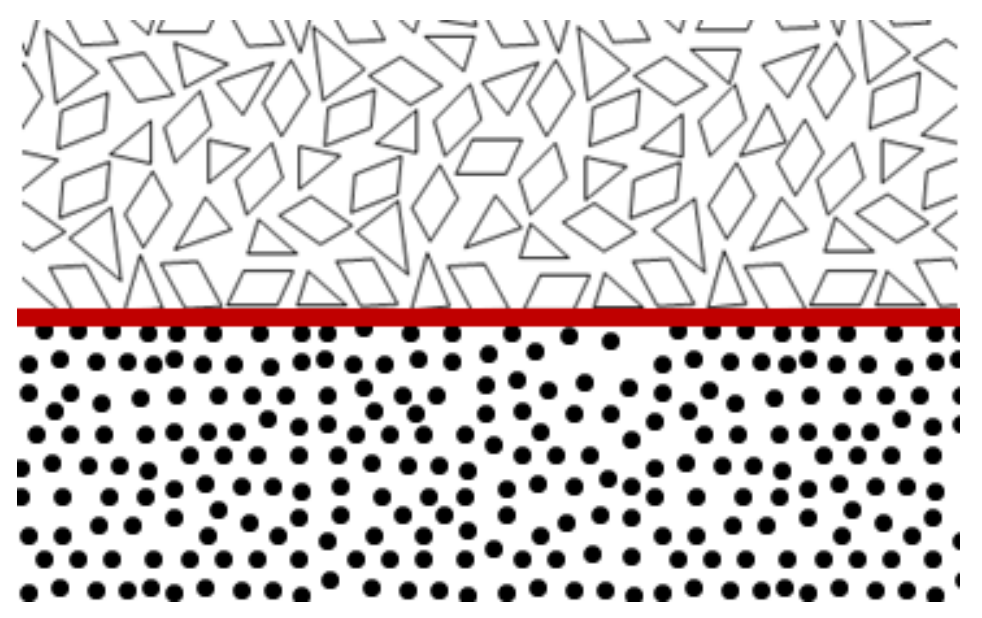

(b) with geotextile

Figure 2.2: Illustration of geotextile as separator.

\subsubsection{Use of Geotextile as a Reinforcement}

Geotextile can be used as a reinforcement layer to improve the strength of a soil system. Geotextile materials have a high tensile strength and soils have high compressive strength but low tensile strength (Koerner, 2005). Since geotextile materials have high tensile strength, placing them within a soil layer results in a reinforced soil with improved strength properties. Improvement in strength can be evaluated in a number of ways.

- Triaxial Tests: Geotextile reinforcement interrupts the potential shear planes in a soil resulting in an increase of the overall shear strength of the reinforced soil. Triaxial 
testing can measure this increase when comparable tests are performed on reinforced and unreinforced soils. (ASTM D7181, 2011).

- Anchorage (Pull out) Tests: This test determines the anchorage strength, or the magnitude of force needed to pull a geotextile from the soil in which it is embedded as described in the literature (Ingram, 2007; Niemic, 2005; Gurung and Iwao, 1999).

- Numerical Modeling (Finite Element Analysis): This method of analysis can be used as an alternative to field scale modeling and laboratory experiments. Through numerical modeling, a countless number of experimental variations can be tested (Karim et al., 2011; Kazemian et al., 2010; Tahmasebipoor et al., 2010; Ling et al, 2010; Villard, 2009; Siriwardane et al., 2008; Cook et al., 2003).

There are three types of reinforcement mechanisms when geotextile is used as reinforcement in soils: (a) membrane type, (b) shear type, and (c) anchorage type. These are mechanisms are described briefly below.

(a) Membrane Type. When a vertical force is applied to a geotextile that has been placed over a deformable subgrade, membrane reinforcement occurs. Depending on the depth at which the geotextile is placed, as illustrated in Figure 2.3, it has been shown that (Koerner, 2005):

$$
\sigma_{h}=\frac{P}{2 \pi \cdot z^{2}}\left[3 \sin ^{2} \theta \cos ^{3} \theta-\frac{(1-2 \mu) \cos ^{2} \theta}{1+\cos \theta}\right]
$$

where

$$
\begin{array}{ll}
\sigma_{h} & =\text { horizontal stress in the membrane at depth } z \text { and angle } \theta, \\
P & =\text { applied vertical force, } \\
Z & =\text { depth beneath surface where } \sigma_{h} \text { is being calculated, } \\
\mu & =\text { Poisson's ratio, and } \\
\theta \quad & =\text { angle from the vertical beneath the surface load } P .
\end{array}
$$

When the point of interest is directly beneath the load, angle $\theta=0 \mathrm{deg}$, the horizontal stress in the membrane can be expressed as: 


$$
\sigma_{h}=-\frac{P}{2 \pi \cdot z^{2}}\left(\frac{1}{2}-\mu\right)
$$

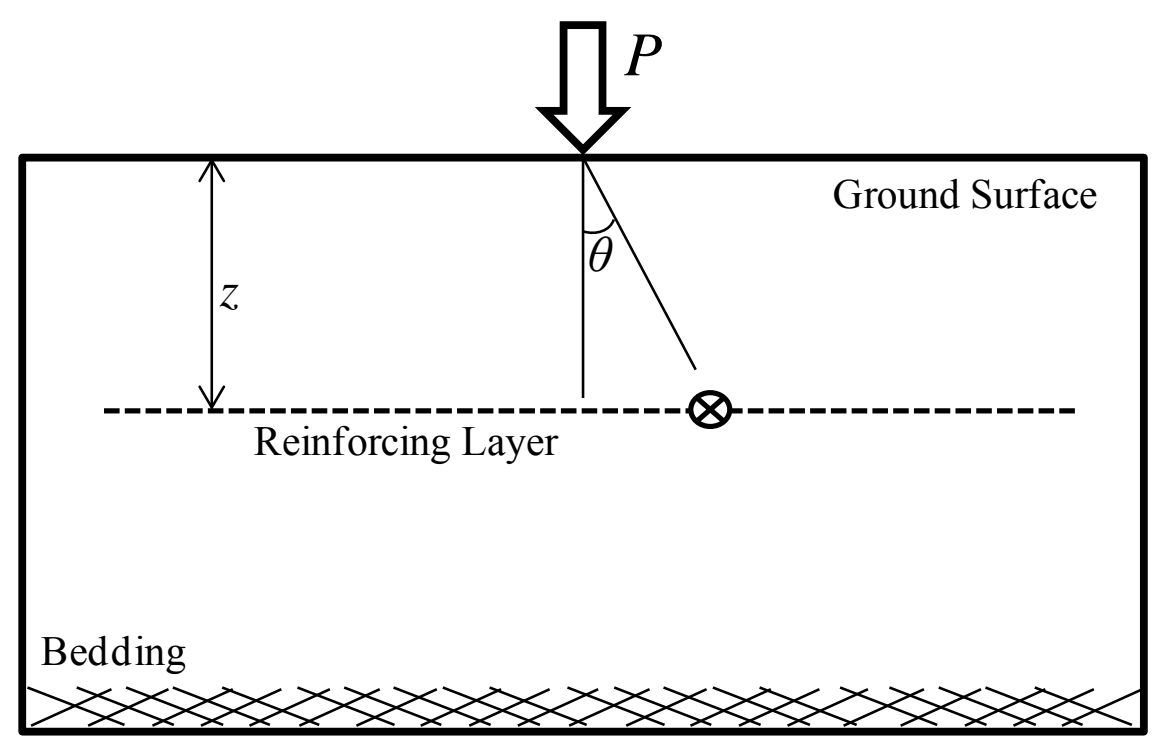

Figure 2.3: Diagram of membrane effect dimensions.

When a vertical load is applied to the geotextile in this situation, a negative horizontal stress is formed in the plane of the geotextile. In other words, tension is created. This mechanism is what allows for soil reinforcement when using geotextiles in this way. As can be seen from Equation 2.2, as the magnitude of $P$ increases, so does the tensile stress, resulting in a higher requirement of tensile strength for the geotextile. Also, the farther the geotextile is from the applied force (i.e., high values for $z$ ), the lower the applied tensile stress will be on the geotextile (Koerner, 2005).

This particular mechanism is often demonstrated when a geotextile is placed over a soft soil and is used relatively frequently today to help stabilize unpaved roadways (Koerner, 2005; Henry, 1999). There are also beneficial effects when incorporated under paved roadways and various other structures, including foundations (Basudar et al, 2007; El Sawwaf, 2007; Koerner, 2005; ). Reinforcement results in several benefits such as increased soil strength, enhanced load spreading, and membrane support. These benefits can be illustrated as follows (Koerner, 2005; Moayedi, 2009): 
- Increased soil strength: Subgrade strength resulting from reinforcement can be seen through the comparison of Equations 2.3 and 2.4. It should be noted that these equations are for the case of an unpaved road and would not be suitable for calculating bearing capacity for other applications such as with a paved road or under the base of a foundation.

$$
\begin{gathered}
p_{e}=\pi c_{u N}+\gamma h_{o} \\
p_{\lim }=(\pi+2) c_{u N}+\gamma h
\end{gathered}
$$

where

$$
\begin{aligned}
& p_{e} \quad=\text { bearing capacity pressure based on the elastic limit (nonreinforced } \\
& \text { case), } \\
& p_{\text {lim }} \quad=\text { bearing capacity pressure based on the plastic limit (reinforced case), } \\
& c_{u N} \quad=\text { undrained soil strength at the Nth vehicle passage, } \\
& \gamma \quad=\text { unit weight of aggregate, } \\
& h_{o} \quad=\text { aggregate thickness without reinforcement, and } \\
& h \quad=\text { aggregate thickness with reinforcement. }
\end{aligned}
$$

- Enhanced Load Spreading: Improved load distribution in the soil subgrade is a result of load spreading by the geosynthetic. Figure 2.4 shows the concept of pyramidal load distribution in the vertical direction in soils without reinforcement. The inclusion of geosynthetic can result in a larger distribution angle $(\alpha)$ and thus a larger area to distribute the vertical load. This concept was also illustrated with Figure 1.3 in Chapter 1.

- Membrane support: A tensioned membrane effect is a result of the tensile modulus, elongation of the geotextile, and the deformation of the subgrade surface. In order for this to take effect the geotextile must have enough anchorage to resist slip. 


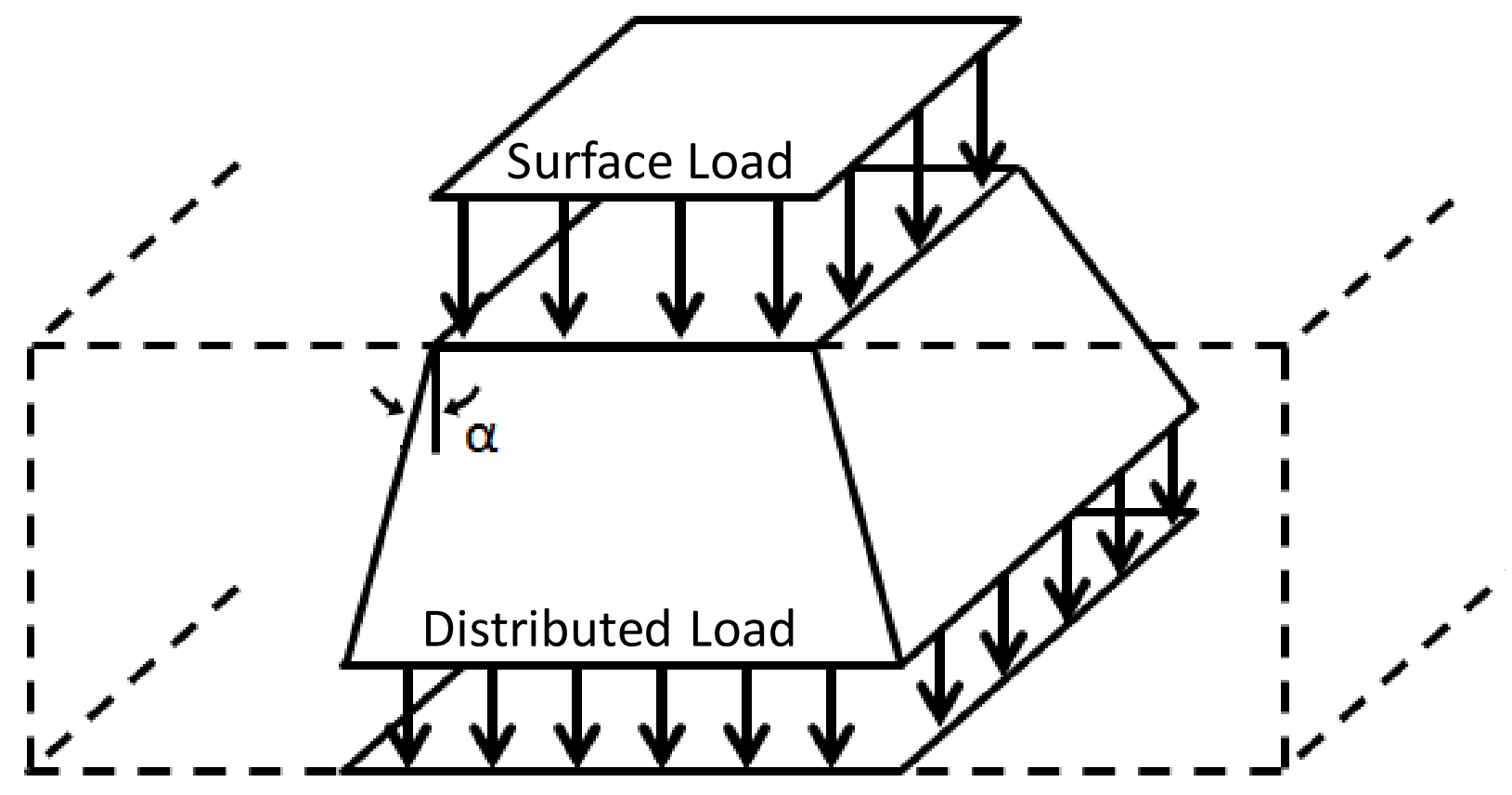

Figure 2.4: Concept of pyramidal load distribution.

(b) Shear Type. Shear reinforcement can be conceptualized with a direct shear test. In this test, a geotextile is placed on a soil and is loaded in the normal direction. After enough force is applied, the two materials are sheared at their interface. An illustration of a direct shear apparatus which incorporates a geotextile is shown in the Figure 2.5. From the resulting data, geotextile-to-soil shear strength parameters, adhesion and angle of friction, can be determined by using an adapted form of the Mohr-Coulomb failure criterion,

$$
\tau=c_{a}+\sigma_{n}^{\prime} \tan \delta
$$

where

$$
\begin{aligned}
& \tau \quad=\text { shear strength (between the geotextile and soil), } \\
& \sigma_{n}^{\prime} \quad=\text { effective normal stress on the shear plane, } \\
& c_{a} \quad=\text { adhesion (of the geotextile on the soil), and }
\end{aligned}
$$


$\delta \quad=$ friction angle (between the geotextile and soil).

This can be compared to the shear strength parameters of soil by itself (i.e. soil against soil) as follows:

$$
\tau=c+\sigma_{n}^{\prime} \tan \phi
$$

where,

$c \quad=$ cohesion (soil-to-soil), and

$\varphi \quad=$ friction angle (soil-to-soil)

Results from these tests have limiting ratios for cohesion and angle of friction, generally known as efficiencies. These efficiencies range from $0 \%$ to $100 \%$ depending on the soilgeosynthetic interaction (Koerner, 2005). Limiting values higher than one hundred percent can occur but these values cannot be mobilized since the failure plane would move into the soil itself, thus reverting to the situation described in Equation 2.6. These efficiencies are shown as follows (Koerner, 2005).

$$
\begin{gathered}
E_{c}=\left(\frac{c_{a}}{c}\right) \cdot 100 \% \\
E_{\phi}=\left(\frac{\tan \delta}{\tan \phi}\right) \cdot 100 \%
\end{gathered}
$$

where

$$
\begin{aligned}
& E_{c} \quad=\text { efficiency of cohesion mobilization, and } \\
& E_{\varphi} \quad=\text { efficiency of soil friction angle mobilization. }
\end{aligned}
$$




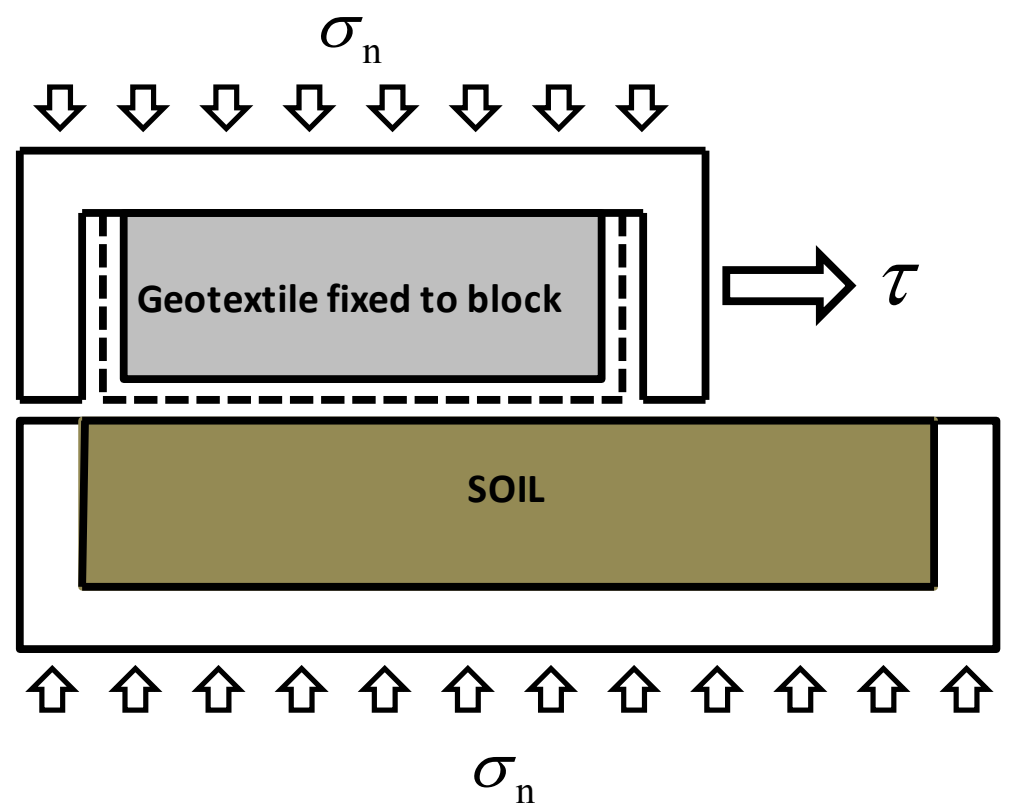

Figure 2.5: Illustration of geotextile direct shear test.

(c) Anchorage Type. Anchorage reinforcement plays a role in most aspects of geotextile reinforcement. While soil acts on both sides of the geotextile, creating frictional resistance, tensile force attempts to pull the geotextile out of the soil; this mechanism is also commonly referred to as a geotextile's anchorage strength, or pullout resistance, and can be evaluated through the use of a pullout test. A diagram of a typical laboratory setup for this procedure is show in Figure 2.6 below. During this test the upper and lower soil layers remain stationary while compressive loading, normal to the geotextile plane, is applied to the geotextile-soil setup. Simultaneously, tension is applied to the geotextile by a device which pulls the geotextile laterally from the test box setup. This situation can be described in terms of shear strength parameters and efficiencies as previously discussed for the shear type reinforcement. Efficiency can also be expressed as a function of the amount of mobilized geotextile strength; wide-width tensile values should be used in this case. It is possible to achieve anchorage efficiencies greater than $100 \%$ in this situation, but these cases are usually limited by the tensile strength of the geotextile (Koerner, 2005; Gurung and Iwao, 1999). 


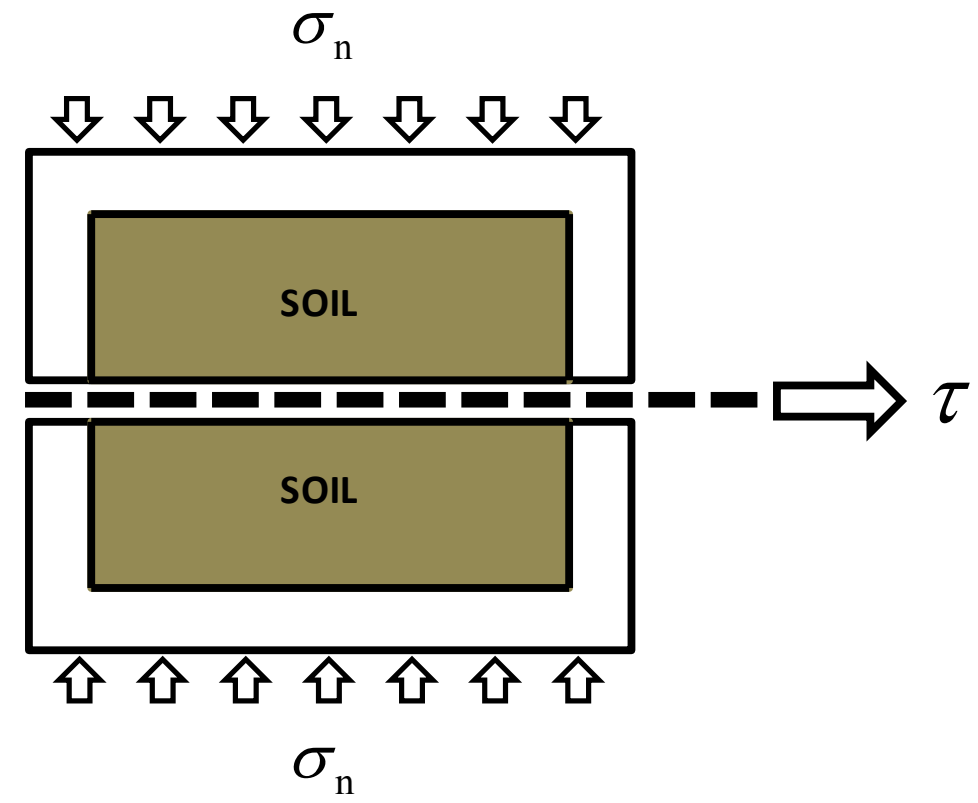

Figure 2.6: Illustration of pullout test.

\subsubsection{Geotextile Failure Modes}

When using geotextiles as reinforcement, there are four possible modes of failure to consider. These failure modes are listed and described below (Koerner, 2005).

- Bearing capacity failure above the geotextile. This form of failure can be avoided when the upper geotextile (layer closest to the surface) is within $300 \mathrm{~mm}$ (approximately $1 \mathrm{ft}$.) of the ground surface.

- Anchorage pullout of geotextiles due to inadequate length of embedment. When the geotextile extends far enough past the potential failure zone to activate the required resisting anchorage force, this type of failure can be avoided.

- Tensile failure breaking of geotextiles. When the tensile force applied to the geotextile exceeds its tensile strength, tensile failure occurs. 
- Excessive long-term deformations (creep). Sustained surface loads and subsequent stress relaxation of the geotextile can cause excessive deformations to occur over time. Once this happens, the fabric can no longer provide the prescribed level of reinforcement.

\subsection{Geotextile Properties and Test Methods}

Due to the variety of manufacturing process involved in the production of geotextiles many different products are available (Das, 2011; Koerner, 2005). These products are categorized into physical, mechanical, and endurance properties. Physical properties are typically tangible and easily measured, whereas mechanical properties are less obvious to determine and require laboratory experiments. Endurance properties describe how the material will perform over long periods of time. All of these attributes are important to consider when selecting a geotextile for a given project. In this study, creep behavior is not considered.

\subsubsection{Physical Properties}

Specific Gravity. Specific gravity is defined as the ratio of the mass of a material to that of an equal volume of distilled water at a temperature of $4^{\circ} \mathrm{C}$. The polymeric materials which make up the fibers of a geotextile are the main determinant of the fabric's specific gravity. Listed below are some typical specific gravity values for the polymeric materials that are commonly used to make geotextiles (Koerner, 2005).

- $\quad$ Specific gravity of Polyvinyl chloride $=1.69$

- $\quad$ Specific gravity of Polyester $=1.38$ to 1.22

- Specific gravity of Nylon $=1.14$ to 1.05

- Specific gravity of Polyethylene $=0.96$ to 0.90

- Specific gravity of Polypropylene $=0.91$

Mass per Unit Area (Weight). When dealing with geotextiles it is common to refer to the "weight" of the geotextile as the mass per unit area of the fabric. This value is usually given in units of grams per square meter $\left(\mathrm{g} / \mathrm{m}^{2}\right)$. While the previously stated units are the most appropriate to use when describing geotextiles, other values are listed in literature such as grams 
per linear meter for a fabric of a given width. Methods in testing this property are described in ASTM D3776.

Thickness. The thickness of a geotextile is measured as the distance between the upper and lower surface of the fabric, measured at a specific pressure. The specifications listed by ASTM D5199-12 state that the thickness of a geotextile is to be measured under a pressure of 2.0 $\mathrm{kPa}(0.29 \mathrm{psi})$ to an accuracy of $+/-0.02 \mathrm{~mm}$ ( $7.8 \times 10^{-4}$ inches $)$. Commonly used geotextiles have thicknesses in the range of 0.25 to $3.5 \mathrm{~mm}$ ( 0.01 to 0.14 inches). While geotextile thickness is sometimes mentioned in specifications, it is actually more of a descriptive property than a design-oriented property, having a negligible effect on design dimensions.

Stiffness. The stiffness of a geotextile is a measure of the rigidity of the fabric and is not to be confused with its elastic modulus. The test method for determining the stiffness of a geotextile is described in ASTM D1388. This property is mainly used as indication of whether a geotextile will provide a suitable working surface during construction. It is desirable to place a stiff geotextile over soft soils (Koerner, 2005).

\subsubsection{Mechanical Properties}

Compressibility. The compressibility of a geotextile is a measure of the variation of its thickness with as a function of the magnitude of applied normal stress. Typically, compressibility is not a concern when using geotextiles for reinforcement since the compressibility of most fabrics is relatively low and has little influence as far as design is concerned (Koerner, 2005). Compressibility does have an affect over nonwoven needle punched or bulky resin-bonded geotextiles; however, these influences deal with the conveyance of liquids and fall outside of the scope of this paper.

Tensile Strength. One of the most important properties of a geotextile is its tensile strength. This is an important factor in nearly all geotextile applications, both as a primary function (as in reinforcement applications) and as a secondary function (as in separation, filtration, or drainage). Tensile strength of geotextile is determined by using a machine which binds opposite ends of the fabric and stretches it at a constant rate until failure occurs (ASTM D4595). During this process both load and deformation are measured in such a way that a stressversus-strain curve can be produced. It is common practice that tensile stress for geotextile is 
given in units of force per unit width of the fabric (i.e. $\mathrm{kN} / \mathrm{m}$ or $\mathrm{lbs} / \mathrm{ft}$ ). It should be noted that this is not a true stress unit and would need to be divided by the fabric's thickness to obtain true stress values; however, this is not a conventional practice since the thickness of the fabric can vary greatly under loading and during the extension process.

In order to obtain modulus values from stress-versus-strain curves produced from geotextile testing one must measure the initial slope of the curve. There are several methods available for this measurement (Koerner, 2005):

- Initial tangent modulus. This method is used for many woven and nonwoven heatbonded geotextiles. The initial slope for these types of fabrics is normally linear, allowing for accurate modulus values to be obtained.

- Offset tangent modulus. When the initial slope is very low, such as with nonwoven needle-punched geotextiles, the offset tangent moduls concept is sometimes used. To obtain this modulus, the initial portion of the curve is omitted from analysis and the yaxis is essentially shifted to the right where it meets the linear portion of the response curve.

- Secant modulus. This method can be used to avoid some of the potential inconsistencies of the previously mentioned methods. Here one can stipulate the procedure of obtaining a modulus value (e.g. secant modulus at $10 \%$ strain). Thus, a line can be drawn from the origin of the axis to the designated point on the curve for the desired strain level. The slope of this line will give a fairly accurate value for the secant modulus of the fabric.

Friction Behavior. Often times it is necessary to know the soil-to-geotextile friction behavior for various engineering problems. To determine this, the common practice is to use an adaptation of the direct shear test with the geotextile securely fixed to one half of the testing apparatus and soil in the other half as illustrated in Figure 2.5. Once a normal force is applied and reaches equilibrium, shearing forces are enacted until sliding occurs between the geotextile and soil. After a series of tests are run at varying normal stresses, Mohr-Coulomb failure 
parameters (adhesion and friction angle) can be established for the soil-geotextile interface. It should be noted that the soil's shear strength parameters are the upper limit to a soil-geotextile interaction. This means that if the soil-geotextile interface is stronger than the soil itself, failure would first occur in the soil and not in the plane of the soil-geotextile interaction. Table 2.1 provides an example of soil-to-geotextile friction angles and efficiencies in selected cohesionless soils.

Table 2.1: Peak soil-to-geotextile friction angles and efficiencies (in parenthesis) in cohesionless soils (Koerner, 2005).

\begin{tabular}{lccc}
\hline & \multicolumn{3}{c}{ Soil Type } \\
\cline { 2 - 4 } Geotextile Type & $\begin{array}{c}\text { Concrete Sand } \\
\left(\phi=30^{\circ}\right)\end{array}$ & $\begin{array}{c}\text { Rounded Sand } \\
\left(\phi=28^{\circ}\right)\end{array}$ & $\begin{array}{c}\text { Silty Sand } \\
\left(\phi=26^{\circ}\right)\end{array}$ \\
\hline Woven, monofilament & $26^{\circ}(84 \%)$ & --- & --- \\
Woven, slit-film & $24^{\circ}(77 \%)$ & $24^{\circ}(84 \%)$ & $23^{\circ}(87 \%)$ \\
Nonwoven, heat-bonded & $26^{\circ}(84 \%)$ & --- & --- \\
Nonwoven, needle-punched & $30^{\circ}(100 \%)$ & $26^{\circ}(92 \%)$ & $25^{\circ}(96 \%)$ \\
\hline
\end{tabular}

Pullout (Anchorage Strength) Tests. Geotextiles are often used to provide anchorage for many applications within the area of reinforcement. This anchorage is the result of having the geotextile held between soil layers on each side. The anchorage resistance can be modeled in the laboratory using a pullout test as previously described in Section 2.3.2. Pullout resistance is dependent on the normal force applied to the geotextile. This normal force is what mobilizes frictional resistances on both surfaces of the geotextile.

Seam Strength. It is often necessary to bind the ends of geotextile together in order to transfer tensile stress between them. This can be the case when the standard geotextile roll size is not large enough to cover the designated area. The method most commonly used is sewing the geotextile together. Various methods of sewing can be implemented but they must all be laboratory evaluated for their load transfer abilities. Testing method for seam strength can be found in ASTM D4884. It should be noted that seam strength is never as strong as the fabric itself, with properly made attachments having approximately $85 \%$ the total strength (Koerner, 2005). Also, as the geotextile strength becomes higher, seam strengths become progressively less efficient. 


\subsubsection{Endurance Properties}

Creep. For a geotextile, creep is defined as the elongation of the fabric under a constant load with time. This can be an important property since polymers are generally considered to be creep sensitive materials and many geotextiles are made from polymers. For testing creep, specimens are usually stressed by means of hanging weights over long periods of time. Details of such experiments can be found in other references (Betten, 2002; Findley and Davis, 1989). The creep behavior of geotextile varies depending mostly on polymer type and the manufacturing processes used in its creation. A creep reduction factor is sometimes necessary in design to avoid excessive creep deformation values (Koerner, 2005).

It can often be necessary to assess the long-term residual deformation of geosyntheticreinforced soil structures. To do so, one must be able to evaluate the time-dependent, stressstrain behavior not only of the soil, but of the geosynthetic reinforcement as well. Predicting the amount of tensile load mobilized by geosynthetic reinforcement can be difficult. For example, if loading applied to a geosyntetically reinforced structure is kept constant for a given duration, it is possible that the tensile load activated in the geosynthetic reinforcement could decrease with time due to the deformation of the backfill and associated stress relaxation of the reinforcement (Hirakawa, 2003). In the study presented in this report, creep behavior was not considered. 


\section{CHAPTER 3: BURIED PIPES}

\subsection{Introduction}

Buried pipes are used all over the world for various applications such as water conveyance, sewage, highway drainage, and landfill drainage. With such high usage of buried pipes, it is important to find ways to enhance their performance. Evaluation of buried pipe performance requires some understanding of soil-pipe interactions. Analysis of soil-pipe interactions has led to more suitable pipe and backfill materials, improved pipe profiles, and new design procedures (Varre, 2011; Arockiasamy et al. 2006; Gondle, 2006; Mada, 2005; Won et al., 2004; Simmons, 2002). The work presented in this paper is an extension of previous work and includes the use of geosyntetic materials as a reinforcement of soil above the buried pipe.

One of the first advancements related to the science of buried pipes came from Marston in the early 1900s when the Marston Load Theory was developed for calculating the soil load on buried conduits (Marston, 1930). Later, this theory was modified to consider the soil load on flexible pipes, which have different design considerations than rigid conduits (Spangler, 1941). Today, powerful digital computing systems along with advanced numerical techniques, such as the finite element method, allow for the use of sophisticated soil models that help to make even greater contributions to pipe performance (Varre, 2011; Dhar and Kabir, 2006; Gondle, 2006; Mada, 2005; Conard et al., 1998).

For proper functionality a pipe must have enough strength and/or stiffness to perform its intended purpose. Durability is also a very important characteristic so that the pipe survives its intended design life. There are many different types of piping materials available on the market today ranging from rigid concrete to flexible thermoplastic pipes such as HDPE (High Density Polyethylene) pipes, PVC (Polyvinyl Chloride) pipes (Moser, 2008). Strength, stiffness, corrosion resistance, abrasion resistance, weight, flexibility and ease of joining are often deciding factors for choosing a particular type of pipe for a given project.

The two most basic categories of buried pipes are rigid pipes and flexible pipes. The American Water Works Association (AWWA) has classified pipes based on deflection, as listed in Table 3.1 (AWWA, 2002). 
Table 3.1: Pipe Flexibility Rating (AWWA, 2002).

\begin{tabular}{cc}
\hline Pipe Classification & Percentage Deflection Before Damage \\
\hline Rigid & 0.1 \\
Simi-rigid & $<3.0$ \\
Flexible & $>3.0$ \\
\hline
\end{tabular}

Flexible pipes will be the focus in this paper since they are frequently used in filed applications. Flexible pipes can be made from polymeric or metallic materials. The ways in which these materials react to loading are very different. Metal pipes show elastic properties where plastic pipes tend to be more viscoelastic in nature. There are many different kinds of metal and plastic pipes. Plastic pipes are made from an assortment of polymers (e.g. HDPE, PVC, etc.) in various structural configurations (e.g. double-wall corrugated, single-wall corrugated, non-corrugated, etc.) (ADS, 2012; Mada, 2005; AWAA, 2002; Chamber et al, 1980).

\subsection{Flexible Pipe Design}

The performance of a buried pipe is not determined by the properties of the pipe alone. The surrounding soil mass also plays a critical role in the overall performance of the pipe. The relationship between the backfill material, in-situ soil, and pipe is typically referred to as the soil-pipe interaction (Goddard, 2003). Factors effecting the soil-pipe interaction include: choice of backfill material, pipe profile, pipe material, environmental conditions, and installation practices (Gondle, 2006).

Buried pipes are defined by the American Association of State Highway and Transportation Officials (AASHTO) as a composite structure comprised of a conduit (such as HDPE pipe) and soil envelope. Over time a portion of the loading projected onto the pipe could be transferred to the surrounding soil. To account for this behavior, AASHTO recommends careful consideration of all aspects of buried pipe design including the behavior of the material beneath, above, and adjacent to the structure as well as the pipe itself. A typical pipe cross section and trench arrangement are illustrated below in Figures 3.1 and 3.2 respectively. 


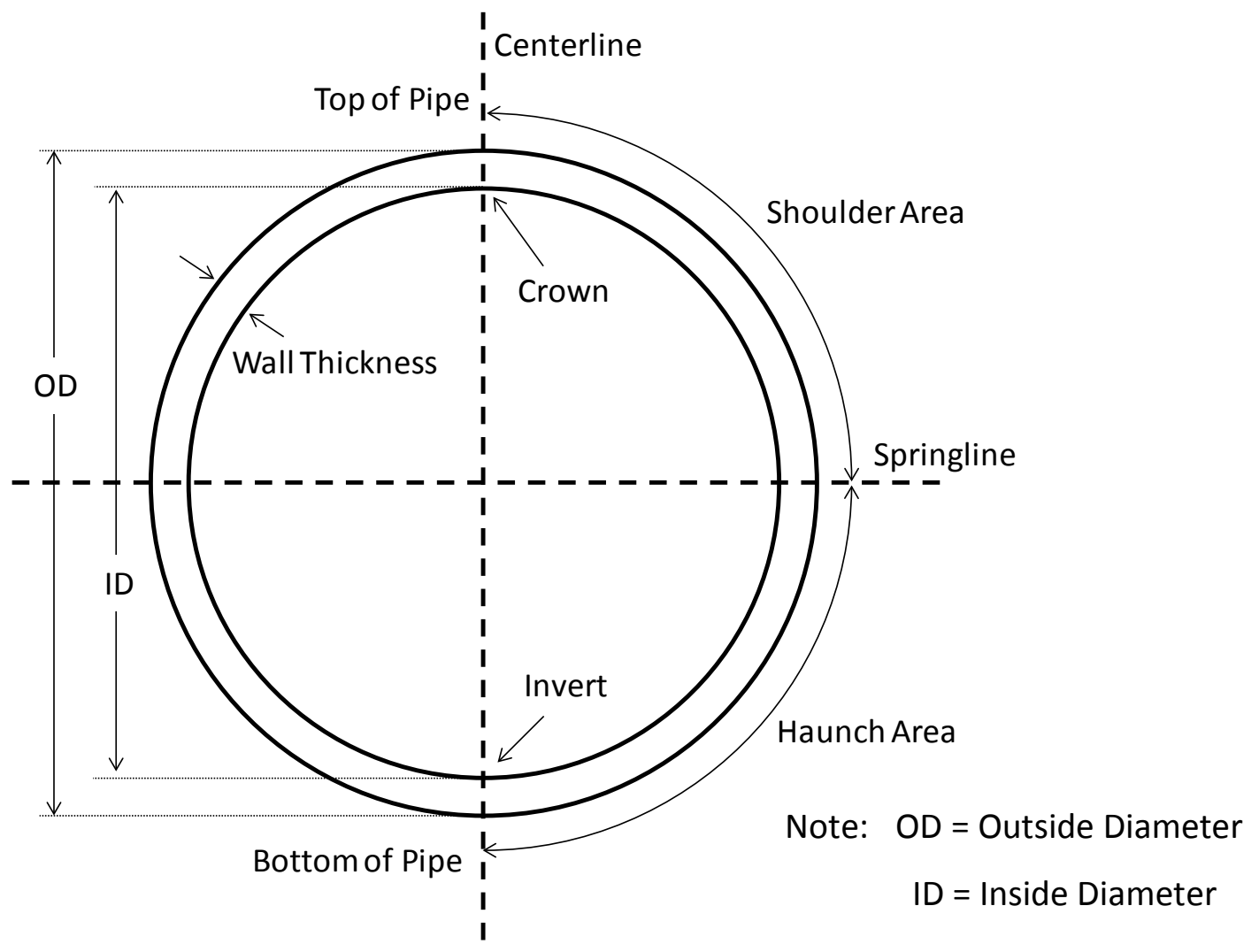

Figure 3.1: Typical pipe cross section.

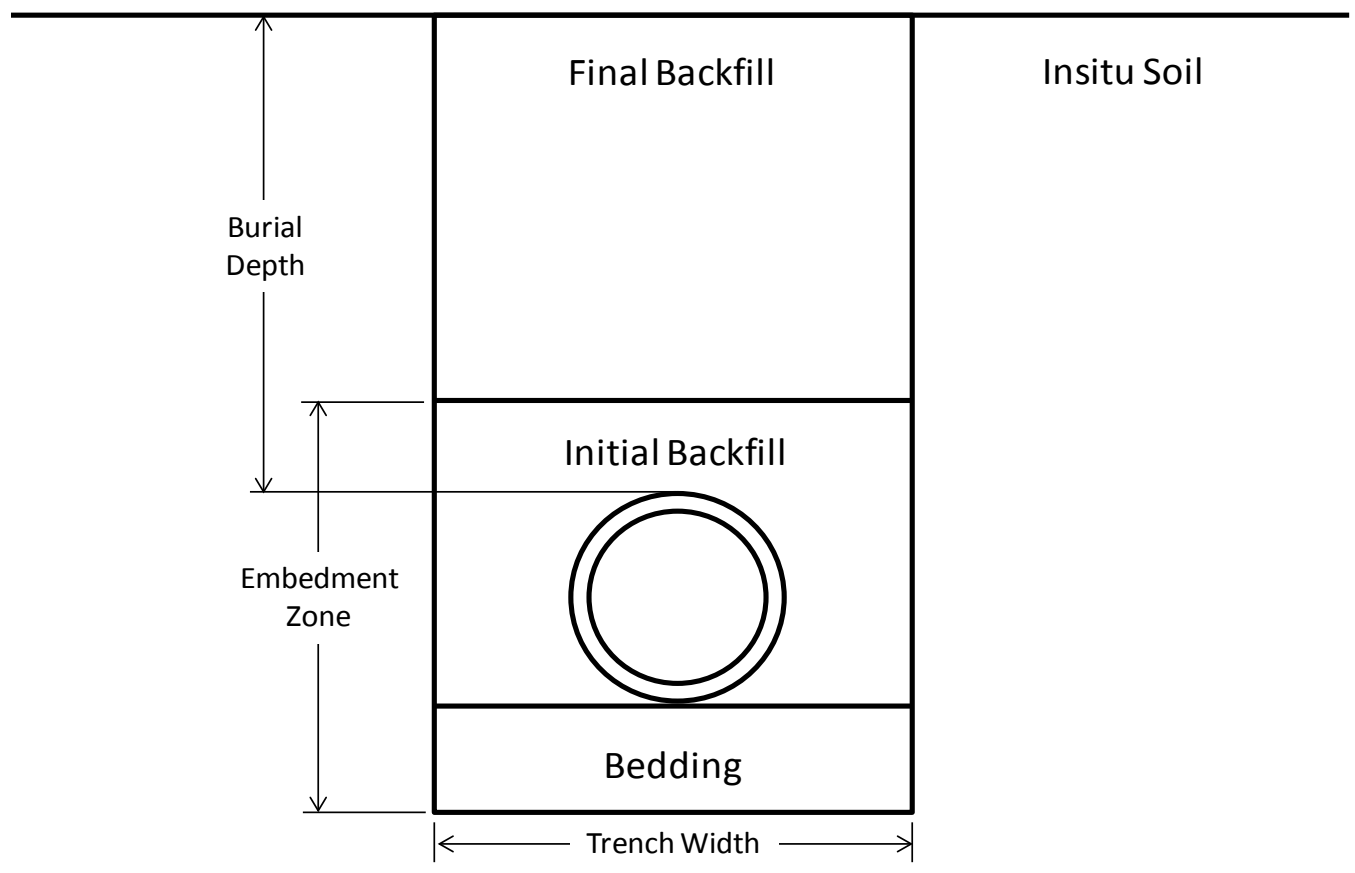

Figure 3.2: Typical trench arrangement for buried pipe. 
Flexible pipes deflect under vertical forces caused by overlaying strata and/or surface loading. When vertical forces are applied passive pressures are induced as the sides of the pipe try to expand into the surrounding soil, redistributing pressure from the top of the pipe into the surrounding soil (Moser, 2008). This behavior, along with the creep properties of the pipe material, can make the understanding of flexible buried pipes complex. Figure 3.3 is an illustration of flexible pipe deflection due to vertical loading.

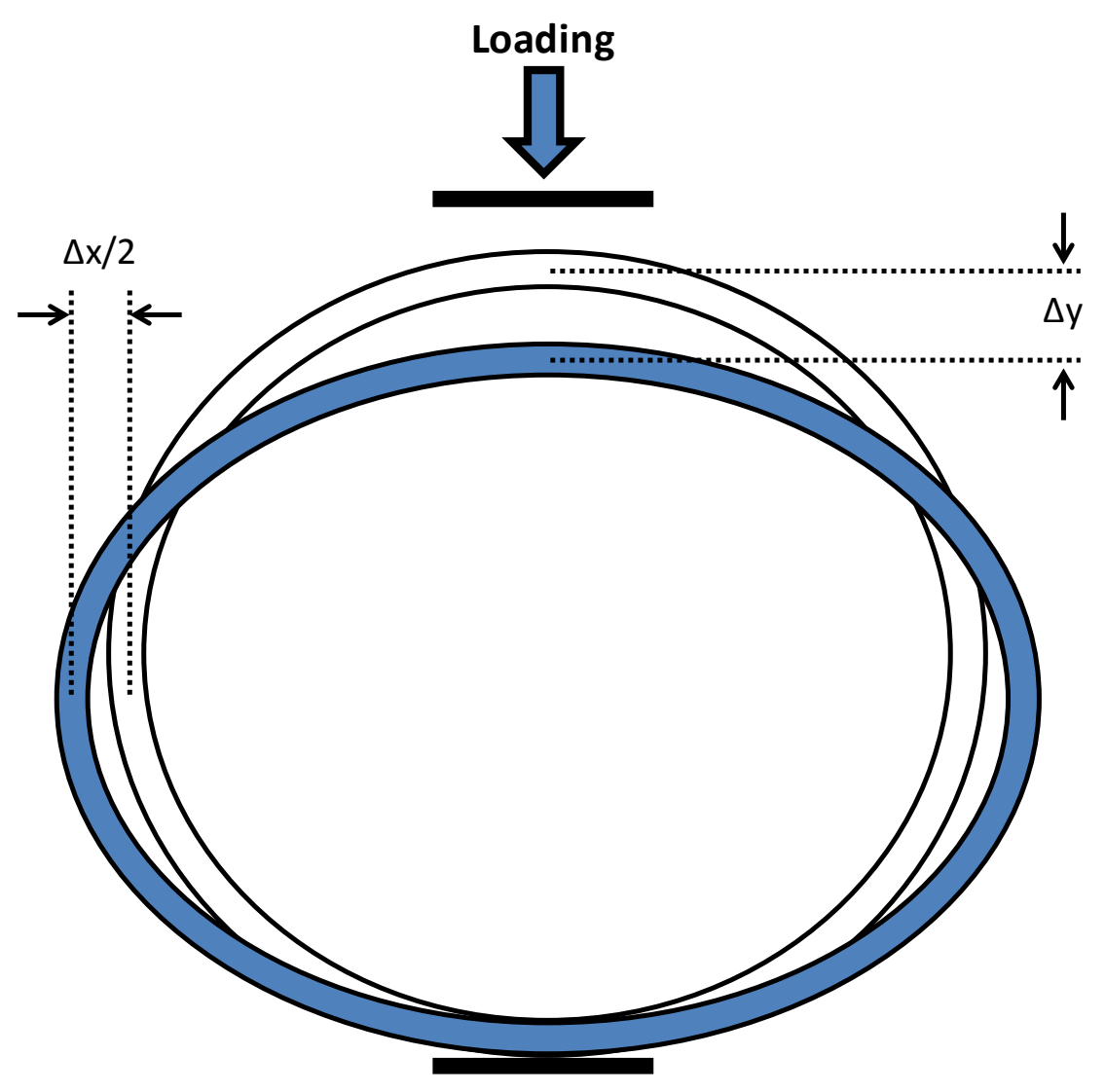

Figure 3.3: Illustration of pipe deflection under vertical load.

\subsubsection{Theoretical Pipe Deflections}

The following differential equation was developed (Timoshenko, 1936) by applying the Elastic Theory of Flexure to thin rings under simple loading conditions, where " $w$ " is equal to the deflection in the curve. Details on the process used to develop this method can be found elsewhere (Timoshenko, 1936).

$$
\frac{w}{r_{0}{ }^{2}}+\frac{d^{2} w}{d s^{2}}=\frac{-M}{E I}
$$


where,

$$
\begin{array}{ll}
w & =\text { displacement resulting from applied forces, } \\
r_{0} & =\text { initial radius of the ring, } \\
S & =\text { axial forces in the ring, } \\
M & =\text { moment at a given point, } \\
E & =\text { modulus of elasticity, and } \\
I & =\text { area moment of inertia. }
\end{array}
$$

Figure 3.4 shows the geometry of ring compression under two identical loads. Through the principle of least work, the bending moment at any point, A, can be expressed as (Timoshenko, 1936):

$$
M=\frac{P r_{0}}{2}\left(\frac{2}{\pi}-\cos \theta\right)
$$

By using the differential equation mentioned above (Equation 3.1), expressions for the theoretical vertical and horizontal displacements can be written as (Timoshenko, 1936):

$$
\begin{aligned}
& \delta_{V}=\frac{2 P r_{0}^{3}}{E I}\left(\frac{\pi}{8}-\frac{1}{\pi}\right)=\frac{0.148 P r_{0}^{3}}{E I} \\
& \delta_{H}=\frac{2 P r_{0}^{3}}{E I}\left(\frac{1}{\pi}-\frac{1}{4}\right)=\frac{0.136 P r_{0}^{3}}{E I}
\end{aligned}
$$

where

$$
\begin{aligned}
& \delta V \quad=\text { vertical change in the pipe diameter, and } \\
& \delta_{H} \quad=\text { horizontal change in the pipe diameter. }
\end{aligned}
$$

It should be noted that Equations 3.3 and 3.4 use small deflection theory assumptions as it pertains to the radius of curvature; therefore, these equations are only valid as long as the 
deflections produced are less than $3 \%$ of the ring diameter (Gondle, 2006). In the case of a larger deflection, the relationship between the load (P) and deflection (w) becomes non-liner. This case has been reported elsewhere (Bulson, 1985; Spangler, 1938) in experimental work on thin walled pipes.

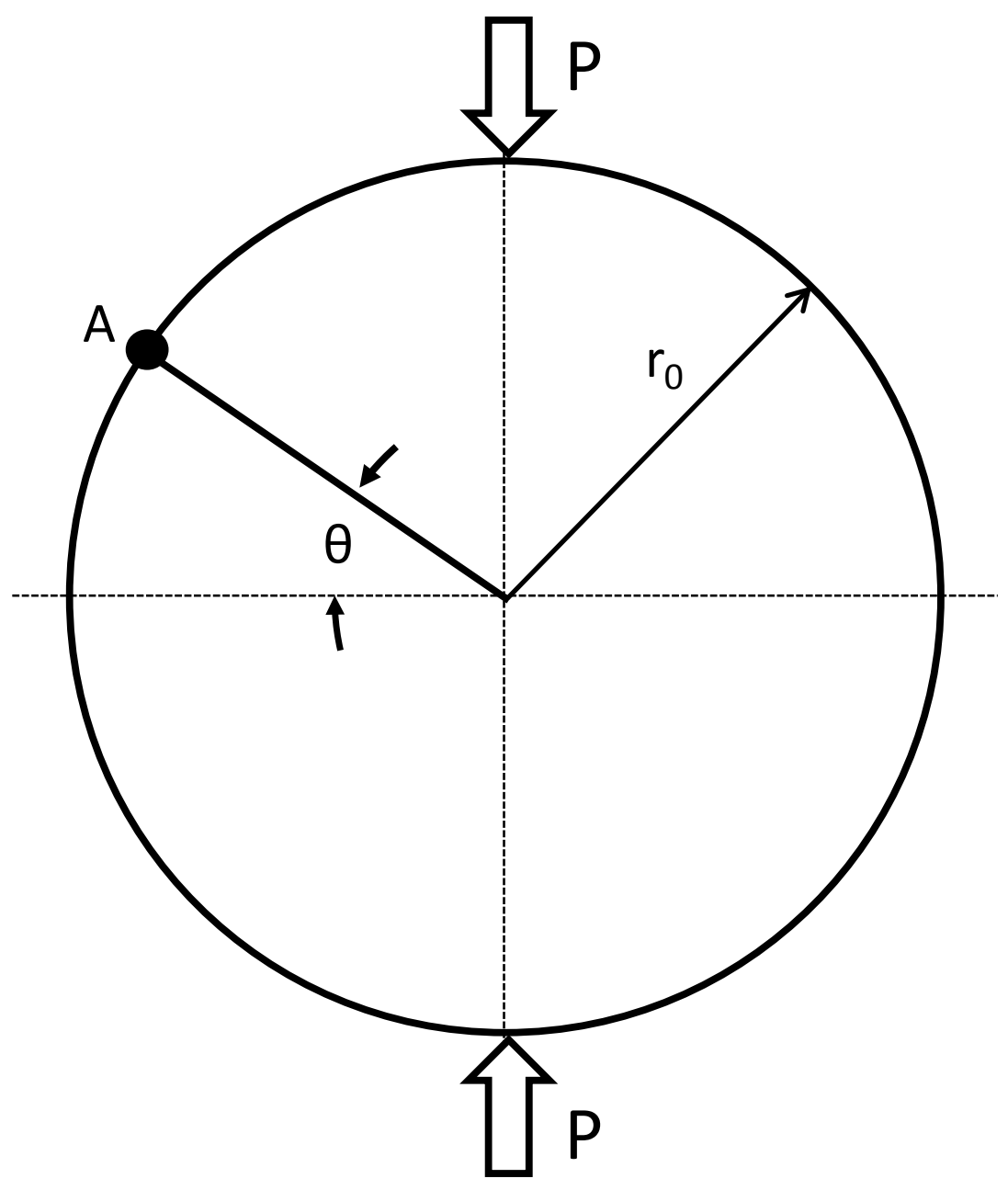

Figure 3.4: Ring compression under identical loads.

\subsubsection{Laboratory Pipe Deflections}

Laboratory testing can be used to calculate pipe bending stiffness as an alternative to calculating theoretical values as previously described. ASTM D 2412 is a common standardized test procedure known as parallel plate testing where pipe stiffness is measured through the application of two opposing, identical loads to the pipe specimen. An illustration of this test is 
shown in Figure 3.5. Loading is administered at a controlled rate while measurements of the applied force and the resulting vertical deflection are recorded. The ratio of applied load per unit length of pipe to the change in inside diameter is known as pipe stiffness. Pipe stiffness can be written as (Moser, 2008):

$$
P S_{f}=\frac{F}{\delta_{v}}=\frac{6.7 E_{f} I}{r^{3}}
$$

where,

$$
\begin{array}{ll}
P S_{f} & =\text { pipe stiffness (psi), } \\
E_{f} & =\text { flexural modulus of pipe (psi), } \\
I & \left.=\text { moment of inertia of pipe walls (in }{ }^{4} / \mathrm{in}\right), \\
r & =\text { mean radius (in), } \\
F & =\text { force per unit length (lbs), } \\
\delta_{v} & =\text { vertical change in pipe diameter (in.). }
\end{array}
$$
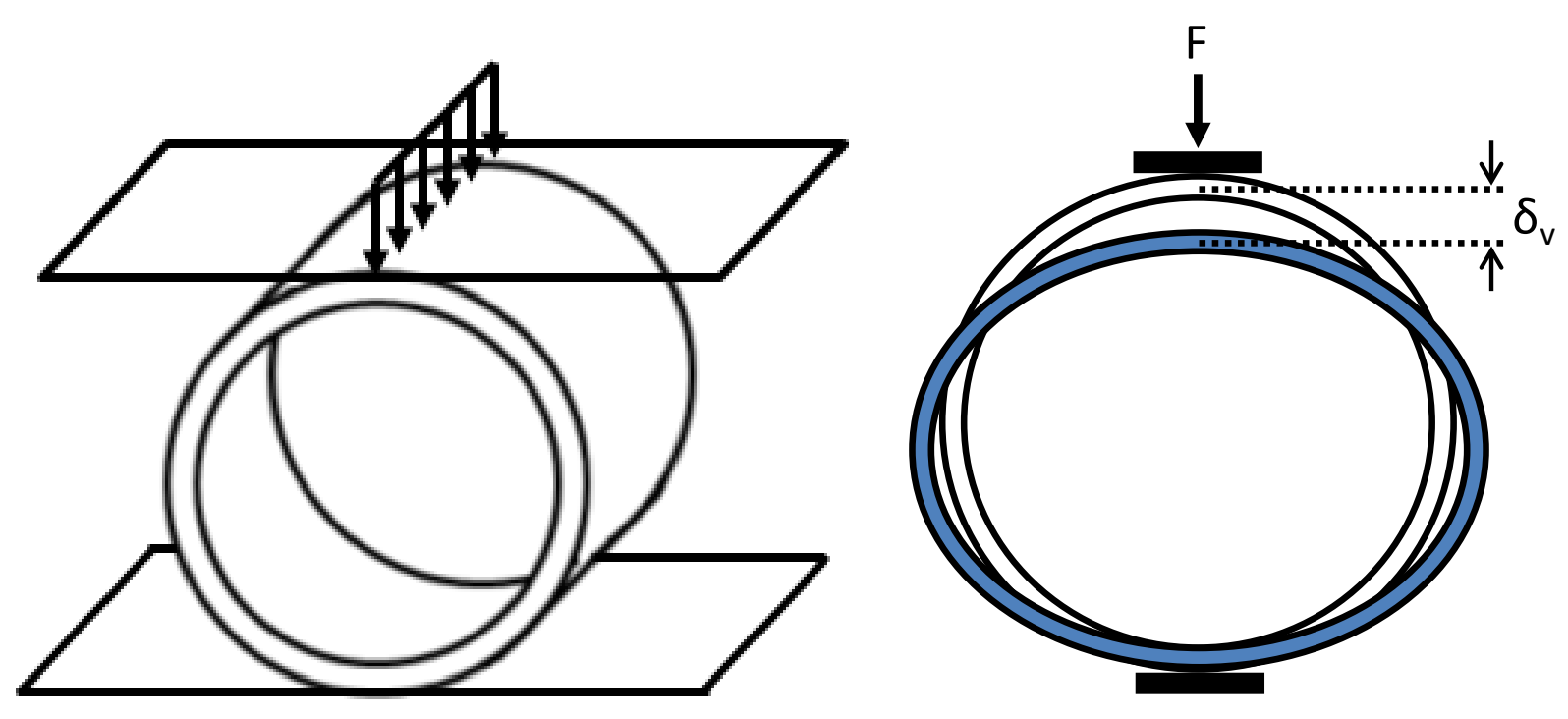

Figure 3.5: Parallel plate testing (ASTM D 2412 Test) for flexible pipe. 
ASTM D 2412 specifies that pipe stiffness values are to be calculated at a vertical deflection of $5 \%$ from the original shape of the pipe. The established safe deflection limit for a flexible pipe is up to $5 \%$ (Katona, 1993; Chamber et al., 1980); although others have made recommendations as high as $7.5 \%$ ( Soleno, 2012). The nomenclature used by the flexible pipe industry is given as follows (Moser, 2008):

- Stiffness factor $=$ EI

- $\quad$ Ring stiffness $=\mathrm{EI} / \mathrm{r}^{3}$

- $\quad$ Pipe stiffness $=\mathrm{P} / \delta \mathrm{v}=6.7 \mathrm{EI} / \mathrm{r}^{3}$

where

$$
\begin{array}{ll}
E & =\text { Modulus of Elasticity of pipe material }\left(\mathrm{lb} / \mathrm{in}^{2}\right), \\
I & =\text { pipe wall moment of inertia per unit length }\left(\mathrm{in}^{4} / \mathrm{in}\right), \\
r & =\text { mean radius of pipe (in), } \\
P & =\text { applied load (lb/in), and } \\
\delta_{v} & =\text { change in inside diameter measured in the direction of applied load (in). }
\end{array}
$$

When a flexible pipe is stressed bending strains are not the only strains that are developed within the pipe. Circumferential strains, while not nearly as substantial as bending strain, are also exhibited by the pipe. Circumferential stiffness (or ring compression stiffness) can be expressed as (Moser, 2008; Zoladz, 1995):

$$
P S_{H}=\frac{p}{\frac{\Delta D}{D}}=\frac{p}{\frac{p r}{E_{r c} A}}=\frac{E_{r c} A}{r}
$$

where

$$
\begin{aligned}
& E_{r c}=\text { compression modulus of pipe material (psi), } \\
& A \quad=\text { unit area of the pipe wall }\left(\mathrm{in}^{2} / \mathrm{in}\right),
\end{aligned}
$$




$$
\begin{array}{ll}
r & =\text { mean radius (in), } \\
p & =\text { radial pressure on pipe (psi), } \\
D & =\text { pipe diameter (in), and } \\
\Delta D & =\text { change in inside diameter (in). }
\end{array}
$$

\subsubsection{Pipe Response to Loading}

Several factors contribute to how a buried pipe will respond under a given load. Pipe stiffness, even more so than pipe strength, has been said to be the controlling parameter for buried pipe design (Moser, 2008). Other aspects including soil stiffness and overlying loads also play a critical role in a soil-pipe system. For the most basic case, an unconfined/unsupported pipe, deformation in the pipe can be directly linked to the load applied to the pipe and the structural rigidity of the pipe by using the following equation which was derived from Equation 3.5 (Soleno, 2012):

$$
\operatorname{Deformation}(\Delta)=\frac{\text { Loading onthe pipe }(P)}{\text { Material stiffness }(E) \times \operatorname{Geometric~stiffness~}\left(I / r^{3}\right)}=\frac{P r^{3}}{E I}
$$

Pipe Stiffness. The pipe stiffness, or structural rigidity of the pipe, refers to the pipe material's ability to resist deformation and is directly related to the Modulus of Elasticity (E) and geometric stiffness $\left(\mathrm{I} / \mathrm{r}^{3}\right)$ of the pipe as shown in Equation 3.7 (Gabriel, 1998). Material stiffness values, such as density and Modulus of Elasticity, are those that are dependent on the nature of the material used to manufacture the pipe. Geometric stiffness values are affected by aspects of pipe geometry, such as pipe radius and wall thickness. It can be seen from Equation 3.7 that pipe deformation can be reduced by using a material with a higher Modulus of Elasticity or by increasing the pipe wall moment of inertia through a larger wall thickness. Additionally, pipe deformation will increase as the radius of the pipe becomes larger (Gondle, 2006).

Transmission of Loading. The load transmitted to a buried pipe depends of a number of factors. While the magnitude of the load applied to the system has a heavy influence over the structural response of a soil-pipe system, it is important to note that stresses and deformations are also affected considerably by the load distribution (Moser, 2008; Gabriel, 1990). The soil surrounding a buried pipe has a major influence over the distribution of the load on the pipe. The 
highest magnitude of deformation results from a loading configuration as seen in a parallel plate loading test (see Figure 3.5), where two equal and opposite concentrated forces are applied at the top and bottom of the pipe section with no confining pressures. This is considered to be the worst case scenario for pipe deflection.

\subsection{HDPE Pipes}

Polyethylene is a polymer that is categorized into two families, low density polyethylene (LDPE) and high density polyethylene (HDPE). HDPE is stronger and harder than LDPE but it is also less flexible. During the past few decades HDPE pipes have become a popular choice for water conveyance due to material characteristics such as durability, flexibility, and lightness. HDPE pipes are widely used for many applications which require the pipe to have long serviceability, simple installation, and flexibility (PPI, 2012).

\subsubsection{Dual-Wall Corrugated Pipe}

Commercially available polyethylene pipes have been categorized by AASHTO as follows (PPI, 2012; AASHTO M 294, 2007):

Type D: Pipes which have a circular cross section with smooth inner and outer surfaces.

Type S: Pipes which have a circular cross section with a smooth inner surface and a corrugated outer surface as shown in Figure 3.6. This type is also referred to as double-wall corrugated pipe.

Type C: Pipes which have a circular cross section with inner and outer corrugations as shown in Figure 3.7. This type is also referred to as single-wall corrugated pipe.

In this study, double-wall corrugated pipes (Type S) were used. The outer corrugations of the pipe provide enhanced structural integrity while the smooth inner surface allows for excellent fluid flow characteristics. This makes Type S piping a popular choice for many applications. The sectional properties of Type S HDPE pipes have been taken from the literature (ADS, 2012) and are presented in Table 3.2 . 


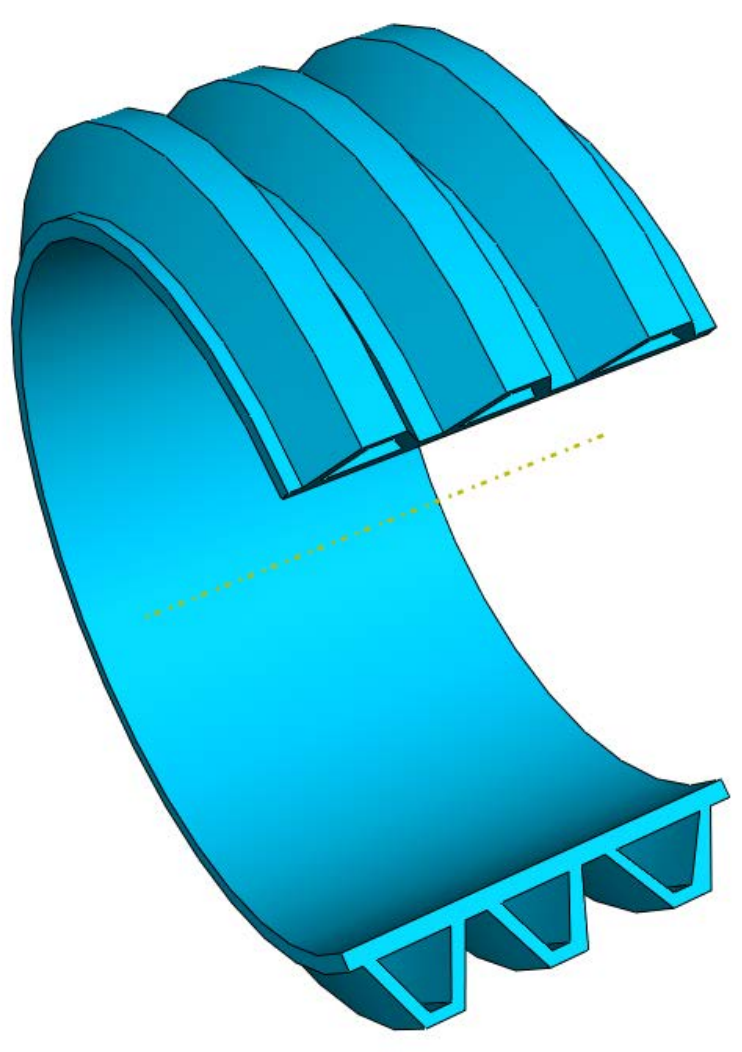

(a) Double-wall corrugated HDPE pipe

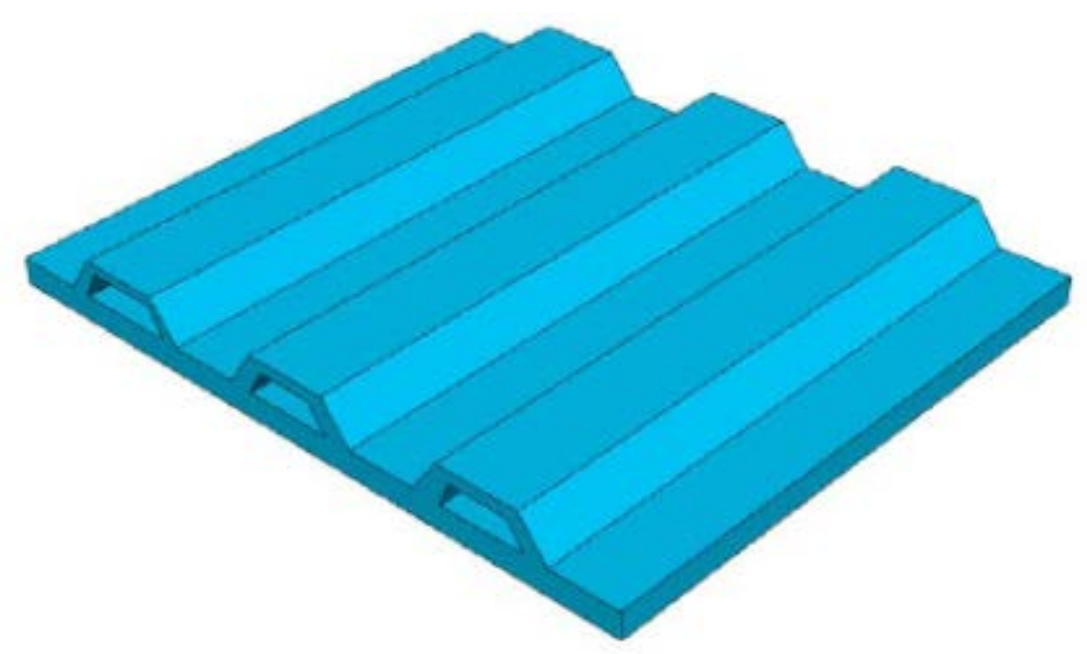

(b) Geometry of double-wall corrugated HDPE pipe

Figure 3.6: Profile of double-wall corrugated HDPE pipe (Varre, 2011). 


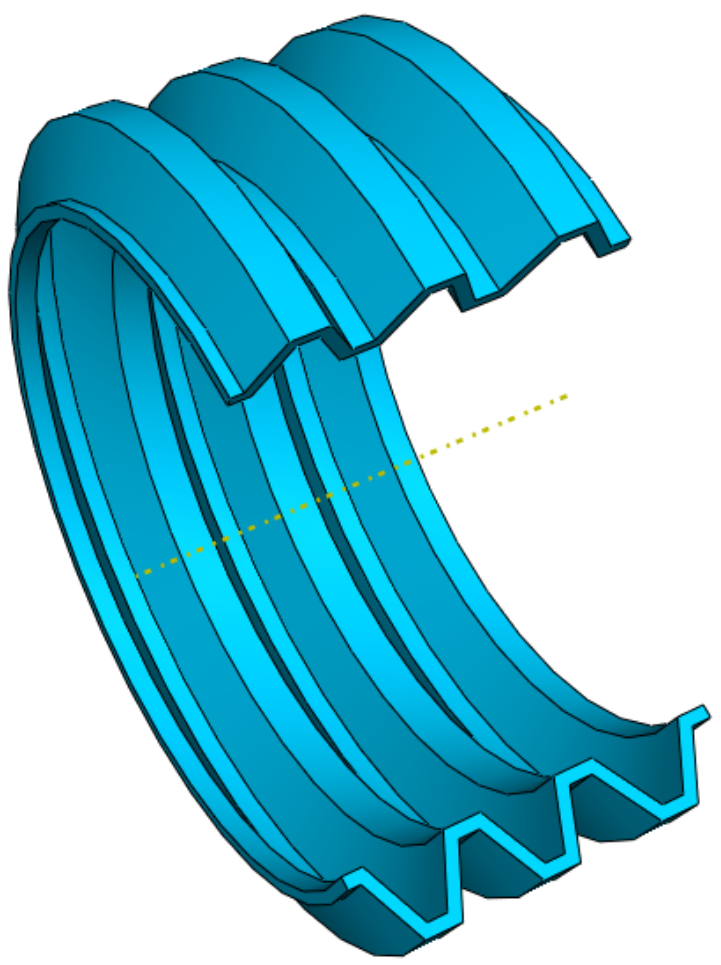

(a) Single-wall corrugated HDPE pipe

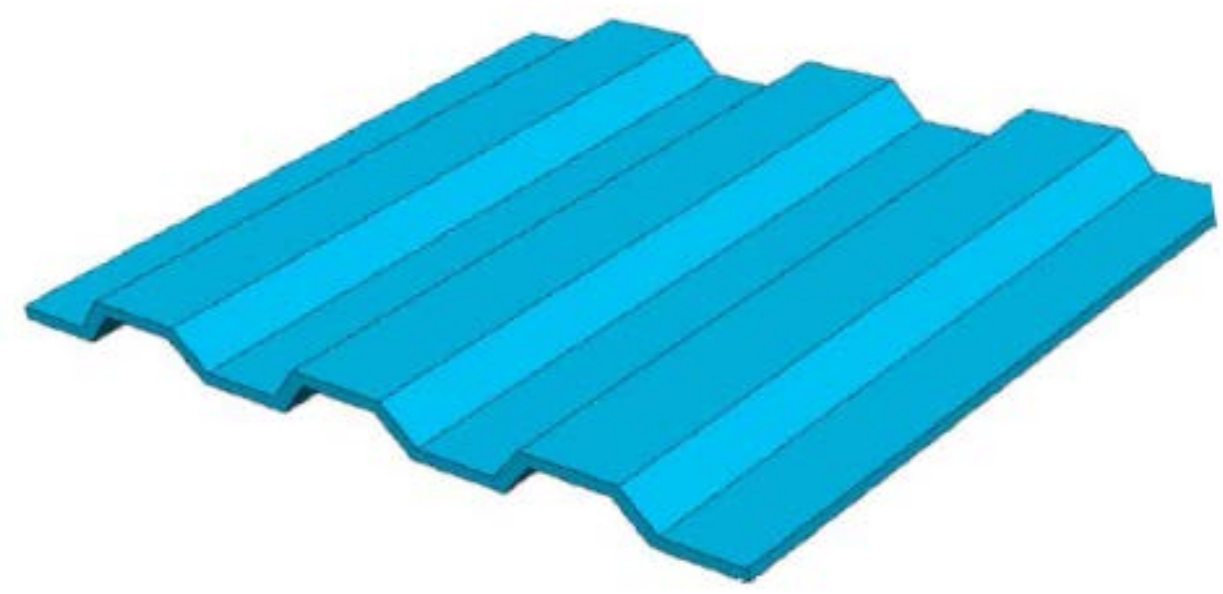

(b) Geometry of single-wall corrugated HDPE pipe

Figure 3.7: Profile view of single-wall corrugated HDPE pipe (Varre, 2011). 
Table 3.2: Section Properties of Double-Wall Corrugated HDPE Pipes* (ADS, 2012).

\begin{tabular}{|c|c|c|c|c|c|c|c|c|}
\hline $\begin{array}{l}\text { Nominal } \\
\text { Diameter }\end{array}$ & $\begin{array}{c}\text { Inside } \\
\text { Diameter }\end{array}$ & $\begin{array}{l}\text { Outside } \\
\text { Diameter } \\
\text { Average }\end{array}$ & $\begin{array}{l}\text { Inner Liner } \\
\text { Thickness, } \\
\text { Minimum }\end{array}$ & $\begin{array}{c}\text { Minimum Pipe } \\
\text { Stiffness at 5\% } \\
\text { Deflection }\end{array}$ & $\begin{array}{l}\text { Weight } \\
\mathrm{kg} / 6 \mathrm{~m}\end{array}$ & $\begin{array}{c}\text { Area } \\
\mathrm{mm}^{2} / \mathrm{m}\end{array}$ & $\begin{array}{c}\text { "I" } \\
\mathrm{cm}^{4} / \mathrm{cm}\end{array}$ & $\begin{array}{l}\text { "C" } \\
\mathrm{mm}\end{array}$ \\
\hline $\begin{array}{l}600 \mathrm{~mm} \\
\left(24^{\prime \prime}\right)\end{array}$ & $\begin{array}{l}612 \mathrm{~mm} \\
\left(24.08^{\prime \prime}\right)\end{array}$ & $\begin{array}{l}719 \mathrm{~mm} \\
\left(27.80^{\prime \prime}\right)\end{array}$ & $\begin{array}{l}1.5 \mathrm{~mm} \\
\left(0.059^{\prime \prime}\right)\end{array}$ & $\begin{array}{c}235 \mathrm{kN} / \mathrm{m}^{2} \\
34 \mathrm{psi}\end{array}$ & $\begin{array}{c}99.93 \mathrm{~kg} \\
(220.30 \mathrm{lbs})\end{array}$ & $\begin{array}{c}8.23 \\
\left(0.324 \mathrm{in}^{2} / \mathrm{in}\right)\end{array}$ & $\begin{array}{c}2.245 \\
\left(0.137 \mathrm{in}^{4} / \mathrm{in}\right)\end{array}$ & $\begin{array}{c}18.80 \\
(0.74 \text { in })\end{array}$ \\
\hline $\begin{array}{c}750 \mathrm{~mm} \\
\left(30^{\prime \prime}\right)\end{array}$ & $\begin{array}{l}762 \mathrm{~mm} \\
\left(30.00^{\prime \prime}\right)\end{array}$ & $\begin{array}{l}892 \mathrm{~mm} \\
\left(35.10^{\prime \prime}\right)\end{array}$ & $\begin{array}{l}1.5 \mathrm{~mm} \\
\left(0.059^{\prime \prime}\right)\end{array}$ & $\begin{array}{c}195 \mathrm{kN} / \mathrm{m}^{2} \\
28 \mathrm{psi}\end{array}$ & $\begin{array}{r}140.00 \mathrm{~kg} \\
(308.6 \mathrm{lbs})\end{array}$ & $\begin{array}{c}9.60 \\
\left(0.378 \mathrm{in}^{2} / \mathrm{in}\right)\end{array}$ & $\begin{array}{c}4.539 \\
\left(0.277 \mathrm{in}^{4} / \mathrm{in}\right)\end{array}$ & $\begin{array}{c}21.84 \\
(0.86 \text { in })\end{array}$ \\
\hline $\begin{array}{l}900 \mathrm{~mm} \\
\left(36^{\prime \prime}\right)\end{array}$ & $\begin{array}{l}914 \mathrm{~mm} \\
\left(36.00^{\prime \prime}\right)\end{array}$ & $\begin{array}{c}1059 \mathrm{~mm} \\
\left(41.70^{\prime \prime}\right)\end{array}$ & $\begin{array}{r}1.7 \mathrm{~mm} \\
\left(0.067^{\prime \prime}\right)\end{array}$ & $\begin{array}{c}150 \mathrm{kN} / \mathrm{m}^{2} \\
22 \mathrm{psi}\end{array}$ & $\begin{array}{r}180.00 \mathrm{~kg} \\
(396.8 \mathrm{lbs})\end{array}$ & $\begin{array}{c}10.19 \\
\left(0.401 \mathrm{in}^{2} / \mathrm{in}\right) \\
\end{array}$ & $\begin{array}{c}6.555 \\
\left(0.400 \mathrm{in}^{4} / \mathrm{in}\right) \\
\end{array}$ & $\begin{array}{c}25.40 \\
(1.00 \mathrm{in})\end{array}$ \\
\hline $\begin{array}{c}1050 \mathrm{~mm} \\
\left(42^{\prime \prime}\right)\end{array}$ & $\begin{array}{l}1054 \mathrm{~mm} \\
\left(41.40^{\prime \prime}\right)\end{array}$ & $\begin{array}{l}1212 \mathrm{~mm} \\
\left(47.70^{\prime \prime}\right)\end{array}$ & $\begin{array}{c}1.8 \mathrm{~mm} \\
\left(0.070^{\prime \prime}\right)\end{array}$ & $\begin{array}{c}140 \mathrm{kN} / \mathrm{m}^{2} \\
20 \mathrm{psi}\end{array}$ & $\begin{array}{c}230.00 \mathrm{~kg} \\
(570.10 \mathrm{lbs})\end{array}$ & $\begin{array}{c}11.64 \\
\left(0.458 \mathrm{in}^{2} / \mathrm{in}\right)\end{array}$ & $\begin{array}{c}9.373 \\
\left(0.572 \mathrm{in}^{4} / \mathrm{in}\right)\end{array}$ & $\begin{array}{c}30.73 \\
(1.21 \mathrm{in})\end{array}$ \\
\hline $\begin{array}{c}1200 \mathrm{~mm} \\
\left(48^{\prime \prime}\right)\end{array}$ & $\begin{array}{c}1209 \mathrm{~mm} \\
\left(47.60^{\prime \prime}\right)\end{array}$ & $\begin{array}{c}1361 \mathrm{~mm} \\
\left(53.60^{\prime \prime}\right)\end{array}$ & $\begin{array}{l}1.8 \mathrm{~mm} \\
\left(0.070^{\prime \prime}\right)\end{array}$ & $\begin{array}{c}125 \mathrm{kN} / \mathrm{m}^{2} \\
18 \mathrm{psi}\end{array}$ & $\begin{array}{c}283.50 \mathrm{~kg} \\
(570.10 \mathrm{lbs})\end{array}$ & $\begin{array}{c}12.58 \\
\left(0.495 \mathrm{in}^{2} / \mathrm{in}\right)\end{array}$ & $\begin{array}{c}9.341 \\
\left(0.570 \mathrm{in}^{4} / \mathrm{in}\right)\end{array}$ & $\begin{array}{c}29.72 \\
(1.17 \mathrm{in})\end{array}$ \\
\hline $\begin{array}{c}1500 \mathrm{~mm} \\
\left(60^{\prime \prime}\right)\end{array}$ & $\begin{array}{c}1512 \mathrm{~mm} \\
\left(59.5^{\prime \prime}\right)\end{array}$ & $\begin{array}{c}1684 \mathrm{~mm} \\
\left(66.3^{\prime \prime}\right)\end{array}$ & $\begin{array}{c}1.8 \mathrm{~mm} \\
\left(0.070^{\prime \prime}\right)\end{array}$ & $\begin{array}{c}95 \mathrm{kN} / \mathrm{m}^{2} \\
14 \mathrm{psi}\end{array}$ & $\begin{array}{c}410.00 \mathrm{~kg} \\
(903.90 \mathrm{lbs})\end{array}$ & $\begin{array}{c}14.68 \\
\left(0.578 \mathrm{in}^{2} / \mathrm{in}\right)\end{array}$ & $\begin{array}{c}14.090 \\
\left(0.860 \mathrm{in}^{4} / \mathrm{in}\right)\end{array}$ & $\begin{array}{c}33.66 \\
(1.32 \mathrm{in})\end{array}$ \\
\hline
\end{tabular}

*Also see reference: Varre, 2011; Gondle, 2006. 


\subsubsection{Determining pipe dimensions and properties for modeling}

In finite element analyses of HDPE pipes, it is difficult to model geometrical features such as corrugations which are present on the outside surface of a section of double-wall corrugated HDPE pipes (see Figure 3.6). Thus, it is assumed that the pipe has a rectangular cross-section having the same structural stiffness as the corrugated section. The method used to determine the Elastic Modulus for a Type S (double-wall corrugated) pipe is shown below for a 24-inch pipe whose sectional properties were obtained from Table 3.2 (Varre, 2011; Gondle, 2006):

For a 24-inch nominal pipe diameter:

Min. Pipe stiffness @ 5\% deflection(K)

Inside diameter (ID)

Outside diameter (OD)

Moment of Inertia $\left(\mathrm{I}_{\mathrm{d}}\right)$

Distance from inner wall to neutral axis (C)

Flexural modulus of the pipe $\left(E_{d}\right)$
$=34 \mathrm{psi}$

$=24.08 \mathrm{in}$.

$=27.80 \mathrm{in}$.

$=0.137 \mathrm{in}^{4} / \mathrm{in}$.

$=0.74$ in

$=110,000 \mathrm{psi}$

$$
\text { Mean diameter } \begin{aligned}
\left(D_{\text {mean }}\right) & =\text { Inside diameter }(I D)+2 C \\
& =24.08+2(0.74)=25.56 \mathrm{in} .=64.92 \mathrm{~cm}
\end{aligned}
$$

The thickness of the pipe can be calculated as shown below:

$$
t=\frac{(O D-I D)}{2}
$$

where,

$$
\begin{aligned}
& t \quad=\text { thickness of pipe (in), } \\
& O D \quad=\text { outside diameter of pipe (in.), and } \\
& I D \quad=\text { inside diameter of pipe (in.) }
\end{aligned}
$$

Therefore, the thickness for a 24-inch pipe can be calculated by using Equation 3.9 as: 


$$
t=\frac{(27.8-24.08)}{2}=1.86 \mathrm{in} .=4.72 \mathrm{~cm}
$$

The obtained value is the thickness used to idealize the cross-section of the pipe as a rectangular section. Thus, the moment of inertia can be calculated as:

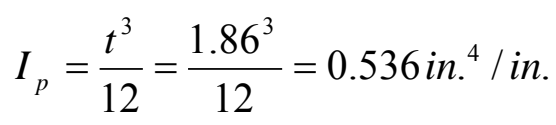

In the steps above, the geometric stiffness has been altered. In order to maintain equilibrium the material stiffness has to be modified. The alteration is shown below:

$$
E_{d} I_{d}=E_{p} I_{p}
$$

where,

$$
\begin{aligned}
& E_{d} \quad=\text { Elastic Modulus of corrugated section for double-wall pipe, } \\
& E_{p} \quad=\text { Elastic Modulus of idealized rectangular section, } \\
& I_{d} \quad=\text { Moment of Inertia of corrugated section for double-wall pipe, and } \\
& I_{p} \quad=\text { Moment of Inertia of idealized rectangular section. }
\end{aligned}
$$

Therefore,

$$
E_{p}=\frac{E_{d} I_{d}}{I_{p}}=\frac{110,000 \times 0.137}{0.536}=28,115.672 \mathrm{psi}=193.851 \mathrm{MPa}
$$

\subsection{Soil properties and mechanics}

The structural properties of the pipe are not the only factors which determine the effectiveness of a soil-pipe system. The characteristics of the surrounding soils are also very important to the overall performance of a buried pipe system and trench configuration. Backfill soil properties including soil type, density, and moisture content have an influence on the appropriate trench configuration (Mada, 2005). Soil and backfill properties are most often determined through laboratory testing procedures. 
Soil provides more than a stable media for a pipe to rest; it also helps to support the external loading applied at the surface over the pipe. The American Association of State Highway and Transportation Officials (AASHTO) as well as the American Society for Testing and Materials (ASTM) have issued standard test methods for the determination of various soil properties. The following are the four most basic groups in which soils are classified (Das, 2011; Moser, 2008).

- Gravel: Individual grains varying from 0.08 to 3.0 inches in diameter

- Sand: Individual grains that are less than 0.08 inch in diameter

- Silt: Fine grains $(<\# 200)$ that are soft and floury in texture

- Clay: Fine grains $(<\# 200)$ that form hard lumps when dry and are sticky when wet.

\subsubsection{Shear strength of soil}

Often, the failure of buried pipes is related to the weakness of the soil surrounding the pipes. Failure occurs when applied stress to the soil exceeds the shear strength of soil. The shear strength of a soil can be defined as the magnitude of shear stress that a soil can sustain. Frequently, the shear strength $(\tau)$ of a soil is given by the Mohr-Coulomb failure criterion (Das, 2011) which is shown below in Equation 3.14.

$$
\tau=c+(\sigma-u)(\tan \phi)
$$

where,

$$
\begin{aligned}
\tau & =\text { shearing strength of a soil }(\mathrm{kPa}), \\
\sigma & =\text { total normal stress }(\mathrm{kPa}) \\
\varphi & =\text { angle of friction (degrees), } \\
c \quad & =\text { cohesion }(\mathrm{kPa}), \\
u & =\text { pore water pressure }(\mathrm{kPa})
\end{aligned}
$$

For a failure analysis, it is necessary to determine the angle of friction $(\phi)$ and cohesion (c) of the soil. Triaxial compression tests are frequently used to determine shear strength 
parameters. Information on the triaxial soil testing procedures can be found elsewhere (ASTM D4767, 2011; ASTM D7181, 2011). Figure 3.8 (a) shows a typical Mohr Circle that would result from triaxial testing. Figure 3.8 (b) shows an illustration of a shear failure in soil. The equations for the magnitude of shear and normal stresses are given below (Das, 2011; Watkins, 1999).

$$
\begin{gathered}
\tau=\left(\frac{\sigma_{1}-\sigma_{3}}{2}\right) \sin 2 \alpha \\
\sigma=\left(\frac{\sigma_{1}+\sigma_{3}}{2}\right)+\left(\frac{\sigma_{1}-\sigma_{3}}{2}\right) \cos 2 \alpha
\end{gathered}
$$

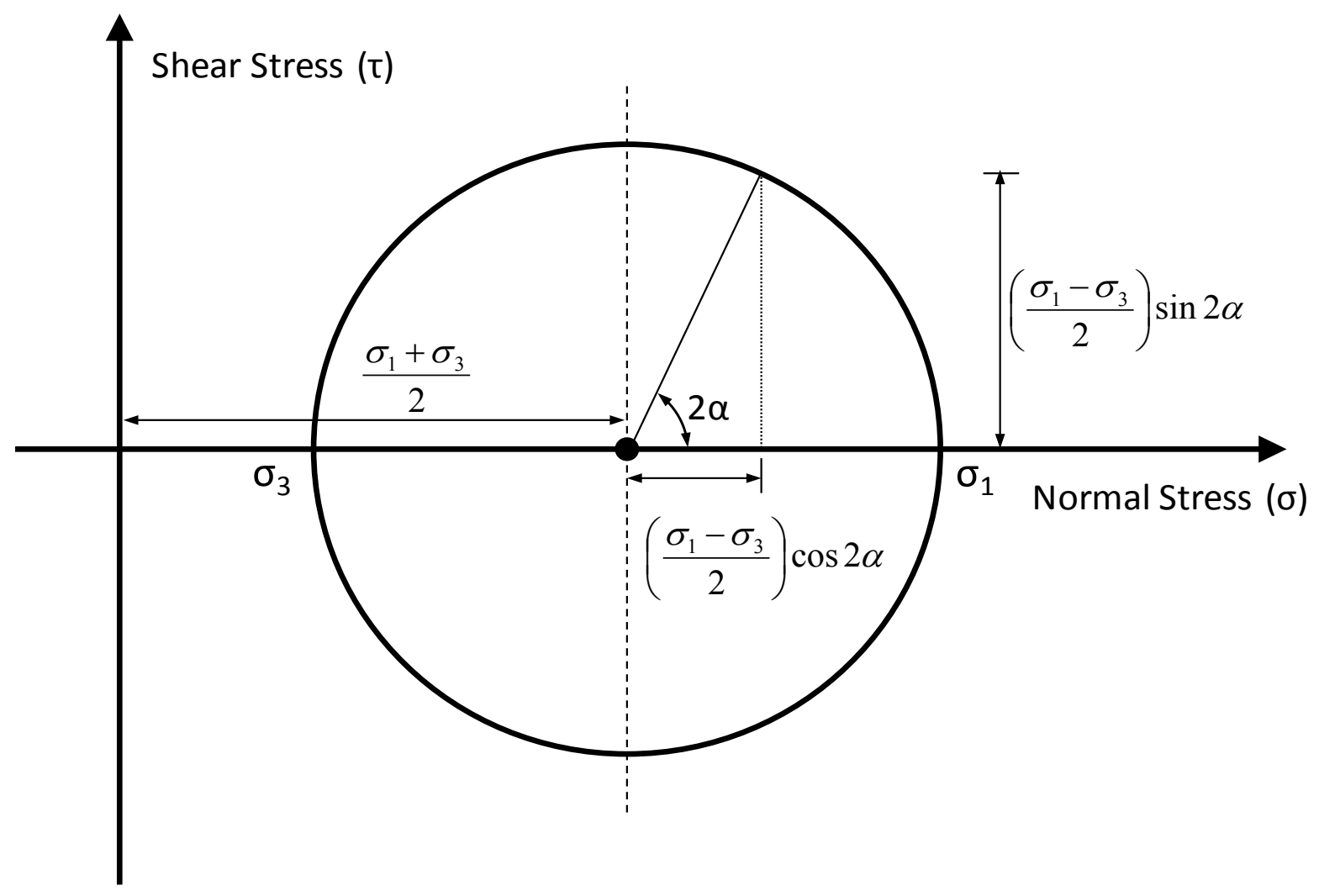

(a) 


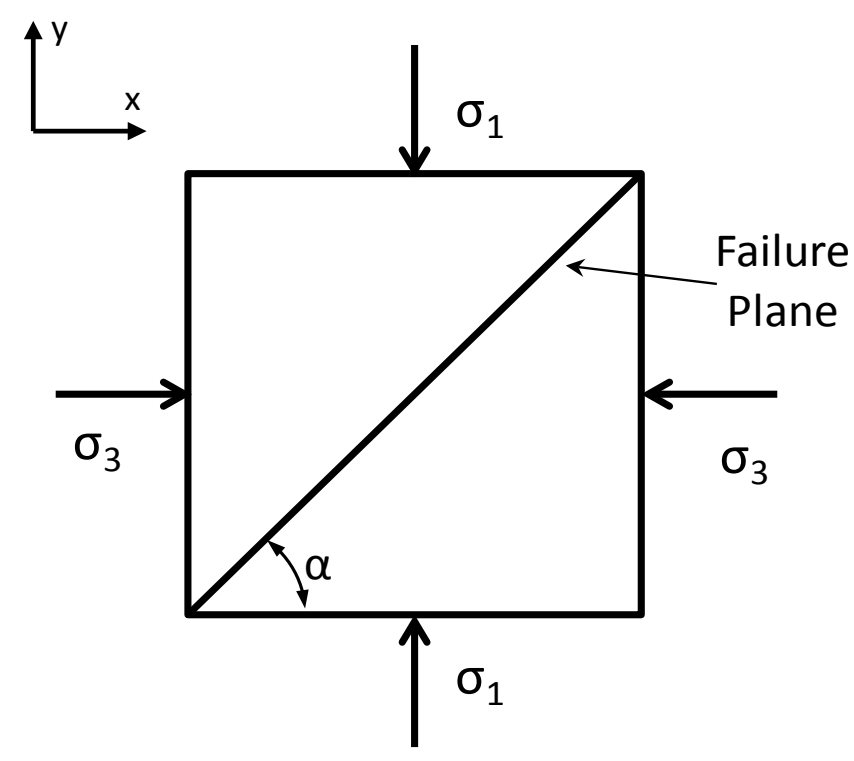

(b)

Figure 3.8: (a) Mohr circle for stress, (b) Illustration of typical failure plane in soil.

\subsubsection{Soil Stiffness}

The modulus of soil reaction (E'), also known as soil stiffness, ranks as one of the most important parameters to consider for buried pipe design (Moser, 2008). Proper soil stiffness can enhance the structural performance of the pipe which, in turn, helps to improve the overall pipe performance. Soil stiffness depends largely on soil properties such as density, soil type, and moisture content (Moser, 2008; Howard, 1977). Design aspects such as the degree of compaction of the backfill, trench geometry, and composition of insitu soil also have an influence over the modulus of soil reaction (Soleno, 2012; Hartley and Duncan, 1987). Table 3.3 shows typical values of the modulus of soil reaction for different soil types and different compaction efforts (Soleno, 2012). Different compaction techniques have a significant influence over soil stiffness (Moser, 2008; Faragher et al., 1998; Hartley and Duncan, 1987; Howard, 1977). Table 3.4 contains typical values for the degree of compaction that can be attained by using different compaction methods (Soleno, 2012). It has also been observed that the modulus of soil reaction depends on the backfill depth (Hartley and Duncan, 1987). Table 3.5 provides the recommended values of soil modulus by various researchers. 
Table 3.3: Modulus of the soil reaction (E').*

\begin{tabular}{|c|c|c|c|c|c|c|c|c|}
\hline \multicolumn{9}{|c|}{ Modulus of soil reaction, $\mathrm{E}^{\prime}$} \\
\hline \multicolumn{4}{|c|}{ Pipe Backfill Material } & \multicolumn{5}{|c|}{$\mathrm{E}^{\prime} \mathrm{kPa}$ (psi) According to the degree of compaction } \\
\hline Class & Description & Symbol & ASTM D2487 & $\begin{array}{l}\text { Minimum } \\
\text { Recommended } \\
\text { Proctor }\end{array}$ & $\begin{array}{l}\text { None } \\
\text { (Dumped) }\end{array}$ & $\begin{array}{l}\text { Light } \\
<85 \% \\
\text { relative density } \\
<40 \%\end{array}$ & $\begin{array}{c}\text { Moderate } \\
85 \%-90 \% \\
\text { relative density } \\
40 \%-70 \%\end{array}$ & $\begin{array}{c}\text { High } \\
>95 \% \\
\text { relative density } \\
>70 \%\end{array}$ \\
\hline $\begin{array}{l}\text { IA } \\
\text { IB }\end{array}$ & $\begin{array}{l}\text { crushed gravel, } \\
\text { manufactured }\end{array}$ & $\mathrm{S} / \mathrm{O}$ & $\begin{array}{l}\text { Crushed gravel, angular } \\
\text { and large }\end{array}$ & Diverse & $\begin{array}{c}6895 \\
(1000)\end{array}$ & $20685(3000)$ & $20685(3000)$ & $20685(3000)$ \\
\hline II & $\begin{array}{c}\text { Granular soils, } \\
\text { clean }\end{array}$ & $\begin{array}{l}\text { GW, GP, } \\
\text { SW, SP }\end{array}$ & $\begin{array}{l}\text { Gravel or sand with little } \\
\text { or no fine particles }\end{array}$ & $85 \%$ & $1379(200)$ & $6895(1000)$ & $13790(2000)$ & $20685(3000)$ \\
\hline III & $\begin{array}{l}\text { Granular soils } \\
\text { with fines }\end{array}$ & $\begin{array}{l}\text { GM, GP, } \\
\text { SW, SP }\end{array}$ & $\begin{array}{l}\text { Mixture of gravel or sand } \\
\text { with other components }\end{array}$ & $90 \%$ & $690(100)$ & $2758(400)$ & $6895(1000)$ & $13790(2000)$ \\
\hline IVA & $\begin{array}{l}\text { Granular, fine } \\
\text { inorganic soils }\end{array}$ & $\mathrm{ML}, \mathrm{CL}$ & $\begin{array}{l}\text { Cohesive soil with little to } \\
\text { moderate plasticity }\end{array}$ & \multirow{3}{*}{\multicolumn{5}{|c|}{$\begin{array}{l}\text { Not Recommended. } \\
\text { Data not availabe. For all usage, request APPROVAL of a soil expert }\end{array}$}} \\
\hline IVB & $\begin{array}{l}\text { Granular, fine } \\
\text { inorganic soils }\end{array}$ & $\mathrm{MH}, \mathrm{CH}$ & $\begin{array}{l}\text { Cohesive soil with high } \\
\text { plasticity }\end{array}$ & & & & & \\
\hline $\mathrm{V}$ & $\begin{array}{l}\text { Organic or highly } \\
\text { organic soils }\end{array}$ & $\begin{array}{l}\mathrm{OL}, \mathrm{OH}, \\
\mathrm{PT}\end{array}$ & --- & & & & & \\
\hline
\end{tabular}

*Reference: Soleno, 2012; ASTM, 2012; Gondle, 2006. 
Table 3.4: Degree of compaction of backfill materials.*

\begin{tabular}{|c|c|c|c|c|}
\hline \multicolumn{5}{|c|}{ Compaction of Backfill Materials } \\
\hline Class of material & I & II & III & IV \\
\hline Description of material & $\begin{array}{c}\text { Angular } \\
\text { manufacturing } \\
\text { stones }\end{array}$ & $\begin{array}{c}\text { Gravel and sand } \\
\text { without fines, clean }\end{array}$ & $\begin{array}{c}\text { Soil mixtures of fine } \\
\text { soils (silt and clay), } \\
\text { little fines }\end{array}$ & $\begin{array}{l}\text { Mixture of fine soils } \\
\text { (silt and clay), with } \\
\text { fines }\end{array}$ \\
\hline $\begin{array}{c}\text { Upper limit of water content, } \\
\% \text { of dry weight }\end{array}$ & --- & $9-12$ & $9-18$ & $6-30$ \\
\hline Compaction technique & \multicolumn{4}{|c|}{$\%$ proctor density ( $\%$ relative density) } \\
\hline $\begin{array}{l}\text { Mechanical compactor (roller, } \\
\text { rammer, etc.) }\end{array}$ & $95-100(75-100)$ & $95-100(80-100)$ & $95-100$ & $90-100$ \\
\hline $\begin{array}{l}\text { Density increased by portable } \\
\text { vibrators }\end{array}$ & $80-95(60-75)$ & $80-95(60-80)$ & $80-95$ & $75-90$ \\
\hline Saturation compaction & $80-95(60-75)$ & $80-95(60-80)$ & --- & --- \\
\hline Placed manually & $80-95(60-75)$ & --- & --- & --- \\
\hline Compressed manually & --- & $60-80(40-60)$ & $60-80$ & $60-75$ \\
\hline Dumped & $60-80(40-60)$ & $60-80(50-60)$ & $60-80$ & $60-75$ \\
\hline
\end{tabular}

*Reference: Soleno, 2012; ASTM, 2012; Gondle, 2006. 
Table 3.5: Recommended values of different soil modulus used by various researchers (Gondle, 2006).

\begin{tabular}{|c|c|c|c|c|}
\hline Author & Type of soil & Soil Modulus, MPa (psi) & $\begin{array}{l}\text { Poisson's } \\
\text { ratio }\end{array}$ & $\begin{array}{l}\text { Density, } \mathrm{kK} / \mathrm{m}^{3} \\
(\mathrm{pcf})\end{array}$ \\
\hline \multirow{2}{*}{$\begin{array}{c}\text { Brachman et al. (2000), } \\
\text { Moore and Branchman (1994) }\end{array}$} & Granular Backfill ( $90 \%$ compacted) & $30(4350)$ & 0.30 & $18(114)$ \\
\hline & Granular Backfill (98\% compacted) & $80(11600)$ & 0.30 & $18(114)$ \\
\hline Suleiman et al. (2004) & Silty Sand (SM) & $6.89(1000)$ & 0.35 & $18.8(120)$ \\
\hline \multirow{3}{*}{ Brachman et al. (1996) } & Stone & $50(7250)$ & 0.25 & --- \\
\hline & Cover soil & $20(2900)$ & 0.20 & --- \\
\hline & Clay & $10(1450)$ & 0.35 & --- \\
\hline \multirow{2}{*}{ Faragher et al. (1998) } & Lightly compacted soil & $18-94(2600-1360)$ & --- & $17.5(111)$ \\
\hline & Gravel surround & $29-148(4200-21465)$ & --- & $14.5(92.0)$ \\
\hline \multirow{3}{*}{ Howard (1998) } & Low plasticity clay (CL) & $2.8(400)$ & --- & --- \\
\hline & Low plasticity silt (ML) & $7.0(1000)$ & --- & --- \\
\hline & Well graded sand (SW) & $14.0(2000)$ & --- & --- \\
\hline \multirow{3}{*}{$\begin{array}{c}\text { Selig (1988), } \\
\text { Hashash and Selig (1990) }\end{array}$} & Low plasticity clay (CL) & $3.4-15.2(500-2200)$ & --- & $8.7-18.6(56-119)$ \\
\hline & Low plasticity silt (ML) & $9.6-40.0(1400-5800)$ & --- & $10-20(66-127)$ \\
\hline & Well graded sand (SW) & $28-82(4060-11900)$ & --- & $14.2-22(91-141)$ \\
\hline Sargand and Masada (2000) & Coarse granular soil ( $85 \%$ compacted) & $3.6-5.6(500-800)$ & 0.30 & $20.4(130)$ \\
\hline \multirow{2}{*}{$\begin{array}{l}\text { Hartley and Duncan (1987), } \\
\text { Goddard et al. (2003) }\end{array}$} & Fine grained soils (CL, ML) & $3.5-18.0(500-2600)$ & $0.35-0.40$ & \multirow{2}{*}{$15-24(100-150)$} \\
\hline & Coarse grained soils (SP, SW, GP, GW) & $4.0-26.0(600-3800)$ & $0.30-0.35$ & \\
\hline
\end{tabular}




\subsubsection{Soil-pipe Interaction}

Performance of a buried pipe is heavily influenced by the interaction between the pipe and its surrounding soil, or soil-pipe interaction. The soil-pipe interaction is a function of the combination of physical and geometric properties for the backfill soil and pipe. The distribution of pressure at the pipe-soil interface and the total load transmitted to the pipe are useful parameters in evaluating the soil-pipe interaction (McGrath, 1993). The design of a soil-pipe system is treated as a statically indeterminate problem signifying that the interface pressure between the soil and pipe cannot be calculated by considering static equilibrium alone (Moser, 2008).

\subsubsection{Soil Arching}

Soil arching is a term which describes the distribution of forces between a buried pipe and the surrounding soil. In the case of flexible buried pipes, the soil arching phenomenon can help pipe performance through what is known as positive soil arching (Moser, 2008). This is because loads acting on the flexible pipe are less than that of the prism load (see Figure 3.9) generated by soil column resting directly above the pipe. Loads acting above the pipe are attracted towards the surrounding soil which is stiffer and capable of supporting more load. With the ability of the flexible pipes to elongate in the horizontal direction, additional passive pressures are developed. These passive pressures reduce the load attracting towards the pipe by distributing part of the load to the surrounding soil (Moser, 2008). For buried rigid pipes, the load acting on the top of the pipe increases larger than the prism load caused by the soil column resting above the pipe. This is due to the pipe's inability to deform horizontally and distribute loading to the surrounding soil. The soil prism resting on the top of the pipe settles more compared to the soil columns standing on the sides, resulting in a differential settlement. This phenomenon is known as negative soil arching (Moser, 2008). Both positive and negative soil arching are illustrated in Figure 3.9 below. 


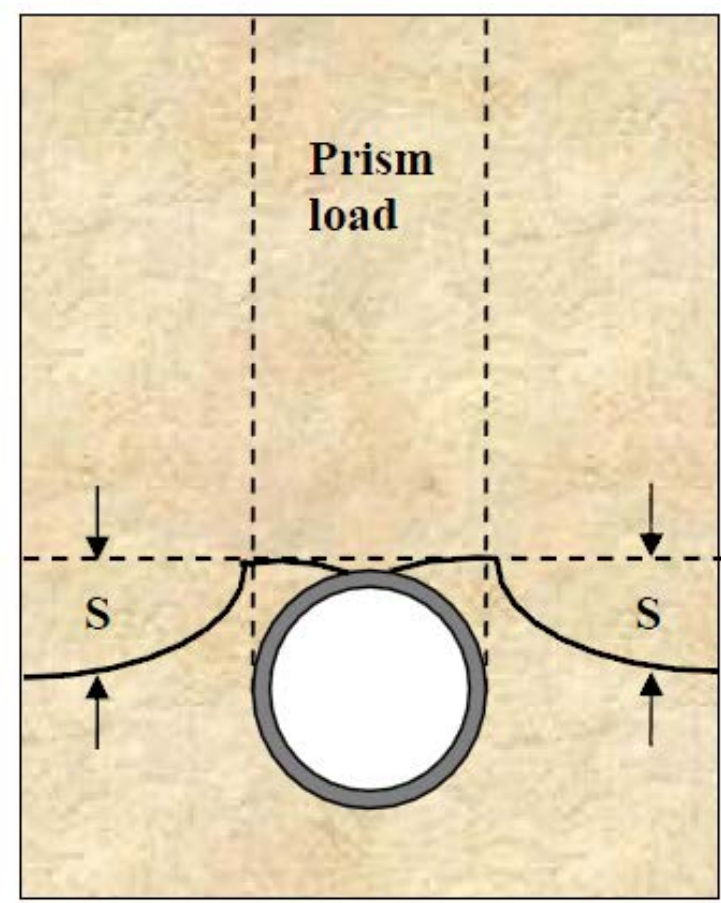

(a) Rigid Pipe

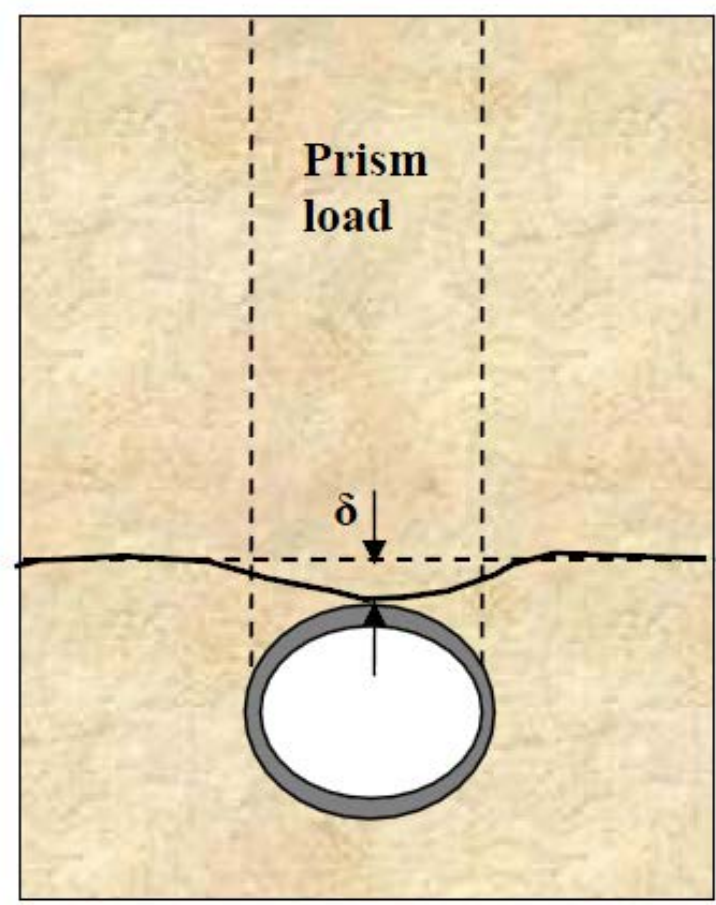

(b) Flexible Pipe

Figure 3.9: Vertical soil arching (Moser, 2008; Gondle, 2006). 


\section{CHAPTER 4: NUMERICAL METHODOLOGY}

\subsection{Introduction}

The finite element method (FEM) was utilized to examine the potential of incorporating a geotextile soil reinforcement with buried pipe design for this research (Figure 1.3). This computational technique offers a wide range of problem solving capabilities from simple deformation and stress analysis to complex non-linear analysis. Over the past several decades FEM has expanded its role into many forms of engineering practice, including several areas in civil and geotechnical engineering (Kazemian et al., 2010; Cook et al., 2003; Cai and Bathurst, 1995). FEM analysis can be used to solve complex geotechnical problems without the need for costly laboratory experiments by including soil-structure interaction mechanics into the analysis. Such work is presented in this research study. All of the finite element modeling work presented in this study was performed by using a commercially available FEM software package (ABAQUS, 2010).

\subsection{Details of the finite element method}

The finite element method is a mathematical technique where a continuum model is discretized into a number of smaller parts known as finite elements. These elements are connected to one another at common points known as nodes. The collection of these finite elements, connected at their nodal points, create a grid that is identified as the finite element mesh. Shape functions are used to relate displacements along the element boundaries to the nodal displacements. These displacements are then used to specify the displacement compatibility between all other adjacent elements by using elemental equations. In order to achieve an approximate solution of the behavior of the continuum, these elemental equations are assembled to obtain global governing equations which can be expressed as (Zienkiewicz and Taylor, 1991; Cook et al., 2003):

$$
[\mathrm{K}]\{\mathrm{r}\}=\{\mathrm{R}\}
$$

where,

$$
\begin{aligned}
& {[\mathrm{K}] \quad=\text { global stiffness matrix, }} \\
& \{\mathrm{r}\} \quad=\text { global displacement vector }
\end{aligned}
$$




$$
\{\mathrm{R}\} \quad=\text { global load vector. }
$$

Global equilibrium equations are obtained by the assembly of element equations. The details of these derivations are given elsewhere (Cook et al., 2003; Zienkewicz and Taylor, 1991). Figure 4.1 shows illustrations of the local and global coordinate systems for a three dimensional brick element that used in this study.

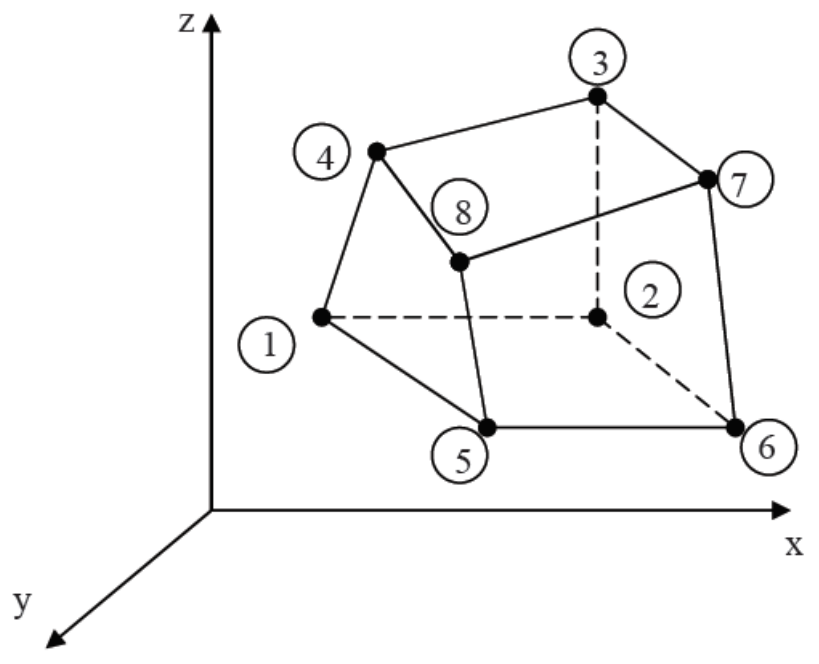

(a) Global coordinate system

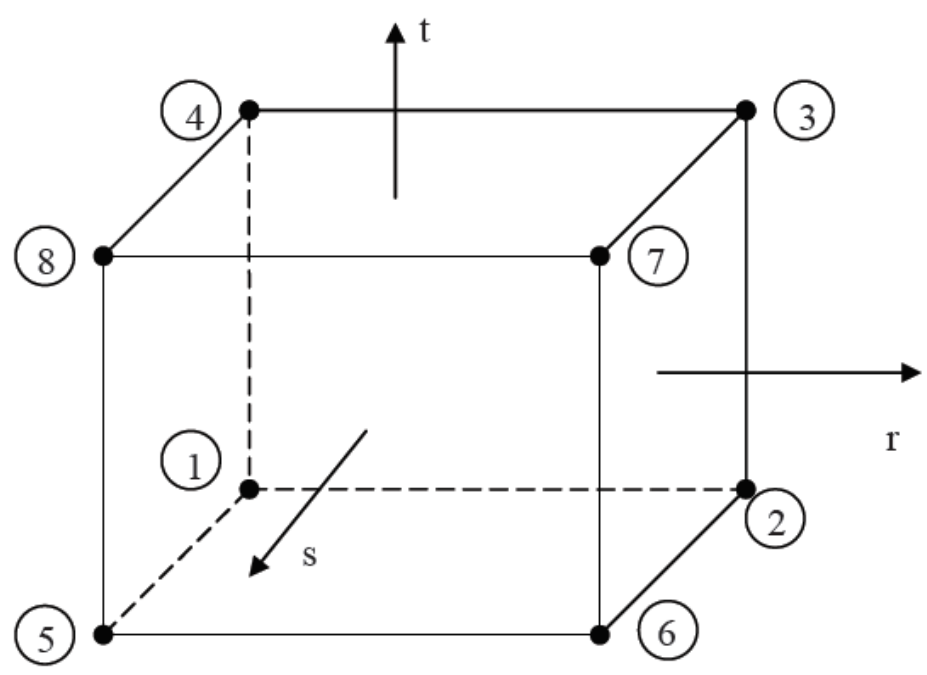

(b) Local coordinate system

Figure 4.1 Three dimensional brick element (Mada, 2005). 


\subsection{Element types and meshing}

Several meshing techniques such as structured, sweep, and free meshing are available within the Abaqus software package to mesh the geometry of a model. In this study, a structured meshing technique with quadrilateral element shapes was used to mesh the soil geometry and geotextile membrane. Free meshing technique was used for meshing the pipe to allow more flexibility than structured meshing. Three-dimensional brick elements were used to model soil, while threedimensional shell and membrane elements were used to model the pipe and geotextile, respectively. Figure 4.2 shows a typical meshed geometry of the buried pipe system.

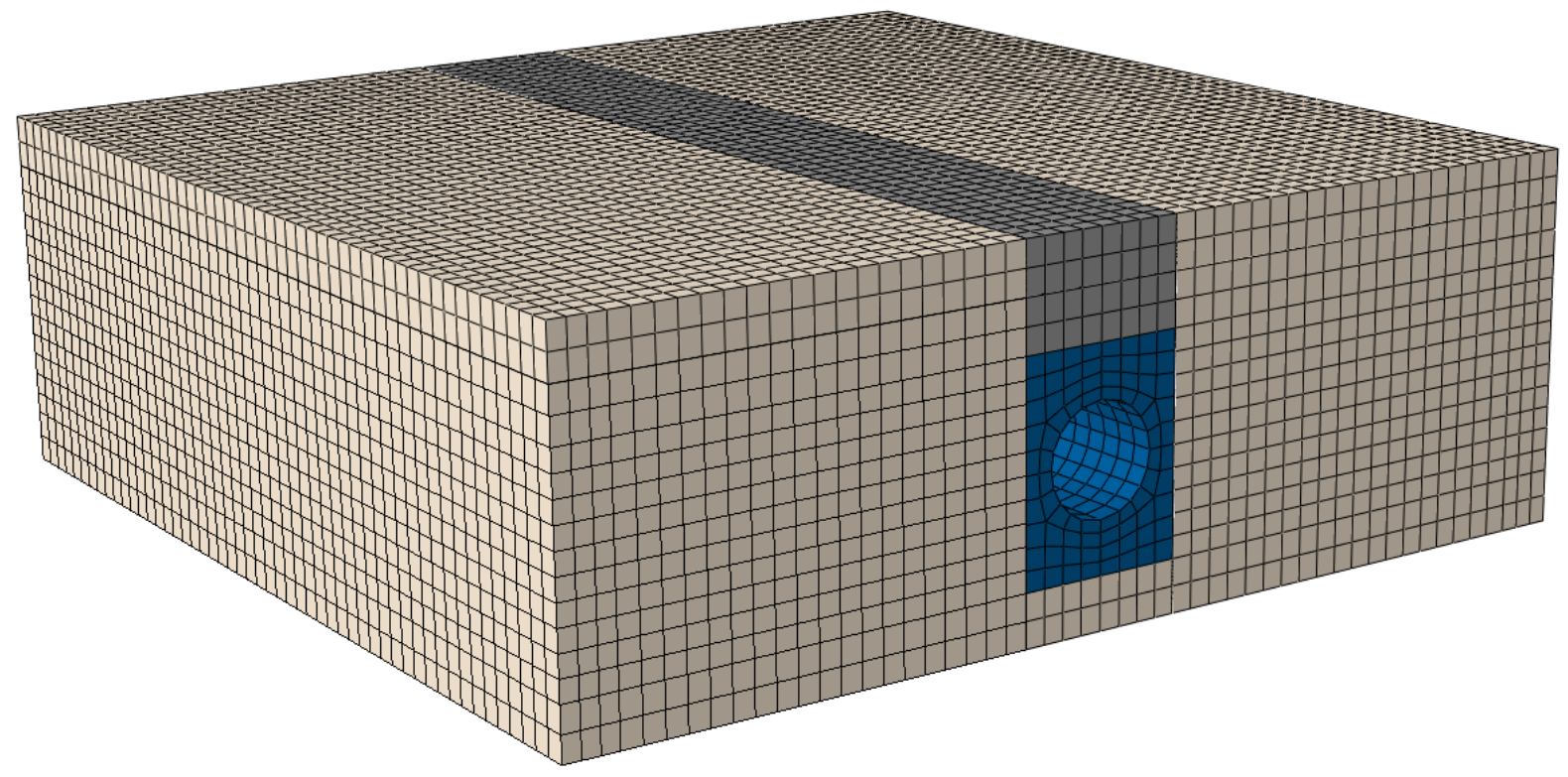

Figure 4.2: Meshed soil-pipe system

The mathematical formulation of the finite element formulation with contact boundary surfaces can be very complicated. In order to give some insight into the inner workings of the finite element method a brief explanation of the element formulation for eight-node brick elements is provided below. More details can be found elsewhere (Cook et al., 2003). Eight-node brick elements were used to model the soil in the current study. Displacements at each node are designated by $\mathrm{u}, \mathrm{v}$, and $\mathrm{w}$, representing the $\mathrm{x}, \mathrm{y}$, and $\mathrm{z}$ directions, respectively, as shown in Figure 4.3. 


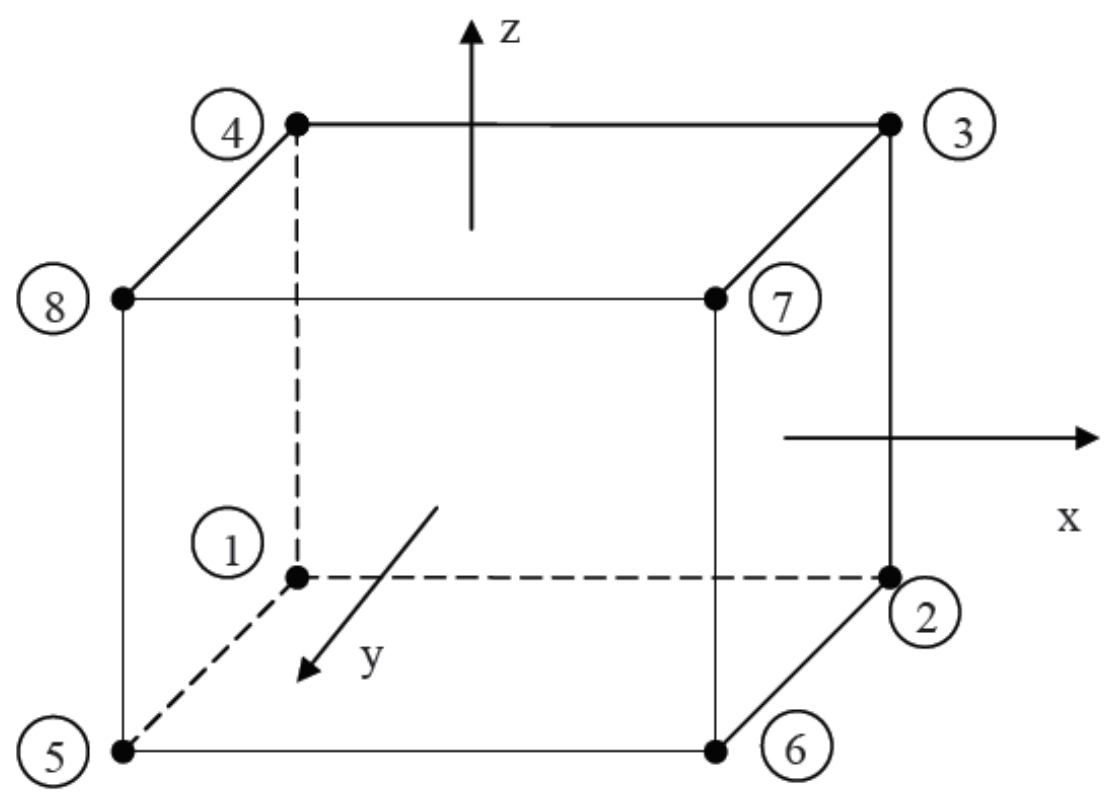

Figure 4.3: Nodal displacements along $x, y$, and $\mathrm{z}$ directions for solid element (Abaqus, 2010).

Displacements at a particular node are expressed by using interpolation functions and nodal displacements as:

$$
\begin{aligned}
& u=N_{1} u_{1}+N_{2} u_{2}+N_{3} u_{3}+\cdots+N_{8} u_{8} \\
& v=N_{1} v_{1}+N_{2} v_{2}+N_{3} v_{3}+\cdots+N_{8} v_{8} \\
& w=N_{1} w_{1}+N_{2} w_{2}+N_{3} w_{3}+\cdots+N_{8} w_{8}
\end{aligned}
$$

Where $\mathrm{N}_{1}, \mathrm{~N}_{2}, \mathrm{~N}_{3} \ldots \mathrm{N}_{8}$ are interpolation functions

The interpolation functions can be written as:

$$
N_{i}=\frac{1}{4}\left(1+r r_{i}\right)\left(1+s s_{i}\right)\left(1+t t_{i}\right)
$$

Where $\mathrm{r}, \mathrm{s}$, and t correspond to the local coordinates which vary from -1 to +1 and the subscript, $i$, denotes the node number. For a solid element the interpolation functions at each node are given as: 


$$
\begin{aligned}
& N_{1}=\frac{1}{8}(1-r)(1-s)(1-t) \\
& N_{2}=\frac{1}{8}(1+r)(1-s)(1-t) \\
& N_{3}=\frac{1}{8}(1+r)(1+s)(1-t) \\
& N_{4}=\frac{1}{8}(1-r)(1+s)(1-t) \\
& N_{5}=\frac{1}{8}(1-r)(1-s)(1+t) \\
& N_{6}=\frac{1}{8}(1+r)(1-s)(1+t) \\
& N_{7}=\frac{1}{8}(1+r)(1+s)(1+t) \\
& N_{8}(1-r)(1+s)(1+t)
\end{aligned}
$$

The strains $\varepsilon_{\mathrm{xx}}, \varepsilon_{\mathrm{yy}}, \varepsilon_{\mathrm{zz}}, \gamma_{\mathrm{xy}}, \gamma_{\mathrm{yz}}$, and $\gamma_{\mathrm{zx}}$ are given as (Zienkiewicz and Taylor, 1991):

$$
\begin{array}{lll}
\varepsilon_{x x}=\frac{\partial u}{\partial x} & \varepsilon_{y y}=\frac{\partial v}{\partial y} & \varepsilon_{z z}=\frac{\partial w}{\partial z} \\
\gamma_{x y}=\frac{\partial u}{\partial y}+\frac{\partial v}{\partial x} & \gamma_{y z}=\frac{\partial v}{\partial z}+\frac{\partial w}{\partial y} & \gamma_{z x}=\frac{\partial w}{\partial x}+\frac{\partial u}{\partial z}
\end{array}
$$

By substituting the expression in Equation 4.2 into Equation 4.4, the following relationship results:

$$
\{\varepsilon\}_{(6 \times 1)}=[B]_{(6 \times 24)}\{q\}_{(24 \times 1)}
$$

where [B] is the strain-displacement transformation matrix (Cook et al., 2003; Zienkewicz and Taylor, 1991). 
The stress strain relationship can be written as shown below:

$$
\left\{\begin{array}{l}
\sigma_{x x} \\
\sigma_{y y} \\
\sigma_{z z} \\
\tau_{x y} \\
\tau_{y z} \\
\tau_{x z}
\end{array}\right\}_{(6 \times 1)}=[C]_{(6 \times 6)}\left\{\begin{array}{l}
\varepsilon_{x x} \\
\varepsilon_{y y} \\
\varepsilon_{z z} \\
\gamma_{x y} \\
\gamma_{y z} \\
\gamma_{x z}
\end{array}\right\}_{(6 \times 1)}
$$

where $[\mathrm{C}]$ is the constitutive matrix.

Element equilibrium equations are given as:

$$
[K]\{q\}=\{Q\}
$$

where $[\mathrm{K}]$ is the element stiffness matrix and $\{\mathrm{Q}\}$ is the element load vector. They can be expressed as:

$$
\begin{gathered}
{[K]=\iint_{V}\{B\}_{(24 \times 6)}^{T}[C]_{(6 \times 6)}\{B\}_{(6 \times 24)} d v} \\
\{Q\}=\iiint_{V}[N]^{T}\{\bar{X}\} d v+\iiint_{S}[N]^{T}\{\bar{T}\} d S-\iiint_{V}[B]^{T}\left\{\sigma_{0}\right\} d v+\{P\}
\end{gathered}
$$

where,

$$
\begin{array}{ll}
\bar{X} & =\text { body force vector, } \\
\bar{T} & =\text { surface traction vector } \\
\sigma_{0} & =\text { initial stress vector, and } \\
\{P\} & =\text { external load vector. }
\end{array}
$$

The element stiffness matrix $[\mathrm{K}]$ is a function of the structural geometry and material properties of the element. Element stiffness matrices are assembled to obtain the global stiffness matrix of the system. For buried pipe analysis, this global stiffness matrix is composed of several element 
properties (soil element properties, backfill element properties, and pipe properties) and the system geometry.

\subsubsection{Shell elements}

Shell elements are typically used to model structures in which one dimension, the thickness, is significantly smaller than the other dimensions. Conventional shell elements are used to discretize a body by defining the geometry at a reference surface. In this case the thickness is defined through the section property definition. Conventional shell elements have displacement and rotational degrees of freedoms. In contrast, continuum shell elements can be used to discretize an entire threedimensional body. The thickness is determined from the element geometry. Continuum shell elements have only displacement degrees of freedom. From a modeling point of view continuum shell elements look like three-dimensional continuum solids, but their kinematic and constitutive behavior is similar to conventional shell elements (Abaqus, 2010). In the case of this research continuum shell elements were utilized to model the flexible pipe. Figure 4.4 illustrates the differences between conventional and continuum shell elements.

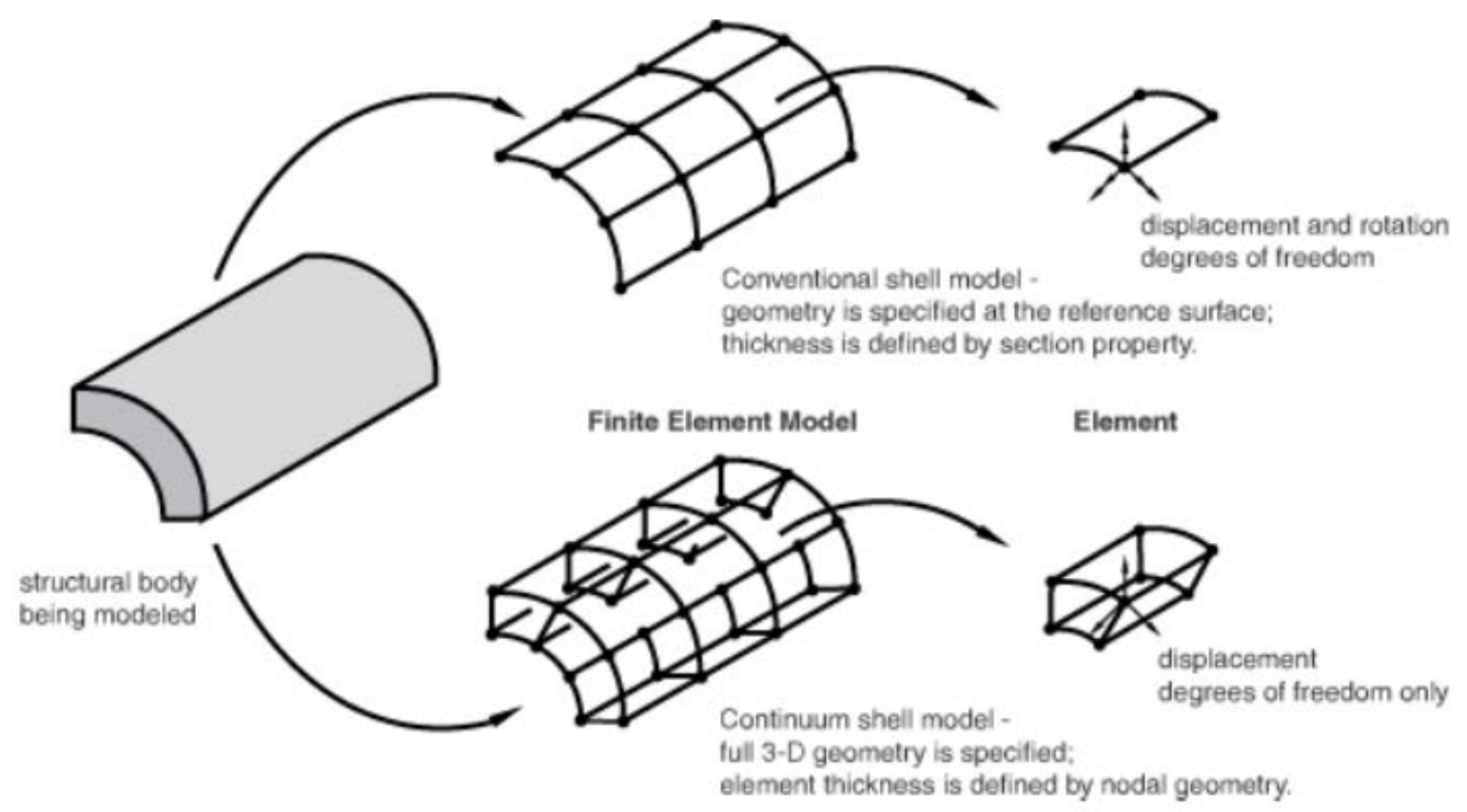

Figure 4.4: Continuum versus conventional shell elements (Abaqus, 2010). 


\subsubsection{Membrane elements}

The geotextile soil reinforcement included in the modeling was created using membrane elements. Membrane elements are typically used to represent thin surfaces in space that offer strength in the plane of the element but have no bending stiffness. A common example of this is the thin rubber sheet that forms a balloon. In the case of this research, membrane elements are used to generate a layer of geotextile soil reinforcement. In addition, they are often used to represent thin stiffening components in solid structures, such as a reinforcing layer in a continuum (Abaqus, 2010).

\subsection{Preliminary studies}

Finite element analysis of soil-structure problems differs from that of basic deformation and stress analysis. For a soil-structure interaction problem, such as with buried pipes, different element types are used to model the geometry of separate parts that are included in the soilstructure system. Table 4.1 lists element types used to model the soil-pipe geometry in previous studies that utilized the finite element method. None of these studies incorporated a geosynthetic material in the pipe-soil system. In the study reported herein, a geosynthetic layer was considered as a reinforcement of the system (Figure 1.3). In order to select an appropriate element type to model the pipe and geotextile geometry, several preliminary studies were performed as described below. 
Table 4.1: Finite element types used for soil-pipe geometry in previous studies."

\begin{tabular}{|c|c|c|}
\hline Author & Pipe & Soil \\
\hline Suleiman (2004) & Beam column elements & Quadrilateral elements \\
\hline Dhar et al. (2002) & $\begin{array}{c}\text { 2-noded beam-column } \\
\text { elements }\end{array}$ & 6-noded continuum elements \\
\hline Sargand and Masada (2000) & Beam elements & Quadrilateral elements \\
\hline Brachman et al. (2000) & $\begin{array}{c}\text { 8-noded rectangular } \\
\text { elements }\end{array}$ & 6-noded triangular elements \\
\hline Zhang and Moore (1998) & 6-noded triangular elements & 6-noded triangular elements \\
\hline Moore (1995) & 6-noded triangular elements & 6-noded triangular elements \\
\hline Hashash and Selig (1990) & Beam-column elements & $\begin{array}{c}\text { 4-noded quadrilateral } \\
\text { elements }\end{array}$ \\
\hline
\end{tabular}

*See reference: Gondle, 2006

\subsubsection{Modeling of pipe}

In order to investigate the effect of using various finite element techniques for the modeling of pipes, a parallel plate test on an unconfined pipe was simulated and the results were compared with that of the theoretical equation shown below. The theoretical pipe deflection for this scenario is presented as (Timosheko, 1936):

$$
\delta_{v}=\frac{2 \mathrm{Pr}_{0}^{3}}{E I}\left(\frac{\pi}{8}-\frac{1}{\pi}\right)=\frac{0.148 \mathrm{Pr}_{0}{ }^{3}}{E I}
$$

where,

$$
\begin{aligned}
& P \quad=\text { vertical loading at the top of the pipe, } \\
& r_{0} \quad=\text { radius of the pipe } \\
& E \quad=\text { Elastic Modulus of the pipe, } \\
& I \quad=\text { moment of the pipe section, and } \\
& \delta_{v} \quad=\text { vertical deflection of the pipe. }
\end{aligned}
$$


Two sizes of double wall corrugated HDPE pipes were considered in this study, 24 in. $(60.96 \mathrm{~cm})$ and 60 in. $(152.4 \mathrm{~cm})$ diameter. The theoretical vertical deflection for such a pipe under a $100 \mathrm{lb}$ point load can be calculated as:

$$
\begin{aligned}
& \text { for } 24 \text { in. pipe, } \quad \delta_{v}=\frac{0.148 \times 100 \times 12.78^{3}}{28115.672 \times 0.536}=2.049 \mathrm{in} .=5.204 \mathrm{~cm} \\
& \text { for } 60 \text { in. pipe, } \quad \delta_{v}=\frac{0.148 \times 100 \times 31.07^{3}}{28885.496 \times 3.275}=4.692 \mathrm{in} .=11.918 \mathrm{~cm}
\end{aligned}
$$

Failure criterion for buried pipe is normally judged based on the percent deflection of the pipe. The following equation is used to determine this value:

$$
\% \delta_{v}=\frac{\delta_{v}}{\text { Pipe Diameter }}
$$

The theoretical equation for pipe deflection is based on the assumption that the pipe depth in the "z" direction in the $x-y-z$ plane is one unit thickness. As a first step, two-dimensional (2D) models were considered before moving to three-dimensional (3-D) models. For the 2-D models, both beam and plane strain elements were considered. Figures 4.5 and 4.6 illustrate beam and plane strain element models, respectively. The transition from 2-D to 3-D modeling was made by comparing 2-D models (with unit thickness) with 3-D models having a thickness equal to 1 with the intention of producing matching results. The $3-\mathrm{D}$ models can then be extended to a greater thickness as long as the loading is appropriately distributed to create a load that is nearly equivalent to the $100 \mathrm{lb}$ load that was applied in the theoretical model. The element types used in the 3-D models were solid and shell elements as described earlier. Figures 4.7 and 4.8 illustrate shell and solid element models, respectively. All models produced equivalent results when mesh densities were high; however, at lower mesh densities results for all cases do not match as well.

In finite element modeling, it is known that increasing the mesh density produces more accurate results; therefore, the mesh densities for the previously mentioned cases were varied within a range that showed how this alteration effected the deflection of the pipe. These results are displayed in Figure 4.9. It can be seen from this graph that pipes modeled with beam and 
shell elements produce more consistent results than those constructed from plane strain and solid elements. Therefore, three-dimensional shell elements are used to model pipes in all other subsequent modeling. It should be noted that the results under discussion were modeled for a 24 inch (60.96) diameter pipe only. Results for a 60 inch $(152.4 \mathrm{~cm})$ diameter pipe will only differ in the magnitude of the deflections, but not in how the pipe reacts to loading.
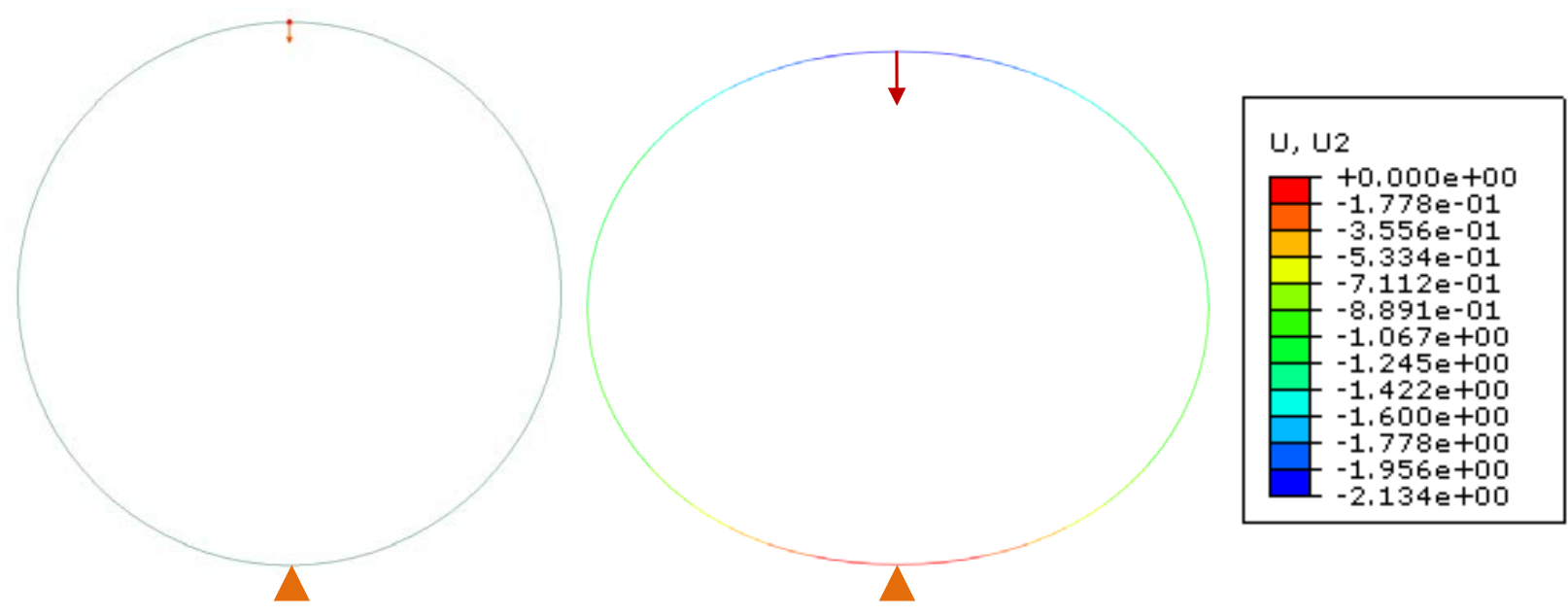

Figure 4.5: Beam elements.
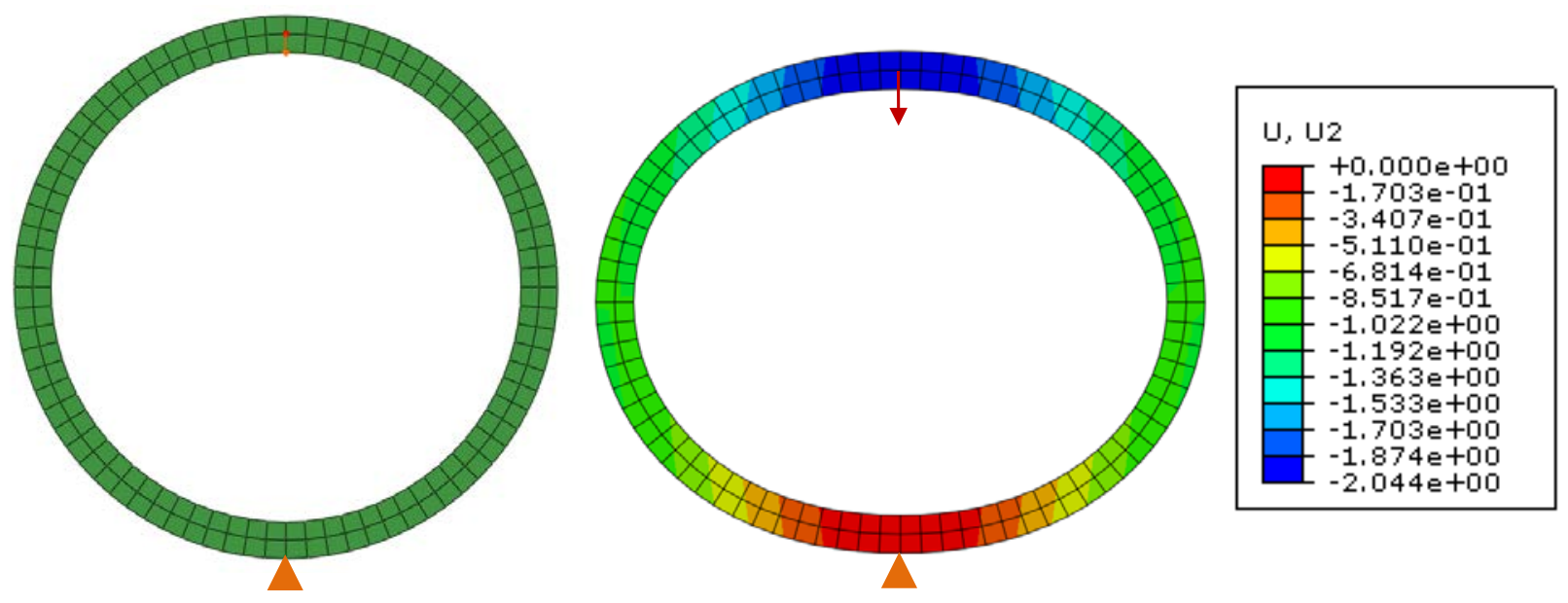

Figure 4.6: Plane strain elements. 

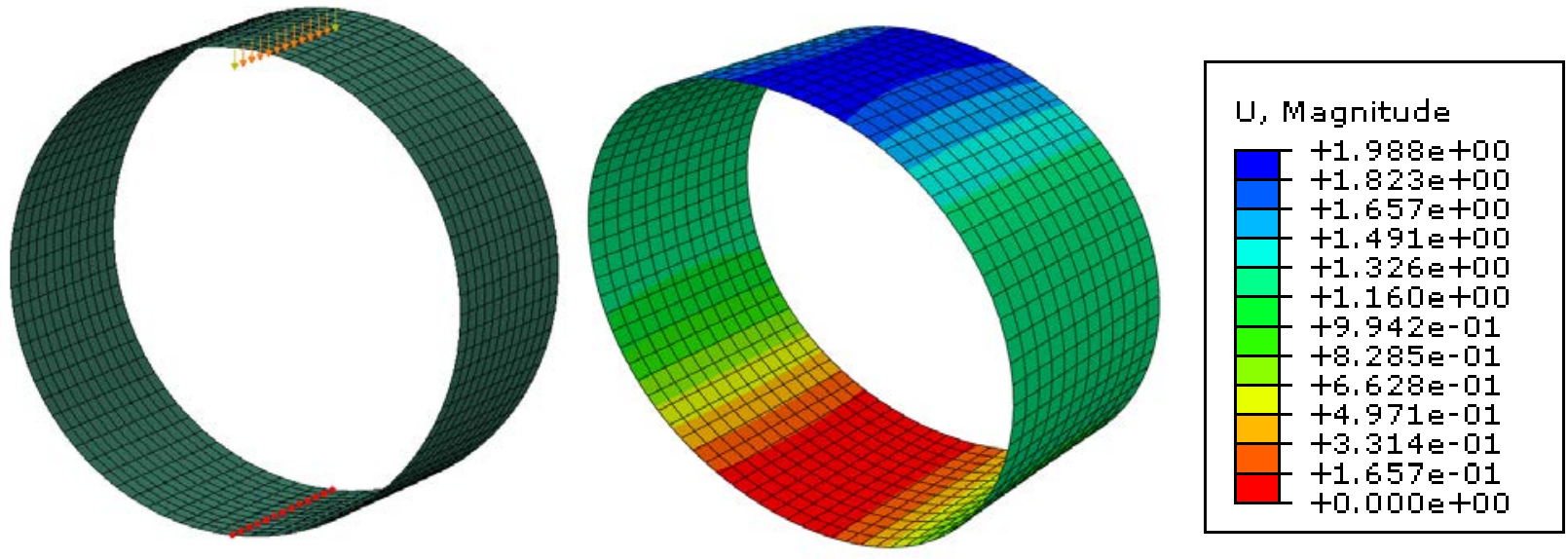

Figure 4.7: Three-dimensional shell elements.
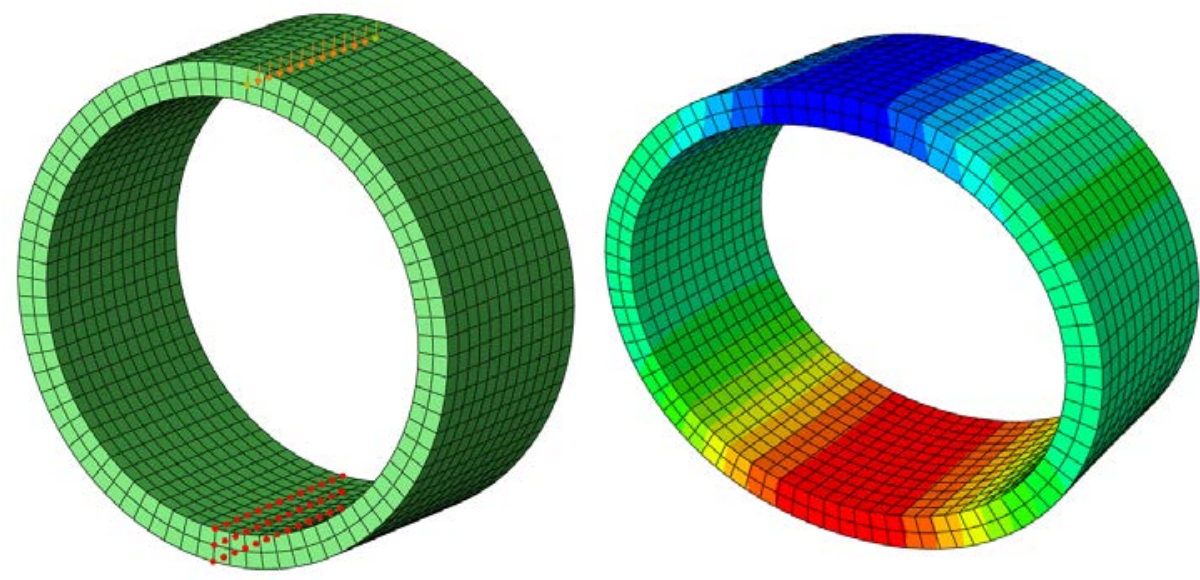

$U$, Magnitude

T $+1.949 e+00$

$+1.786 \mathrm{e}+00$

$+1.624 \mathrm{e}+00$

$+1.462 \mathrm{e}+00$

$+1.299 e+00$

$+1.137 \mathrm{e}+00$

$+9.743 \mathrm{e}-01$

$+8.119 \mathrm{e}-01$

$+6.496 \mathrm{e}-01$

$+4.872 \mathrm{e}-01$

$+3.248 \mathrm{e}-01$

$+1.624 \mathrm{e}-01$

$+0.000 e+00$

Figure 4.8: Three-dimensional solid elements. 


\section{Pipe Deflections with Varying Mesh Denisty}

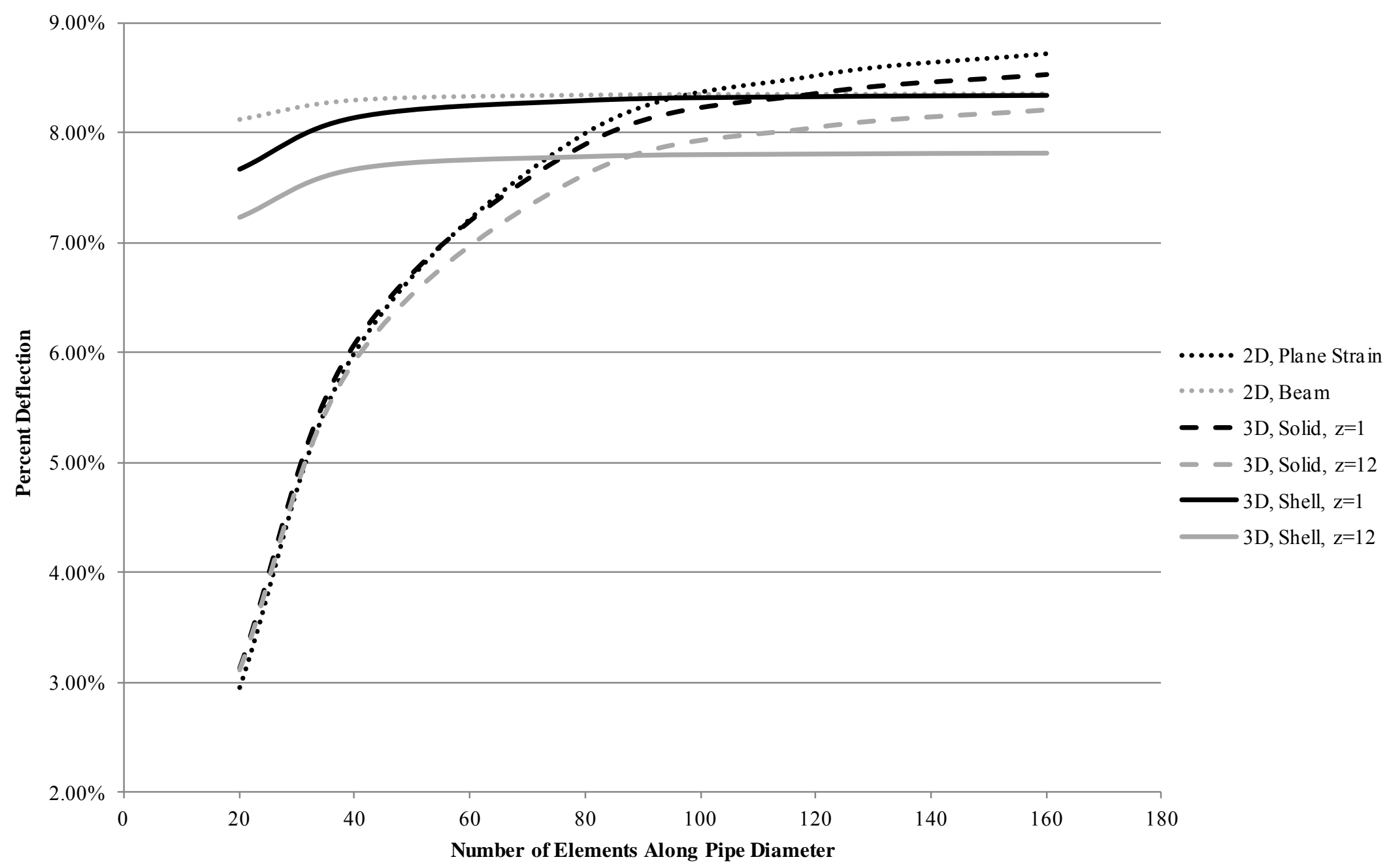

Figure 4.9: Percent pipe deflection with variation of mesh density for different element types. 


\subsubsection{Modeling of Geotextile}

In finite element analysis membranes represent thin surfaces that offer strength in the plane of the surface, but have no bending stiffness. This is exactly the effect that is desired from the geotextile reinforcement in the current study. An advantage of using membrane elements is that they do not have a tangible thickness within the modeling space. This means that the membrane can be placed in a plane where two soil sections meet without disrupting the contact adjacent to the area where there is no geotextile. The thickness of the membrane is specified as a property for calculating the membrane stiffness in the analysis procedure. If solid elements were to be used in place of membrane elements for the geotextile, voids would be created by the geotextile's thickness in these areas where the geotextile does not extend. These voids would need to be filled by very thin soil sections, thereby creating the need for additional contact interactions. The addition of more interactions raises the required computational effort and the chances of disrupting continuity within the model which could then lead to inaccuracies in the results. For that reason membrane elements were preferred for this study.

In order to test the reaction to loading of a geotextile constructed from membrane elements versus that of solid elements an observational test was conducted. For this test two geotextiles of identical geometry were constructed from both solid and membrane type elements. The geotextiles were fixed at opposing ends and left free at the other two ends. Identical point loads were applied to the center of each model. As can be seen from Figures 4.10 and 4.11 the patterns of deformation for both models are very similar. Both models resisted the force adequately and produced similar deflection values. The slight difference in the deflection pattern is likely caused by the incorporation of bending stiffness in the solid elements. With these results it was clear that a textile made from membrane element could withstand forces just as well as one made from solid elements. This, along with the idea mentioned in the previous paragraph, justifies the use of membrane elements for the modeling of geotextile in this study. 


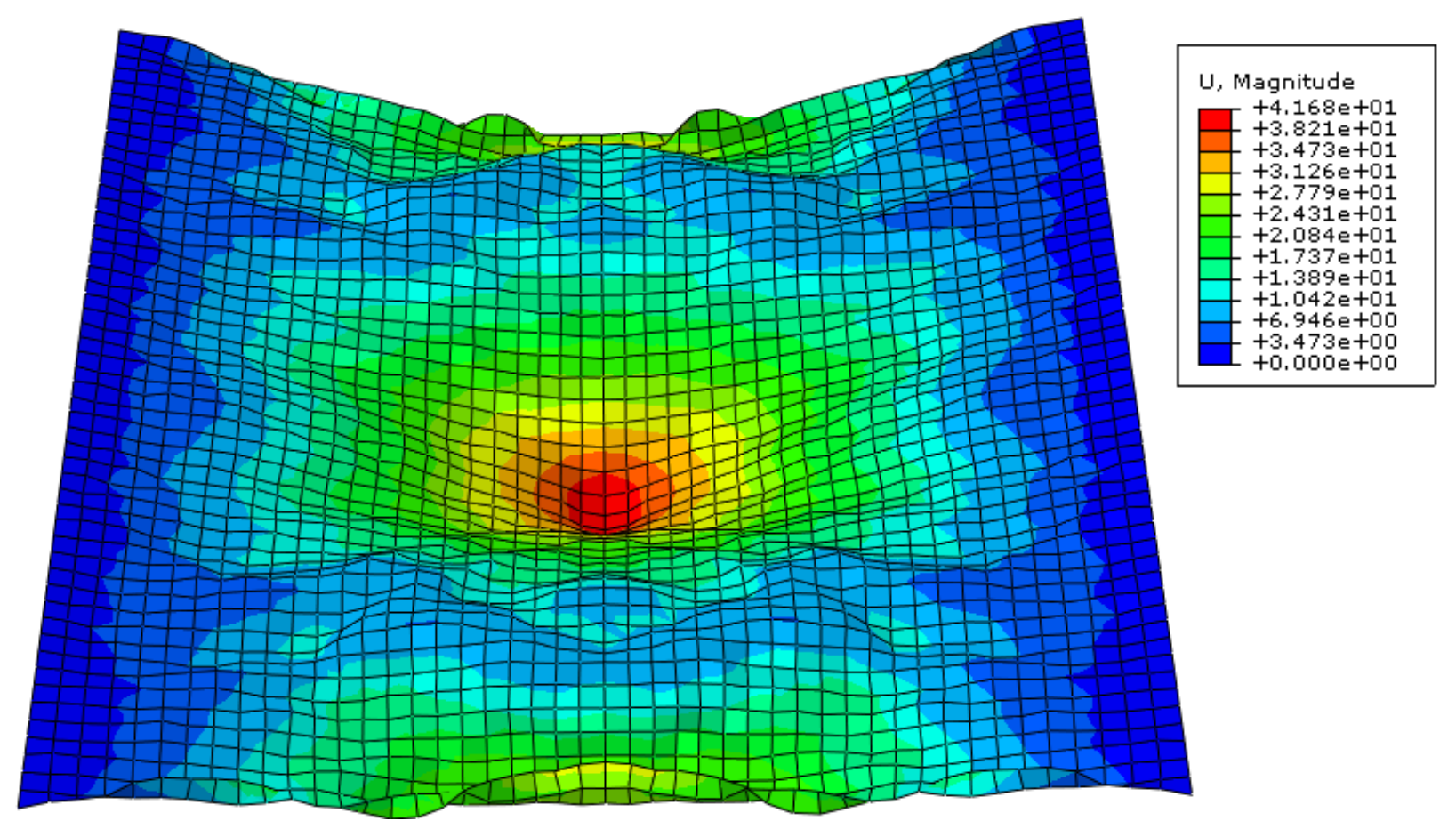

Figure 4.10: Geotextile constructed with membrane elements.

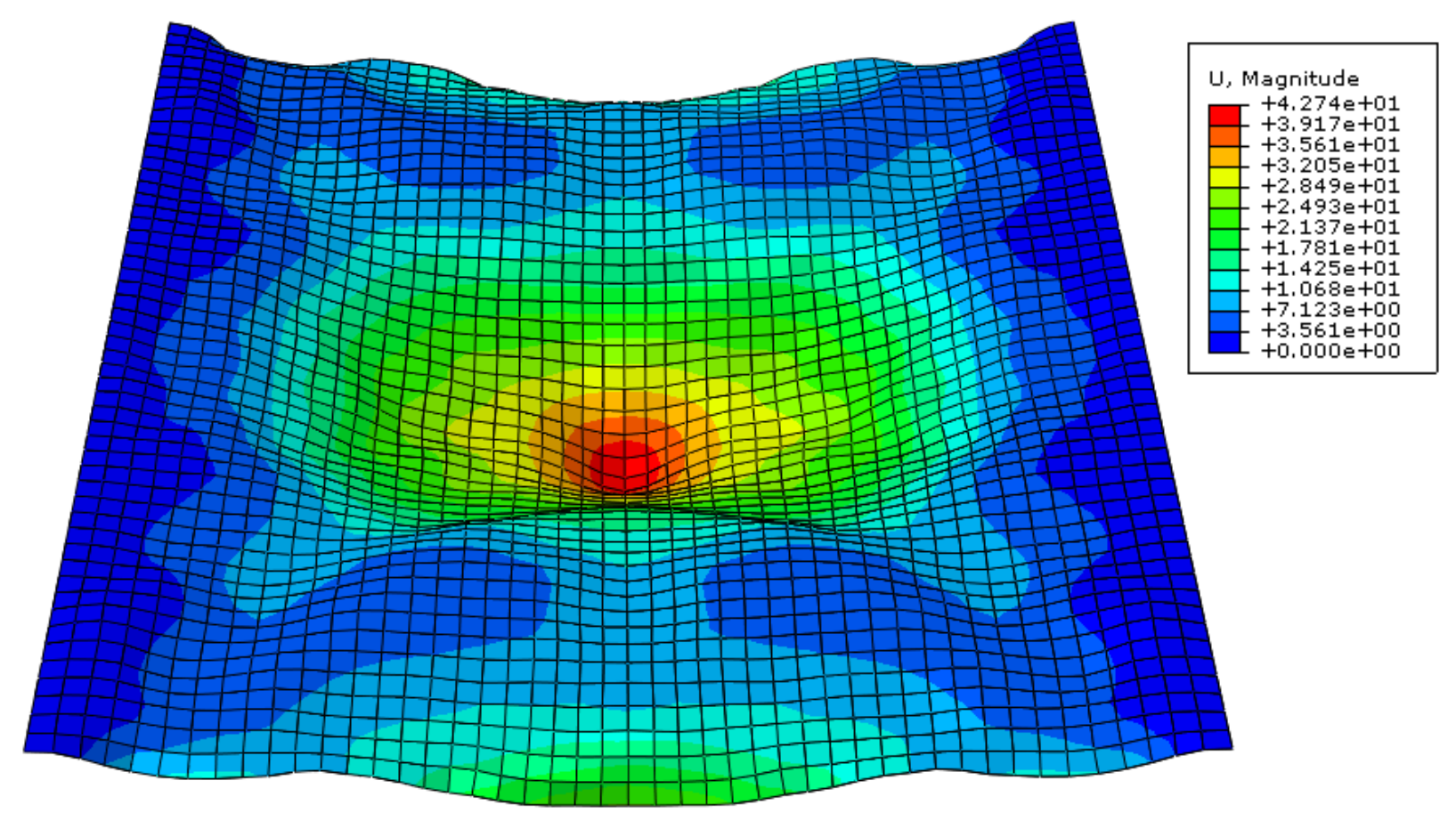

Figure 4.11: Geotextile constructed with solid elements. 


\subsection{Geotextile failure}

When geotextiles are used as soil reinforcement, anchorage force plays an important role in the reinforcement mechanism. When force is applied at the ground surface the buried geotextile needs to account for some of that loading in order to help reduce pipe deflections. If the geotextile deforms or slips excessively then it will not provide any benefit to the buried pipe system. Two types of failure mechanisms were observed in this study, geotextile slip and geotextile stretching. Geotextile slip occurs when the force applied to the geotextile is greater than the sum of frictional forces holding it in place. Stretching occurs if the force applied does not overcome the frictional forces, but the geotextile elongates under loading. In most cases, both slip and stretching occur simultaneously. It was necessary to ensure that the modeling techniques utilized in this study allowed these types of failure modes. The following calibration techniques were used to check for these failure modes.

\subsubsection{Pullout test}

Anchorage resistance is typically measured in the laboratory using a pullout test (see Figure 2.6). For such a test a geotextile is sandwiched between two soil layers which are held together by a specified normal force. The pullout resistance is dependent on the normal force applied to the soil which mobilizes shearing resistances on both surfaces of the geotextile as well as the angle of friction between the geotextile and soil medium (Koerner, 2005). Additional information on this test can be found in Chapter 2 of this paper. Demonstrating that a pullout test can be modeled by using FEM was essential for this study. Figure 4.12 shows the initial setup for the FEM pullout test and Figure 4.13 shows the tension resulting in the geotextile after a displacement of 5 inches $(12.7 \mathrm{~cm})$ as applied to one end of the textile. These results show that the mechanisms used are appropriate for modeling geotextile anchorage. More information on modeling pullout tests with FEM can be found elsewhere (Siriwardane et al., 2008; Perkins, 2003). 


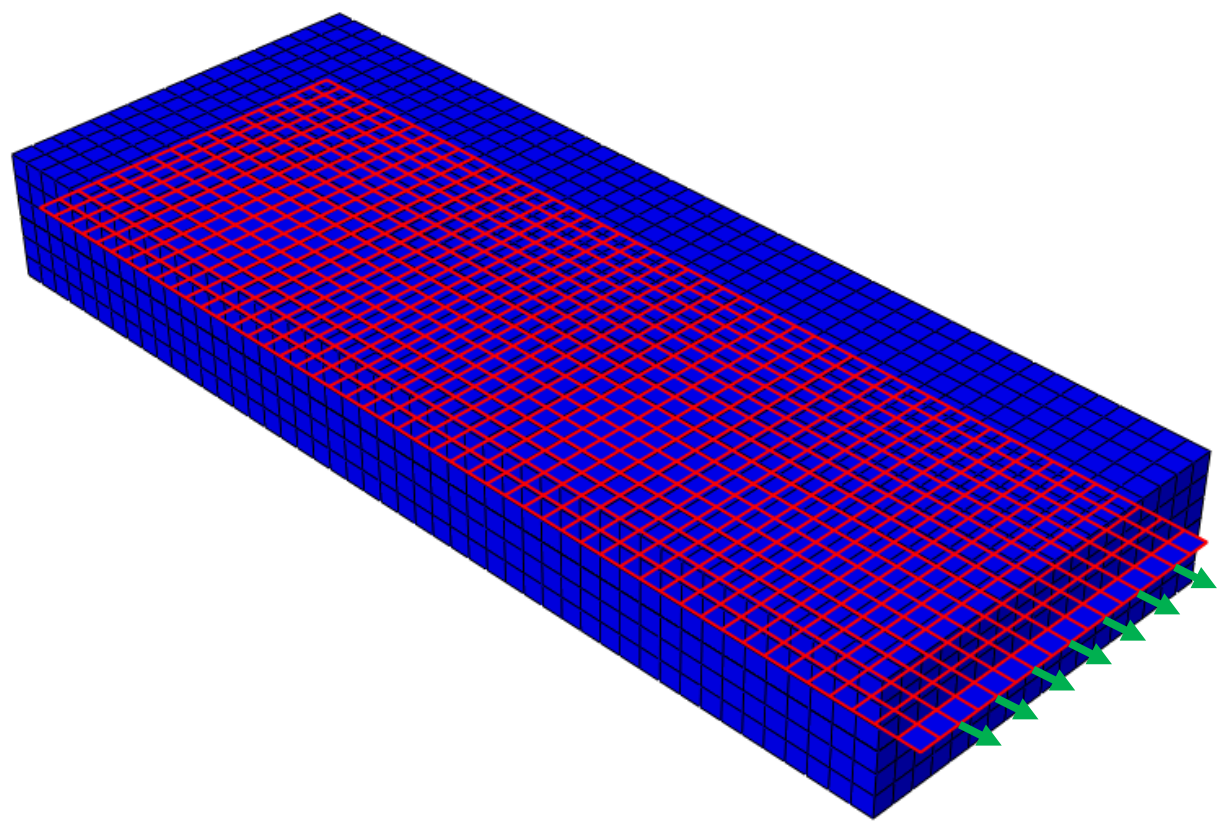

Figure 4.12: FEM pullout test (before loading).

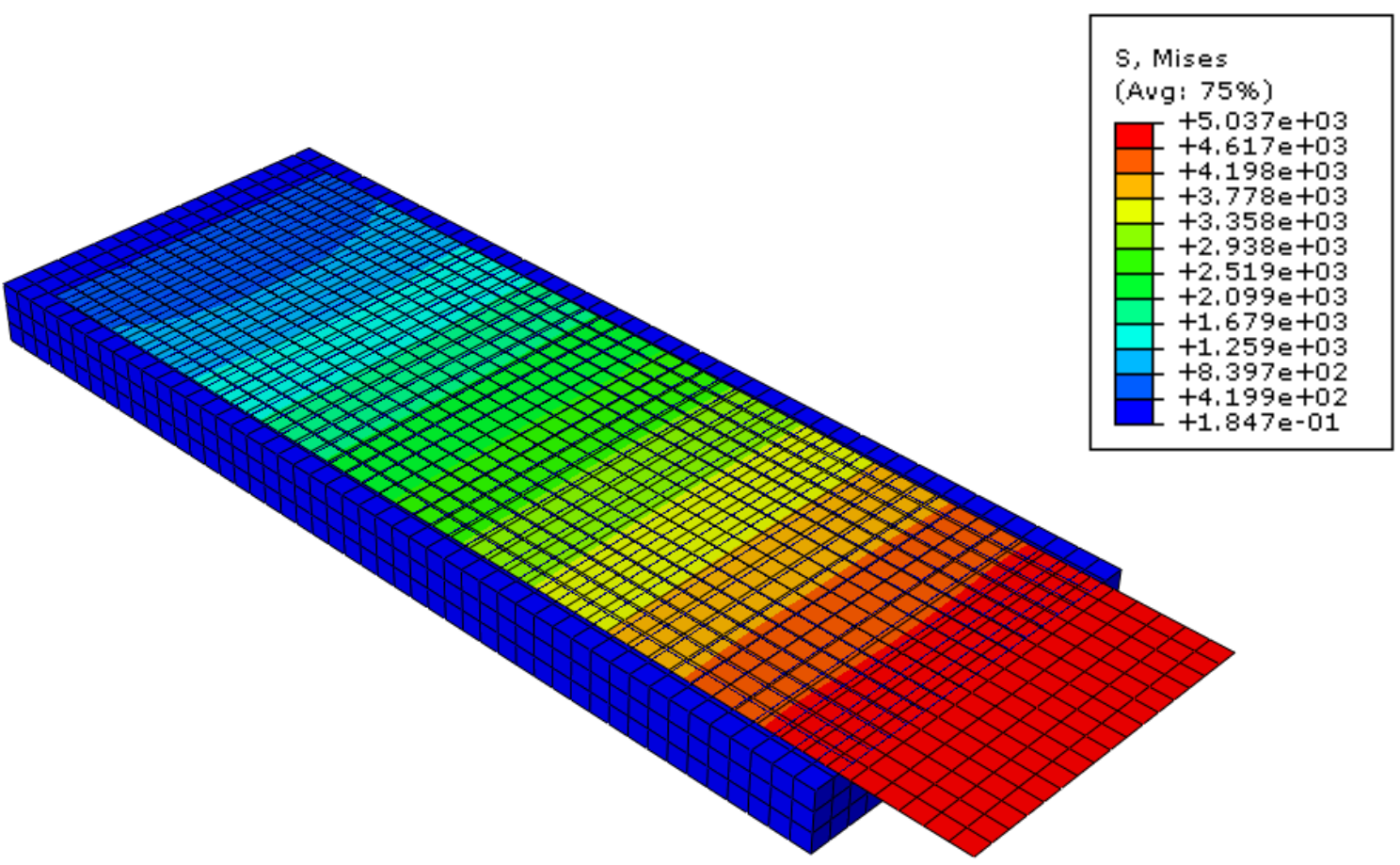

Figure 4.13: FEM pullout test after 5 inch displacement. 


\subsubsection{Modeling of Membrane Effects}

To gain a better understanding of the failure modes that are present in this finite element analysis, a direct vertical loading of the geosynthetic without any underburden support ("no trench test") as shown in Figure 4.14 was simulated. For this test, all soil in the trench that was below the geotextile was removed. The trench soil was removed so that nearly all of the applied force was carried by the geotextile reinforcement, rather than the soil below the geotextile. With this geometry in place, the mechanisms which cause failure in the geotextile, slip and stretching, are clearer to see and more easily produced. It was found that the two primary parameters which determine the failure type are geotextile stiffness and the magnitude of frictional resistance. With higher stiffness, the geotextile is less likely to stretch. If the applied force is greater than the sum of frictional forces, and the geotextile is less likely to stretch, then the geotextile must slip. Figure 4.15 shows a case where the elastic modulus of the geotextile is high and the frictional coefficient is low. This resulted in high geotextile slip. On the other hand, if the frictional resistance is high enough to hold the geotextile in place, then the geotextile is more likely to stretch under significant loading. Figure 4.16 shows geotextile stretching.

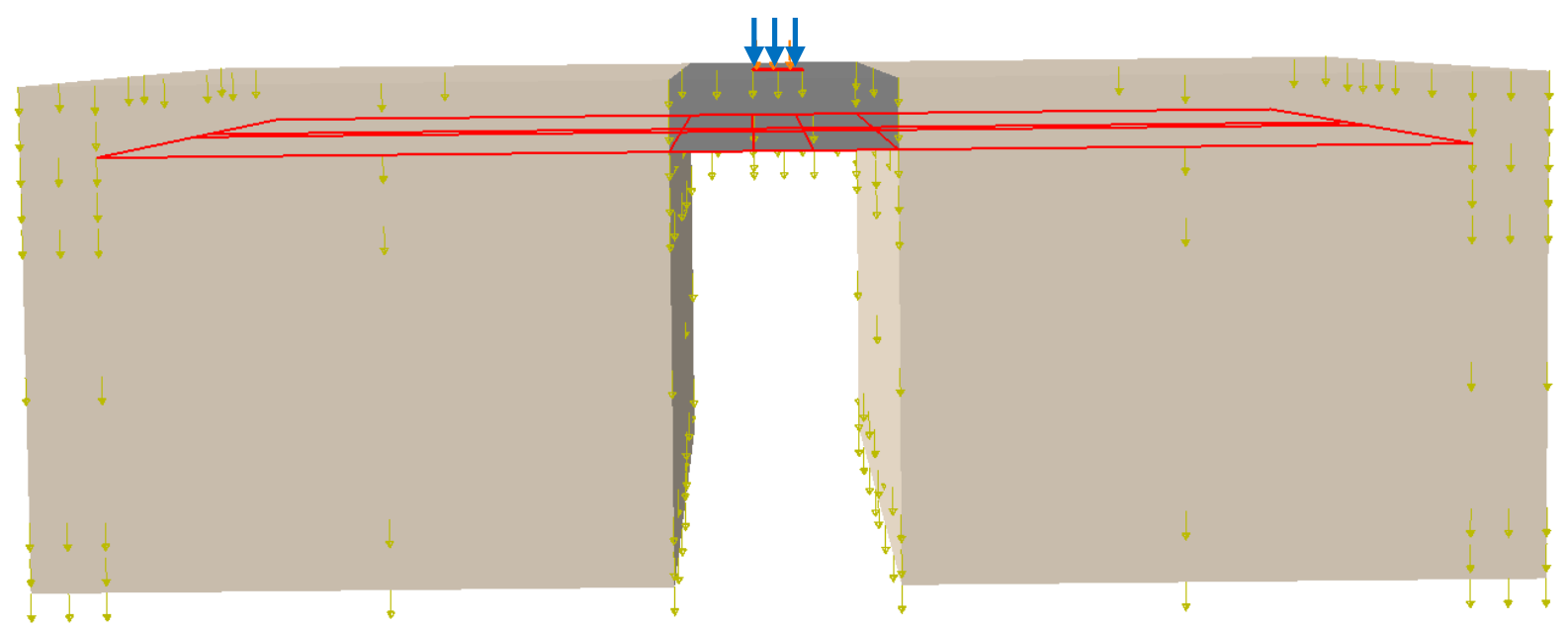

Figure 4.14: Geometry of “No Trench Test”. 


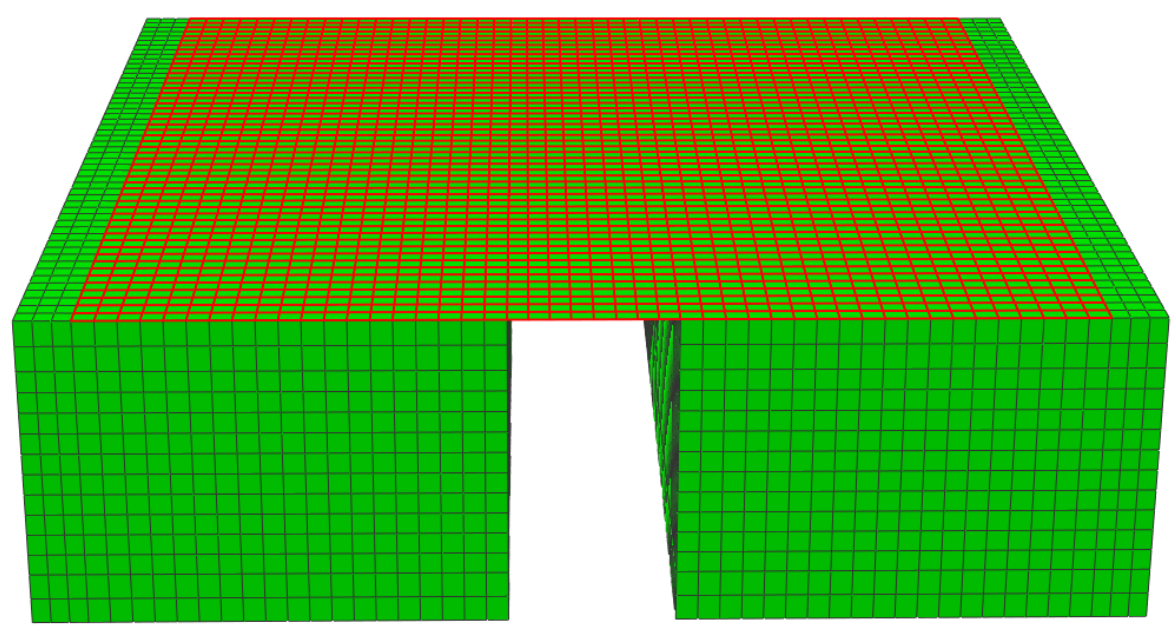

Before Loading

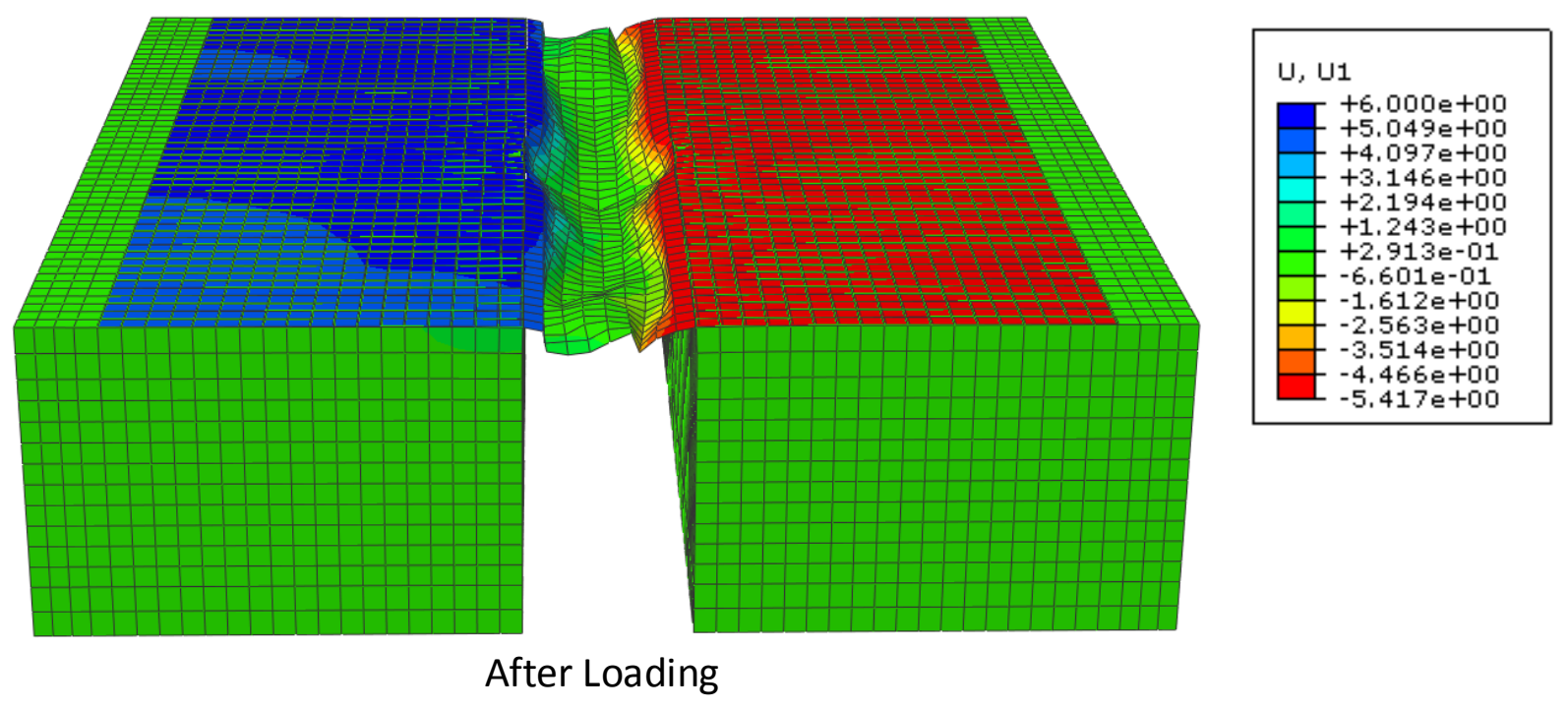

Figure 4.15: Geotextile slip. 


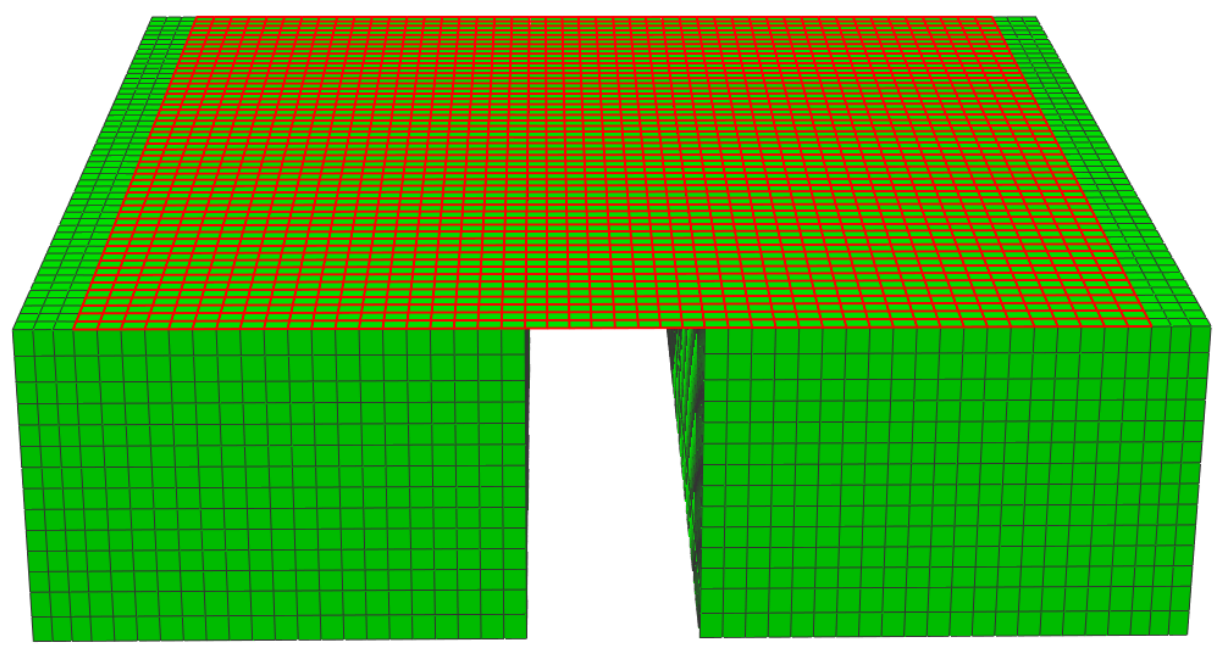

Before Loading

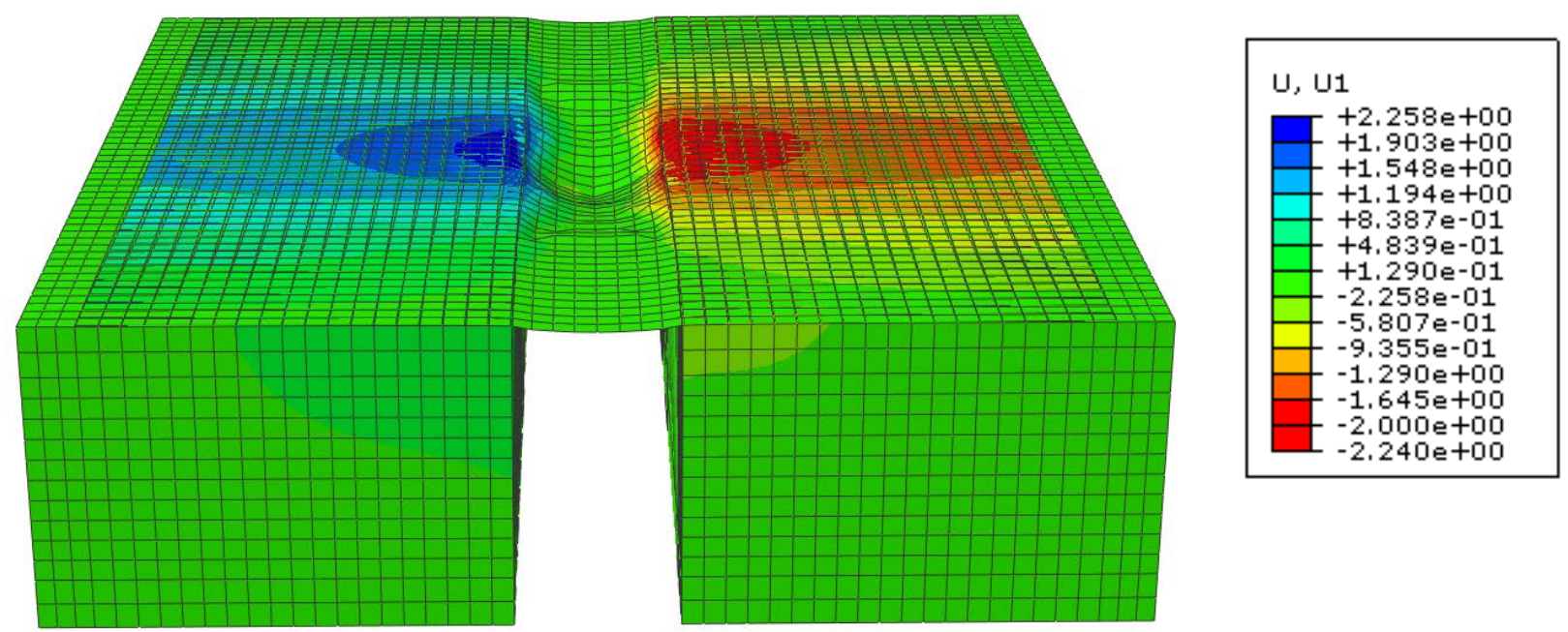

After Loading

Figure 4.16: Geotextile stretching.

\subsection{Loading and boundary conditions}

The evaluation of geotextile performance for this study was performed under a loading combination that considered three types of forces: (a) self weight of the soil (dead load), (b) normal force that would be generated from the soil overburden above the geotextile (dead load), and (c) HS-25 truck loading at the surface (live load). For the soil loading it was assumed that all soils used had equal densities of 125 pcf $\left(2002.31 \mathrm{~kg} / \mathrm{m}^{3}\right)$, resulting in a uniform dead load throughout the entire model. This strategy was used to ensure symmetry and provide more consistent results. This force (body force) is shown in Figure 4.17. The normal force over the geotextile is necessary to activate the frictional resistance at the geotextile-soil interaction. This 
frictional force is the key component of geotextile soil reinforcement. The normal force is applied to very stiff loading plates that rest on top of the geotextile layer rather than on the geotextile itself. These loading plates were needed to insure that the normal force remained stationary and did not move when the geotextile was pulled into the trench as the HS-25 loading was applied. The normal force load application is shown in Figure 4.18. HS-25 truck loading is equal to a magnitude of $100 \mathrm{psi}(13.79 \mathrm{kPa})$ force applied over a 20 "x 10 " $(50.8 \mathrm{~cm}$ x $25.4 \mathrm{~cm})$ rectangular area (AASHTO, 2007). Figure 4.20 is an illustration of the HS-25 load distribution. Figure 4.19 displays the HS-25 load application in the FEM model.

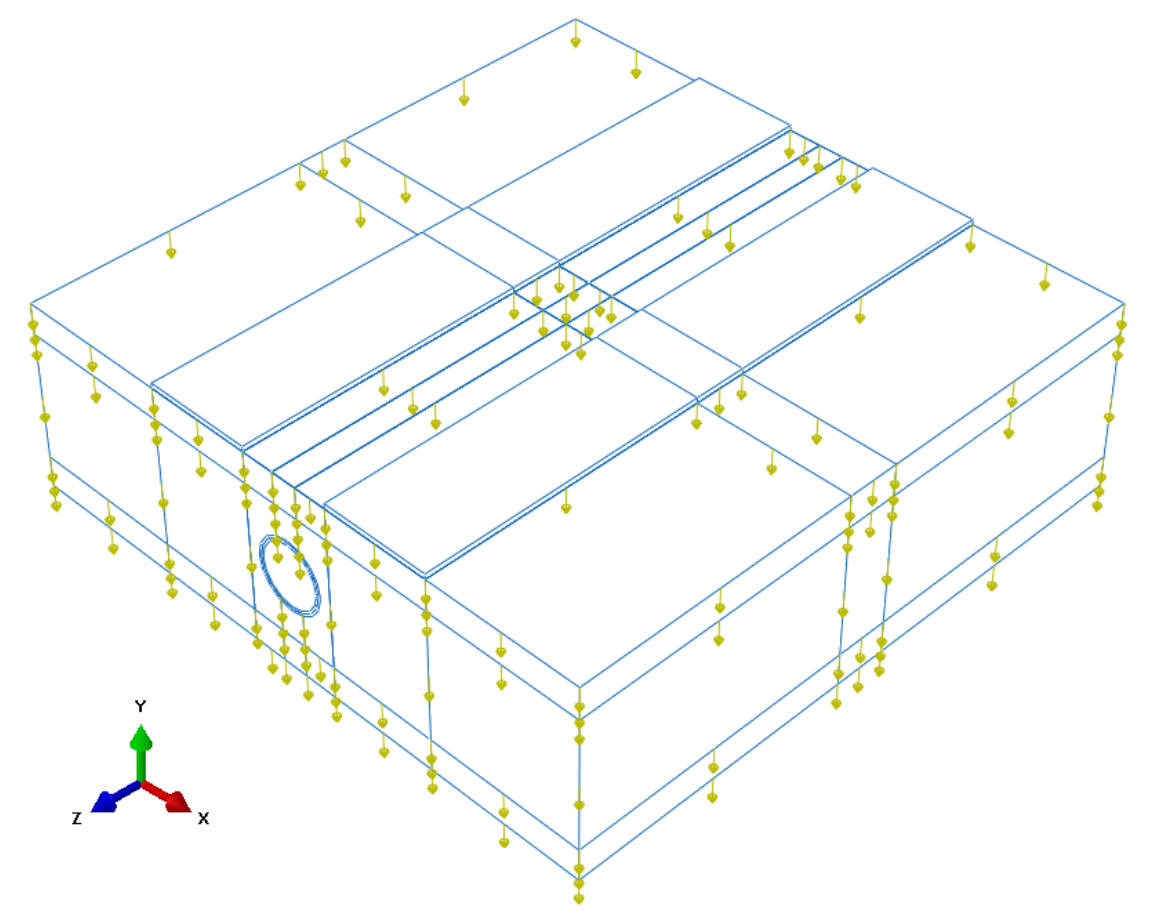

Figure 4.17: Soil weight body force. 


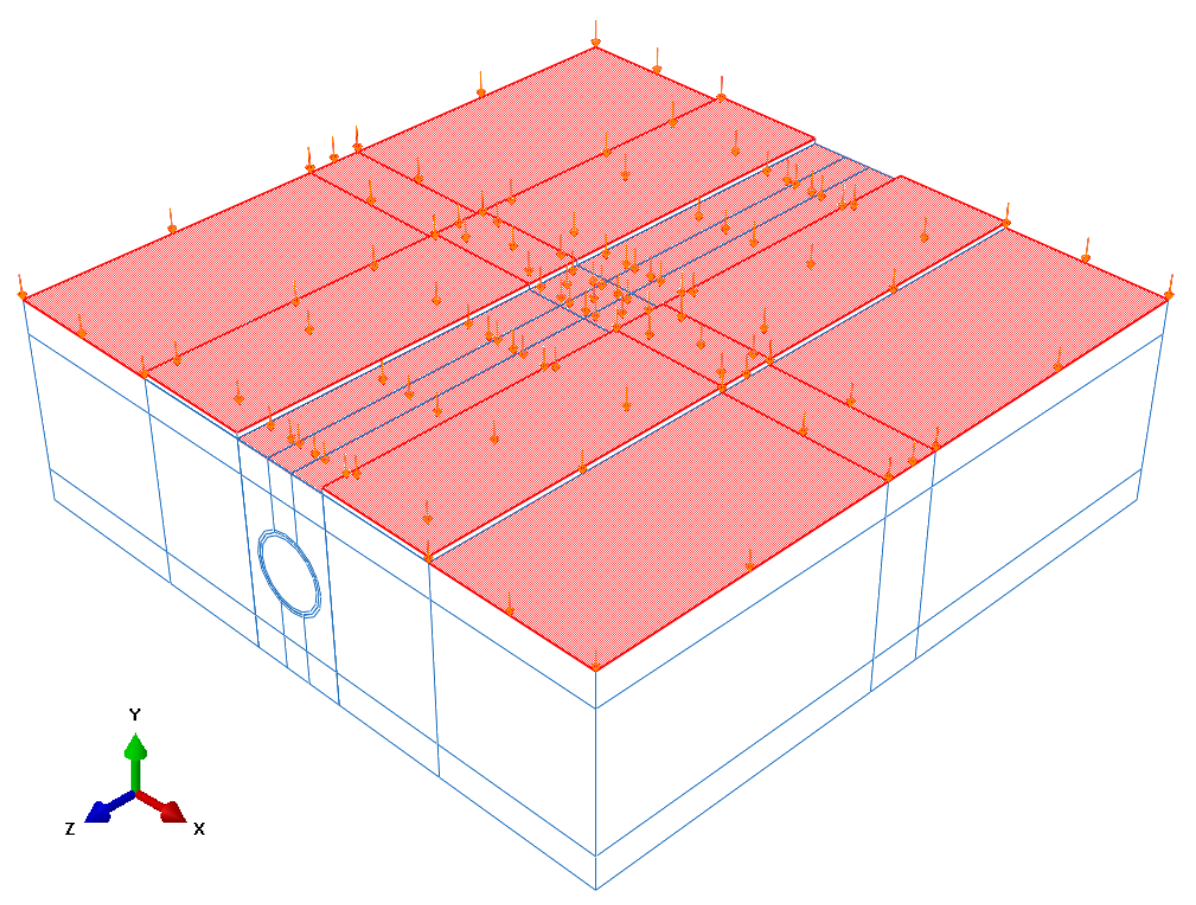

Figure 4.18: Normal force from overburden.

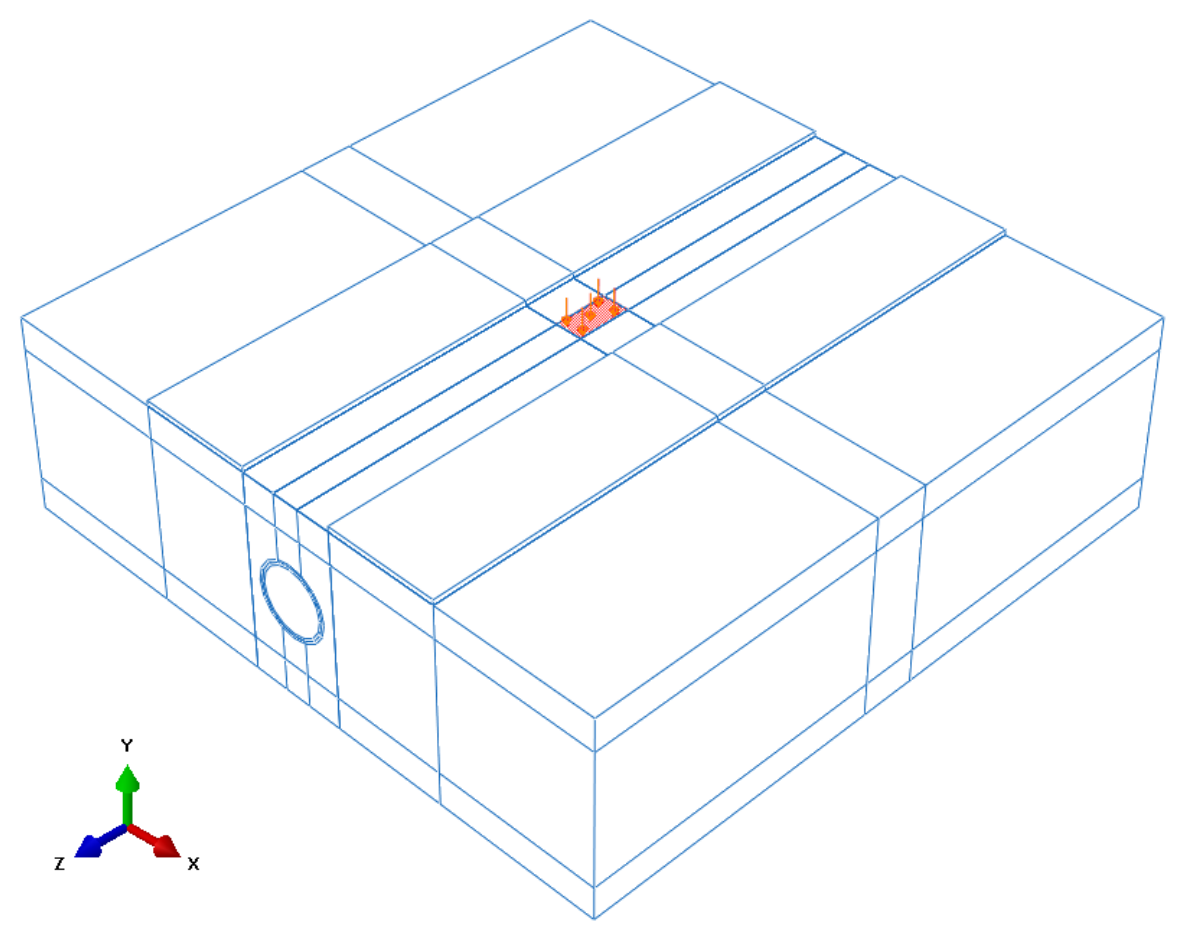

Figure 4.19: HS-25 loading. 
Figures $4.21,4.22$, and 4.23 show the boundary conditions applied to the model geometry for the bottom, front $\&$ back, and sides, respectively. These boundary conditions include a fixed base, $\mathrm{x}$-symmetry on the left and right sides of the soil geometry and loading plates, and zsymmetry on the front and back faces of the soil geometry and loading plates. No boundary conditions were applied to the geotextile or pipe. This combination of boundary conditions results in a model that has rollers at the front, back, and side faces, while remaining fixed at the bottom allowing unimpeded movement in the y-direction.

Loading for this analysis was applied instantaneously over several steps. The scope of this work does not account for time-dependent phenomena such as creep. Such work can be found elsewhere (Varre, 2011; Gondle, 2006). The step increments were in the following order:

Initial Conditions: $\quad$ All boundary conditions and contact interactions are applied.

Step 1: $\quad$ Body forces from soil weight are implemented and normal forces from simulated overburden are applied to the loading plates.

Step 2: $\quad$ HS-25 loading is applied at the surface.

\section{HS 25 TRUCK LOAD}

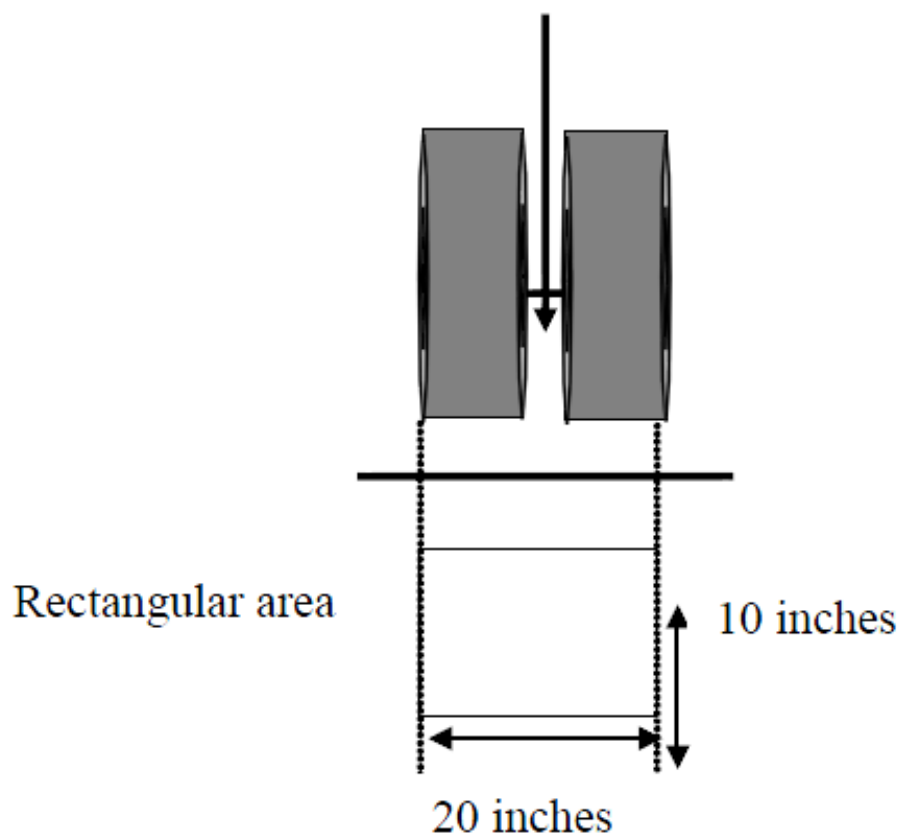

Figure 4.20: HS-25 load distribution (Varre, 2011). 


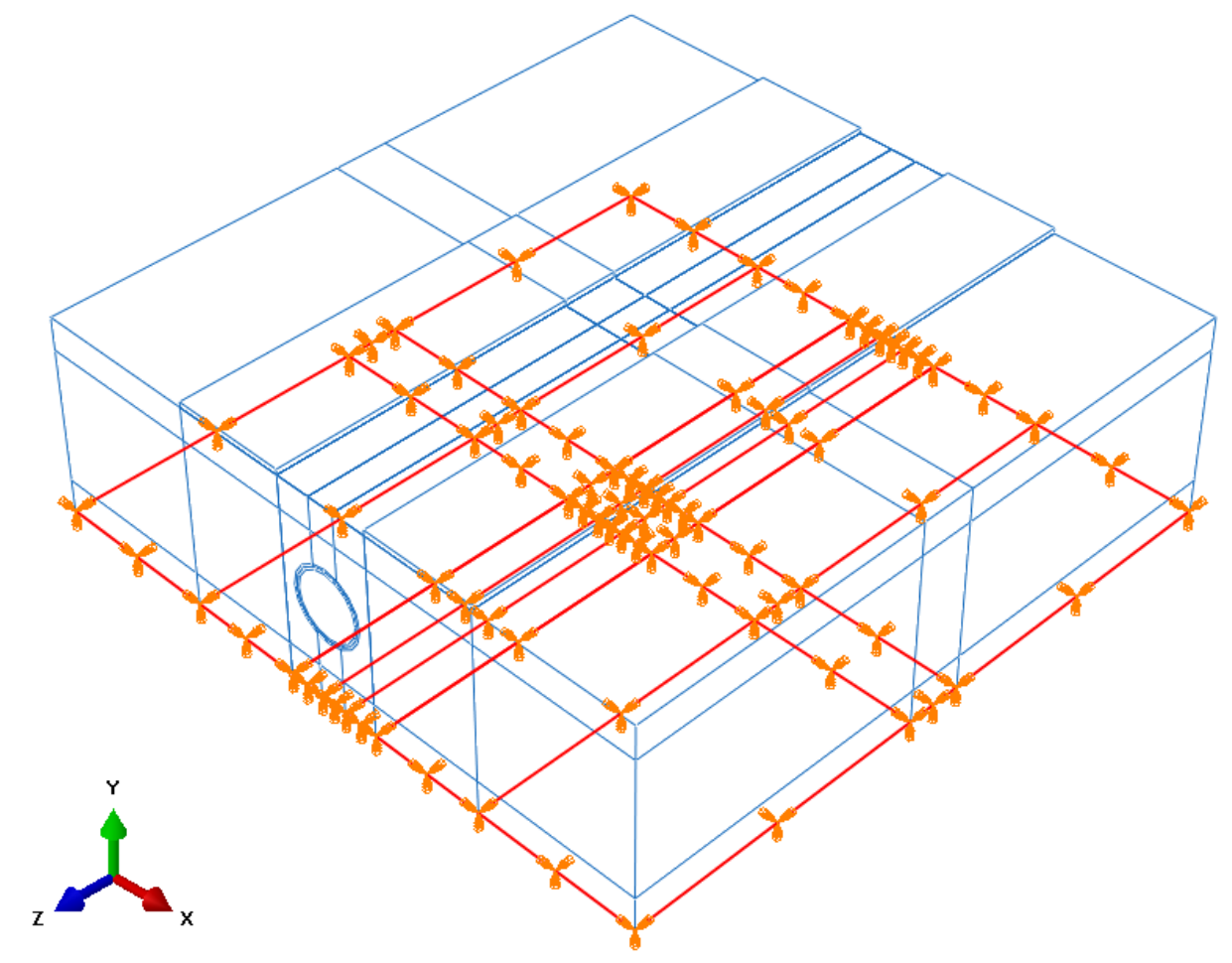

Figure 4.21: ENCASTRE boundary condition on bottom face.

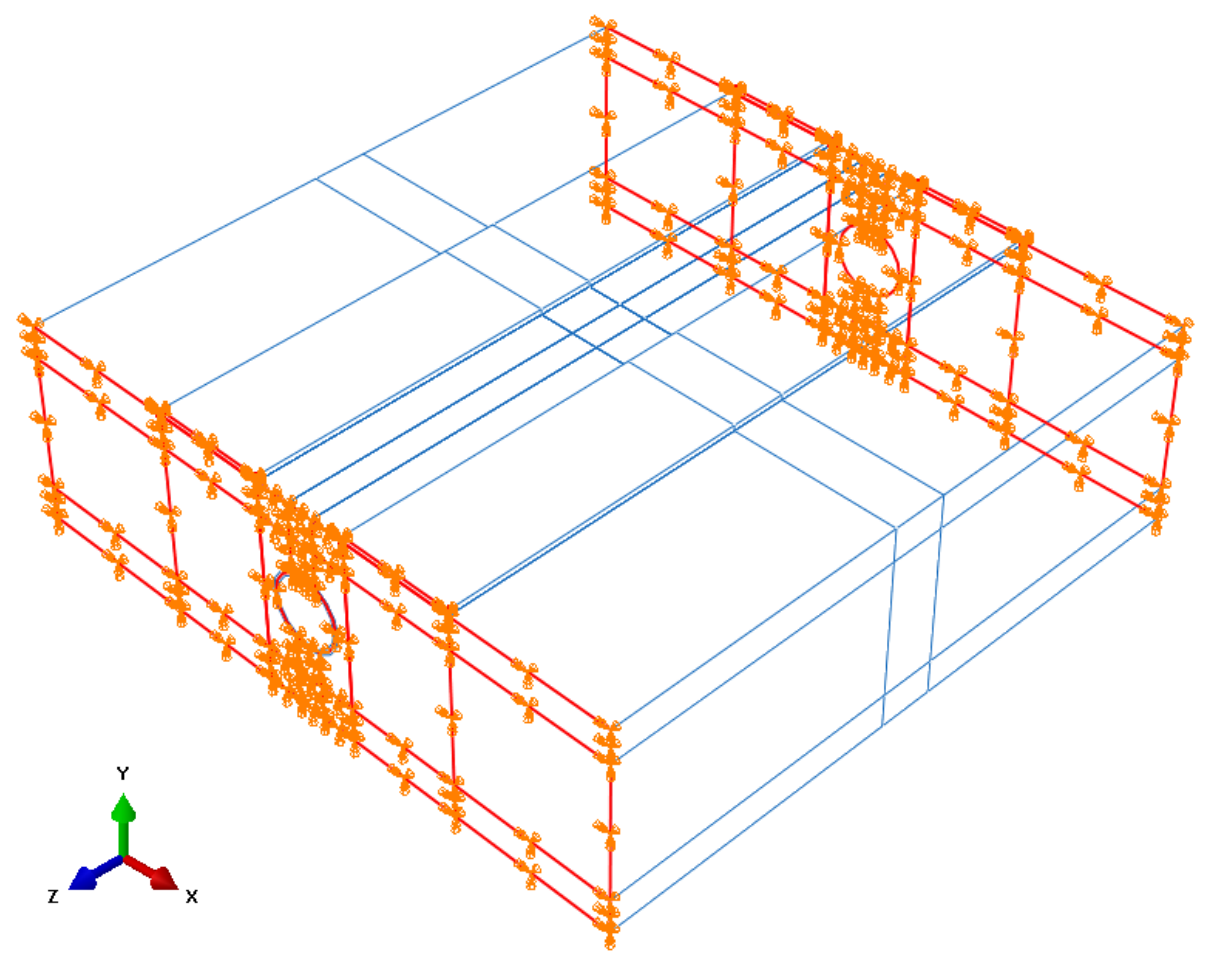

Figure 4.22: Z-SYMM boundary condition on front/back face. 


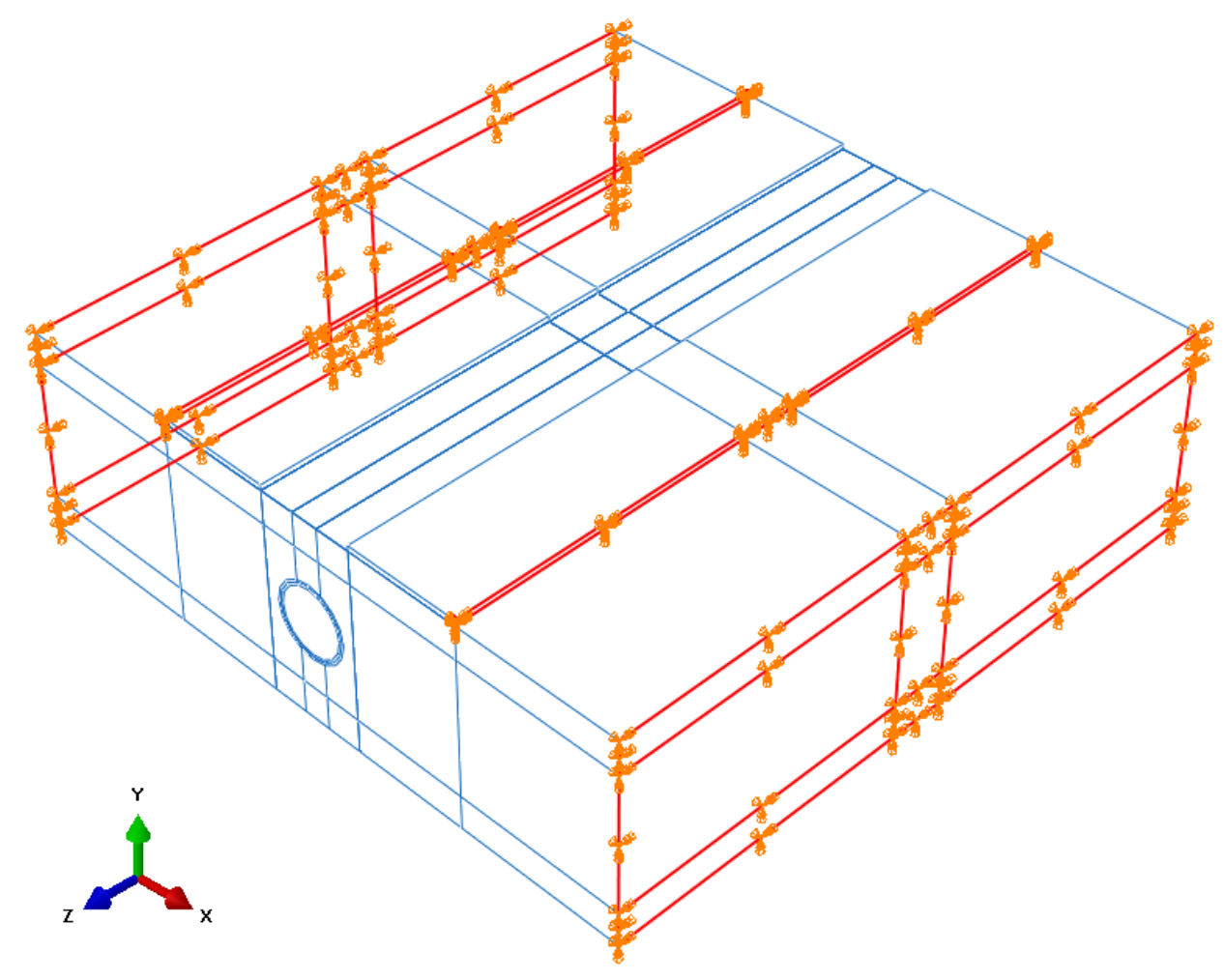

Figure 4.23: X-SYMM boundary condition on side faces.

\subsection{Interactions}

To assemble the buried pipe models in this study seven separate parts were created and various interactions were specified so that the parts could interact. The parts include the pipe, geotextile, three soil sections below the geotextile (left side, right side, and trench), and two loading plates on top of the geotextile. In order for these separate parts to interact with one another, interaction properties must be specified at the surfaces where the faces of each part are in contact. There are four regions that required unique interaction properties. These regions are: pipe-soil contact, geotextile-soil contact, plate-geotextile contact, and the trench wall interactions.

\subsubsection{Soil-pipe interaction}

A tie constraint was used to connect the pipe elements with the surrounding soil elements. This insures that both soil and the pipe act as a composite structure (ABAQUS, 2010; Gondle and Siriwardane, 2008). This constraint is shown in Figure 4.24. 


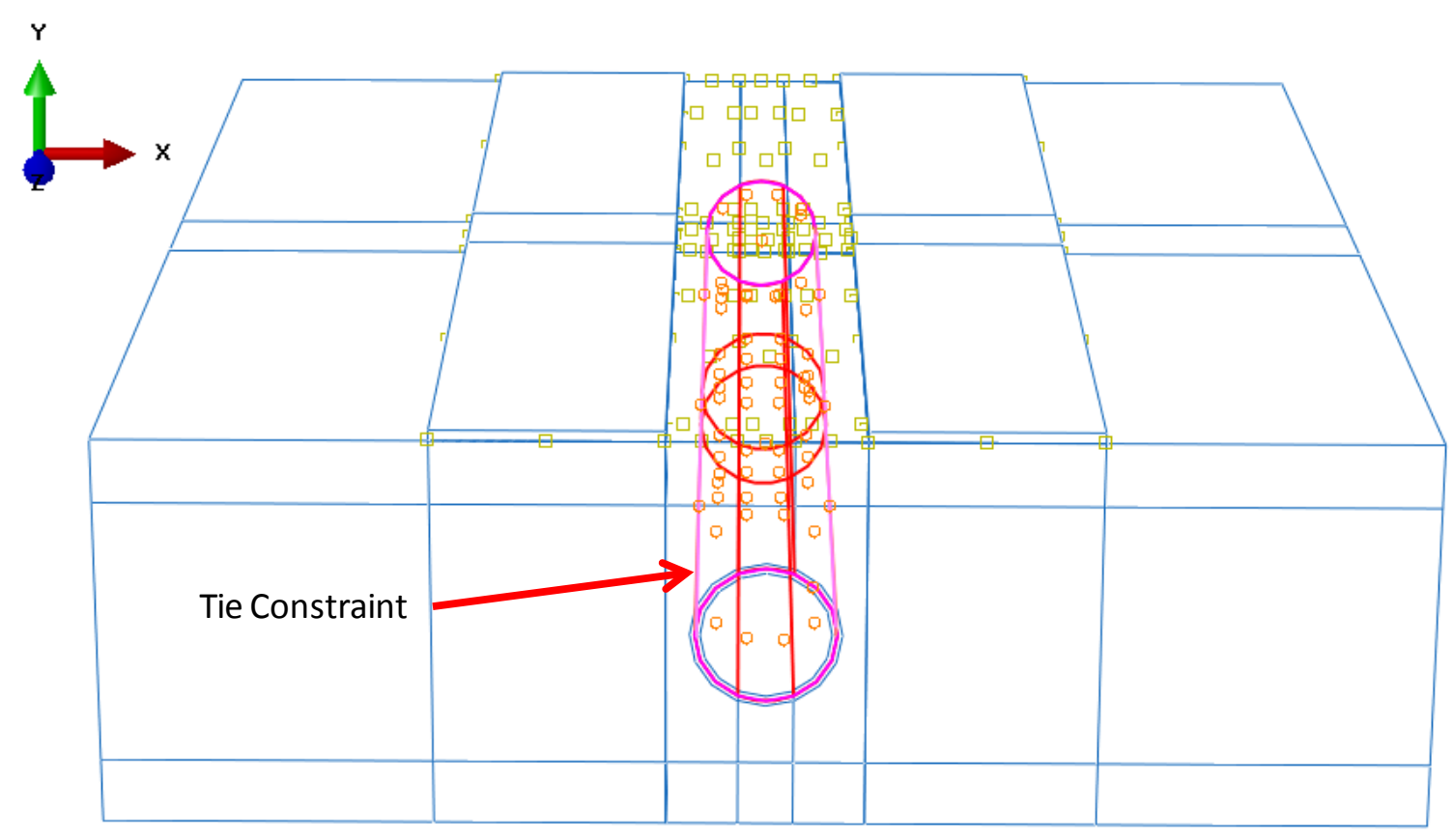

Figure 4.24: Pipe-Soil interaction.

\subsubsection{Geotextile interactions}

The contact between the geotextile and the soil is the main factor in resisting the vertical loading at the surface. Through this frictional contact, some of the magnitude of the vertical load is transferred to the geotextile and diverted into the tangential direction of the textile plane. Based on references in the literature (Koerner, 2005; Perkins, 2003; Lee, 2000), a frictional coefficient of 0.3 was used as the base value for the geotextile-soil contact areas. Frictional contacts, rather than tie constraints, were used for this interaction to allow geotextile slip to occur. This idea is further elaborated in the remaining sections of this paper. The geotextile-soil interaction is shown in Figure 4.25.

Loading plates were used as a mechanism to place a consistent vertical pressure over the geotextile to allow the activation of the frictional contacts. A frictionless contact was placed between the loading plates and the textile. This was done to avoid introducing excess frictional resistance resulting from the contact surface between the geotextile and the artificial plate used for simulating the normal force. The boundary conditions placed on the loading plates allowed the loading plates to remain static laterally while still supplying the necessary vertical surcharge loading. This interaction is shown in Figure 4.26. 


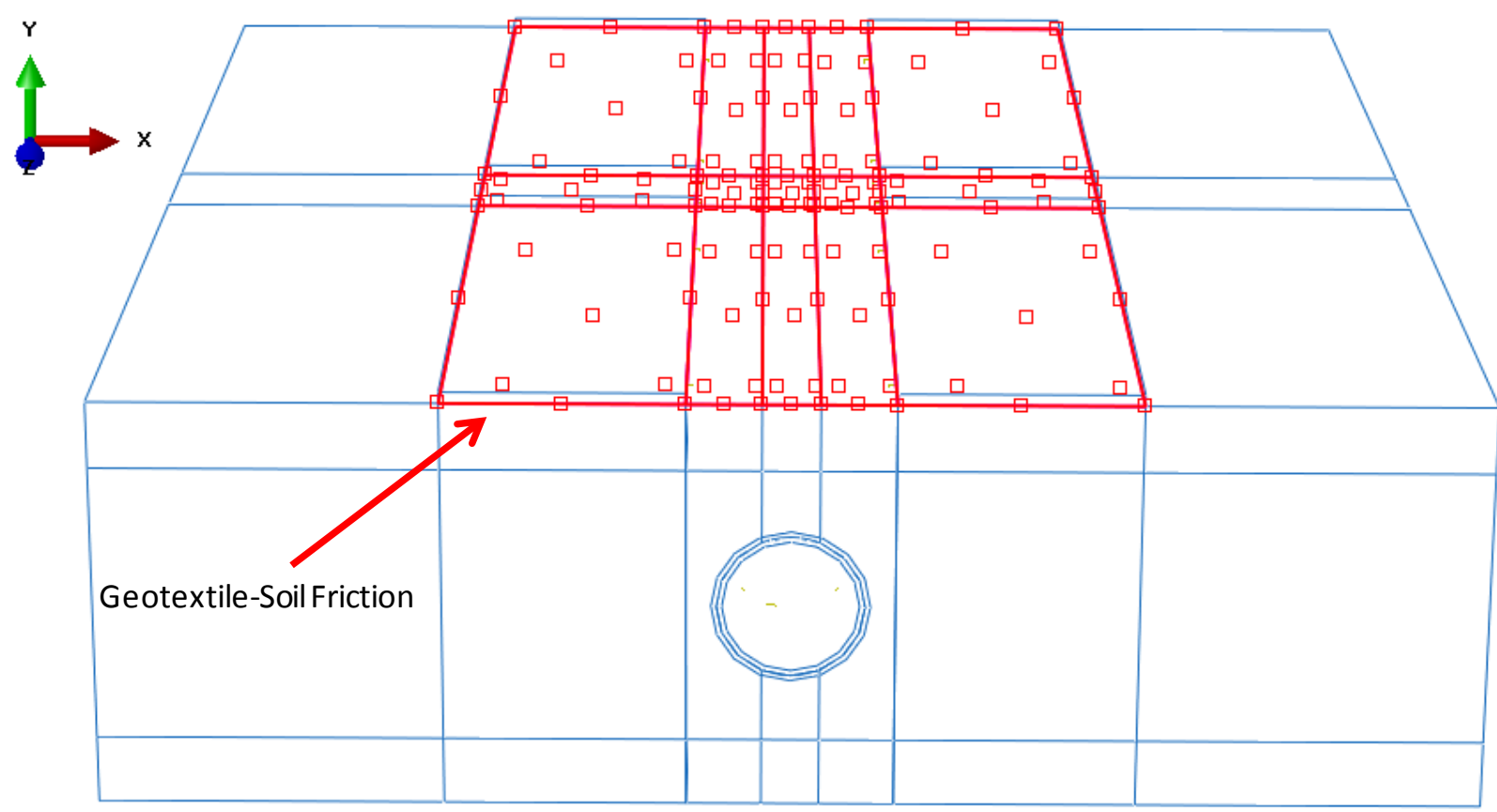

Figure 4.25: Geotextile-soil interaction.

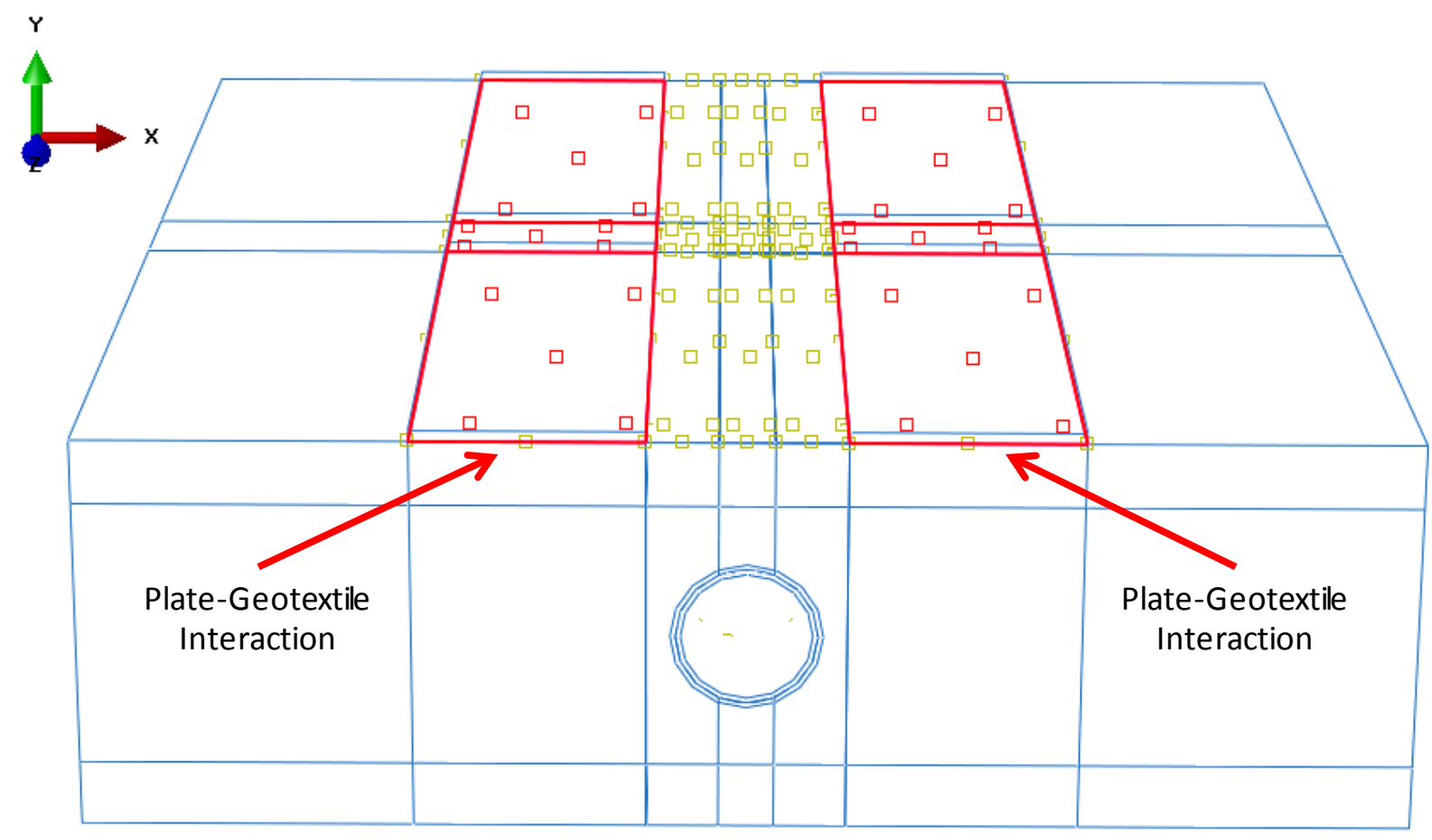

Figure 4.26: Plate-geotextile interaction. 


\subsubsection{Trench interactions}

The frictional interaction between a trench fill and the walls of the excavation is known to be considerably low, approximately equal to $\mu=0.13$ (CPC, 2011). To account for the absolute worst case scenario for pipe deflection, the interaction between the trench fill and the trench walls for all models was assumed to be frictionless, or $\mu=0$. Figure 4.27 shows the trench wall interaction.

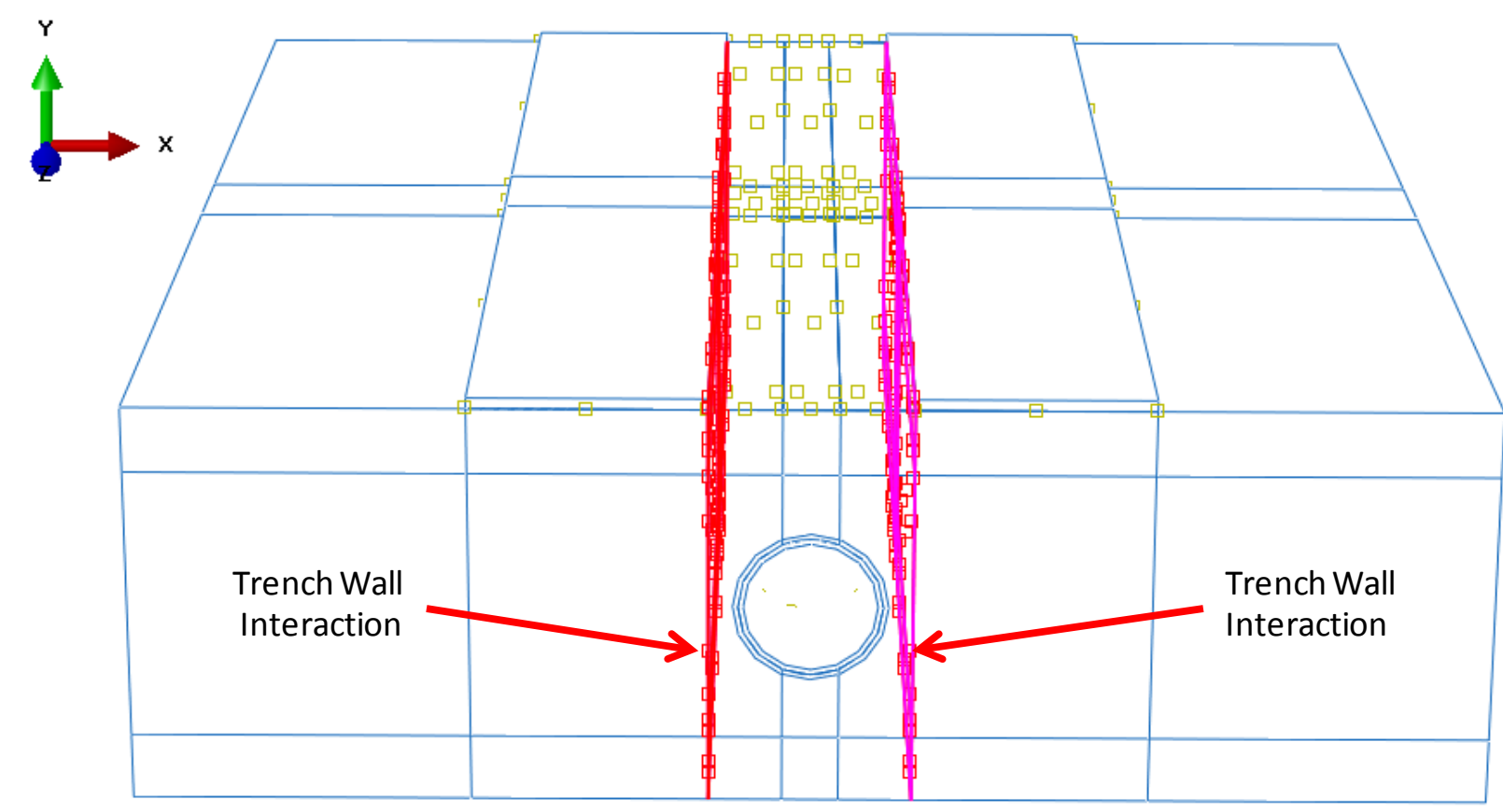

Figure 4.27: Trench wall interaction

\subsection{Material properties of soil and pipe}

Finite element modeling performed in this study includes three soil sections with different material properties. These sections include trench backfill, pipe backfill, and insitu soil as shown in Figure 4.28. The material properties used for soil in this study are presented in Table 4.2. To investigate the influence of the elastic modulus of the trench backfill, three cases with differing modulus values were considered. The material properties for the HDPE pipe used in this study have been discussed in a previous chapter, see Chapter 3. Table 4.3 shows the values used for the material properties of the HDPE pipe. The loading plates were made to function in 
the same way as a 2 inch $(5.08 \mathrm{~cm})$ thick steel loading plate. The material properties were specified to be that of steel, with the elastic modulus, density, and Poisson's ratio equal to $29 \times 10^{6} \mathrm{psi}\left(2.0 \times 10^{8} \mathrm{kPa}\right), 0.26 \mathrm{pci}\left(7.20 \mathrm{~g} / \mathrm{cm}^{3}\right)$, and 0.3 , respectively.

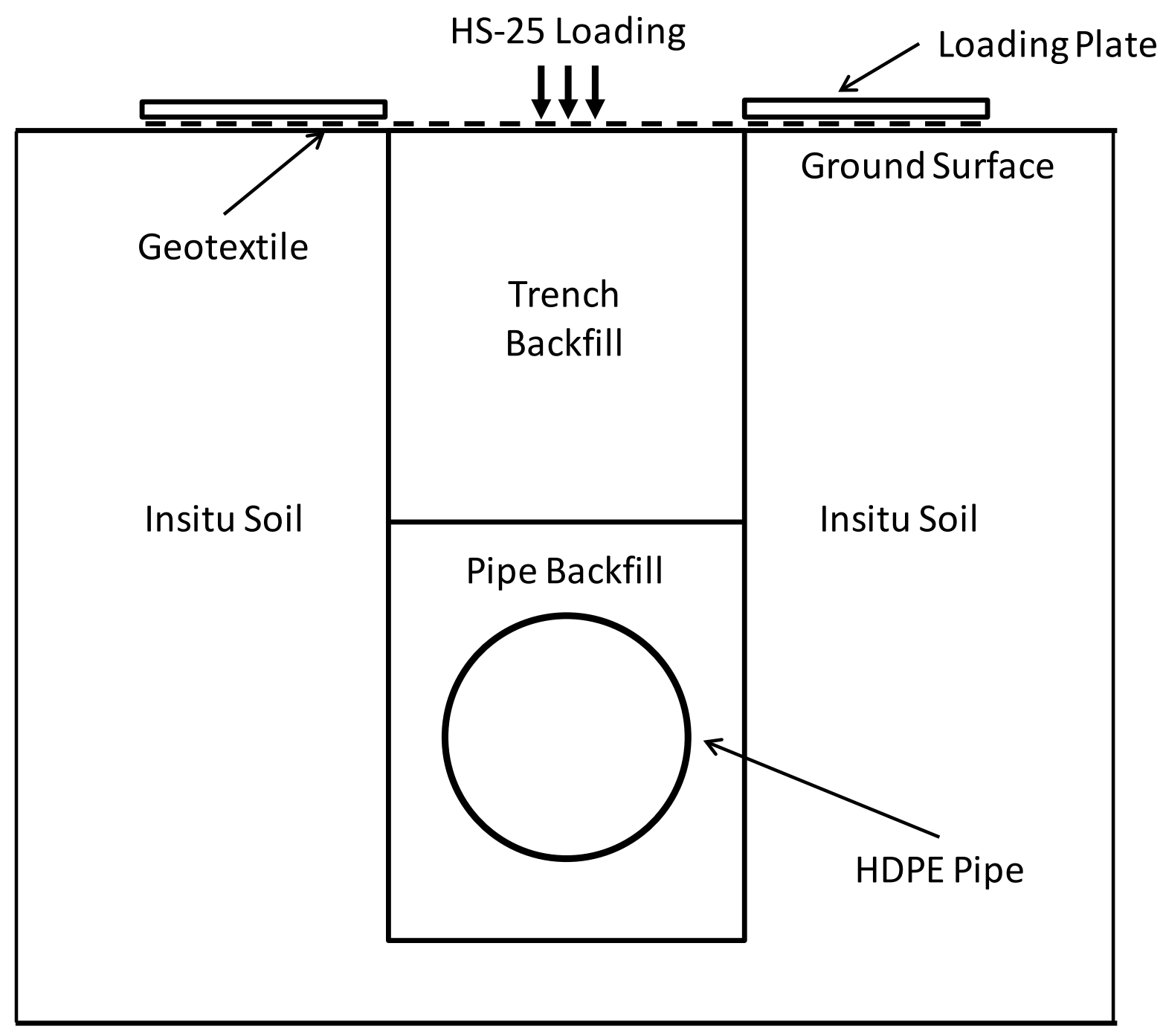

Figure 4.28: Soil sections used in finite element modeling. 
Table 4.2: Soil material properties.

\begin{tabular}{|c|c|c|c|}
\hline \multicolumn{4}{|c|}{ Weak Trench } \\
\hline Property/Material & Trench Backfill Soil & Insitu Soil & Pipe Backfill Soil \\
\hline $\begin{array}{c}\text { Elastic Modulus, E } \\
\text { psi }(\mathrm{MPa})\end{array}$ & $500(3.45)$ & $1500(10.34)$ & $500(3.45)$ \\
\hline Poisson's ratio, $v$ & 0.3 & 0.3 & 0.3 \\
\hline $\begin{array}{l}\text { Mass density, } \rho \\
\operatorname{pcf}\left(\mathrm{g} / \mathrm{cm}^{3}\right)\end{array}$ & $125(2.00)$ & $125(2.00)$ & $125(2.00)$ \\
\hline Friction Angle, ${ }^{\circ}$ & 10 & 10 & 10 \\
\hline $\begin{array}{c}\text { Cohesion, c } \\
\text { psi (MPa) }\end{array}$ & $15(0.10)$ & $15(0.10)$ & $15(0.10)$ \\
\hline \multicolumn{4}{|c|}{ Normal Trench } \\
\hline Property/Material & Trench Backfill Soil & Insitu Soil & Pipe Backfill Soil \\
\hline $\begin{array}{c}\text { Elastic Modulus, E } \\
\text { psi }(\mathrm{MPa})\end{array}$ & $1000(6.89)$ & $1500(10.34)$ & $1000(6.89)$ \\
\hline Poisson's ratio, $v$ & 0.3 & 0.3 & 0.3 \\
\hline $\begin{array}{l}\text { Mass density, } \rho \\
\operatorname{pcf}\left(\mathrm{g} / \mathrm{cm}^{3}\right)\end{array}$ & $125(2.00)$ & $125(2.00)$ & $125(2.00)$ \\
\hline Friction Angle, ${ }^{\circ}$ & 10 & 10 & 10 \\
\hline $\begin{array}{c}\text { Cohesion, c } \\
\text { psi (MPa) }\end{array}$ & $15(0.10)$ & $15(0.10)$ & $15(0.10)$ \\
\hline \multicolumn{4}{|c|}{ Strong Trench } \\
\hline Property/Material & Trench Backfill Soil & Insitu Soil & Pipe Backfill Soil \\
\hline $\begin{array}{c}\text { Elastic Modulus, E } \\
\text { psi }(\mathrm{MPa})\end{array}$ & $1500(10.34)$ & $1500(10.34)$ & $1500(10.34)$ \\
\hline Poisson's ratio, $v$ & 0.3 & 0.3 & 0.3 \\
\hline $\begin{array}{c}\text { Mass density, } \rho \\
\operatorname{pcf}\left(\mathrm{g} / \mathrm{cm}^{3}\right)\end{array}$ & $125(2.00)$ & $125(2.00)$ & $125(2.00)$ \\
\hline Friction Angle, ${ }^{\circ}$ & 10 & 10 & 10 \\
\hline $\begin{array}{l}\text { Cohesion, c } \\
\text { psi (MPa) }\end{array}$ & $15(0.10)$ & $15(0.10)$ & $15(0.10)$ \\
\hline
\end{tabular}


Table 4.3: Pipe material properties

\begin{tabular}{|c|c|c|}
\hline \multirow{2}{*}{ Property/Material } & \multicolumn{2}{|c|}{ Double Wall Corrugated HDPE Pipe } \\
\cline { 2 - 3 } & 24 inch & 60 inch \\
\hline $\begin{array}{c}\text { Elastic Modulus, E } \\
\text { psi (MPa) }\end{array}$ & $28115.672(193.86)$ & $28885.496(199.16)$ \\
\hline Poisson's ratio, $v$ & 0.46 & 0.46 \\
\hline $\begin{array}{c}\text { Mass density, } \rho \\
\text { pcf }\left(\mathrm{g} / \mathrm{cm}^{3}\right)\end{array}$ & $60(0.96)$ & $60(0.96)$ \\
\hline
\end{tabular}

\subsection{Material properties of geotextile}

Due to the relative unavailability of geosynthetic material properties in the literature, in particular the modulus of elasticity and thickness of the material, it was necessary to determine these values through other means. The geotextile used in this study was based on values publicly available from the website of the geosynthetic manufacturer Tencate Geosynthetics for their product, Mirafi HP570, which is a woven geotextile composed of high-tenacity polypropylene (TenCate Geosynthetics, 2012). This fabric is commonly used for filtration, separation of dissimilar materials, and/or soil reinforcement; making it an appropriate choice for this study. The density used in the analysis is that of the material from which the geotextile fabric is constructed, polypropylene. The density of polypropylene material has been reported in the range of 55 - 60 psf (2.63 - $2.87 \mathrm{kPa}$ ) (TenCate Geosynthetics, 2012; Koerner, 2005). Some material properties such as tensile strength at various strains, seam strength, permeability, and apparent opening size can be found in the manufacturer website for this product (TenCate Geosynthetics, 2012); however, values needed for modeling inside of Abaqus, such as the elastic modulus and the material thickness are not included from the data that is available. Consequently, the following procedure was developed to determine these values.

\subsubsection{Geotextile thickness}

ASTM method D5199-12, "Standard Test Method for Measuring the Nominal Thickness of Geosynthetics", was utilized to determine the thickness value for the geotextile (ASTM, 
2012). To summarize this method, the nominal thickness is determined by observing the distance between two parallel surfaces that confine the test material under a specified pressure. Once the pressure has stabilized and the material has settled, thickness can be measured. All specifications for the apparatus and procedure were met during testing. These specifications can be found in the literature (ASTM, 2012). The procedure was performed on a geotextile sample (Mirafi HP570) provided by the manufacturer, Tencate Geosynthetics. The testing apparatus used to obtain the geotextile thickness can be seen in Figure 4.29. Results from this assessment are listed in Table 4.4. Based on the information given in Table 4.4, an average value of 0.07 inch $(1.78 \mathrm{~mm})$ was used in the finite element modeling work.

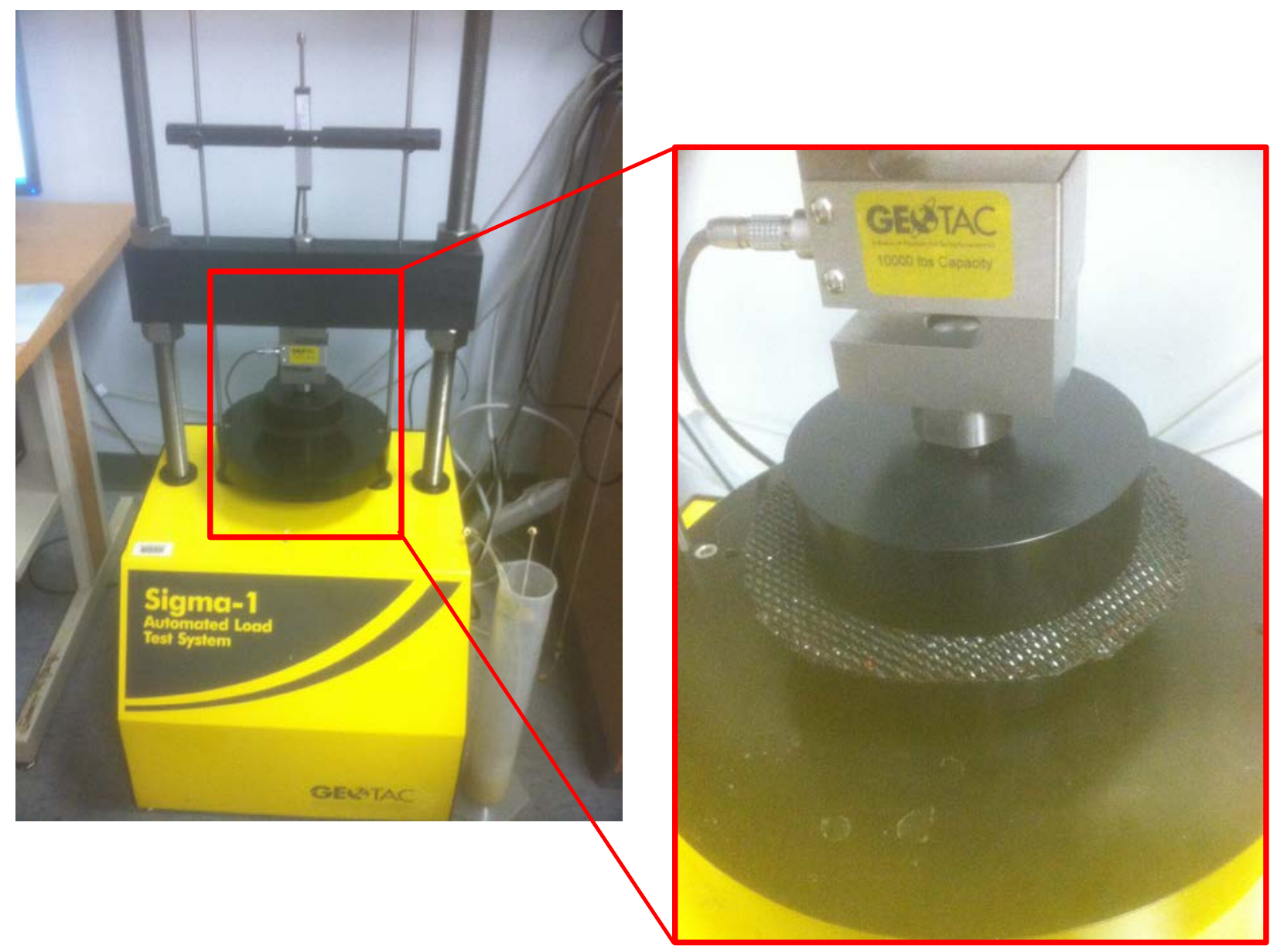

Figure 4.29: Geotextile thickness testing apparatus. 
Table 4.4: Measured geotextile sample thickness

\begin{tabular}{|c|c|c|}
\hline \multirow{4}{*}{ Model } & Sample Number & $\begin{array}{c}\text { Thickness, } \\
\text { inches }(\mathrm{mm})\end{array}$ \\
\hline \multirow{4}{*}{ Mirafi HP570 } & 1 & $0.0696(1.77)$ \\
\cline { 2 - 3 } & 2 & $0.0693(1.76)$ \\
\cline { 2 - 3 } & 3 & $0.0708(1.80)$ \\
\cline { 2 - 3 } & 4 & $0.0702(1.78)$ \\
\cline { 2 - 3 } & Average & $0.0700(1.78)$ \\
\cline { 2 - 3 } & Standard Deviation & $0.0007(0.02)$ \\
\hline
\end{tabular}

\subsubsection{Geotextile modulus of elasticity}

The modulus of elasticity can be calculated by using a combination of values supplied by the manufacturer and the geotextile thickness values that were obtained in the laboratory. For the geotextile, Mirafi HP570, the tensile strength at 5\% strain is reported as 2,400 lb/ft $(35.0$ $\mathrm{kN} / \mathrm{m}$ ) in the machine direction and $2,700 \mathrm{lb} / \mathrm{ft}(39.4 \mathrm{kN} / \mathrm{m}$ ) in the cross direction (TenCate Geosynthetics, 2012). Since the forces applied to the geotextile in the buried pipe problem are bidirectional, the smaller strength value was used to represent the worst case scenario and assure conservative modeling aproach. Using these values, combined with an average nominal thickness of 0.07 inches $(1.78 \mathrm{~mm})$, the modulus of elasticity can be calculated as follows: 


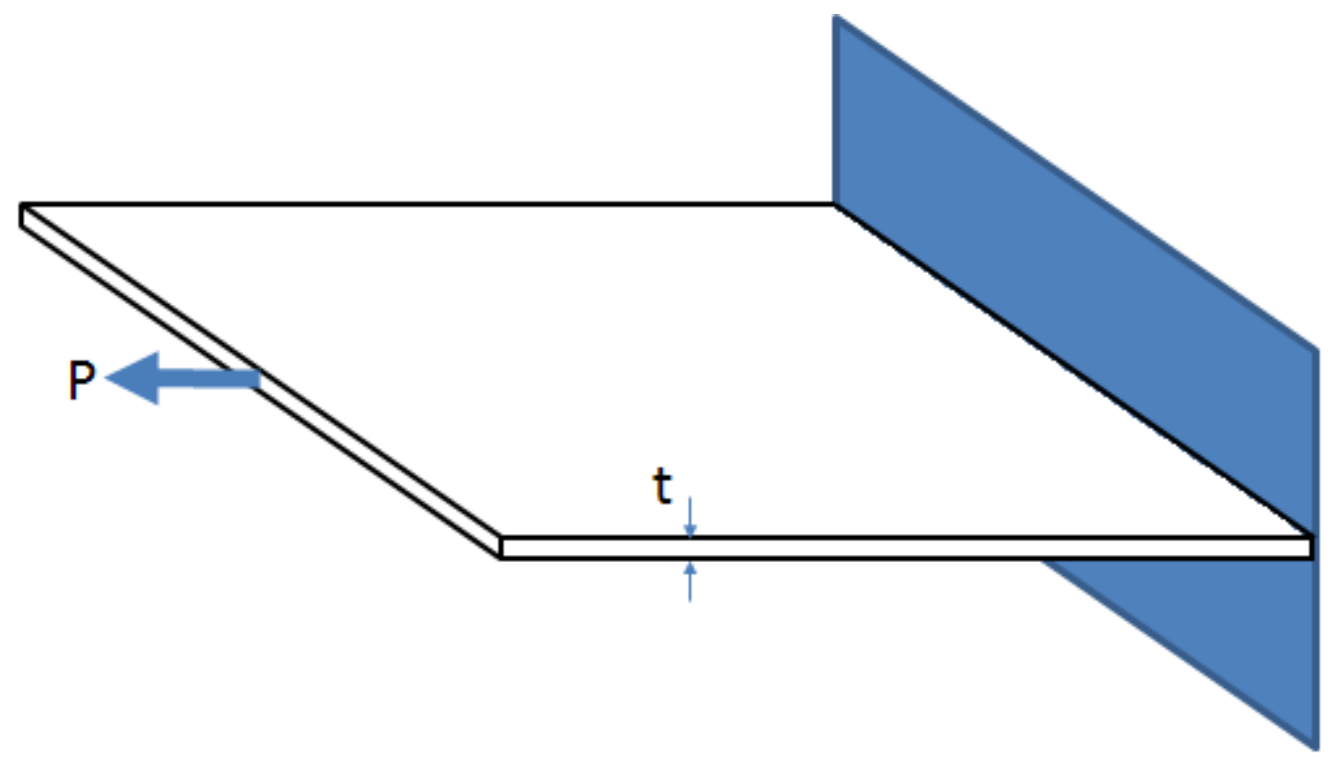

* where "P" is the applied tensile force and " $\mathrm{t}$ " is the thickness

Figure 4.30: Geotextile tensile strength test.

Tensile strength at $5 \%$ strain $(\mathrm{P})$

Geotextile Thickness (t)
$=2,400 \mathrm{lb} / \mathrm{ft}(=200 \mathrm{lb} / \mathrm{in})(35.0 \mathrm{kN} / \mathrm{m})$

$=0.07$ inches $(1.78 \mathrm{~mm})$

By dividing the tensile strength by the designated strain an intermediate modulus can be obtained. Through unit analysis, it is apparent that the modulus of elasticity can be generated by dividing the intermediate modulus by the material thickness. This process is shown in Equations 4.14 and 4.15. The material properties used for the geotextile material in this study are listed in Table 4.5 .

$$
\begin{gathered}
M=\frac{P}{\varepsilon}=\frac{200 \mathrm{lb} / \mathrm{in}}{0.05}=4,000 \mathrm{lb} / \mathrm{in}=7.0 \mathrm{kN} / \mathrm{cm} \\
E=\frac{M}{t}=\frac{P}{t \varepsilon}=\frac{200 \mathrm{lb} / \mathrm{in}}{0.07 \times 0.05}=57,142.857 \mathrm{lb} / \mathrm{in}^{2}=393.99 \mathrm{MPa}
\end{gathered}
$$


where,

$$
\begin{aligned}
& M \quad=\text { intermediate modulus }(\mathrm{lb} / \mathrm{in}), \\
& \varepsilon \quad=\text { strain, } \\
& E \quad=\text { modulus of elasticity }\left(\mathrm{lb} / \mathrm{in}^{2}\right) .
\end{aligned}
$$

Table 4.5: Geotextile material properties.

\begin{tabular}{|c|c|}
\hline Property/Material & Geotextile \\
\hline $\begin{array}{c}\text { Elastic Modulus, } \mathrm{E} \\
\mathrm{psi}(\mathrm{MPa})\end{array}$ & $57142.857(393.99)$ \\
\hline Poisson's ratio, $v$ & 0.4 \\
\hline $\begin{array}{c}\text { Mass density, } \rho \\
\mathrm{pcf}\left(\mathrm{g} / \mathrm{cm}^{3}\right)\end{array}$ & $56.78(0.91)$ \\
\hline
\end{tabular}

\subsubsection{Definition of Geotextile Slip}

To investigate the potential for geotextile anchorage failure, the maximum geotextile slip needed to be measured in the results of this research. This idea is illustrated in Figure 4.31 below. Geotextile slip was measured as the difference in horizontal position that one node, at either end of the geotextile, moved from its stating position at the beginning of the analysis to its final position at the end of the analysis. The largest value of horizontal slip along either edge of the geotextile was the value listed in the results shown in Chapter 5. 
HS-25 Loading

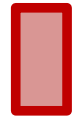

(a) Undeformed Geotextile

Before Loading

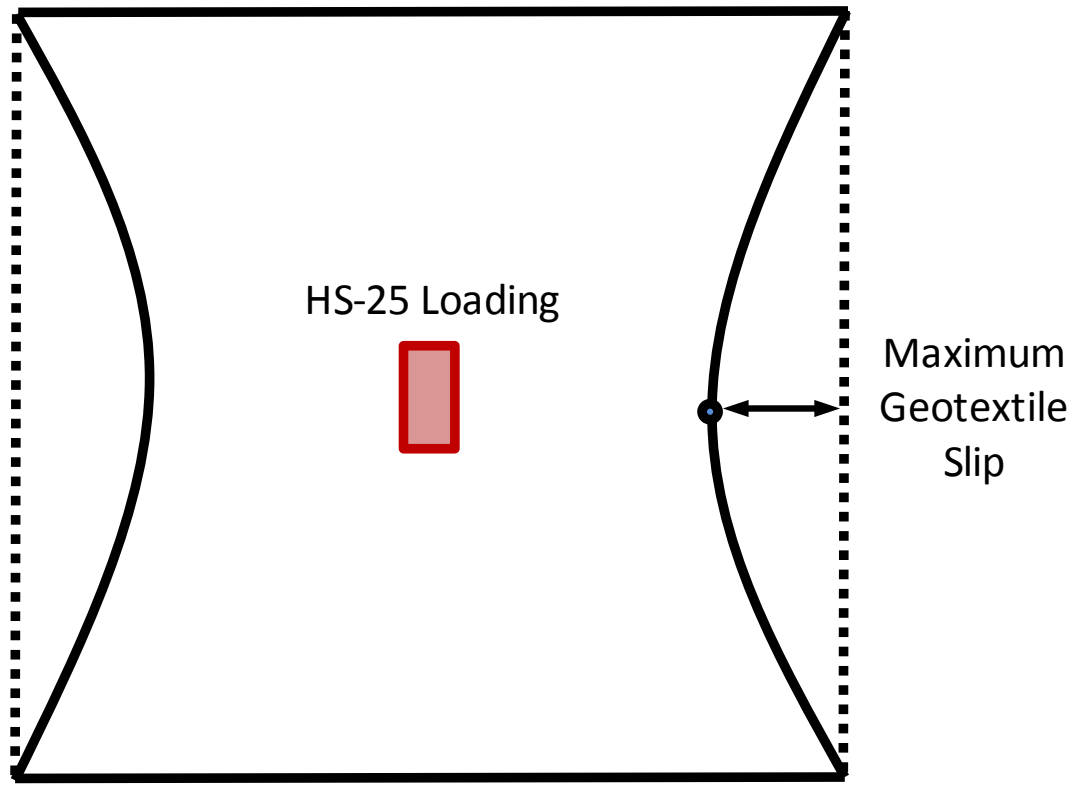

(b) Deformed Geotextile

After Loading

Figure 4.31: Illustration of Geotextile Slip 


\section{CHAPTER 5: RESULTS}

\subsection{Introduction}

The primary objective of this research is to determine the influence of adding geotextile soil reinforcement to a flexible buried pipe - soil system. Overall pipe performance was measured on the basis of vertical pipe deflection. Geotextile performance was based on the percent reduction of vertical pipe deflection when compared to the corresponding non-reinforced case. Analysis was completed by using three-dimensional finite element modeling as described in Chapter 4. The variables that remained constant in the analysis are the trench width ratio, overall model geometry dimensions, insitu soil strength, and external loading. The independent variables are the pipe diameter, pipe depth, pipe stiffness, normal force at the ground surface, geotextile width, geotextile stiffness, and trench fill stiffness. The major dependent variables that were observed after the analysis are the pipe deflection and geotextile slip. Geotextile slip was measured as the difference in horizontal position that one node, at either end of the geotextile, moved from its stating position at the beginning of the analysis to its final position at the end of the analysis. The largest value of horizontal slip along either edge of the geotextile was the value listed in the results (see Figure 4.31). The basic geometry of the models used in this analysis can be seen in Figure 5.1. Data collected from this analysis is described in further detail in the following sections.

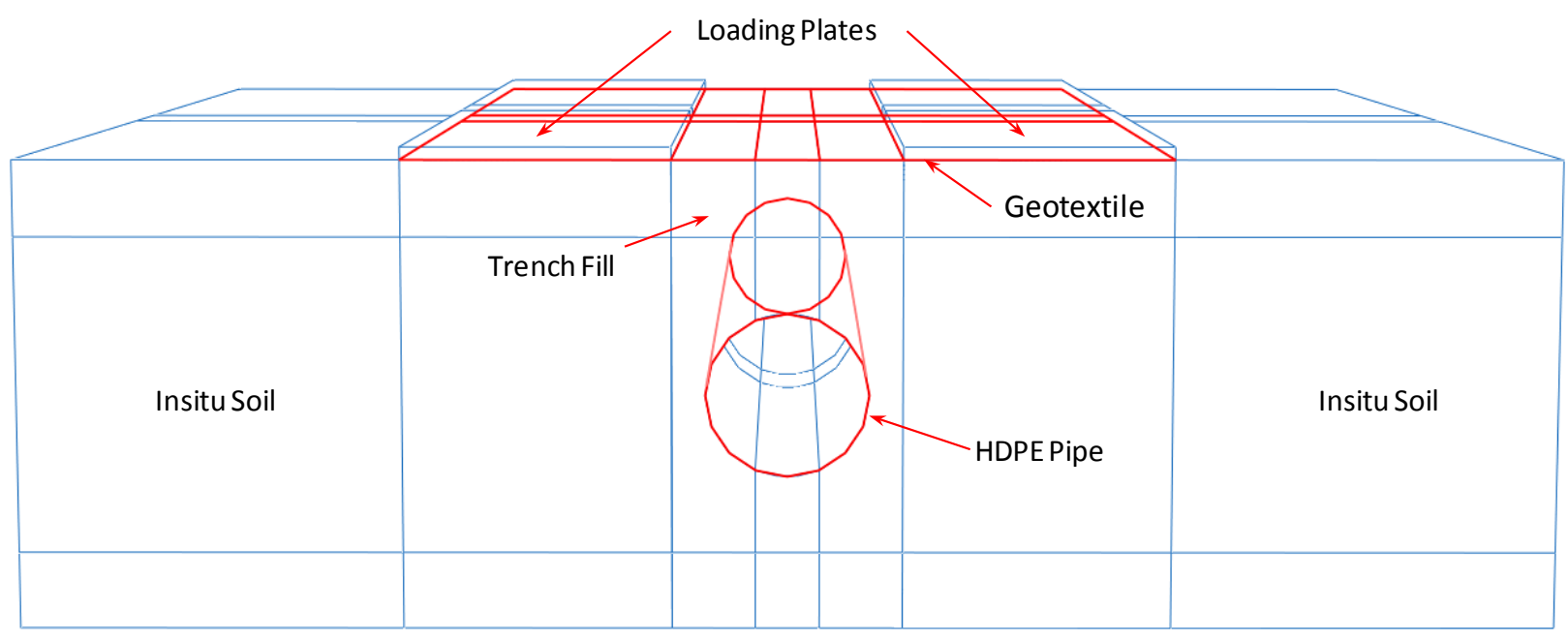

Figure 5.1: Schematic of buried pipe with geotextile overlay. 


\subsection{Geotextile effectiveness with varying pipe depth}

When a load is applied at the ground surface the burial depth has a significant influence over the magnitude of the pipe deflection. In general, when more soil is between the load and the pipe, more of the force from the load is dissipated throughout the soil medium; resulting in a lower magnitude of force being transmitted to the pipe. This idea holds true until the increased weight from additional overburden soil overcomes the benefit that is generated from the dissipation of forces. The effect of pipe depth was tested using a weak trench scenario (see Table 4.2) where pipe deflections resulting from surface loading would be most significant.

The effect of pipe depth was tested for both 24 inch $(60.96 \mathrm{~cm})$ and 60 inch $(152.4 \mathrm{~cm})$ diameter pipes. Pipe depth is measured from the loading surface to the crown of the pipe (Figure 3.2). For the 24 inch $(60.96 \mathrm{~cm})$ diameter case, the pipe depths that were tested include: $12 \mathrm{in}$. $(30.48 \mathrm{~cm}), 24$ in. $(60.96 \mathrm{~cm}), 36$ in. $(91.44 \mathrm{~cm})$, and $48 \mathrm{in}$. $(121.92 \mathrm{~cm})$. It can be seen from the results in Table 5.1 that at a depth of 48 inches $(121.92 \mathrm{~cm})$ the geotextile reinforcement has virtually no influence on pipe deflection. Figures 5.2, 5.3, and 5.4 display the results contained in Table 5.1 for a 24 -inch $(60.96 \mathrm{~cm})$ diameter pipe. The 60 -inch diameter pipe was tested at depths of $12 \mathrm{in.}(30.48 \mathrm{~cm})$ and $24 \mathrm{in.}(60.96 \mathrm{~cm})$. The results are presented in Table 5.2. This case follows the same trend as the 24 inch $(60.96 \mathrm{~cm})$ diameter pipe case. Figures 5.5, 5.6, and 5.7 display the results contained in Table 5.2 for a 60 inch $(152.4 \mathrm{~cm})$ diameter pipe.

It is clear from these results (Table 5.1, Table 5.2, Figures 5.2-5.7) that adding geotextile soil reinforcement to the buried pipe system aids in the performance of the pipe to an extent. Results suggest that the reinforcement is most beneficial at very shallow pipe depths. The percent reduction is greatest at a pipe depth of 12 inches $(30.48 \mathrm{~cm})$ for the 24 -inch $(60.96 \mathrm{~cm})$ diameter pipe, yielding $36.27 \%$ reduction in vertical deflection when a geosynthetic reinforcement was used. At the largest pipe depth (48 in. $(121.92 \mathrm{~cm})$ ) the percent reduction drops to only $1.14 \%$. It can be seen that incorporating geotextile soil reinforcement with a buried pipe at depths near or greater than 48 in. $(121.92 \mathrm{~cm})$ will have little or no influence over pipe performance. Based on these results, it can be concluded that the geotsynthetic reinforcement is beneficial only at shallow pipe depths. 
Table 5.1: Pipe deflections with varying pipe depth for 24 inch diameter pipe.

\begin{tabular}{|c|c|c|c|c|c|}
\hline \multicolumn{6}{|c|}{ Variation of Pipe Depth, Normal Force $=12$ in. } \\
\hline $\begin{array}{l}\text { Pipe Depth } \\
\text { (in.) } \\
\end{array}$ & $\begin{array}{l}\text { Geotextile } \\
\text { Width (in.) } \\
\end{array}$ & $\begin{array}{l}\text { Vertical Pipe } \\
\text { Deflection (in.) } \\
\end{array}$ & $\begin{array}{c}\text { Percent } \\
\text { Deflection } \\
\end{array}$ & $\begin{array}{c}\text { Percent Reduction } \\
\text { of Deflection }\end{array}$ & $\begin{array}{l}\text { Geotextile } \\
\text { Slip (in.) }\end{array}$ \\
\hline 12 & 0 & 1.8586 & $7.27 \%$ & $0.00 \%$ & $\mathrm{n} / \mathrm{a}$ \\
\hline 12 & 60 & 1.2130 & $4.75 \%$ & $34.74 \%$ & 0.4029 \\
\hline 12 & 72 & 1.2012 & $4.70 \%$ & $35.37 \%$ & 0.3624 \\
\hline 12 & 90 & 1.1977 & $4.69 \%$ & $35.56 \%$ & 0.3162 \\
\hline 12 & 120 & 1.1882 & $4.65 \%$ & $36.07 \%$ & 0.2378 \\
\hline 12 & 144 & 1.1876 & $4.65 \%$ & $36.10 \%$ & 0.2117 \\
\hline 12 & 180 & 1.1845 & $4.63 \%$ & $36.27 \%$ & 0.1635 \\
\hline 24 & 0 & 0.9590 & $3.75 \%$ & $0.00 \%$ & $\mathrm{n} / \mathrm{a}$ \\
\hline 24 & 60 & 0.7691 & $3.01 \%$ & $19.81 \%$ & 0.6048 \\
\hline 24 & 72 & 0.7623 & $2.98 \%$ & $20.51 \%$ & 0.5712 \\
\hline 24 & 90 & 0.7597 & $2.97 \%$ & $20.79 \%$ & 0.4930 \\
\hline 24 & 120 & 0.7484 & $2.93 \%$ & $21.96 \%$ & 0.3859 \\
\hline 24 & 144 & 0.7467 & $2.92 \%$ & $22.14 \%$ & 0.3013 \\
\hline 24 & 180 & 0.7455 & $2.92 \%$ & $22.26 \%$ & 0.2283 \\
\hline 36 & 0 & 0.8315 & $3.25 \%$ & $0.00 \%$ & $\mathrm{n} / \mathrm{a}$ \\
\hline 36 & 60 & 0.7993 & $3.13 \%$ & $3.87 \%$ & 0.6621 \\
\hline 36 & 72 & 0.7995 & $3.13 \%$ & $3.85 \%$ & 0.5556 \\
\hline 36 & 90 & 0.7933 & $3.10 \%$ & $4.60 \%$ & 0.4593 \\
\hline 36 & 120 & 0.7903 & $3.09 \%$ & $4.96 \%$ & 0.3433 \\
\hline 36 & 144 & 0.7863 & $3.08 \%$ & $5.44 \%$ & 0.2505 \\
\hline 36 & 180 & 0.7858 & $3.07 \%$ & $5.49 \%$ & 0.1603 \\
\hline 48 & 0 & 0.7701 & $3.01 \%$ & $0.00 \%$ & $\mathrm{n} / \mathrm{a}$ \\
\hline 48 & 60 & 0.7575 & $2.96 \%$ & $1.64 \%$ & 0.7159 \\
\hline 48 & 72 & 0.7606 & $2.98 \%$ & $1.23 \%$ & 0.6086 \\
\hline 48 & 90 & 0.7607 & $2.98 \%$ & $1.22 \%$ & 0.5365 \\
\hline 48 & 120 & 0.7613 & $2.98 \%$ & $1.14 \%$ & 0.3591 \\
\hline 48 & 144 & 0.7604 & $2.98 \%$ & $1.26 \%$ & 0.2758 \\
\hline 48 & 180 & 0.7576 & $2.96 \%$ & $1.62 \%$ & 0.1825 \\
\hline
\end{tabular}




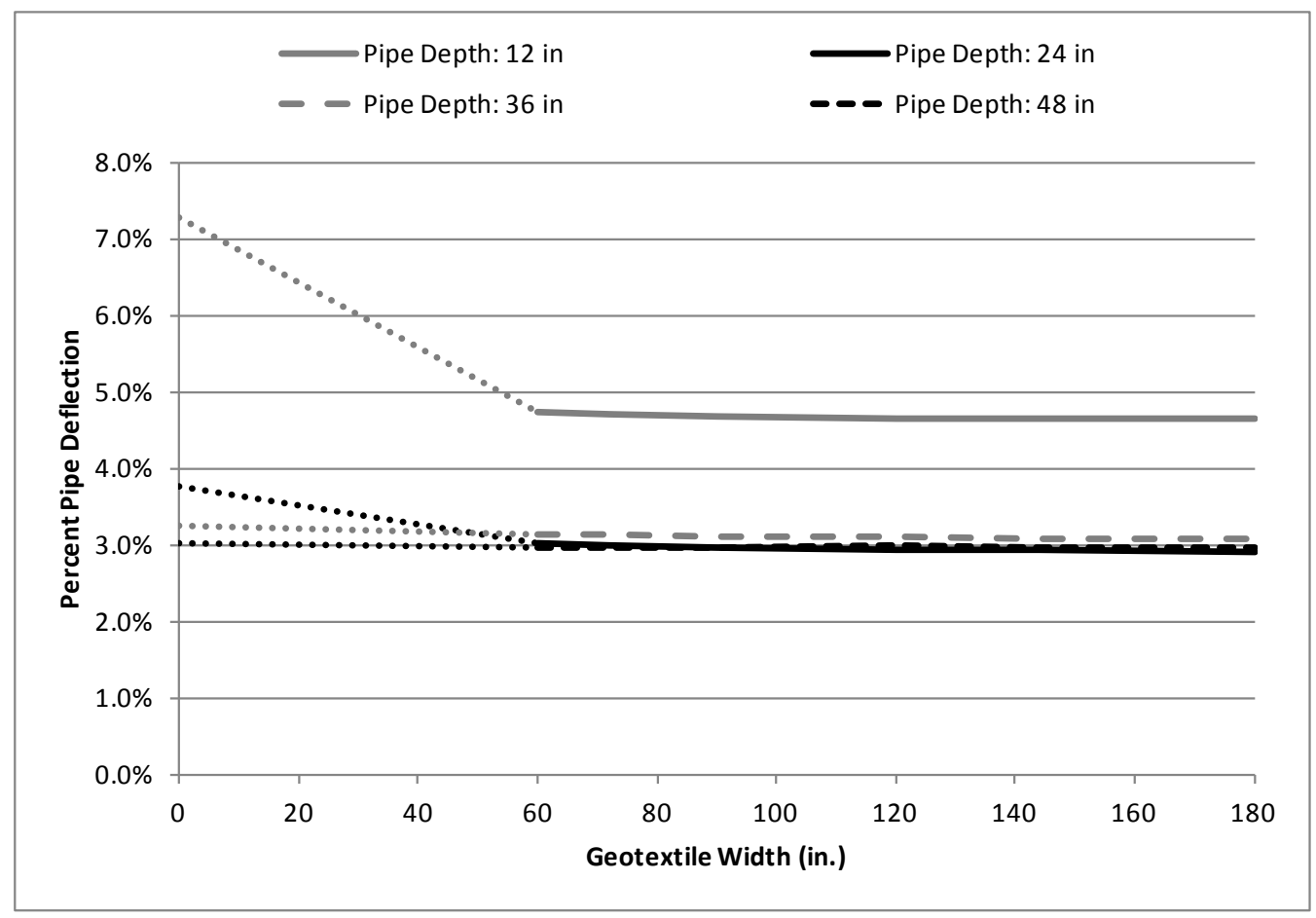

Figure 5.2: Percent pipe deflection vs. geotextile width with varying pipe depths for 24 in. diameter pipe.

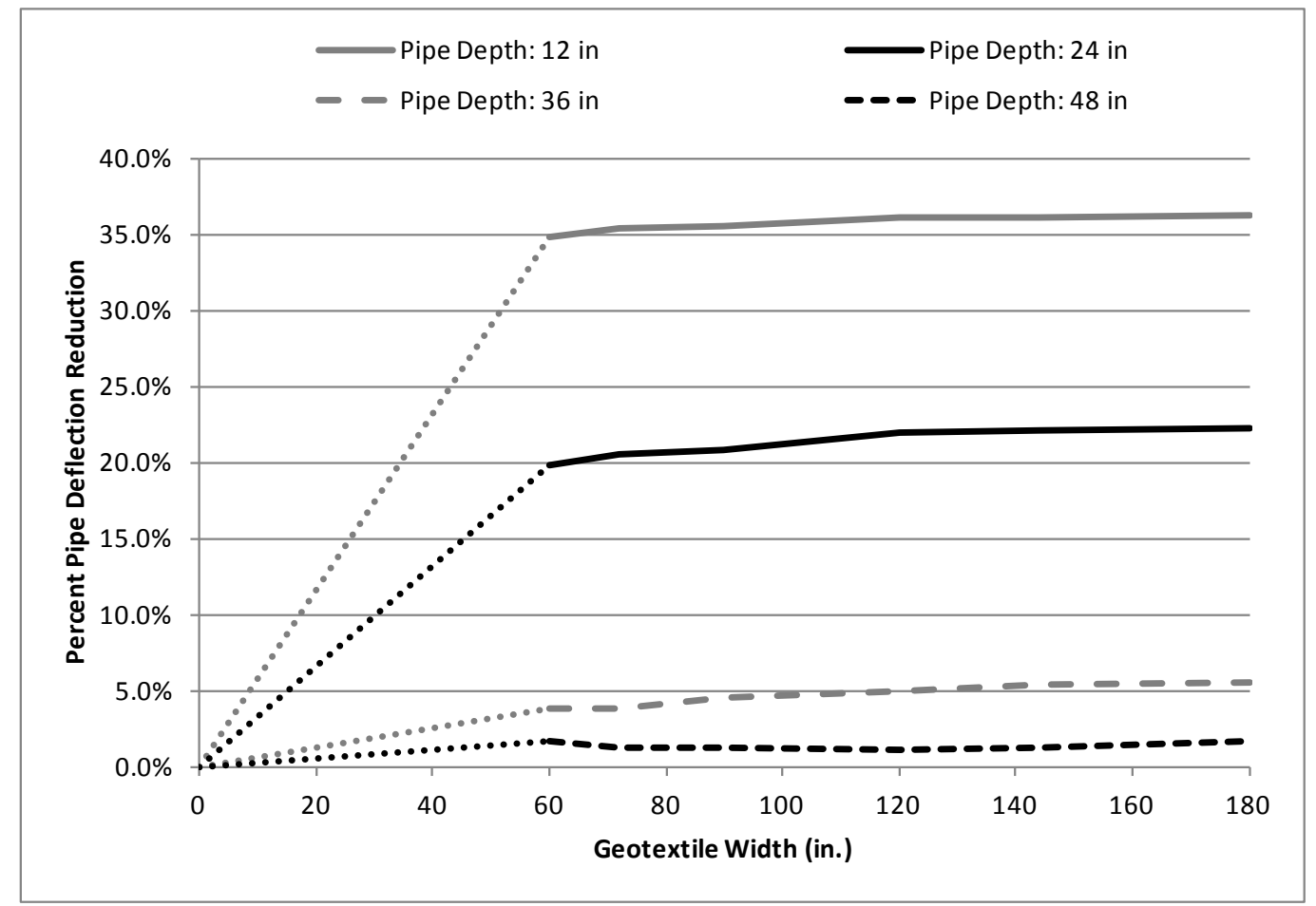

Figure 5.3: Percent reduction in pipe deflection vs. geotextile width with varying pipe depth for 24 in. diameter pipe. 


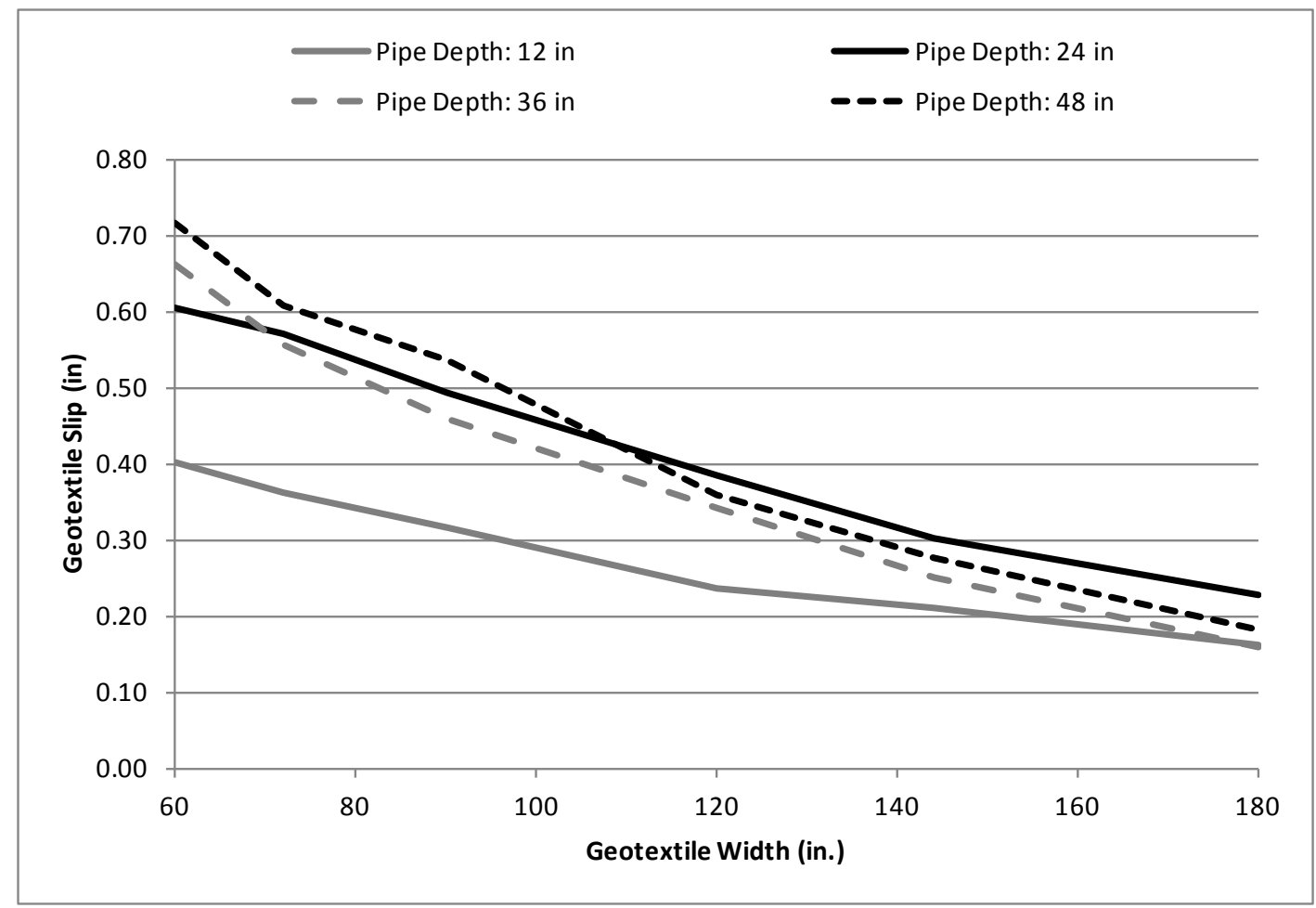

Figure 5.4: Geotextile slip distance vs. geotextile width with varying pipe depths for 24 inch pipe. 
Table 5.2: Pipe deflections with varying pipe depth for 60 inch diameter pipe.

\begin{tabular}{|c|c|c|c|c|c|}
\hline \multicolumn{7}{|c|}{ Variation of Pipe Depth: Normal Force = 12" } \\
\hline $\begin{array}{c}\text { Pipe Depth } \\
\text { (in.) }\end{array}$ & $\begin{array}{c}\text { Geotextile } \\
\text { Width (in.) }\end{array}$ & $\begin{array}{c}\text { Vertical Pipe } \\
\text { Deflection (in.) }\end{array}$ & $\begin{array}{c}\text { Percent } \\
\text { Deflection }\end{array}$ & $\begin{array}{c}\text { Percent Reduction } \\
\text { of Deflection }\end{array}$ & $\begin{array}{c}\text { Geotextile } \\
\text { Slip (in.) }\end{array}$ \\
\hline 12 & 0 & 1.7750 & $2.86 \%$ & $0.00 \%$ & $\mathrm{n} / \mathrm{a}$ \\
\hline 12 & 120 & 1.4760 & $2.38 \%$ & $16.85 \%$ & 0.1354 \\
\hline 12 & 144 & 1.4754 & $2.37 \%$ & $16.88 \%$ & 0.0902 \\
\hline 12 & 180 & 1.4699 & $2.37 \%$ & $17.19 \%$ & 0.0372 \\
\hline 12 & 240 & 1.4566 & $2.34 \%$ & $17.94 \%$ & 0.0135 \\
\hline 12 & 288 & 1.4510 & $2.33 \%$ & $18.26 \%$ & 0.0097 \\
\hline 12 & 360 & 1.4489 & $2.33 \%$ & $18.37 \%$ & 0.0070 \\
\hline 24 & 0 & 1.2954 & $2.08 \%$ & $0.00 \%$ & $\mathrm{n} / \mathrm{a}$ \\
\hline 24 & 120 & 1.1798 & $1.90 \%$ & $8.92 \%$ & 0.1651 \\
\hline 24 & 144 & 1.1821 & $1.90 \%$ & $8.75 \%$ & 0.0934 \\
\hline 24 & 180 & 1.1784 & $1.90 \%$ & $9.03 \%$ & 0.0179 \\
\hline 24 & 240 & 1.1698 & $1.88 \%$ & $9.70 \%$ & 0.0142 \\
\hline 24 & 288 & 1.1665 & $1.88 \%$ & $9.95 \%$ & 0.0114 \\
\hline 24 & 360 & 1.1694 & $1.88 \%$ & $9.73 \%$ & 0.0058 \\
\hline
\end{tabular}

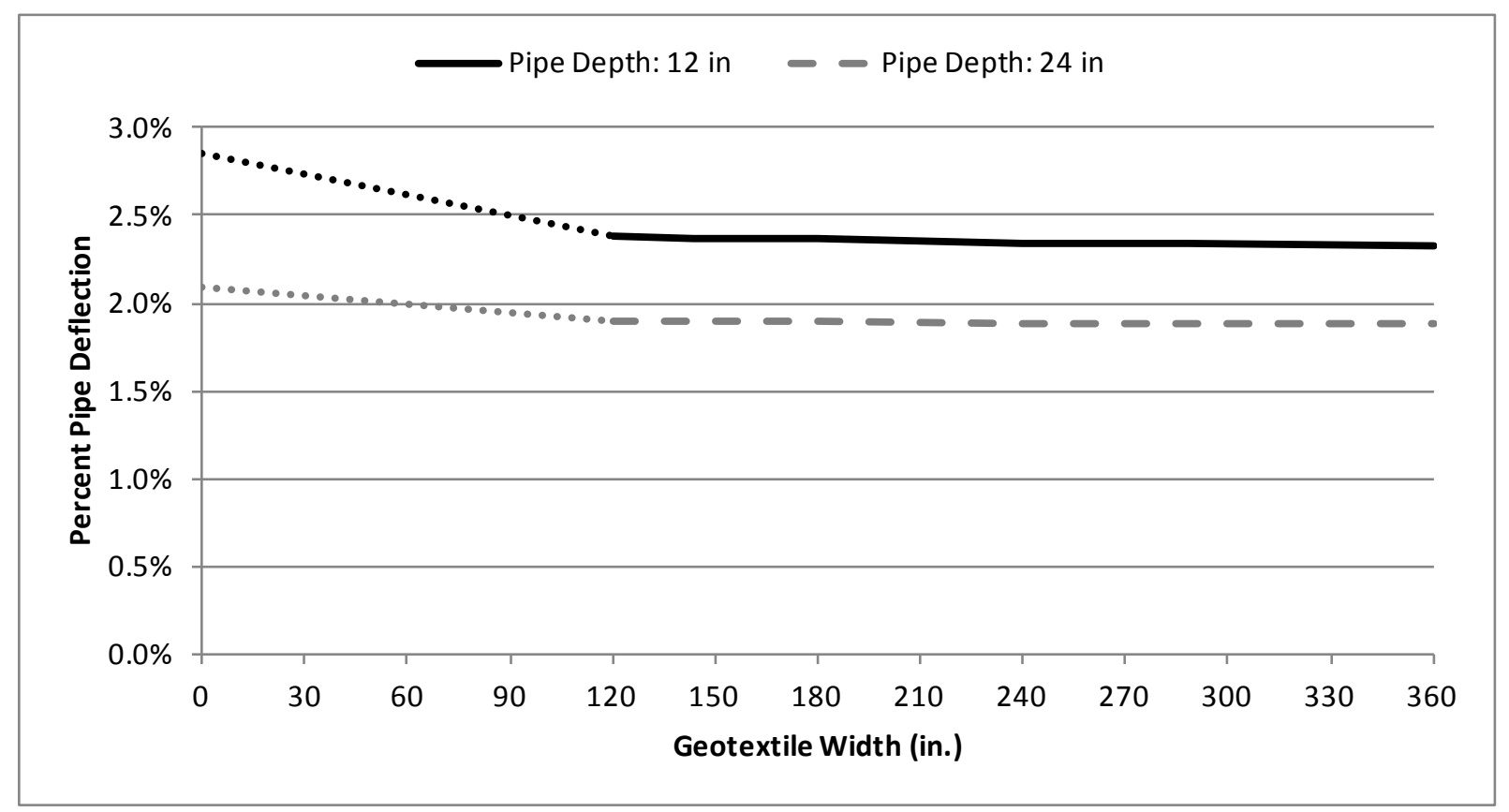

Figure 5.5: Percent pipe deflection vs. geotextile width with varying pipe depths for 60 in. diameter pipe. 


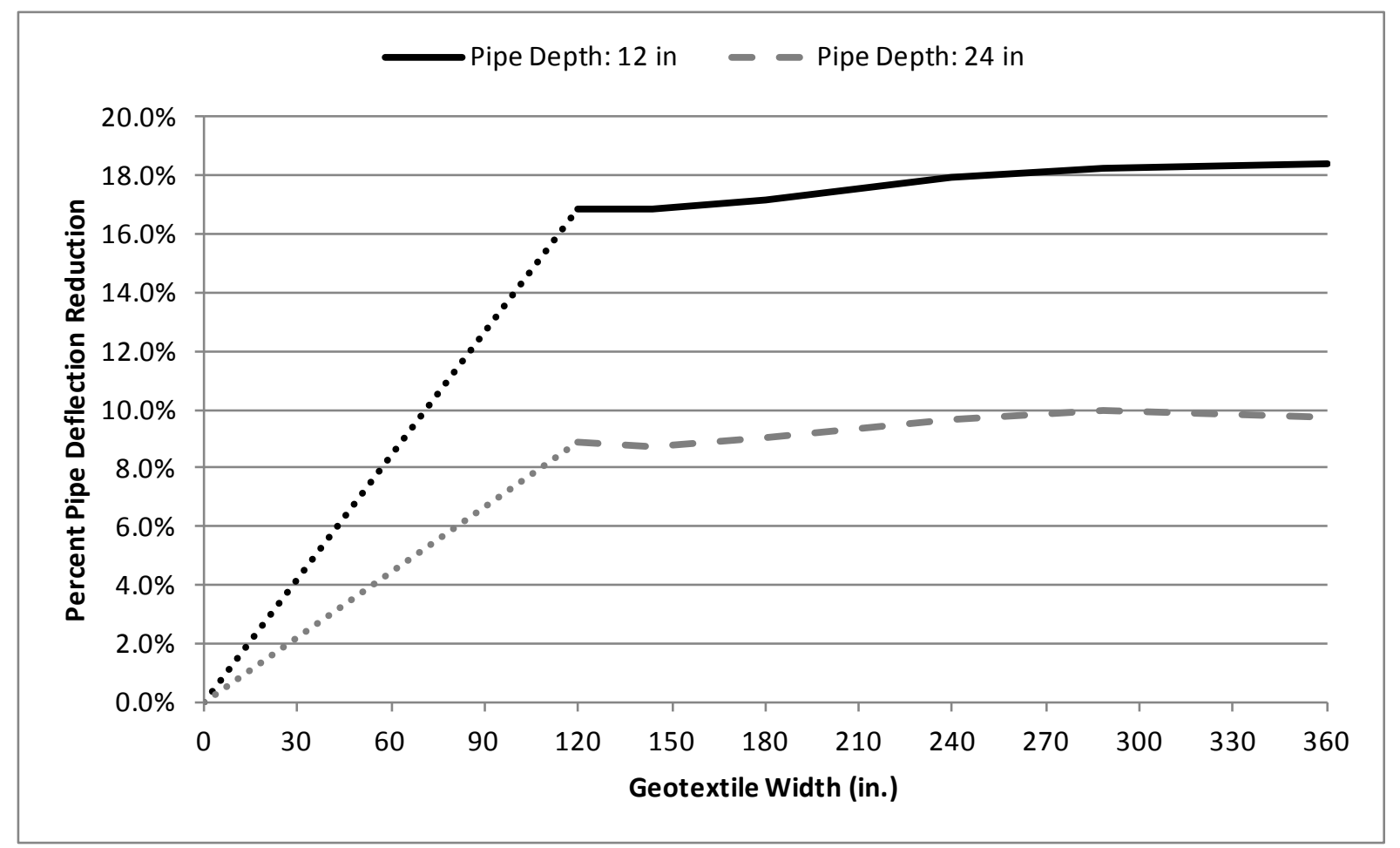

Figure 5.6: Percent reduction in pipe deflection vs. geotextile width with varying pipe depth for 60 in. diameter pipe.

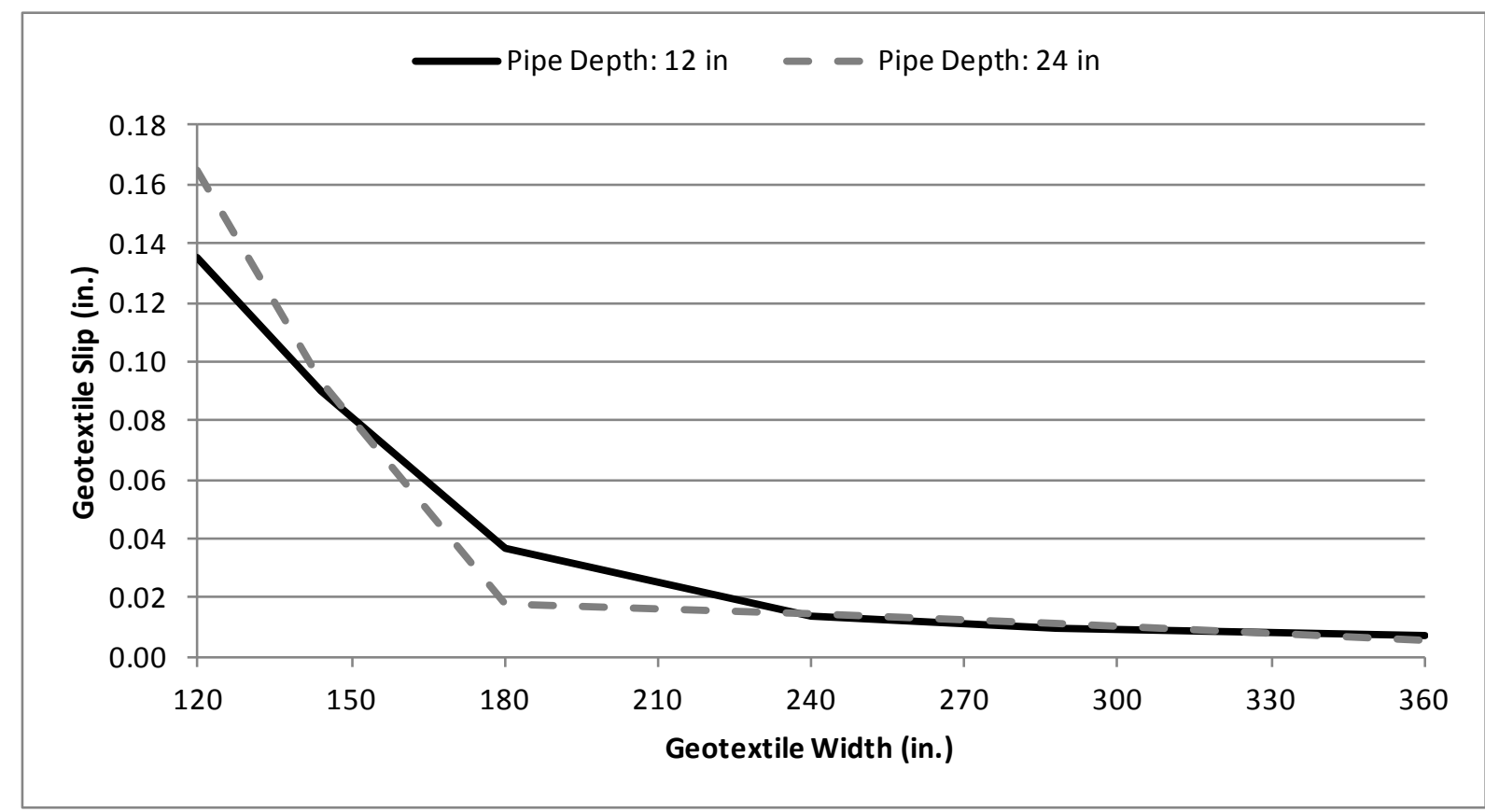

Figure 5.7: Geotextile slip distance vs. geotextile width with varying pipe depths for 60 inch pipe. 


\subsection{Effect of Depth of Cover}

The depth of cover to the reinforcement was varied by changing the magnitude of the surcharge load. One of the key components of geosynthetic soil reinforcement is the frictional resistance that is generated in the tangential direction. This concept was discussed in previous chapters of this paper. One of the main components of frictional resistance is the force that is applied in the normal direction of the contact surface. Typically the normal force acting on the geotextile would be generated by soil overburden (i.e., depth of cover). For this research, the surcharge loading is simulated through a uniformly distributed load over the entire top surface of the model (Figure 4.18). This load is transmitted through stiff loading plates that rest on top of the geotextile. The frictional resistance develops when the HS-25 loading is applied and the geotextile tries to pull into the trench. Frictional resistance is increased as the applied normal force rises.

Several cases were developed to test the effect of varying surcharge loading. Each case considers three levels of overburden surcharge depths: 12 in. $(30.48 \mathrm{~cm}), 24$ in. $(60.96 \mathrm{~cm})$, and 36 in. $(91.44 \mathrm{~cm})$. These overburden depths correspond to surcharge loading of 0.8681 psi (5.99 $\mathrm{kPa}), 1.7362 \mathrm{psi}(11.72 \mathrm{kPa})$, and $2.6042 \mathrm{psi}(17.96 \mathrm{kPa})$, respectively. For the 24 -inch diameter pipe the analysis was run at pipe depths of 24 inches $(60.96 \mathrm{~cm})$ and 48 inches $(121.92 \mathrm{~cm})$. Corresponding results can be found in Tables 5.3 and 5.4 for pipe depths of 24 inches $(60.96 \mathrm{~cm})$ and 48 inches $(121.92 \mathrm{~cm})$, respectively. These results are also presented in Figures 5.8, 5.9, and 5.10. All cases produced a similar trend of results. As can be seen from Figure 5.8, pipe deflections decrease with the introduction of the geosynthetic. Figure 5.9 shows that the reduction in pipe deflection can be as high as $30 \%$ when a geosynthetic reinforcement was introduced. As the surcharge loading is increased, geotextile slip distance is reduced as seen from Figure 5.10. This indicates that the geotextile may be taking more of the load. When comparing pipe deflections for the three cases of surcharge depths, it can be noticed that (Figure 5.8) pipe deflections are reduced significantly with the introduction of the geosynthetic reinforcement, and as expected, the pipe deflection increases slightly as the surcharge loading is increased. For the 60 -inch diameter pipe the analysis was run at a pipe depth of 24 inches $(60.96 \mathrm{~cm})$. Results for

this case are shown in Table 5.5, and Figures 5.14, 5.15, and 5.16. These figures also show the same trend - an improvement when a geotextile reinforcement is introduced. 
Table 5.3: Pipe deflections with varying normal loading for 24 in. diameter pipe at 24 in. pipe depth.

\begin{tabular}{|c|c|c|c|c|c|c|}
\hline \multicolumn{7}{|c|}{ Variation of Normal Force: Pipe Depth = 24" } \\
\hline $\begin{array}{c}\text { Overburden } \\
\text { Depth (in.) }\end{array}$ & $\begin{array}{c}\text { Eq. Normal } \\
\text { Force (lb/in }{ }^{2} \text { ) }\end{array}$ & $\begin{array}{c}\text { Geotextile } \\
\text { Width (in.) }\end{array}$ & $\begin{array}{c}\text { Vertical Pipe } \\
\text { Deflection (in.) }\end{array}$ & $\begin{array}{c}\text { Percent } \\
\text { Deflection }\end{array}$ & $\begin{array}{c}\text { Percent Reduction } \\
\text { of Deflection }\end{array}$ & $\begin{array}{c}\text { Geotextile } \\
\text { Slip (in.) }\end{array}$ \\
\hline 12 & 0.8681 & 0 & 0.9590 & $3.75 \%$ & $0.00 \%$ & n/a \\
\hline 12 & 0.8681 & 60 & 0.7691 & $3.01 \%$ & $19.81 \%$ & 0.6048 \\
\hline 12 & 0.8681 & 72 & 0.7623 & $2.98 \%$ & $20.51 \%$ & 0.5712 \\
\hline 12 & 0.8681 & 90 & 0.7597 & $2.97 \%$ & $20.79 \%$ & 0.4930 \\
\hline 12 & 0.8681 & 120 & 0.7484 & $2.93 \%$ & $21.96 \%$ & 0.3859 \\
\hline 12 & 0.8681 & 144 & 0.7467 & $2.92 \%$ & $22.14 \%$ & 0.3013 \\
\hline 12 & 0.8681 & 180 & 0.7455 & $2.92 \%$ & $22.26 \%$ & 0.2283 \\
\hline 24 & 1.7362 & 0 & 1.0044 & $3.93 \%$ & $0.00 \%$ & n/a \\
\hline 24 & 1.7362 & 60 & 0.7964 & $3.12 \%$ & $20.71 \%$ & 0.5959 \\
\hline 24 & 1.7362 & 72 & 0.7888 & $3.09 \%$ & $21.47 \%$ & 0.5078 \\
\hline 24 & 1.7362 & 90 & 0.7795 & $3.05 \%$ & $22.39 \%$ & 0.4412 \\
\hline 24 & 1.7362 & 120 & 0.7726 & $3.02 \%$ & $23.08 \%$ & 0.3183 \\
\hline 24 & 1.7362 & 144 & 0.7698 & $3.01 \%$ & $23.36 \%$ & 0.2266 \\
\hline 24 & 1.7362 & 180 & 0.7686 & $3.01 \%$ & $23.48 \%$ & 0.1382 \\
\hline 36 & 2.6042 & 0 & 1.0487 & $4.10 \%$ & $0.00 \%$ & n/a \\
\hline 36 & 2.6042 & 60 & 0.8236 & $3.22 \%$ & $21.46 \%$ & 0.5903 \\
\hline 36 & 2.6042 & 72 & 0.8119 & $3.18 \%$ & $22.57 \%$ & 0.5216 \\
\hline 36 & 2.6042 & 90 & 0.8016 & $3.14 \%$ & $23.56 \%$ & 0.4208 \\
\hline 36 & 2.6042 & 120 & 0.7984 & $3.12 \%$ & $23.86 \%$ & 0.2279 \\
\hline 36 & 2.6042 & 144 & 0.7924 & $3.10 \%$ & $24.44 \%$ & 0.1366 \\
\hline 36 & 2.6042 & 180 & 0.7956 & $3.11 \%$ & $24.13 \%$ & 0.0254 \\
\hline
\end{tabular}




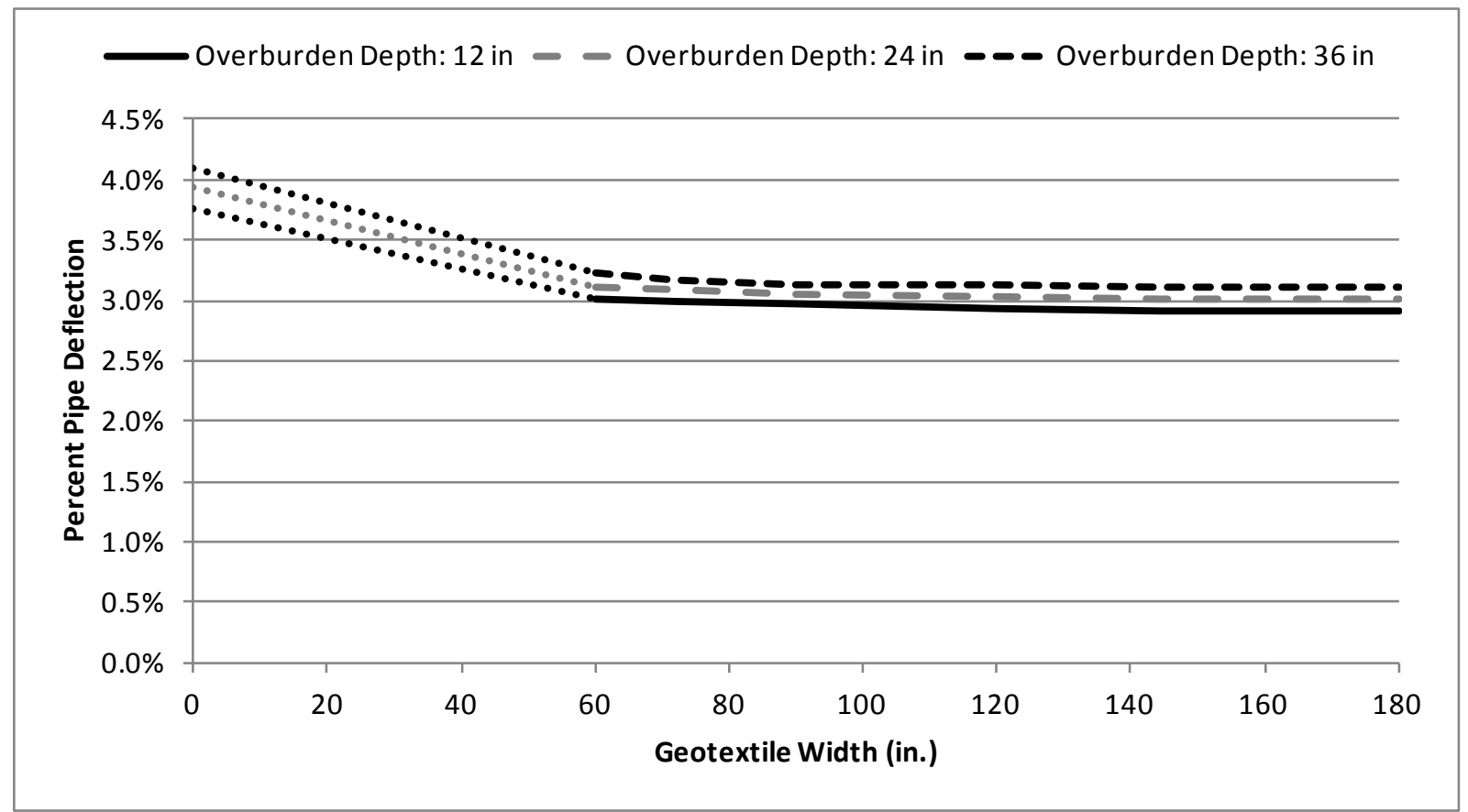

Figure 5.8: Percent pipe deflection vs. geotextile width with varying normal loading for 24 inch diameter pipe.

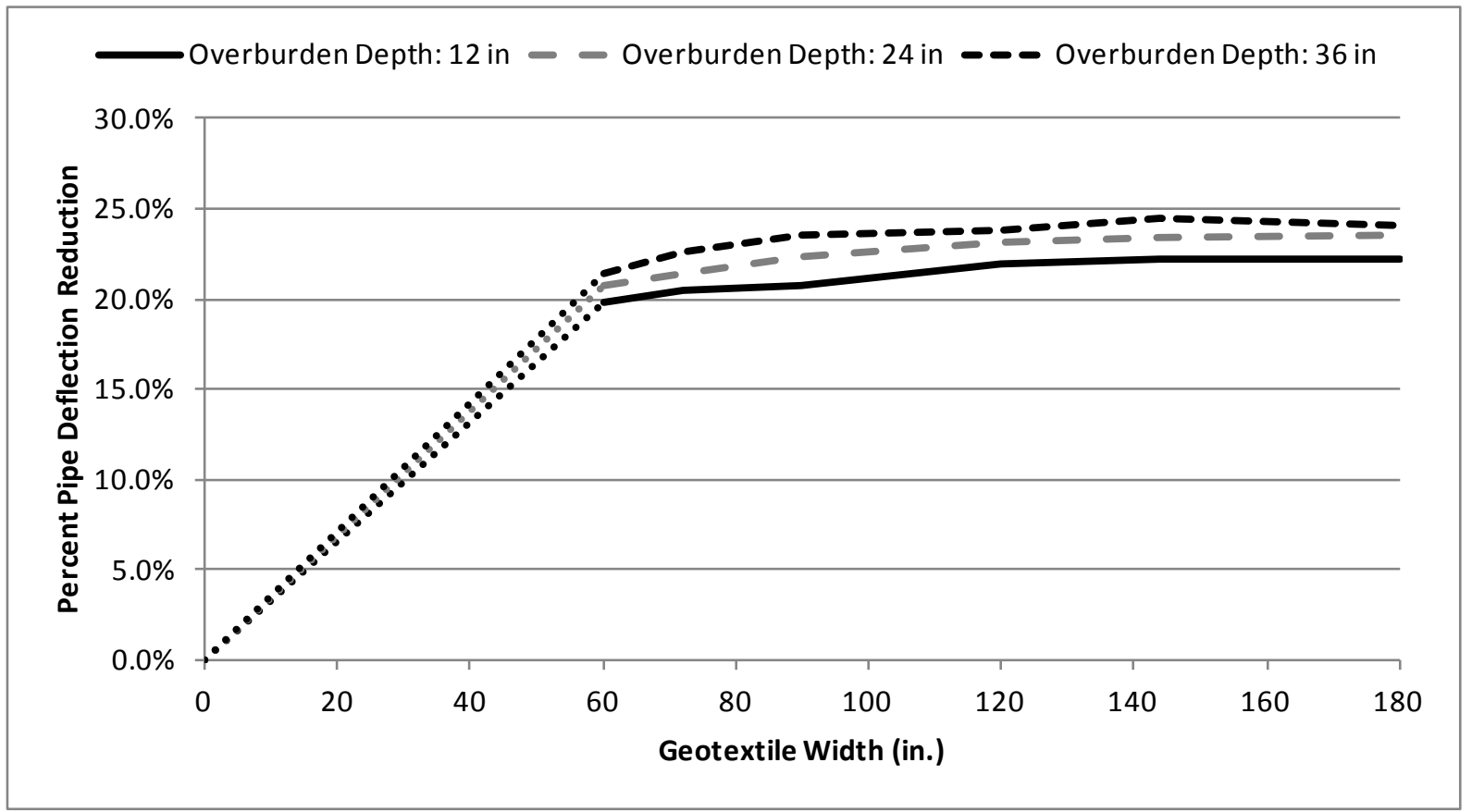

Figure 5.9: Percent reduction in pipe deflection vs. geotextile width with varying normal loading for 24 inch diameter pipe. 


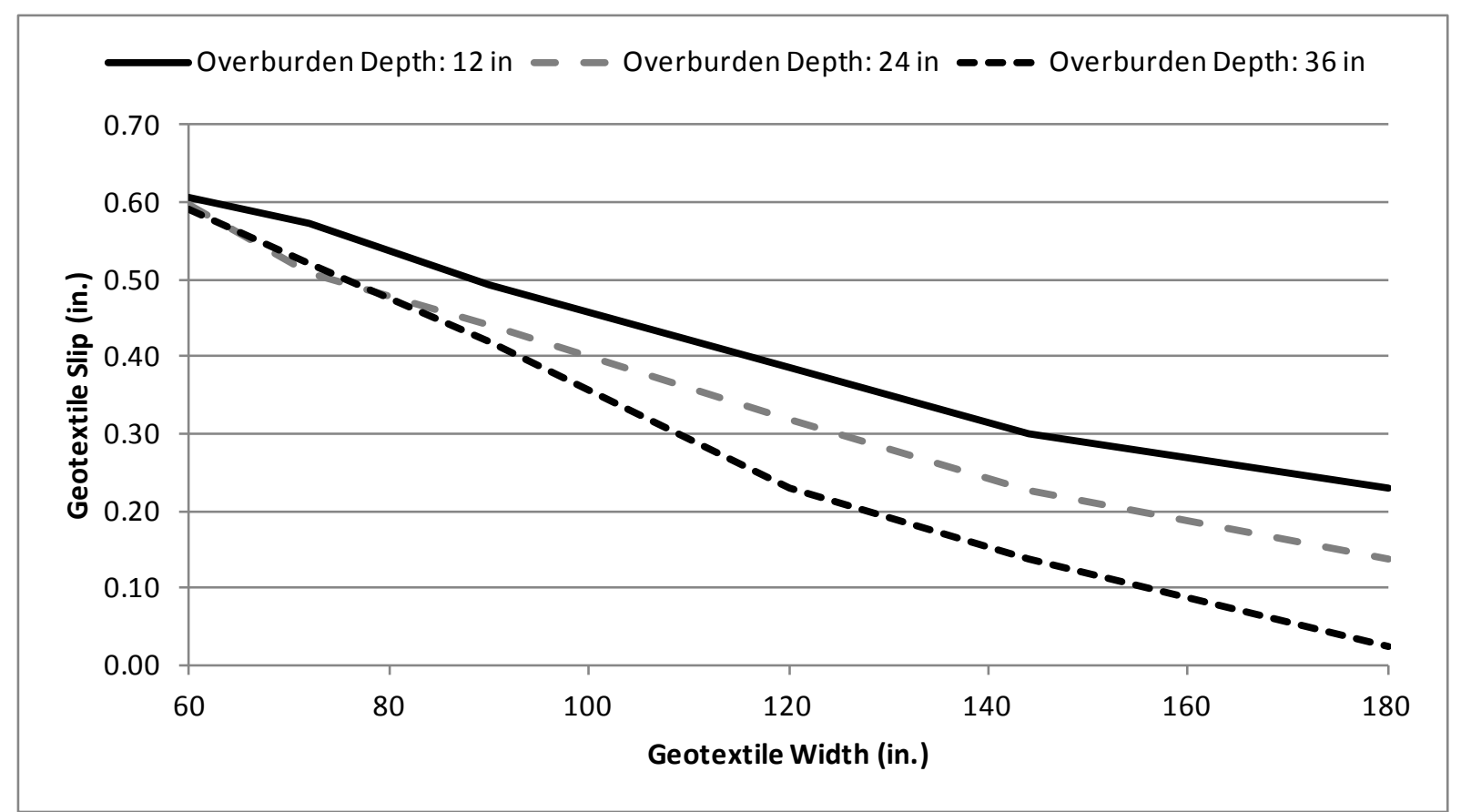

Figure 5.10: Geotextile slip distance vs. geotextile width with varying normal loading for 24 inch pipe diameter. 
Table 5.4: Pipe deflections with varying normal loading for 24 in. diameter pipe at 48 in. pipe depth.

\begin{tabular}{|c|c|c|c|c|c|c|}
\hline \multicolumn{7}{|c|}{ Variation of Normal Force : Pipe Depth = 48" } \\
\hline $\begin{array}{l}\text { Overburden } \\
\text { Depth (in.) }\end{array}$ & $\begin{array}{l}\text { Eq. Normal } \\
\text { Force }\left(\mathrm{lb} / \mathrm{in}^{2}\right)\end{array}$ & $\begin{array}{l}\text { Geotextile } \\
\text { Width (in.) }\end{array}$ & $\begin{array}{c}\text { Vertical Pipe } \\
\text { Deflection (in.) }\end{array}$ & $\begin{array}{c}\text { Percent } \\
\text { Deflection }\end{array}$ & $\begin{array}{c}\text { Percent Reduction } \\
\text { of Deflection } \\
\end{array}$ & $\begin{array}{c}\text { Geotextile } \\
\text { Slip (in.) }\end{array}$ \\
\hline 12 & 0.8681 & 0 & 0.7701 & $3.01 \%$ & $0.00 \%$ & $\mathrm{n} / \mathrm{a}$ \\
\hline 12 & 0.8681 & 60 & 0.7613 & $2.98 \%$ & $1.14 \%$ & 0.7159 \\
\hline 12 & 0.8681 & 72 & 0.7607 & $2.98 \%$ & $1.22 \%$ & 0.6086 \\
\hline 12 & 0.8681 & 90 & 0.7606 & $2.98 \%$ & $1.23 \%$ & 0.5365 \\
\hline 12 & 0.8681 & 120 & 0.7604 & $2.98 \%$ & $1.26 \%$ & 0.3591 \\
\hline 12 & 0.8681 & 144 & 0.7576 & $2.96 \%$ & $1.62 \%$ & 0.2758 \\
\hline 12 & 0.8681 & 180 & 0.7575 & $2.96 \%$ & $1.64 \%$ & 0.1825 \\
\hline 24 & 1.7362 & 0 & 0.8353 & $3.27 \%$ & $0.00 \%$ & $\mathrm{n} / \mathrm{a}$ \\
\hline 24 & 1.7362 & 60 & 0.8252 & $3.23 \%$ & $1.21 \%$ & 0.7503 \\
\hline 24 & 1.7362 & 72 & 0.8246 & $3.23 \%$ & $1.28 \%$ & 0.6189 \\
\hline 24 & 1.7362 & 90 & 0.8240 & $3.22 \%$ & $1.36 \%$ & 0.4680 \\
\hline 24 & 1.7362 & 120 & 0.8224 & $3.22 \%$ & $1.55 \%$ & 0.2641 \\
\hline 24 & 1.7362 & 144 & 0.8215 & $3.21 \%$ & $1.65 \%$ & 0.1386 \\
\hline 24 & 1.7362 & 180 & 0.8193 & $3.21 \%$ & $1.91 \%$ & 0.0127 \\
\hline 36 & 2.6042 & 0 & 0.9009 & $3.52 \%$ & $0.00 \%$ & $\mathrm{n} / \mathrm{a}$ \\
\hline 36 & 2.6042 & 60 & 0.8900 & $3.48 \%$ & $1.21 \%$ & 0.7682 \\
\hline 36 & 2.6042 & 72 & 0.8878 & $3.47 \%$ & $1.45 \%$ & 0.5895 \\
\hline 36 & 2.6042 & 90 & 0.8858 & $3.47 \%$ & $1.67 \%$ & 0.4108 \\
\hline 36 & 2.6042 & 120 & 0.8855 & $3.46 \%$ & $1.70 \%$ & 0.1714 \\
\hline 36 & 2.6042 & 144 & 0.8833 & $3.46 \%$ & $1.95 \%$ & 0.0361 \\
\hline 36 & 2.6042 & 180 & 0.8795 & $3.44 \%$ & $2.37 \%$ & 0.0368 \\
\hline
\end{tabular}




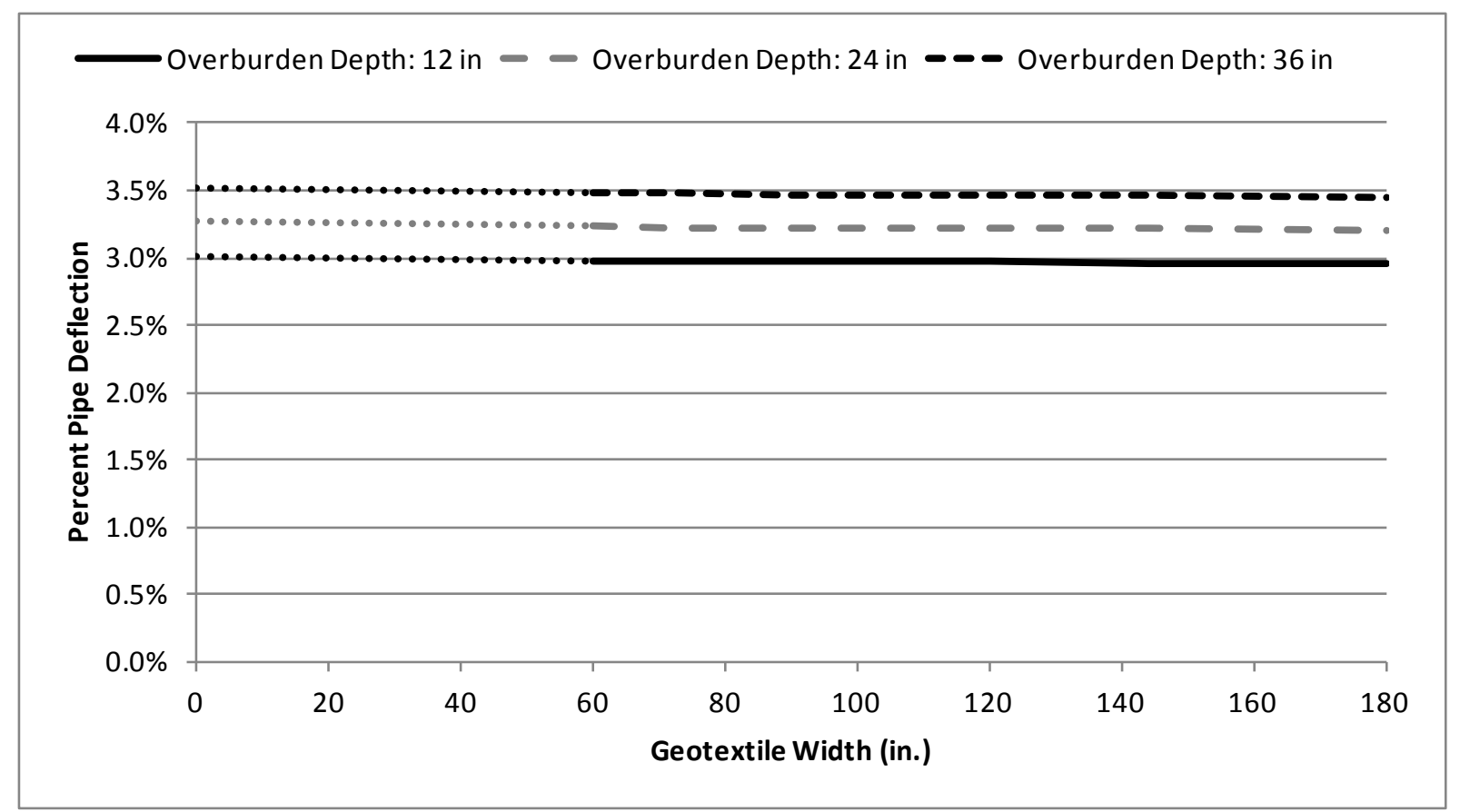

Figure 5.11: Percent pipe deflection vs. geotextile width with varying normal loading for 24 inch diameter pipe.

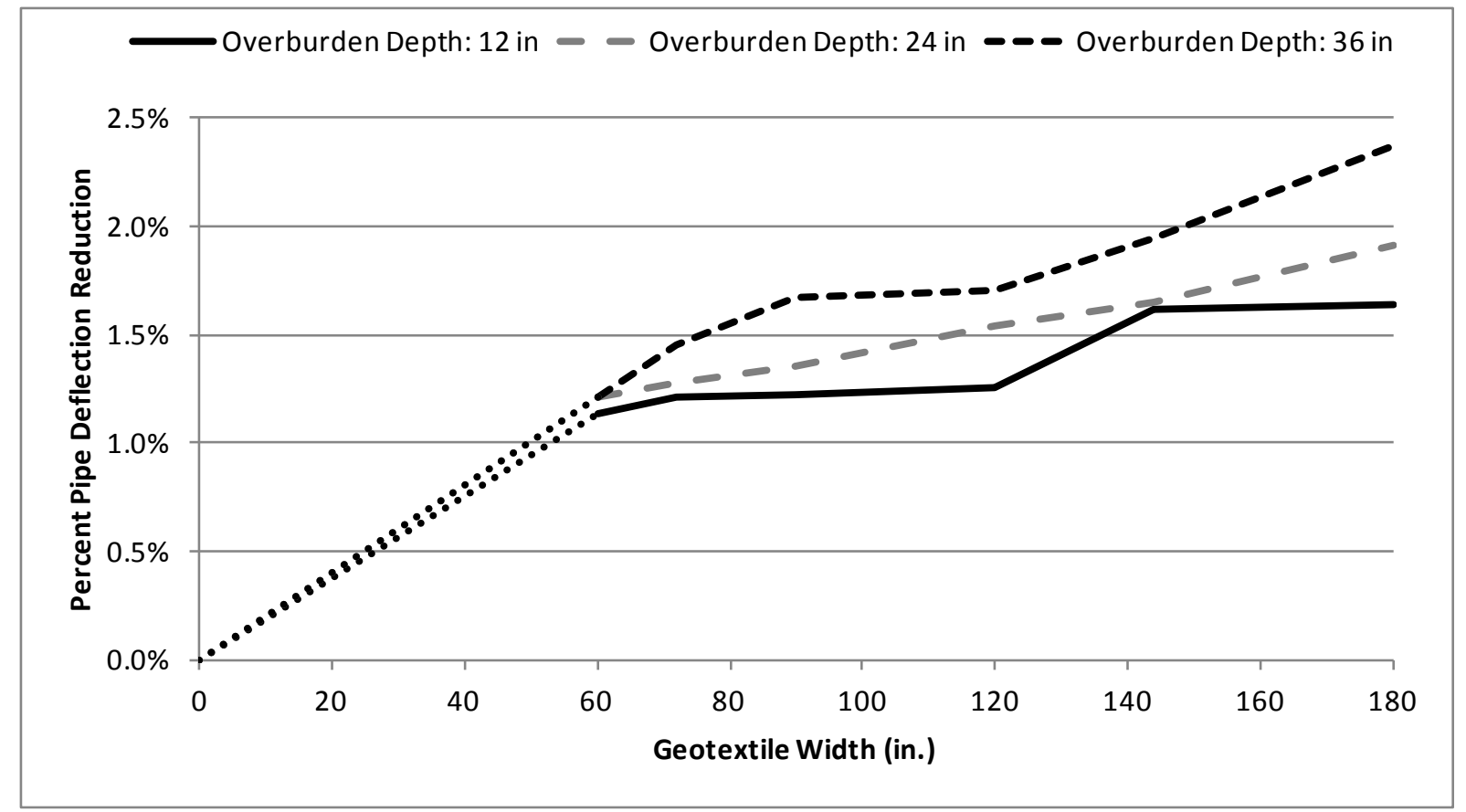

Figure 5.12: Percent reduction in pipe deflection vs. geotextile width with varying normal loading for 24 inch diameter pipe. 


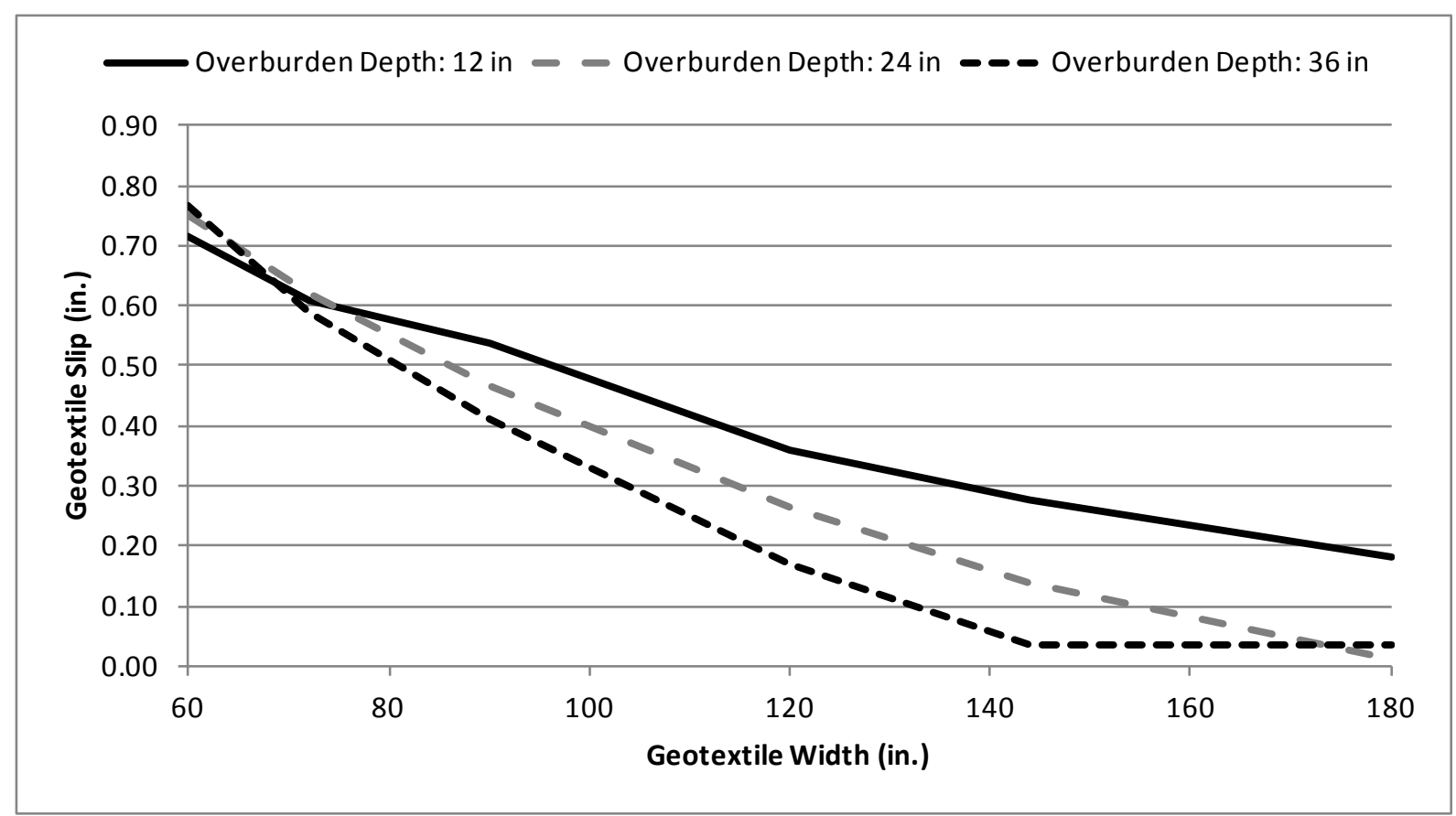

Figure 5.13: Geotextile slip distance vs. geotextile width with varying normal loading for 24 inch pipe diameter. 
Table 5.5: Pipe deflections with varying normal loading for 60 in. diameter pipe at 24 in. pipe depth.

\begin{tabular}{|c|c|c|c|c|c|c|}
\hline \multicolumn{7}{|c|}{ Variation of Normal Force: Pipe Depth = 24" } \\
\hline $\begin{array}{c}\text { Overburden } \\
\text { Depth (in.) }\end{array}$ & $\begin{array}{c}\text { Eq. Normal } \\
\text { Force (lb/in }{ }^{2} \text { ) }\end{array}$ & $\begin{array}{c}\text { Geotextile } \\
\text { Width (in.) }\end{array}$ & $\begin{array}{c}\text { Vertical Pipe } \\
\text { Deflection (in.) }\end{array}$ & $\begin{array}{c}\text { Percent } \\
\text { Deflection }\end{array}$ & $\begin{array}{c}\text { Percent Reduction } \\
\text { of Deflection }\end{array}$ & $\begin{array}{c}\text { Geotextile } \\
\text { Slip (in.) }\end{array}$ \\
\hline 12 & 0.8681 & 0 & 1.2954 & $2.08 \%$ & $0.00 \%$ & n/a \\
\hline 12 & 0.8681 & 120 & 1.1798 & $1.90 \%$ & $8.92 \%$ & 0.1651 \\
\hline 12 & 0.8681 & 144 & 1.1821 & $1.90 \%$ & $8.75 \%$ & 0.0934 \\
\hline 12 & 0.8681 & 180 & 1.1784 & $1.90 \%$ & $9.03 \%$ & 0.0179 \\
\hline 12 & 0.8681 & 240 & 1.1698 & $1.88 \%$ & $9.70 \%$ & 0.0142 \\
\hline 12 & 0.8681 & 288 & 1.1665 & $1.88 \%$ & $9.95 \%$ & 0.0114 \\
\hline 12 & 0.8681 & 360 & 1.1694 & $1.88 \%$ & $9.73 \%$ & 0.0058 \\
\hline 24 & 1.7362 & 0 & 1.4522 & $2.34 \%$ & $0.00 \%$ & $\mathrm{n} / \mathrm{a}$ \\
\hline 24 & 1.7362 & 120 & 1.3317 & $2.14 \%$ & $8.30 \%$ & 0.1388 \\
\hline 24 & 1.7362 & 144 & 1.3318 & $2.14 \%$ & $8.29 \%$ & 0.0496 \\
\hline 24 & 1.7362 & 180 & 1.3294 & $2.14 \%$ & $8.46 \%$ & 0.0232 \\
\hline 24 & 1.7362 & 240 & 1.3188 & $2.12 \%$ & $9.18 \%$ & 0.0105 \\
\hline 24 & 1.7362 & 288 & 1.3173 & $2.12 \%$ & $9.28 \%$ & 0.0098 \\
\hline 24 & 1.7362 & 360 & 1.3196 & $2.12 \%$ & $9.13 \%$ & 0.0077 \\
\hline 36 & 2.6042 & 0 & 1.6118 & $2.59 \%$ & $0.00 \%$ & $\mathrm{n} / \mathrm{a}$ \\
\hline 36 & 2.6042 & 120 & 1.4845 & $2.39 \%$ & $7.90 \%$ & 0.1332 \\
\hline 36 & 2.6042 & 144 & 1.4846 & $2.39 \%$ & $7.89 \%$ & 0.0343 \\
\hline 36 & 2.6042 & 180 & 1.4813 & $2.38 \%$ & $8.10 \%$ & 0.0313 \\
\hline 36 & 2.6042 & 240 & 1.4708 & $2.37 \%$ & $8.75 \%$ & 0.0115 \\
\hline 36 & 2.6042 & 288 & 1.4691 & $2.36 \%$ & $8.85 \%$ & 0.0093 \\
\hline 36 & 2.6042 & 360 & 1.4691 & $2.36 \%$ & $8.85 \%$ & 0.0051 \\
\hline & & & & & & \\
\hline
\end{tabular}




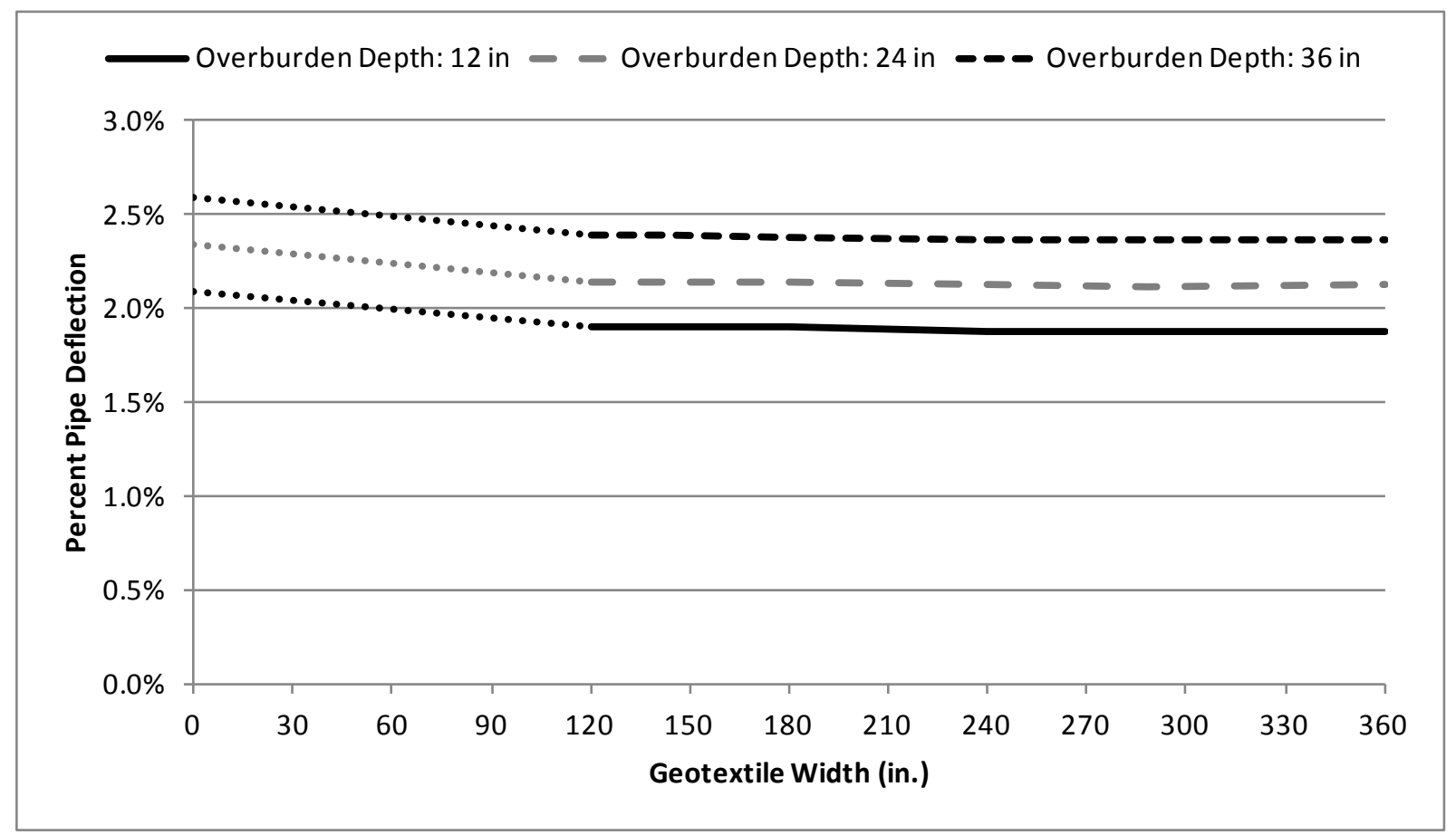

Figure 5.14: Percent pipe deflection vs. geotextile width with varying normal loading for 60 inch diameter pipe.

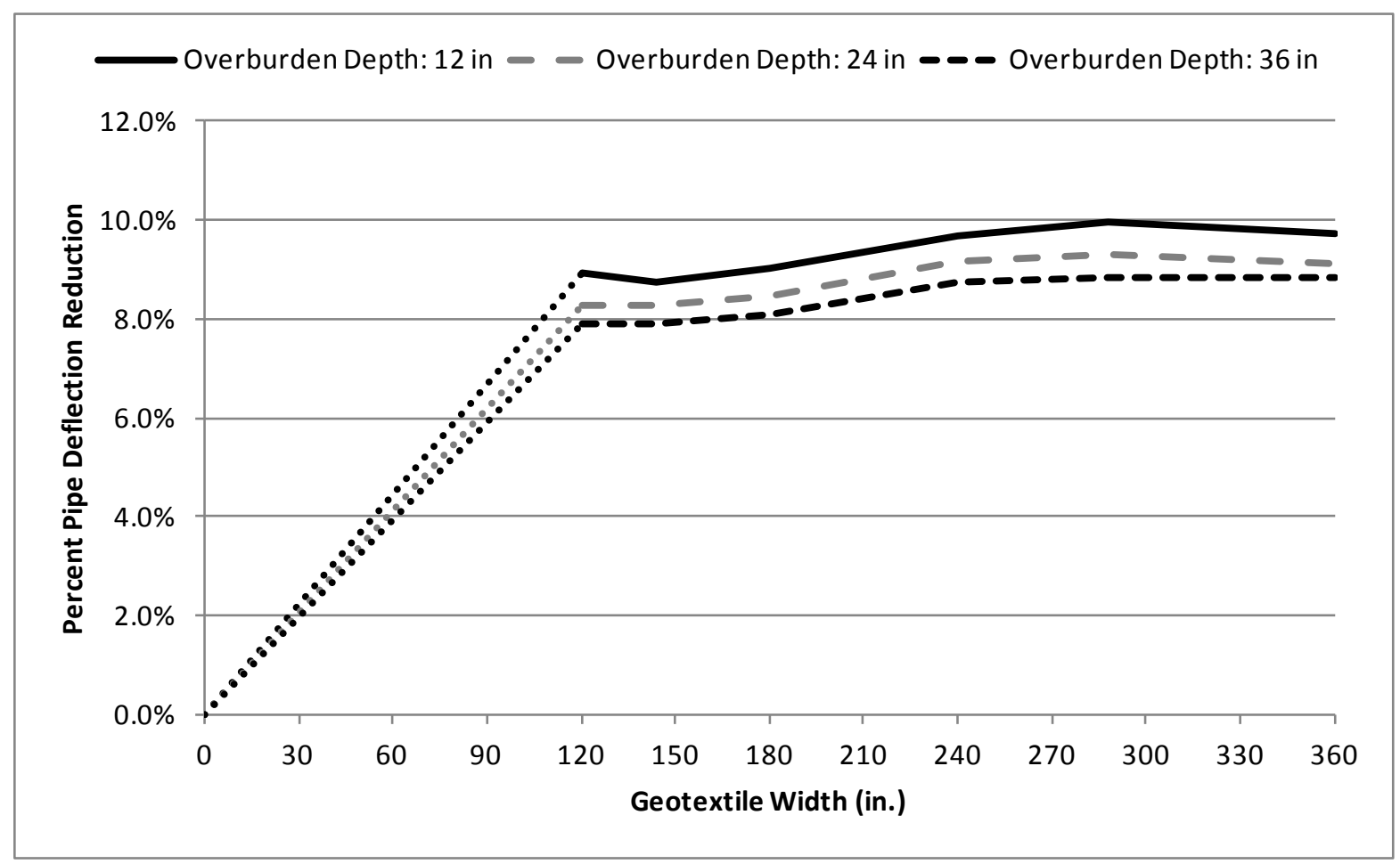

Figure 5.15: Percent reduction in pipe deflection vs. geotextile width with varying normal loading. 


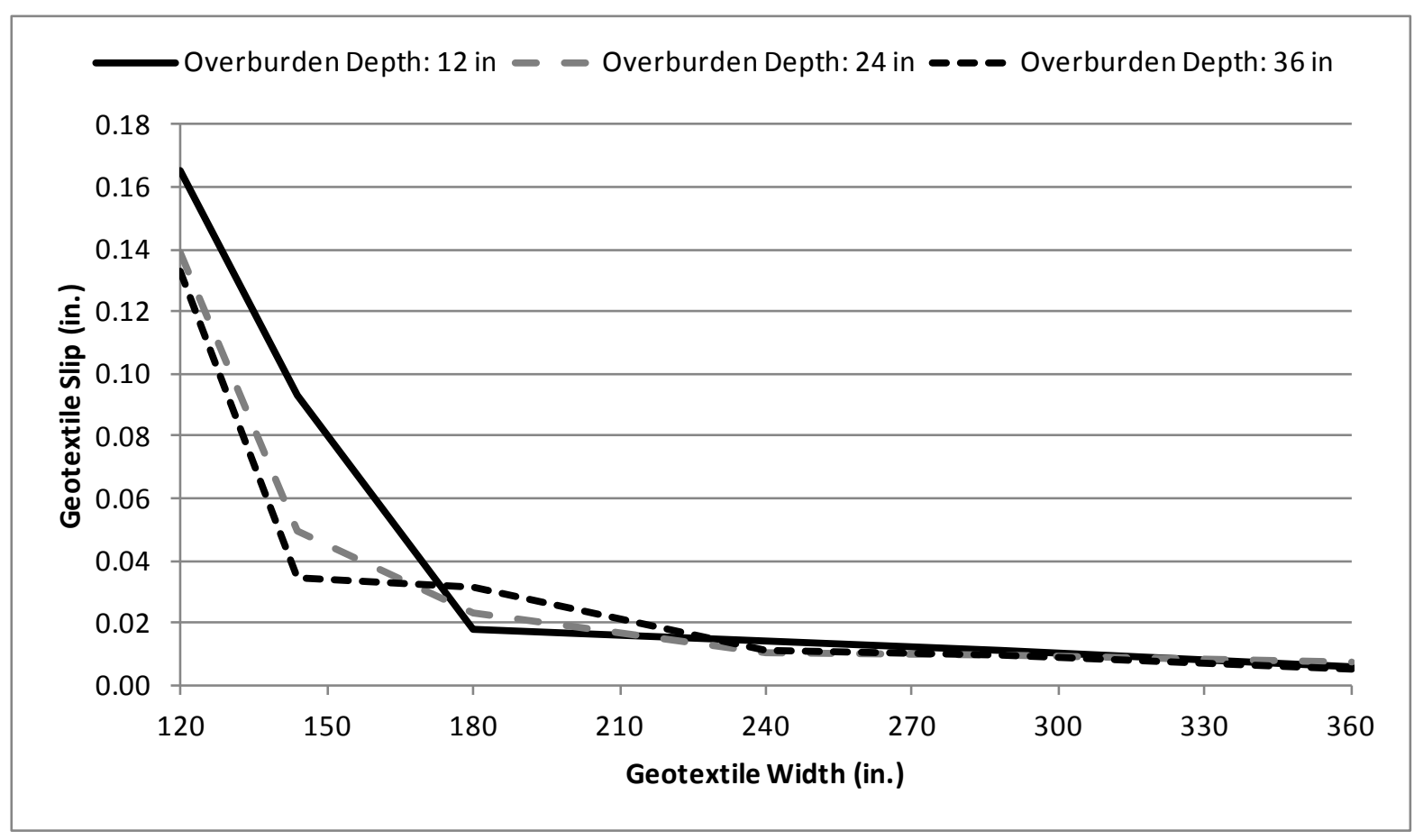

Figure 5.16: Geotextile slip distance vs. geotextile width with varying normal loading for 60 inch pipe diameter.

\subsection{Effect of varying geotextile stiffness}

For this portion of the analysis the elastic modulus of the geotextile was varied by a factor of 10. The standard geotextile stiffness that was used in this analysis, as discussed in the previous chapter (see section 4.9.2), is approximately 57,143 psi (393.99 MPa). Two alternative cases were considered where the elastic modulus was increased by a factor of 10 and decreased by a factor of 10 from the base value of 57,143 psi (393.99 MPa), resulting in the values 571,428 psi (3939.86 MPa) and 5,714 psi (39.40 MPa), respectively. These values represent extremely high and low stiffness values for a geotextile. In theory, a stronger geotextile should result in lower pipe deflections as long as it remains anchored in the soil. This idea was tested for a pipe depth of 24 in. $(60.96 \mathrm{~cm})$ and a normal force equivalent to 24 in. $(60.96 \mathrm{~cm})$ of overburden. The results from this exercise can be seen in Table 5.6 with corresponding Figures 5.17, 5.18, and 5.19. Increasing the geotextile stiffness only slightly improved pipe performance. In other words, the improvement of pipe performance is not significantly influenced by the geotextile 
stiffness, when linear elastic behavior was assumed. It should be noted that in the present analysis, failure of the geotextile was not considered.

Table 5.6: Pipe deflections with varying geotextile stiffness for 24 inch diameter pipe.

\begin{tabular}{|c|c|c|c|c|c|}
\hline \multicolumn{5}{|c|}{ Variation of Geotextile Elastic Modulus: Pipe Depth = 24", Normal Force = 24" } \\
\hline $\begin{array}{c}\text { Geotextile } E^{\prime} \\
\text { (psi) }\end{array}$ & $\begin{array}{c}\text { Geotextile } \\
\text { Width (in.) }\end{array}$ & $\begin{array}{c}\text { Vertical Pipe } \\
\text { Deflection (in.) }\end{array}$ & $\begin{array}{c}\text { Percent } \\
\text { Deflection }\end{array}$ & $\begin{array}{c}\text { Percent Reduction } \\
\text { of Deflection }\end{array}$ & $\begin{array}{c}\text { Geotextile } \\
\text { Slip (in.) }\end{array}$ \\
\hline 5,714 & 0 & 1.0044 & $3.93 \%$ & $0.00 \%$ & n/a \\
\hline 5,714 & 60 & 0.8274 & $3.24 \%$ & $17.63 \%$ & 0.3586 \\
\hline 5,714 & 72 & 0.8262 & $3.23 \%$ & $17.75 \%$ & 0.3537 \\
\hline 5,714 & 90 & 0.8215 & $3.21 \%$ & $18.21 \%$ & 0.1560 \\
\hline 5,714 & 120 & 0.8121 & $3.18 \%$ & $19.15 \%$ & 0.1412 \\
\hline 5,714 & 144 & 0.8125 & $3.18 \%$ & $19.10 \%$ & 0.1214 \\
\hline 5,714 & 180 & 0.8162 & $3.19 \%$ & $18.74 \%$ & 0.0810 \\
\hline 57,142 & 0 & 1.0044 & $3.93 \%$ & $0.00 \%$ & $\mathrm{n} / \mathrm{a}$ \\
\hline 57,142 & 60 & 0.7964 & $3.12 \%$ & $20.71 \%$ & 0.5959 \\
\hline 57,142 & 72 & 0.7888 & $3.09 \%$ & $21.47 \%$ & 0.5078 \\
\hline 57,142 & 90 & 0.7795 & $3.05 \%$ & $22.39 \%$ & 0.4412 \\
\hline 57,142 & 120 & 0.7726 & $3.02 \%$ & $23.08 \%$ & 0.3183 \\
\hline 57,142 & 144 & 0.7698 & $3.01 \%$ & $23.36 \%$ & 0.2266 \\
\hline 57,142 & 180 & 0.7686 & $3.01 \%$ & $23.48 \%$ & 0.1382 \\
\hline 571,428 & 0 & 1.0044 & $3.93 \%$ & $0.00 \%$ & $\mathrm{n} / \mathrm{a}$ \\
\hline 571,428 & 60 & 0.7901 & $3.09 \%$ & $21.34 \%$ & 0.3000 \\
\hline 571,428 & 72 & 0.7767 & $3.04 \%$ & $22.67 \%$ & 0.2865 \\
\hline 571,428 & 90 & 0.7621 & $2.98 \%$ & $24.13 \%$ & 0.2602 \\
\hline 571,428 & 120 & 0.7476 & $2.92 \%$ & $25.57 \%$ & 0.2082 \\
\hline 571,428 & 144 & 0.7378 & $2.89 \%$ & $26.54 \%$ & 0.1461 \\
\hline 571,428 & 180 & 0.7354 & $2.88 \%$ & $26.79 \%$ & 0.1137 \\
\hline & & & & & \\
\hline
\end{tabular}




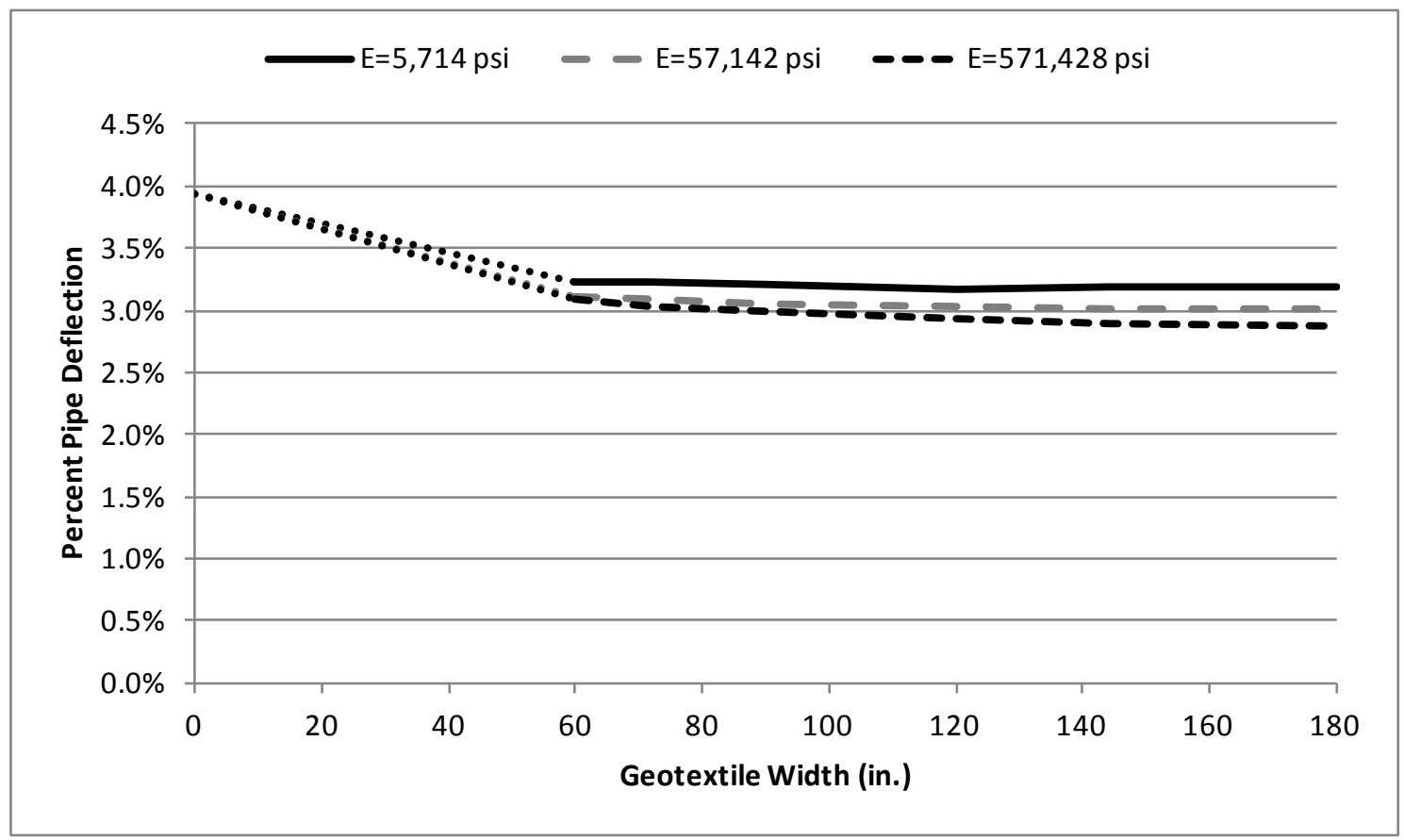

Figure 5.17: Percent pipe deflection vs. geotextile width with varying geotextile stiffness for 24 inch diameter pipe.

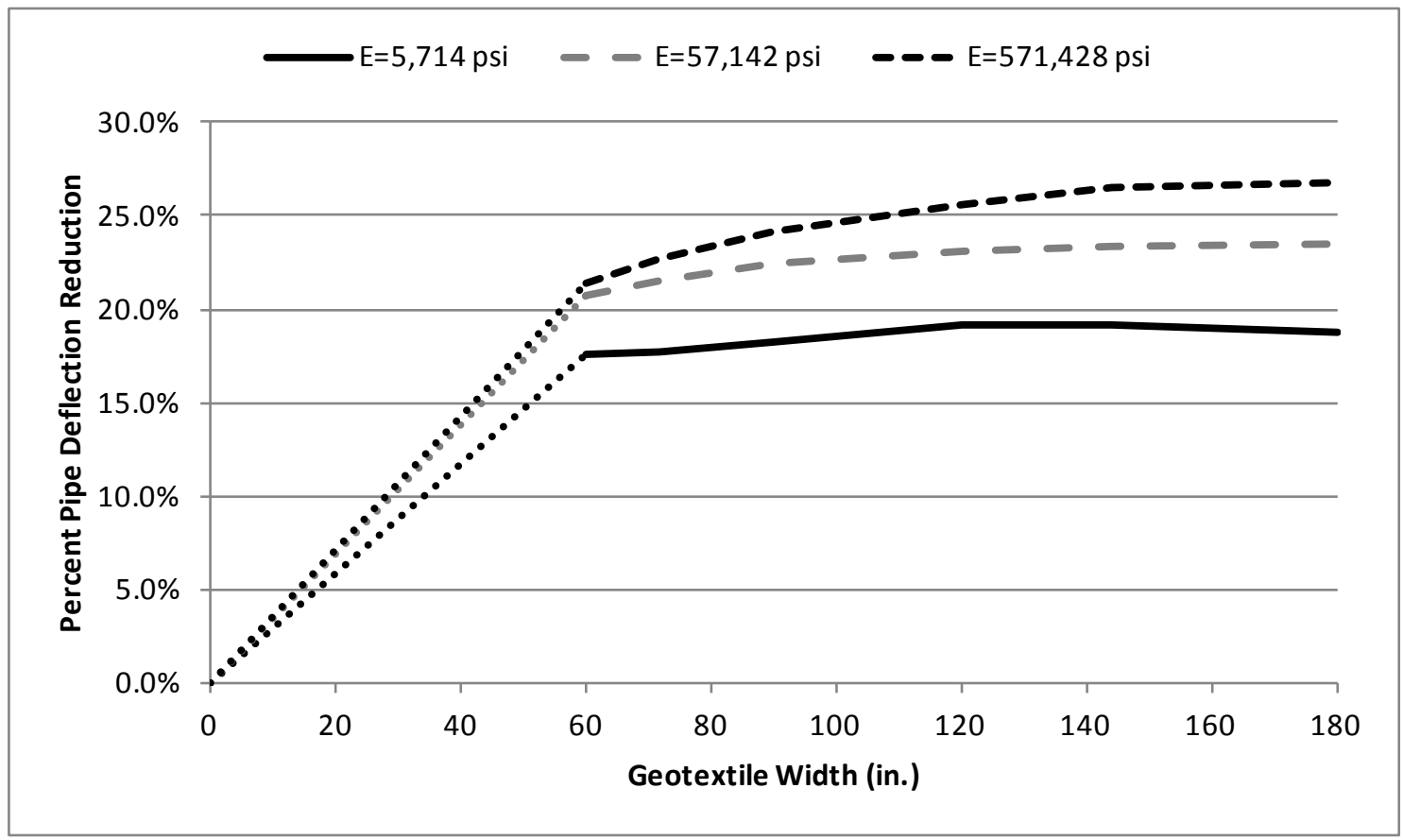

Figure 5.18: Percent reduction in pipe deflection vs. geotextile width with varying geotextile stiffness for 24 inch diameter pipe. 


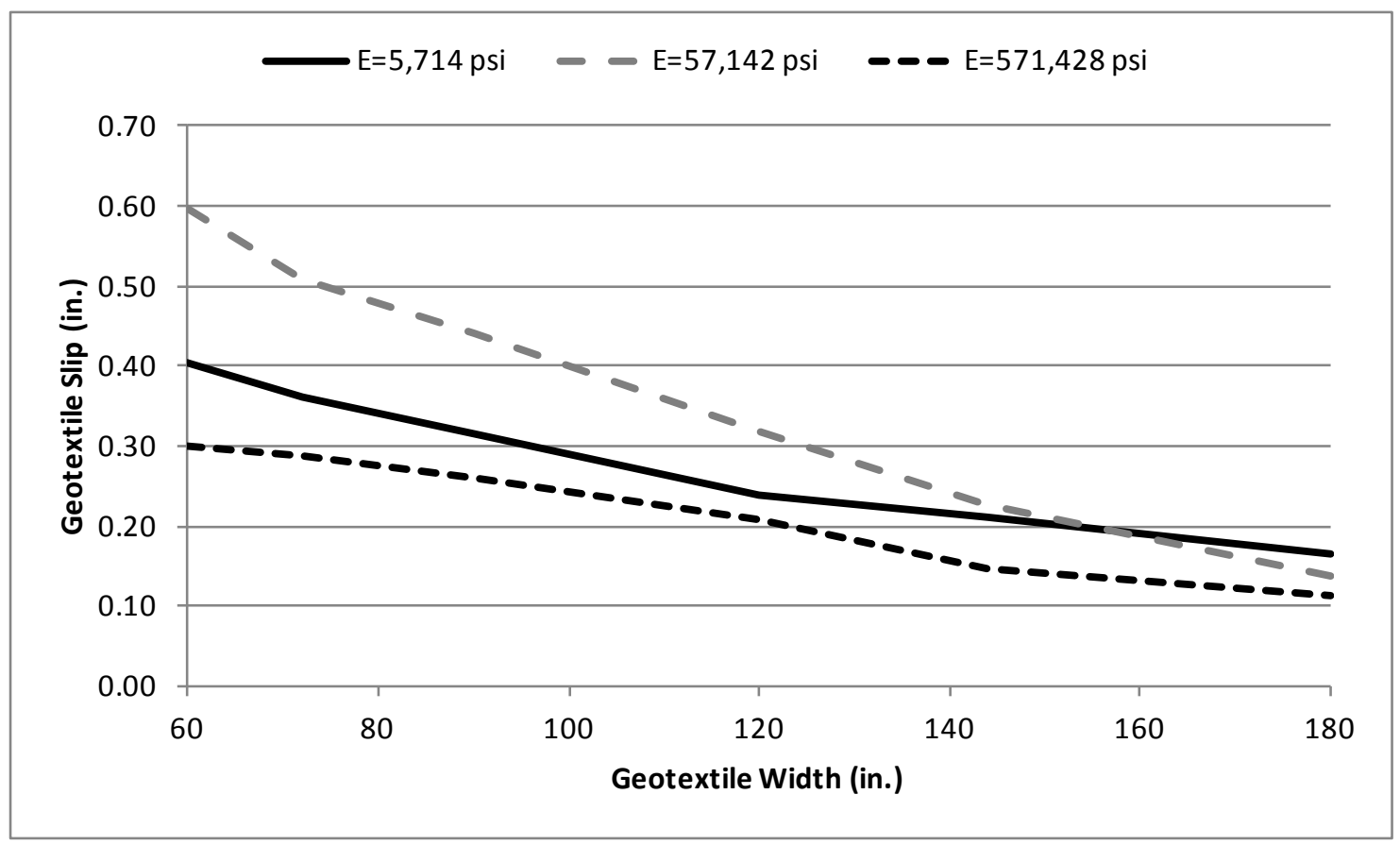

Figure 5.19: Geotextile slip distance vs. geotextile width with varying geotextile stiffness for 24 inch diameter pipe.

\subsection{Effect of geotextile width}

In order for geotextile reinforcement to be effective it must have enough anchorage resistance between soil and fabric surfaces to allow tensile forces to develop in the plane of the geotextile rather than allowing it to be pulled out of the soil. The two main factors that control the magnitude of frictional resistance between a geotextile and soil are the confining pressure (or normal force) and the contact area between the fabric and soil for a fixed value of frictional coefficient. These values are then multiplied by the coefficient of friction to find the total frictional resistance. In this study a coefficient of friction equal to 0.3 was used. The total contact area can be controlled by specifying the geotextile width. The geotextile length is assumed to be continuous (end-to-end distance in the model) for this study.

A range of geotextile widths were used in all phases of this research. These values are based on the typical roll widths available for many commercial geotextiles on the market. These widths are 120 in. $(3.05 \mathrm{~m}), 144$ in. $(3.66 \mathrm{~m})$, and 180 in $(4.57 \mathrm{~m})$. For the 24-inch diameter pipe models these values were each divided in half so that a range of six sizes could be used in the 
analysis. The range is as follows: 60in. $(1.52 \mathrm{~m}), 72$ in. $(1.83 \mathrm{~m}), 90$ in. $(2.29 \mathrm{~m}), 120$ in. $(3.05$ m), 144 in. $(3.66 \mathrm{~m}), 180$ in. $(4.57 \mathrm{~m})$. For the 60 -inch diameter pipe models the standard values were doubled. The range of geotextile widths used for this case is as follows: 120 in. (3.05 m), 144 in. (3.66 m), 180 in. (4.57 m), 240 in. $(6.10 \mathrm{~m}), 288$ in. $(7.32 \mathrm{~m})$, and 360 in. $(9.14 \mathrm{~m})$. As can be seen from Figure 5.20, the geotextile width does not have a significant influence on the reduction of pipe deflection. This can be clearly seen from Figure 5.20 where the percent of pipe deflection is only reduced by approximately one tenth of a percent when the geotextile width is increased from 60 inches $(1.52 \mathrm{~m})$ to 180 inches $(4.57 \mathrm{~m})$. This same trend can be observed in all data presented in this chapter. It is clear that the geotextile width has little influence over the reduction in pipe deflection. Once the initial reduction is made from the smallest geotextile size, the reduction gained for larger widths is only minimal. This is most likely due to the large overall area of the geotextile, resulting in enough anchorage to build adequate tension in all geotextiles. 


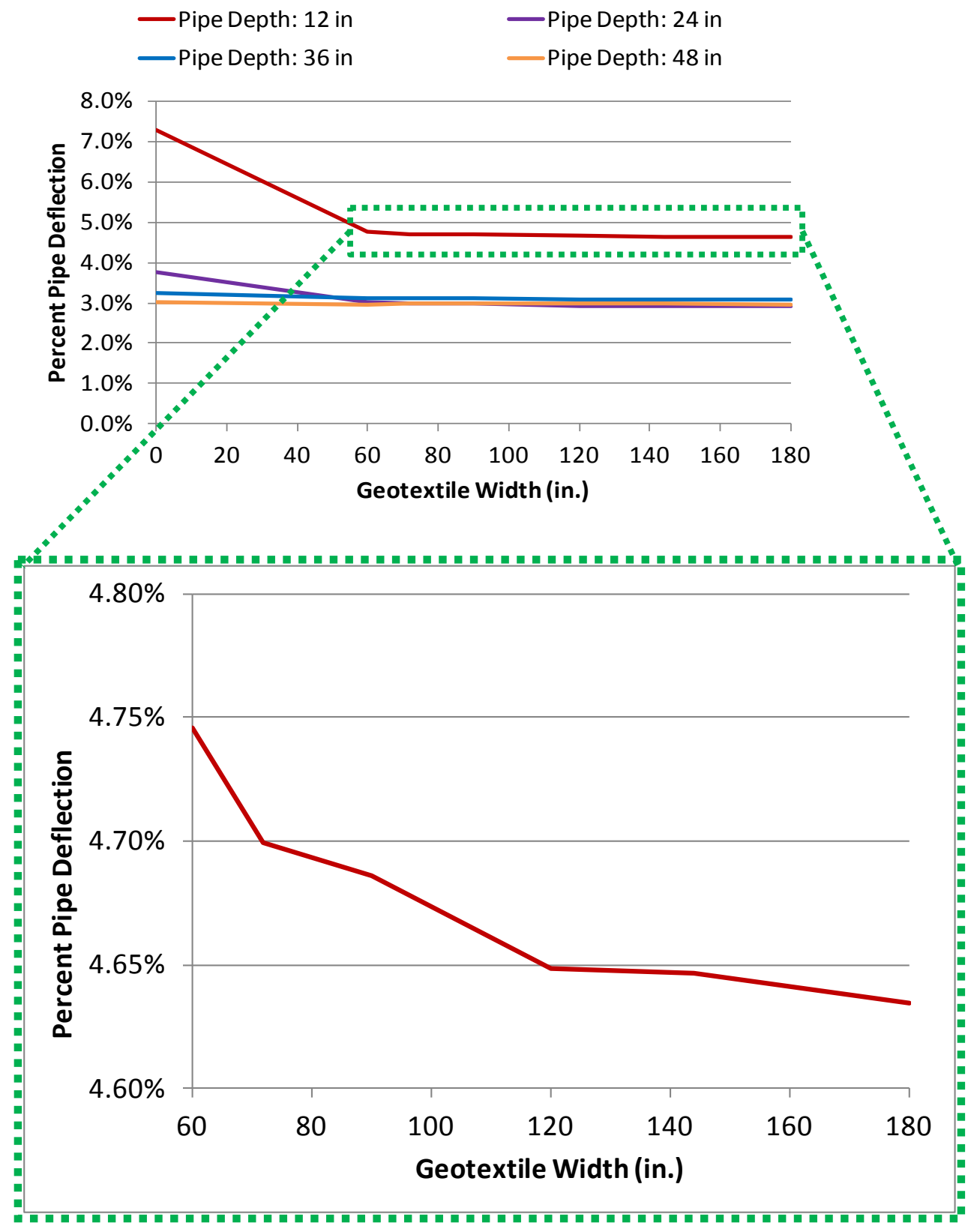

Figure 5.20: Effect of Geotextile Width

\subsection{Geotextile effectiveness with varying trench stiffness}

All analysis to this point has assumed a worst case scenario of a poorly constructed, weak trench where geotextile reinforcement would have the greatest effect on pipe performance. The question still remains whether the geotextile reinforcement helps in a situation where the pipe 
trench is properly constructed. Two additional cases are used for this evaluation. First, a "normal trench" scenario, where trench fill is only slightly less stiff than the surrounding insitu soil. In this case the trench backfill has an elastic modulus of 1,000 psi (6.89 MPa). Second, a "strong trench" scenario, where the trench backfill modulus is equal to the insitu soil modulus at $1,500 \mathrm{psi}(10.34 \mathrm{MPa})$.

The results for this study are shown in Table 5.7 with corresponding Figures 5.21, 5.22, and 5.23 for the 24 in. $(60.96 \mathrm{~cm})$ diameter pipe. Figures 5.24, 5.25, and 5.26 together with Table 5.8 show the results for the 60 in. $(152.4 \mathrm{~cm})$ diameter pipe case. These results show that while pipe performance is significantly improved in these cases, the benefits from adding geosynthetic reinforcement are much less noteworthy. This leads one to conclude that if a buried pipe is installed correctly with a strong, properly compacted trench fill, geotextile reinforcement would be unnecessary; however, in a scenario where a pipe cannot be installed properly geotextile reinforcement could be highly beneficial. 
Table 5.7: Geotextile performance with varying trench stiffness for 24 in. diameter pipe.

\begin{tabular}{|c|c|c|c|c|c|}
\hline \multicolumn{6}{|c|}{ Variation of Trench Fill Elastic Modulus: Pipe Depth = 12", Normal Force = 12" } \\
\hline $\begin{array}{c}\text { Trench Fill E' } \\
\text { (psi) }\end{array}$ & $\begin{array}{c}\text { Geotextile } \\
\text { Width (in.) }\end{array}$ & $\begin{array}{c}\text { Vertical Pipe } \\
\text { Deflection (in.) }\end{array}$ & $\begin{array}{c}\text { Percent } \\
\text { Deflection }\end{array}$ & $\begin{array}{c}\text { Percent Reduction } \\
\text { of Deflection }\end{array}$ & $\begin{array}{c}\text { Geotextile } \\
\text { Slip (in) }\end{array}$ \\
\hline 500 & 0 & 1.8586 & $7.27 \%$ & $0.00 \%$ & n/a \\
\hline 500 & 60 & 1.2130 & $4.75 \%$ & $34.74 \%$ & 0.4029 \\
\hline 500 & 72 & 1.2012 & $4.70 \%$ & $35.37 \%$ & 0.3624 \\
\hline 500 & 90 & 1.1977 & $4.69 \%$ & $35.56 \%$ & 0.3162 \\
\hline 500 & 120 & 1.1882 & $4.65 \%$ & $36.07 \%$ & 0.2378 \\
\hline 500 & 144 & 1.1876 & $4.65 \%$ & $36.10 \%$ & 0.2117 \\
\hline 500 & 180 & 1.1845 & $4.63 \%$ & $36.27 \%$ & 0.1635 \\
\hline 1000 & 0 & 1.2497 & $4.89 \%$ & $0.00 \%$ & $\mathrm{n} / \mathrm{a}$ \\
\hline 1000 & 60 & 1.0659 & $4.17 \%$ & $14.71 \%$ & 0.2133 \\
\hline 1000 & 72 & 1.0594 & $4.14 \%$ & $15.23 \%$ & 0.1898 \\
\hline 1000 & 90 & 1.0636 & $4.16 \%$ & $14.89 \%$ & 0.1635 \\
\hline 1000 & 120 & 1.0693 & $4.18 \%$ & $14.43 \%$ & 0.1304 \\
\hline 1000 & 144 & 1.0699 & $4.19 \%$ & $14.39 \%$ & 0.0946 \\
\hline 1000 & 180 & 1.0666 & $4.17 \%$ & $14.65 \%$ & 0.0590 \\
\hline 1500 & 0 & 1.0186 & $3.99 \%$ & $0.00 \%$ & $\mathrm{n} / \mathrm{a}$ \\
\hline 1500 & 60 & 0.9306 & $3.64 \%$ & $8.64 \%$ & 0.1229 \\
\hline 1500 & 72 & 0.9269 & $3.63 \%$ & $9.00 \%$ & 0.1167 \\
\hline 1500 & 90 & 0.9261 & $3.62 \%$ & $9.08 \%$ & 0.0989 \\
\hline 1500 & 120 & 0.9304 & $3.64 \%$ & $8.66 \%$ & 0.0736 \\
\hline 1500 & 144 & 0.9299 & $3.64 \%$ & $8.71 \%$ & 0.0517 \\
\hline 1500 & 180 & 0.9336 & $3.65 \%$ & $8.34 \%$ & 0.0210 \\
\hline
\end{tabular}




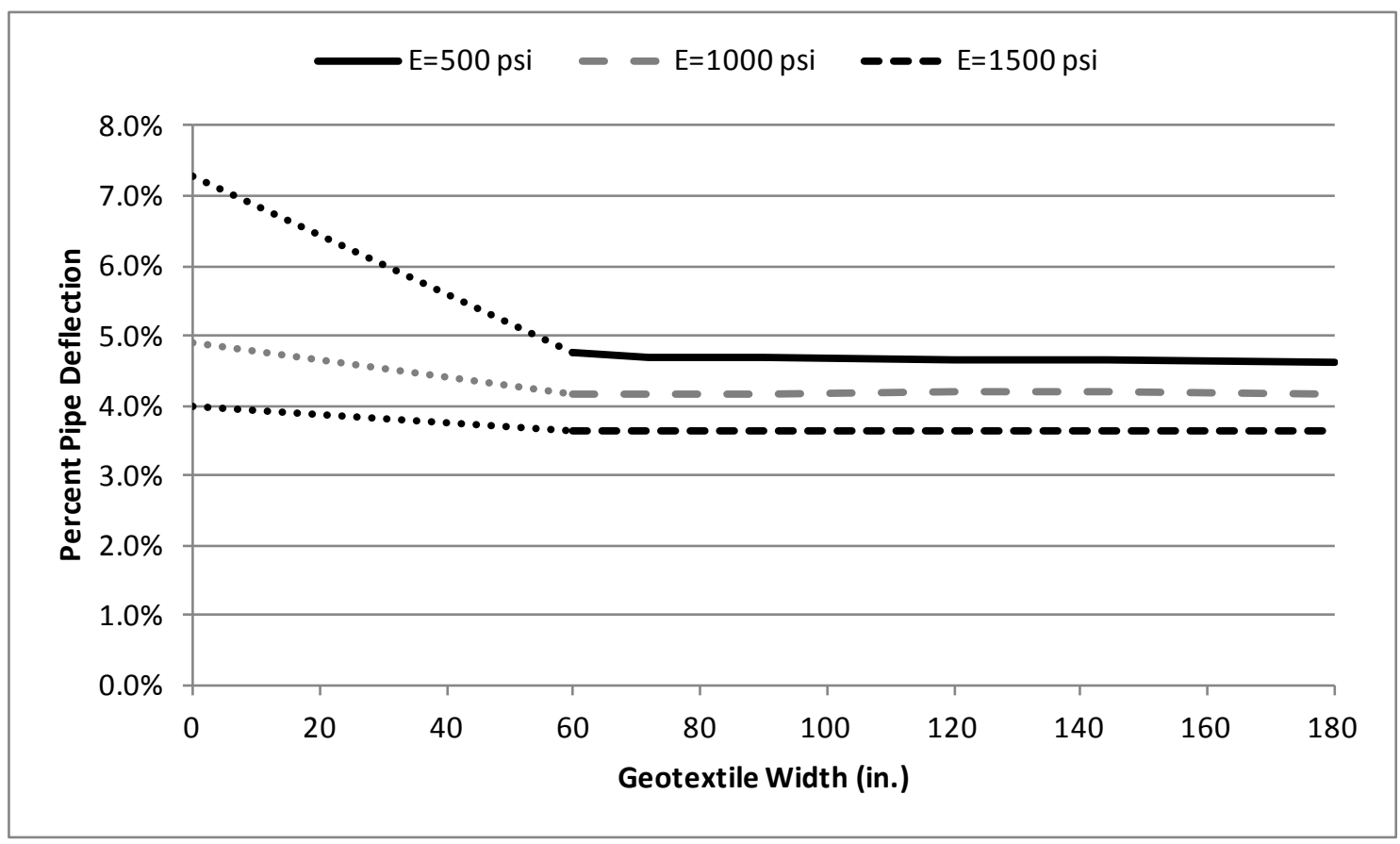

Figure 5.21: Percent pipe deflection vs. geotextile width with varying trench stiffness for 24 inch diameter pipe.

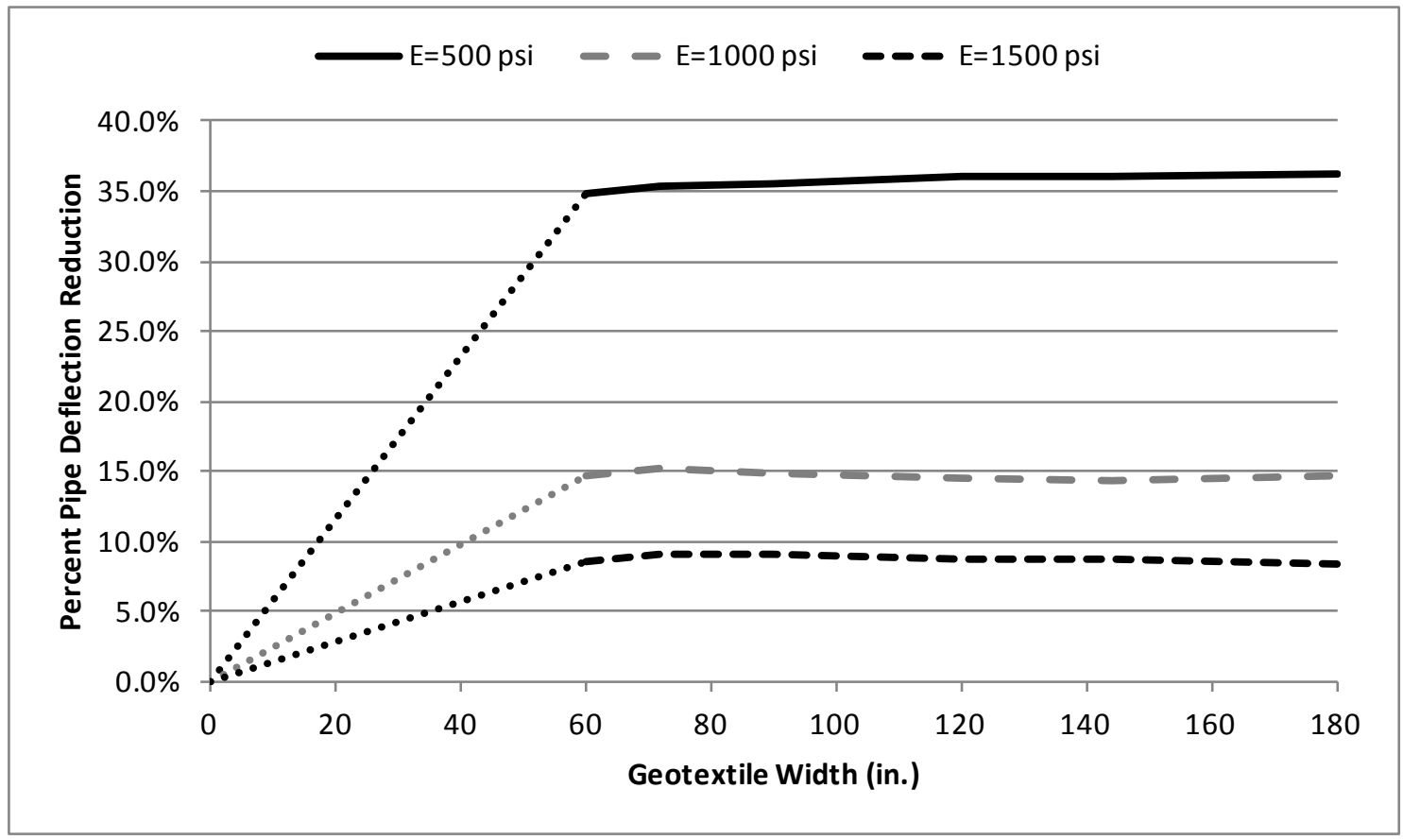

Figure 5.22: Percent reduction in pipe deflection vs. geotextile width with varying trench stiffness for 24 inch diameter pipe. 


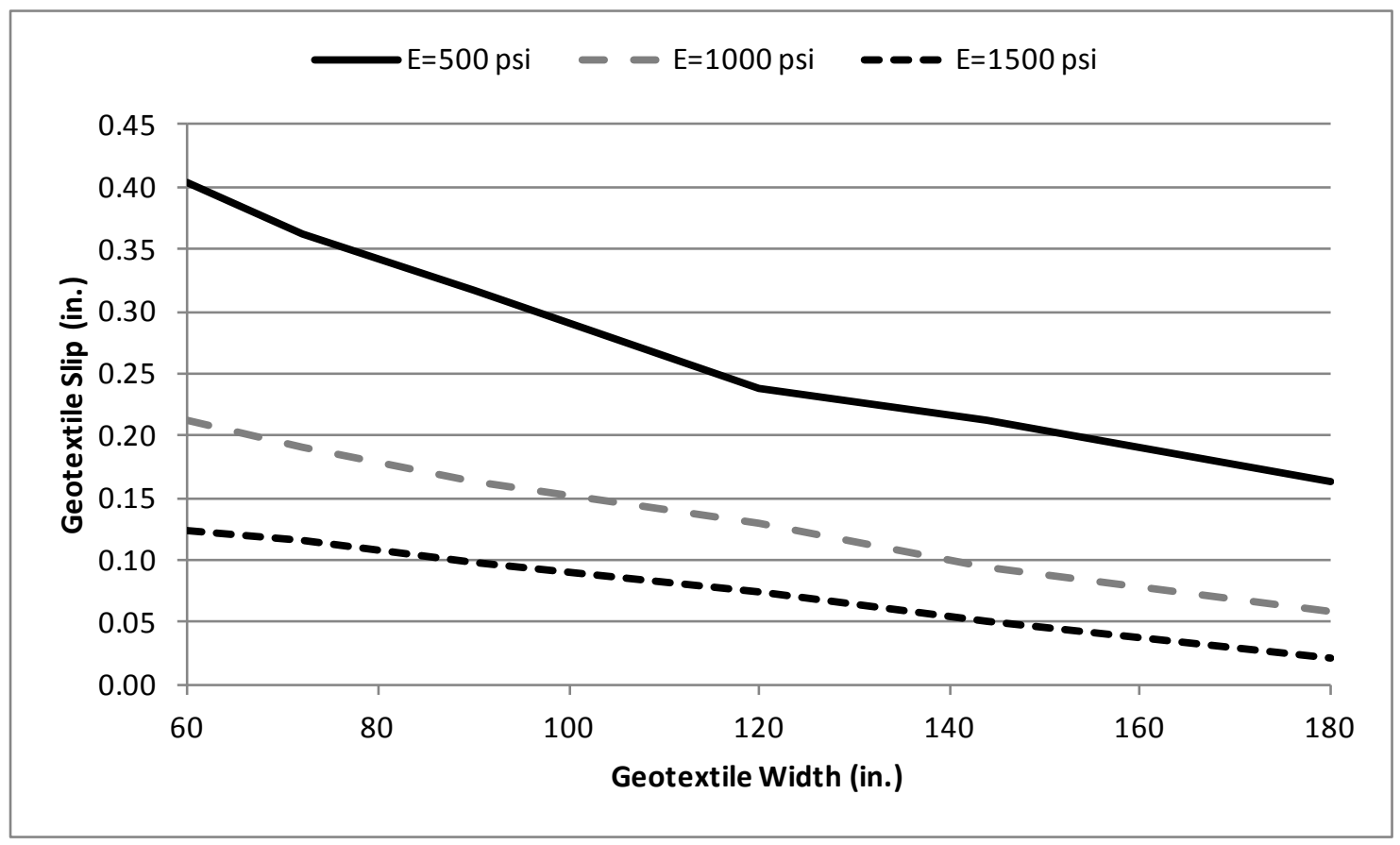

Figure 5.23: Geotextile slip distance vs. geotextile width with varying trench stiffness for 24 inch diameter pipe. 
Table 5.8: Geotextile performance with varying trench stiffness for 60 in. diameter pipe.

\begin{tabular}{|c|c|c|c|c|c|}
\hline \multicolumn{6}{|c|}{ Variation of Trench Fill Elastic Modulus: Pipe Depth = 12", Normal Force = 12" } \\
\hline $\begin{array}{c}\text { Trench Fill } \\
E^{\prime} \text { (psi) }\end{array}$ & $\begin{array}{c}\text { Geotextile } \\
\text { Width (in.) }\end{array}$ & $\begin{array}{c}\text { Vertical Pipe } \\
\text { Deflection (in.) }\end{array}$ & $\begin{array}{c}\text { Percent } \\
\text { Deflection }\end{array}$ & $\begin{array}{c}\text { Percent Reduction } \\
\text { of Deflection }\end{array}$ & $\begin{array}{c}\text { Geotextile } \\
\text { Slip (in) }\end{array}$ \\
\hline 500 & 0 & 1.7750 & $2.86 \%$ & $0.00 \%$ & n/a \\
\hline 500 & 120 & 1.4760 & $2.38 \%$ & $16.85 \%$ & 0.1354 \\
\hline 500 & 144 & 1.4754 & $2.37 \%$ & $16.88 \%$ & 0.0902 \\
\hline 500 & 180 & 1.4699 & $2.37 \%$ & $17.19 \%$ & 0.0372 \\
\hline 500 & 240 & 1.4566 & $2.34 \%$ & $17.94 \%$ & 0.0135 \\
\hline 500 & 288 & 1.4510 & $2.33 \%$ & $18.26 \%$ & 0.0097 \\
\hline 500 & 360 & 1.4489 & $2.33 \%$ & $18.37 \%$ & 0.0070 \\
\hline 1000 & 0 & 1.0019 & $1.61 \%$ & $0.00 \%$ & $\mathrm{n} / \mathrm{a}$ \\
\hline 1000 & 120 & 0.9661 & $1.55 \%$ & $3.58 \%$ & 0.0519 \\
\hline 1000 & 144 & 0.9575 & $1.54 \%$ & $4.44 \%$ & 0.0469 \\
\hline 1000 & 180 & 0.9517 & $1.53 \%$ & $5.01 \%$ & 0.0337 \\
\hline 1000 & 240 & 0.9350 & $1.50 \%$ & $6.68 \%$ & 0.0200 \\
\hline 1000 & 288 & 0.9275 & $1.49 \%$ & $7.43 \%$ & 0.0185 \\
\hline 1000 & 360 & 0.9258 & $1.49 \%$ & $7.60 \%$ & 0.0113 \\
\hline 1500 & 0 & 0.7658 & $1.23 \%$ & $0.00 \%$ & $\mathrm{n} / \mathrm{a}$ \\
\hline 1500 & 120 & 0.7626 & $1.23 \%$ & $0.42 \%$ & 0.0437 \\
\hline 1500 & 144 & 0.7610 & $1.22 \%$ & $0.62 \%$ & 0.0275 \\
\hline 1500 & 180 & 0.7597 & $1.22 \%$ & $0.80 \%$ & 0.0268 \\
\hline 1500 & 240 & 0.7533 & $1.21 \%$ & $1.63 \%$ & 0.0140 \\
\hline 1500 & 288 & 0.7542 & $1.21 \%$ & $1.50 \%$ & 0.0115 \\
\hline 1500 & 360 & 0.7500 & $1.21 \%$ & $2.06 \%$ & 0.0018 \\
\hline
\end{tabular}




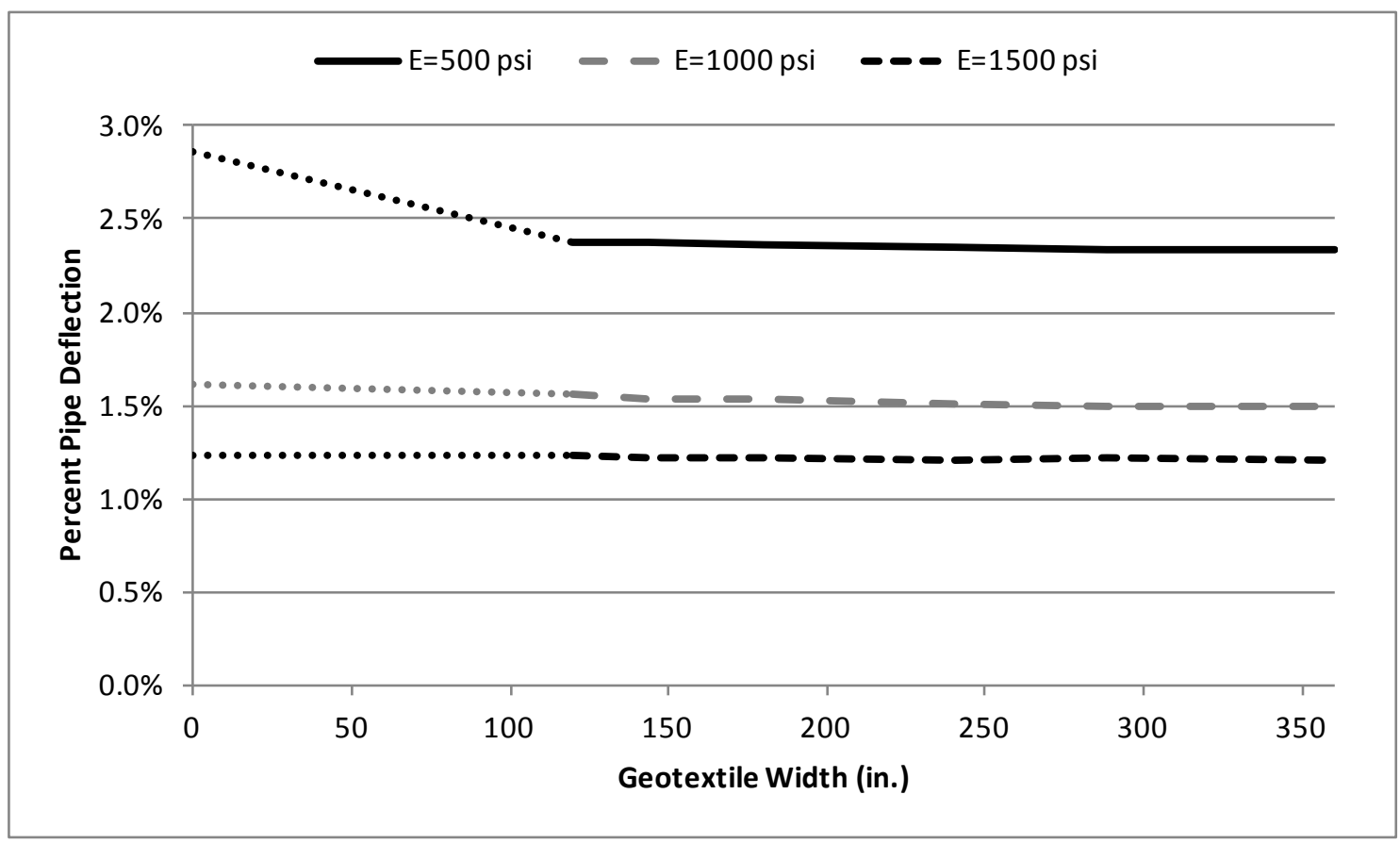

Figure 5.24: Percent pipe deflection vs. geotextile width with varying trench stiffness for $\mathbf{6 0}$ inch diameter pipe.

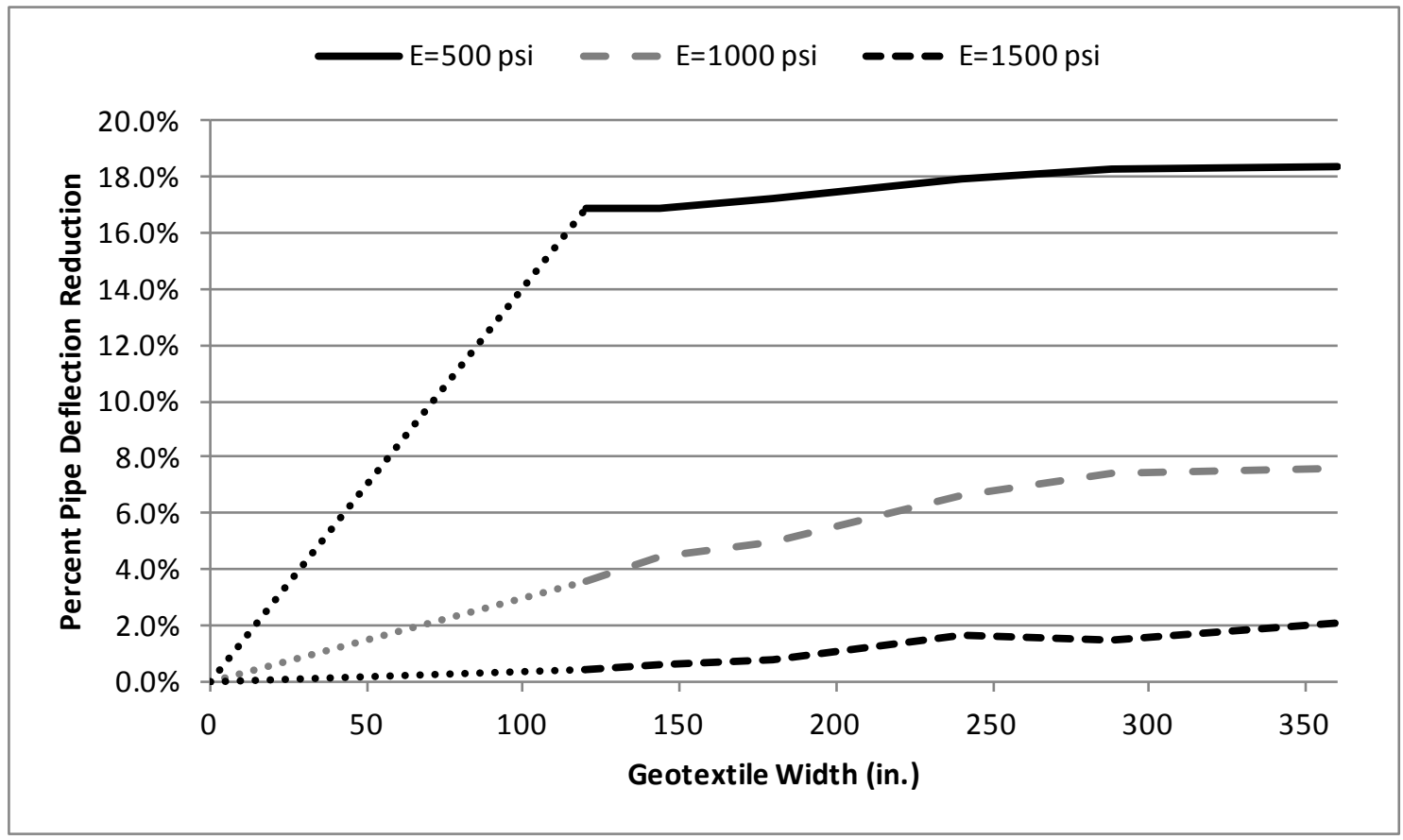

Figure 5.25: Percent reduction in pipe deflection vs. geotextile width with varying trench stiffness for 60 inch diameter pipe. 


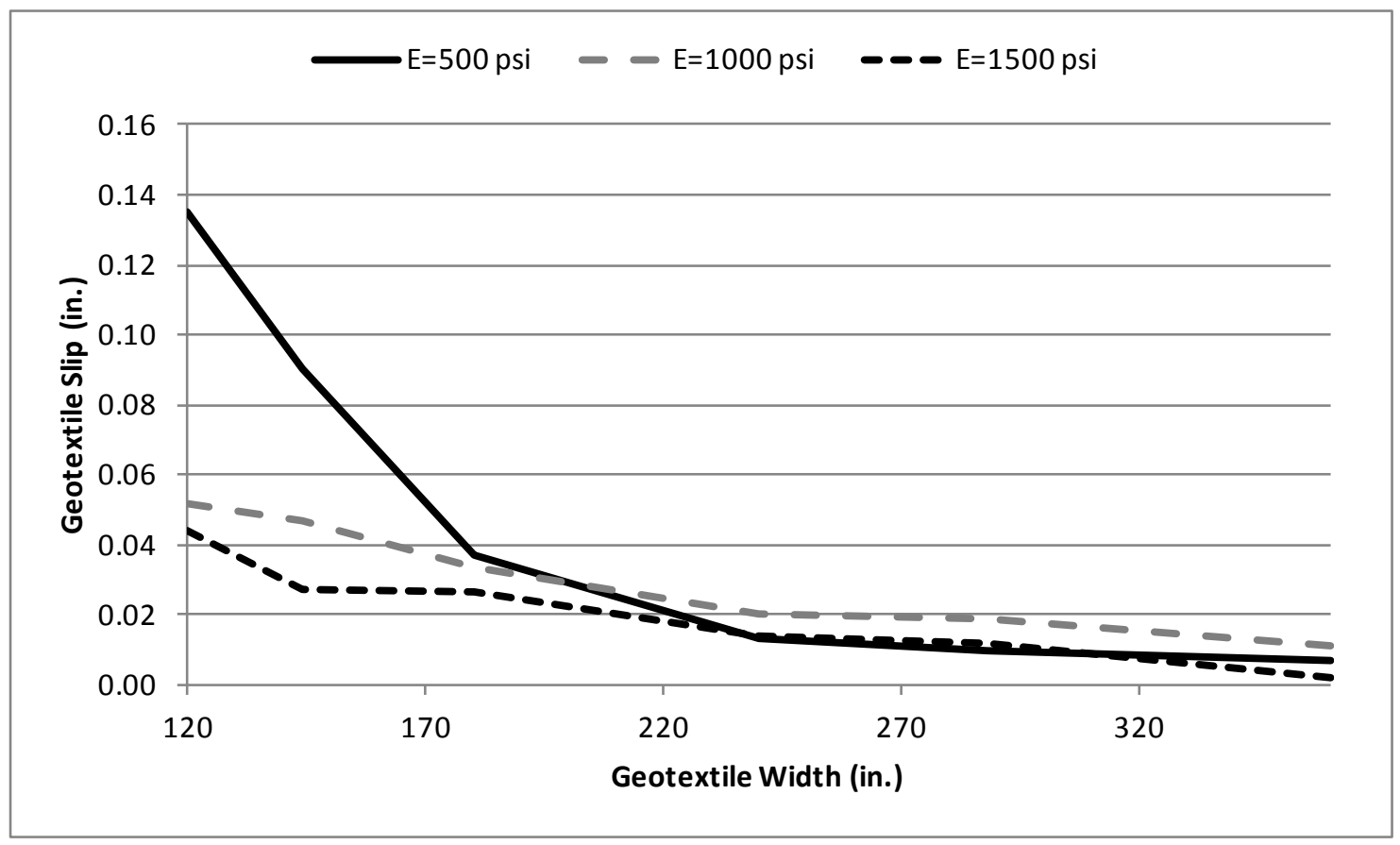

Figure 5.26: Geotextile slip distance vs. geotextile width with varying trench stiffness for 60 inch diameter pipe.

\subsection{Geotextile effectiveness with larger diameter pipe}

The primary pipe used for this study was a $24-i n c h(60.96 \mathrm{~cm})$ diameter HDPE pipe. To undertake a more comprehensive study, a 60 -inch $(152.4 \mathrm{~cm})$ diameter pipe was also considered for several scenarios, including: geotextile effectiveness with varying pipe depth, effect of varying surcharge load from overburden, and geotextile effectiveness with varying trench stiffness. These results were discussed previously in sections 5.2, 5.3, and 5.6, respectively for a 60 -inch $(152.4 \mathrm{~cm})$ diameter pipe. The results for the 60 -inch $(152.4 \mathrm{~cm})$ diameter pipe models follow the same trends as the 24-inch $(60.96 \mathrm{~cm})$ diameter models, only the magnitude of the pipe deflections is noticeably lower and the geotextile has slightly less influence over the reduction of deflections. This outcome can be attributed to several factors. First, the elastic modulus of the 60 -inch $(152.4 \mathrm{~cm})$ diameter pipe is higher than that of the 24 -inch $(60.96 \mathrm{~cm})$ pipe. The method for calculation of pipe stiffness can be found in Section 3.3.2 of this paper and the material properties used for pipe models are located in Table 4.3 of Chapter 4 . Since the 
trench width is obviously much larger for the 60-inch $(152.4 \mathrm{~cm})$ pipe, the geotextile effectiveness may be influenced by the extended width of the trench in the larger pipe models. Trench width was determined by using a ratio of 1.5 times the pipe diameter, significantly increasing the width of the trench for the 60-inch $(152.4 \mathrm{~cm})$ diameter case compared to the 24inch $(60.96 \mathrm{~cm})$ diameter case. A larger trench increases the length of the span of weak soil that the geotextile needs to cross to reach the anchorage support provided at the insitu soil sections; thus resulting in a less beneficial outcome for larger diameter pipes. Nonetheless, the geotextile reinforcement also helps in the performance of larger diameter pipes, but with slightly lower effectiveness. 


\section{CHAPTER 6: SUMMARY AND CONCLUSIONS}

\subsection{Summary}

The primary goal of this study was to investigate a new role for geotextile in the improvement of a buried pipe system. This was achieved through the use of finite element analysis. Preceding the finite element analysis was a critical literature review conducted to strengthen understanding of geotextile reinforcement and buried pipe system mechanics. The performance of buried pipes was investigated with and without geotextile reinforcement for various cases. The parameters tested in this study are the pipe depth from the surface, width of geotextile, stiffness of geotextile, frictional resistance, and trench backfill stiffness. Models were developed for 24 inch and 60 inch $(60.56 \mathrm{~cm}$ and $152.4 \mathrm{~cm})$ double wall corrugated high density polyethylene (HDPE) pipes with a standard trench width ratio of 1.5. Insitu soil properties remained constant throughout the modeling work. However, the trench backfill was altered to represent three soil cases: weak trench, normal trench, and strong trench. The loading applied during modeling includes soil self weight and surcharge loading (dead load) together with HS-25 truck loading (live load). The results and analysis were presented in Chapter 5 of this paper.

\subsection{Conclusions}

The following conclusions can be drawn from the results generated in this research:

- Geotextile soil reinforcement can have a significant positive influence, up to $34 \%$ reduction of vertical pipe deflections when the trench is weak and the pipe depth is shallow. A weak trench can be a result of poor installation practices.

- As pipe depth is increased, the effectiveness of geotextile soil reinforcement is reduced. Geotextile reinforcement has nearly no effect by the time pipe depth reaches 48 inches $(121.92 \mathrm{~cm})$.

- When frictional resistance is increased through a higher surcharge loading, geotextile performance is improved; however, the increase was not large enough to offset the additional forces transmitted to the pipe. 
- Geotextile width had little influence over how well the geotextile performed. This is likely because the specified loading was not large enough to cause anchorage failure. Further insight on FEM modeling techniques for solid element / membrane element interactions may be needed for conclusive results.

- Geotextile stiffness has an effect on performance. A stiff geotextile will deform less than one that is less stiff and will therefore absorb more loading. Stiffer geotextile resulted in lower pipe deflections.

- The quality of the buried pipe system construction has a significant influence over how well a geotextile reinforcement will perform. Under weak trench conditions geotextile reinforcement helps pipes to deform considerably less at shallow pipe depths. When the trench is well constructed with more soil stiffness, the geotextile reinforcement has very little influence over pipe deflection and would not warrant installation.

- Geotextile reinforcement performs in the same manner for various pipe sizes, however the magnitude of its effectiveness may vary from pipe to pipe.

\subsection{Recommendations}

- Investigate finite element modeling techniques for incorporating three dimensional membrane elements with solid elements. Modeling work done in this study points to a need for better understanding of this issue.

- Geogrid reinforcements can fill a similar role as the geotextile reinforcement used in this study. A similar study incorporating geogrids could give insight on this topic. Also, due to the generally higher stiffness of geogrids, they may be better suited for this application. 
- Explore the possibility using techniques such as soil nailing or adding an anchorage trench with the geotextile. Such methods could prevent geotextile slip and increase its effectiveness. These methods may also make it possible to reduce the geosyntetic reinforcement embedment length.

- Due to the increase in installation cost of geotextile reinforcement and the assumptions made in this research work, it is not recommended that this practice be considered for use in all field applications, unless the topic is more thoroughly developed through future research. 


\section{REFERENCES}

AASHTO (2007). American Association of State Highway and Transportation Officials (AASHTO) LFRD Bridge Design Specifications, Customary U.S. Units, 4th Edition, Washington D.C.

AASHTO M294 (2002). Standard specification for corrugated polyethylene pipe. American Association of State Highway and Transportation Officials.

ABAQUS version 6.10 (2010). ABAQUS user's manual. Dassault Systèmes Simulia Corp., Providence, RI, USA.

ACPA, American Concrete Pipe Association: Highway Live Loads on Concrete Pipe [Online]. (2012) Available: www.concrete-pipe.org, [2012].

ADS, Inc., Advanced drainage systems: Technical notes [Online]. (2012) Available: http://www.ads-pipe.com, [2012].

Alawaji, H. A. (2001). "Settlement and bearing capacity of geogrid-reinforced sand over collapsible soil." Geotextiles and Geomembranes 19: 75-88.

Arockiasamy, M., O. Chaallal and T. Limpeteeprakarn (2006). "Full-Scale Field Tests on Flexible Pipes under Live Load Application." Journal of Performance of Constructed Facilities ASCE February: 21-27.

ASTM D4884 (2011). Standard Test Method for Determination of External Loading Characteristics of Plastic Pipe by Parallel-Plate Loading. American Standard for Testing Materials.

ASTM D4884 (2012). Standard Test Method for Strength of Sewn or Thermally Bonded Seams of Geotextiles. American Standard for Testing Materials.

ASTM D4595 (2011). Standard Test Method for Tensile Properties of Geotextiles by the WideWidth Strip Method. American Standard for Testing Materials.

ASTM D1388 (2012). Standard Test Method for Stiffness of Fabrics. American Standard for Testing Materials.

ASTM D5199 (2012). Standard Test Method for Measuring the Nominal Thickness of Geosynthetics. American Standard for Testing Materials.

ASTM D3776 (2012). Standard Test Methods for Mass Per Unit Area (Weight) of Fabric. American Standard for Testing Materials.

ASTM D2487 (2012). Standard Classification of soils for engineering purposes (Unified soil classification system). American Standard for Testing Materials. 
ASTM D 2321 (2012). Standard practice for underground installation of thermoplastic pipe for sewers and other gravity-flow applications. American Standard for Testing Materials.

ASTM D7181 (2011). Method for Consolidated Drained Triaxial Compression Test for Soils. American Standard for Testing Materials.

ASTM D4767 (2011). Standard Test Method for Consolidated Undrained Triaxial Compression Test for Cohesive Soils. American Standard for Testing Materials.

AWAA (2002). Standard specification for plastic pipes. American water works association.

Basudhar, P. K., S. Saha, and K. Deb (2007). "Circular footings resting on geotextile-reinforced sand bed." Geotextiles and Geomembranes 25(6): 377-384.

Betten, J. (2002). Creep Mechanics. Springer Publishing. Germany.

Brachman, R.W.I., Moore, I.D., and Rowe, R.K. (1996). "Interpretation of Buried Pipe Test: Small Diameter Pipe in Ohio University facility." Transportation Research Record 1541, Structures, Culverts, and Tunnels, pp. 64-75.

Brachman, R.W.I., Moore, I.D., and Rowe, R.K. (2000). "The design of a laboratory facility for evaluating the structural response of small-diameter buried pipe." Canadian Geotechnical Journal. Vol. 37, pp. 281-295.

Bulson, P.S. (1985). Buried structures: Static and Dynamic Strength. Chapman \& Hall, New York.

Cai, Z. and R. J. Bathurst (1995). "Seismic response analysis of geosynthetic reinforced soil segmental retaining walls by finite element method." Computers and Geotechnics 17: 523546.

Chamber R.F., McGrath, T.J., and Heger, F.J. (1980). "Plastic Pipe for Subsurface Drainage for Drainage of Transportation Facilities." NCHRP Report 225, Transportation Research Board, Washington, D.C., October, pp. 122-140.

Conard, B.E., Lohnes, R.A., Klaiber, F.W., and Wipe, T.J. (1998). "Boundary effects on response of polyethylene pipe under simulated live load." Transportation Research Record 1624, No. 98-0588, pp. 196-205.

Cook, R.D., Malkus, D.S., Plesha, M.E., and Witt, R.J. (2003). Concepts and applications of finite element analysis. John Wiley \& Sons, Inc., Indianapolis, Indiana.

Das, B.M. (2011). Principles of Foundation Engineering. Seventh Edition. Cengage Learning. Stamford, CT. 
Dhar, A. S. and A. Kabir (2006). A simplified soil-structure interaction based method for calculating deflection of buried pipe. Soil Stress-Strain Behavior: Measurement, Modeling and Analysis. H. I. L. e. al. Netherlands, Springer: 909-919.

Dhar, A.S., Moore, I.D., and McGrath, T.J. (2002). "Evaluation of Simplified Design Methods for Buried Thermoplastic pipe.” Proceeding of Pipeline Division Speciality Conference, Kurz, G.E., August 4-7, Cleveland, Ohio.

El Sawwaf, M. A. (2007). "Behavior of strip footing on geogrid-reinforced sand over a soft clay slope." Geotextiles and Geomembranes 25(1): 50-60.

Erickson, H. and A. Drescher (2001). The Use of Geosynthetis to Reinforce Low Volume Roads. St. Paul, Minnesota, Minnesota Department of Transportation.

Faragher, E., Rogers, C.D.F., and Fleming, P.R. (1998). Laboratory Determination of Soil Stiffness Data for Buried Plastic Pipes. Transportation Research Record 1624, Washington D.C., Paper No. 98-0773, pp. 231-236.

Findley, W. N., F. A. Davis (1989). Creep and Relaxation of Nonlinear Viscoelastic Materials. Courier Dover Publications, New York.

Fleckenstein, L.J. and Allen, D.L. (1993). Field performance report on corrugated polyethylene pipe. Proceedings of the second conference on structural performance of pipes, Sargand, G.F., \& Hurd, J.O. (eds), March 14-17, Columbus, Ohio, pp. 67-77.

Gabriel, L.H. (1990). Keynote address: Pipe deflections - A redeemable asset. Structural Performance of Flexible Pipes, Proceedings of the first national conference on flexible pipes, Sargand, S.M., Mitchell, G.F., \& Hurd, J.O. (eds), October 21-23, Columbus, Ohio, pp.1-6.

Gabriel, L.H. (1998). When plastic pipe responds - relax and enjoy. Structural performance of pipes, Proceedings of the third conference on structural performance of pipes , Sargand, S.M., Mitchell, G.F., \& White, K. (eds), March 22-24, Athens, Ohio, pp. 27-38.

Giroud, J. P. (2004). "Poisson's ratio of unreinforced geomembranes and nonwoven geotextiles subjected to large strains." Geotextiles and Geomembranes 22(4): 297-305.

Goddard, J.B. (2003). Structural Performance of Corrugated PE Pipe using Burns and Richards Solution, Technical Notes, Advanced Drainage Systems, October.

Gondle, R. (2006). Finite Element Analysis of Long-Term Performance of Buried High Density Polyethylene Pipes. Master of Science in Civil Engieering, College of Engineering and Mineral Resources at West Virginia University.

Gondle, R. and H. Siriwardane (2008). "Finite Element Modeling of Long Term Performance of Buried Pipes." International Association for Computer Methods and Advances in Geomechanics (IACMAG). Goa, India. 
Gurung, N. and Y. Iwao (1999). "Pull-out test analysis for goe-reinforcement." Geotextiles and Geomembranes (17): 151-175.

Hartley, J.D. and Duncan, J.M. (1987). E' and its variation with Depth. Journal of Transportation Engineering, September, Vol. 113, No. 5, Paper No. 21813.

Hashash, N., and Selig, E.T. (1990). Analysis of the performance of a buried high density polyethylene pipe. Structural Performance of Flexible Pipes, Proceedings of the first national conference on flexible pipes, Sargand, S.M., Mitchell, G.F., \& Hurd, J.O. (eds), October 2123, Columbus, Ohio, pp. 95-103.

Henry, K. S. (1999). Geotextile Reinforcement of Low-Bearing-Capacity Soils: Comparison of Two Design Methods Applicable to Thawing Soils, US Army Corps of Engineers.

Hinchberger, S. (2003). "Geosynthetic reinforced embankments on soft clay foundations: predicting reinforcement strains at failure." Geotextiles and Geomembranes 21(3): 151-175.

Hirakawa, D., W. Kongkitkul, F. Tatsuoka and T. Uchimura (2003). "Time-dependent stress-strain behaviour due to viscous properties of geogrid reinforcement." Geosynthetics International 10(6).

Holtz, R. D. (2001). Geosynthetics for Soil Reinfrocement. The Ninth Spencer J. Buchanan Lecture, Seattle, Washington, University of Washington.

Honegger, D., H. Karimian, and D. Wijewickreme (2006). Full-scale laboratory testing to assess methods for reduction of soil loads on buried pipes subjected to transverse ground movement. International Pipeline Conference. Calgary, Alberta, Canada, ASME.

Howard, A.K., (1977). "Modulus of Soil Reaction values for Buried Flexible Pipe." Journal of the Geotechnical Engineering Division, January, pp. 33-43.

Howard A.K. and Hitch J.L. (1998). The Design and Application of Controlled Low Strength Materials (Flowable Fill), ASTM STP 1331, American Society for Testing and Materials.

International, A. (2011). Standard Practice for Underground Installation of Thermoplastic Pipe for Sewers and Other Gravity-Flow Applications. ASTM: D2321

Karim, M. R., G. Manivannan, C. T. Gnanendran and S. C. R. Lo (2011). "Predicting the longterm performance of a geogrid-reinforced embankment on soft soil using two-dimensional finite element analysis." Canadian Geotechnical Journal 48(5): 741-753.

Katona M.G., (1993). On the analysis of buried conduits - Past, present, and future. Structural performance of pipes, Proceedings of the second conference on structural performance of pipes , Sargand, S.M., Mitchell, G.F., \& Hurd, J.O. (eds), March 14-17, Columbus, Ohio, pp. 1-5. 
Kazemian, S., M. Barghchi, A. Prasad, H. Maydi and B. K. Bujang (2010). "Reinforced pavement above trench under urban traffic load: Case study and finite element (FE) analysis." Scientific Research and Essays 5(21): 3313-3329.

Koerner, R. M. (2005). Designing with Geosynthetics. Fifth Edition. Pearson Prentice Hall. Upper Saddle River, New Jersey.

Lee, K. M. and V. R. Manjunath (2000). "Soil-geotextile interface friction by direct shear tests." Canadian Geotechnical Journal 37: 238-252.

Ling, H. I., H. Liu, V. N. Kaliakin and D. Leshchinsky (2004). "Analyzing Dynamic Behavior of Geosynthetic-Reinfoced Soil Retaining Walls." Journal of Engineering Mechanics ASCE August: 911-920.

Ling, H. I., S. Yang, D. Leshchinsky, H. Liu and C. Burke (2010). "Finite-Element Simulations of Full-Scale Modular-Block Reinforced Soil Retaining Walls under Earthquake Loading." Journal of Engineering Mechanics ASCE May: 653-661.

Mada, H. (2005). Numerical Modeling of Buried Pipes with Flowable Fill as a Backfill Material. Master of Sicence in Civil Engineering, College of Engineering and Mineral Resources at West Virginia University.

Marston, A. (1930). The theory of external loads on closed conduits in the loght of the latest experiments. Bulletin 96, Iowa Engineering experiment station, Ames, Iowa.

McGrath, T.J. (1993). Design of Reinforced Concrete Pipe- A Review of Traditional and Current Methods. Proceedings of the Second Conference on Structural Performance of Pipes , Sargand, S.M., Mitchell, G.F., \& Hurd, J.O. (eds), March 14-17, Columbus, Ohio, pp. 1-5.

Moayedi, H., S. Kazemian, A. Prasad and B. B. Huat (2009). "Effect of Geogrid Reinforcement Location in Paved Road Improvement." EJGE 14.

Moghaddas Tafreshi, S. N. and O. Khalaj (2008). "Laboratory tests of small-diameter HDPE pipes buried in reinforced sand under repeated-load." Geotextiles and Geomembranes 26(2): 145163.

Moore, I.D. and Brachman (1994). "Three-Dimensional Analysis of Flexible Circular Culverts." Journal of Geotechnical Engineering, Vol. 120, No. 10, pp. 1829-1844.

Moore, I.D., and Fuping, Hu. (1995). Response of Profiled High-Density Polyethylene Pipe in Hoop Compression. Transportation Research Record 1514, Transportation Research Board, Washington, D.C., pp. 29-36.

Moser, A.P. (2008). Buried pipe design. McGraw-Hill, Inc., New York. 
Narejo, D. (2003). "Opening size recommendations for separation geotextiles used in pavements." Geotextiles and Geomembranes 21(4): 257-264.

Palmeira, E. M. (2009). "Soil-geosynthetic interaction: Modeling and analysis." Geotextiles and Geomembranes 27(5): 368-390.

Palmeira, E. M. and H. K. P. A. Andrade (2010). "Protection of buried pipes against accidental damage using geosynthetics." Geosynthetics International 17(4): 228-241.

Perkins, S. W. and M. Q. Edens (2003). "Finite element modeling of a geosynthetic pullout test." Geotechnical and Geological Engineering 21: 357-375.

Phares, B. M., T. J. Wipf, F. W. Klaiber, and R. A. Lohnes (1998). Behavior of High-Density Polyethylene Pipe with Shallow Cover, Committee on Subsurface Soil-Structure Interaction.

Polomino, A. M., X. Tang and S. M. Stoffels (2010). Determination of Structural Benifits of PennDOT-Approved Geogrids in Pavement Design. December 31, 2010, Pennsylvania Department of Transportation.

PPI, Plastic pipe institute [Online] (2012). Available: http://www.plasticpipe.org, [2012].

Rajkumar, R. and K. Ilamparuthi (2008). "Experimental Study on the Behaviour of Buried Flexible Plastic Pipe." EJGE 13.

Reddy, D.V., and Ataoglu, S. (2002). Experimental Analysis of Buried High Density Polyethylene pipes. Turkish Journal of Engineering and Environmental Sciences, Vol. 26, pp. 293-300.

Sargand, S.M., and Masada, T. (2000). Performance of Large-Diameter Honeycomb-design HDPE pipe under a Highway Embankment. Canadian Geochemical Journal, NRC Research Press Website, October 25, Vol. 37, pp. 1099-1108.

Selig, E.T. (1988). Soil parameter for design of buried pipelines. Pipeline infrastructure; Proceedings of the Conference, Westin Copley Plaza Hotel, Boston, Massachusetts, June 6-7.

Seasack, L.A. (2011). Time-Dependent Performance of Buried Pipes in a Consolidating Soil Medium. Master of Science in Civil Engieering, College of Engineering and Mineral Resources at West Virginia University.

Sharma, R., Q. Chen, M. Abu-Farsakh and S. Yoon (2009). "Analytical modeling of geogrid reinforced soil foundation." Geotextiles and Geomembranes 27(1): 63-72.

Simmons, A. R. (2002). Use of Flowable Fill as a Backfill Material around Buried Pipes. Master of Science in Civil Engineering, College of Engineering and Mineral Resources at West Virginia University. 
Siriwardane, H., R. Gondle and B. Kutuk (2008). "Analysis of Flexible Pavements Reinforced with Geogrids." Geotechnical and Geological Engineering 28(3): 287-297.

Siriwardane, H., R. Gondle, B. Kutuk and R. Ingram (2008). "Experimental and Numerical Investigation of Reinforced Geologic Media." The 12th Inernational Conference of International Association of Computer Methods and Advances in Geomechanics (IACMAG). Goa, India.

Spangler, M.G. and Handy, R.L. (1941). The structural design of flexible pipe culverts. Bulletin 153, Iowa Engineering experiment station, Ames, Iowa.

Spangler, M.G. (1938). The Structural Design of Flexible Pipe Culverts. Public Roads, February, Vol. 18, No. 12.

Soderman, K. L. and J. P. Giroud (1994). "Relationships between uniaxial and biaxial stresses and strains in geosynthetics." Geosynthetics International 2(2).

Soleno, Inc., Technical manual: Characteristics of corrugated HDPE pipe [Online] (2012). Available: http://soleno.com, [2012].

Suleiman, M. T. and B. J. Coree (2004). "Constitutive Model for High Density Polyethylene Material: Systematic Approach." Journal of Materials in Civil Engineering ASCE November/December: 511-515.

Tafreshi, S.N., Khalaj, O. (2008). "Laboratory tests of small-diameter HDPE pipes buried in reinforced sand under repeated-load." Geotextiles and Geomembranes, 26 (145-163).

Tafreshi, S. N. M., T. Mehrjardi and S. M. M. Tafreshi (2007). "Analysis of Buried Pipes in Reinforced Sand under Repeated-Load using Neural Network and Regression Model." International Journal of Civil Engieering 5(2).

Tahmasebipoor, A., R. Noorzad, E. Shooshpasha and A. Barari (2010). "A parametric study of stability of geotextile-reinforced soil above an underground cavity." Arabian Journal of Geosciences 5(3): 449-456.

Tahmasebipoor, A., S. E. G. Tayyebi and M. R. Babatabar (2010). "Numerical Analysis of Geosynthetic Reinforced Soil above a Tunnel." IJRRAS.

TenCate Geosynthetics, Mirafi Geosynthetics Technical Specifications [Online] (2012). Availible: http://tencate.com, [2012]

Timoshenko, S., (1936) Theory of Elastic Stability. McGraw Hill Book Company, Inc., New York. 
Tupa, N. and E. M. Palmeira (2007). "Geosynthetic reinforcement for the reduction of the effects of explosions of internally pressurised buried pipes." Geotextiles and Geomembranes 25(2): 109-127.

Varre, S. B. K. (2011). Long-Term Performance of Buried Pipes Under Flowable Fill and Granular Stone Backfill. Master of Science in Civil Engineering, College of Engineering and Mineral Resources at West Virginia University.

Villard, P., B. Chevalier, B. Le Hello and G. Combe (2009). "Coupling between finite and discrete element methods for the modelling of earth structures reinforced by geosynthetic." Computers and Geotechnics 36(5): 709-717.

Wang, M. C., Y. X. Feng and M. Jao (1996). "Stability of Geosynthetic-Reinforced Soil above a Cavity." Geotextiles and Geomembranes 14: 95-109.

Watkins, R.K., and Anderson, L.R. (1999). Structural mechanics of buried pipes. CRC press, New York.

Won, M. S., H. I. Ling and Y. S. Kim (2004). "A Study of the Deformation of Flexible Pipes Buried Under Model Reinforced Sand." KSCE Journal of Civil Engineering 8(4): 377-385.

Wu, T.-Y. and E. C. Ting (2008). "Large deflection analysis of 3D membrane structures by a 4node quadrilateral intrinsic element." Thin-Walled Structures 46(3): 261-275.

Zhan, C. and J. H. Yin (2001). "Elastic Analysis of Soil-Geosynthetic Interaction." Geosynthetics International 8(1): 27-48.

Zhang, C. (1998). Non-linear Finite Element Analysis of Thermoplastic pipes. Transportation Research Record 1624, Washington D.C., Paper No. 98-0588, pp. 225-230.

Zienkewicz, O.C., and Taylor, R.L. (1991). The finite element method, Vol. 1 \& 2. McGraw-Hill Company, London.

Zoladz, G. V. (1995). Laboratory Testing of Buried Pipe. Master of Science Project Report. Department of Civil and Environmental Engineering, University of Massachusetts, Amherst. 